POLLYANA GIL CUNHA AMARAL

\title{
ANÁLISE DINÂMICA DE PONTES PARA TRENS DE ALTA VELOCIDADE
}


POLLYANA GIL CUNHA AMARAL

\section{ANÁLISE DINÂMICA DE PONTES PARA TRENS DE ALTA VELOCIDADE}

Tese apresentada à Escola Politécnica da Universidade de São Paulo para obtenção do título de Doutor em Ciências. 
POLLYANA GIL CUNHA AMARAL

\section{ANÁLISE DINÂMICA DE PONTES PARA TRENS DE ALTA VELOCIDADE}

Tese apresentada à Escola Politécnica da Universidade de São Paulo para obtenção do título de Doutor em Ciências.

Área de concentração: Engenharia de Estruturas

Orientador: Prof. Dr. Carlos Eduardo Nigro Mazzilli 
Este exemplar foi revisado e corrigido em relação à versão original, sob responsabilidade única do autor e com a anuência de seu orientador.

São Paulo, 28 de março de 2017.

Assinatura do autor:

Assinatura do orientador:

Amaral, Pollyana Gil Cunha

Análise dinâmica de pontes para trens de alta velocidade / P.G.C.

Amaral - versão corr. -- São Paulo, 2017.

$134 \mathrm{p}$.

Tese (Doutorado) Escola Politécnica da Universidade de São Paulo. Departamento de Engenharia de Estruturas e Geotécnica.

1.Dinâmica das estruturas 2.Ponte ferroviária 3.Trens de alta velocidade I.Universidade de São Paulo. Escola Politécnica. Departamento de Engenharia de Estruturas e Geotécnica II.t. 
Ao meu esposo, por toda ajuda, paciência, apoio e carinho. 


\section{AGRADECIMENTOS}

Agradeço em primeiro lugar a Deus, por me amparar nos momentos difíceis e me dar forças para superar as dificuldades e coragem para seguir em frente.

Agradeço a toda minha família, que sempre esteve me apoiando e incentivando, além de entender todo o tempo em que não pude estar presente na vida deles. Em especial ao meu marido Carlos Eduardo, com quem dividi todos os momentos e dificuldades e sempre esteve ao meu lado me ajudando e dando força, apoio, carinho e amor. Sempre foi muito paciente, compreensivo, companheiro e amigo. Agradeço-o imensamente por fazer este caminho junto a mim!

Agradeço à Escola Politécnica, por toda a formação pessoal e profissional, além me proporcionar conhecimento, espaço físico e as ferramentas necessárias para desenvolver este trabalho.

Grande agradecimento ao Prof. Dr. Carlos Eduardo Nigro Mazzilli, que aceitou orientar-me mesmo diante das dificuldades da minha realidade e dos riscos de que o trabalho não fosse concluído. Agradeço-o pela oportunidade, por toda orientação, ensinamento, incentivo, paciência e amizade, além das excelentes contribuições em meu trabalho. Agradeço-o também por estar sempre disponível em me ajudar e por fazer isso sempre com muita dedicação.

Agradeço à Intertechne Consultores na pessoa do Eng. Marcos Dalcin, que me disponibilizou o tempo e a compreensão necessários para a conclusão deste trabalho. Aos meus amigos de trabalho, que acompanharam toda essa trajetória, sempre me ouvindo e incentivando.

Ao Prof. Dr. Guilherme Franzini, que sempre esteve disponível em me ajudar e a colaborar com seu conhecimento.

Ao Prof. Dr. Rui Calçada, pela formação oferecida na disciplina "Infraestrutura Ferroviária: Modelação e Monitoração", extremamente importante para adquirir conhecimentos necessários para o desenvolvimento deste trabalho, bem como pela disponibilização de dados referentes ao projeto de pontes utilizado nos estudos de caso.

À Patrícia, com quem tive a oportunidade de desenvolver uma grande amizade e poder compartilhar todos os momentos que passamos. Além de todo apoio e amizade, 
agradeço por estar sempre disponível em me ajudar e por poder discutir os assuntos técnicos e dificuldades do meu trabalho.

À Erika Schmidt, que também sempre esteve disponível em me ajudar e a compartilhar discussões técnicas comuns ao nosso trabalho.

À minha amiga Érika Mieko, que sempre esteve me incentivando, dando força e coragem para a conclusão deste trabalho. Agradeço-a imensamente pelo carinho! 
Toda conquista começa com a decisão de tentar.

(Gail Devers) 


\section{RESUMO}

AMARAL, P.G.C. Análise dinâmica de pontes para trens de alta velocidade, 2017. Tese (Doutorado) - Escola Politécnica, Universidade de São Paulo, 2017.

Este trabalho utiliza uma metodologia simplificada de análise dinâmica para 0 estudo das vibrações em pontes ferroviárias, produzidas pela passagem de um trem de alta velocidade, associadas à presença de irregularidades nos trilhos. Iniciou-se o estudo a partir de um modelo do veículo composto por quinze graus de liberdade, referentes aos deslocamentos verticais e horizontais transversais, e rotações em torno dos eixos longitudinal, transversal e vertical. Os modelos dinâmicos do trem e da ponte foram tratados de forma desacoplada, sendo conectados pelas forças de interação trem-ponte. Desta forma, foram calculados os carregamentos provenientes da modelação dinâmica do trem, adotando-se inicialmente a hipótese de tabuleiro rígido e indeslocável e, ainda, considerando-se a presença de irregularidades geométricas nos trilhos no plano vertical. Neste trabalho, foi considerado um estudo de caso utilizando-se o modelo veicular Alfa Pendular, avaliando-se a resposta dinâmica do trem e da estrutura, considerando o efeito das irregularidades geométricas nos trilhos, bem como a presença do lastro. As forças de interação obtidas da modelagem do veículo foram aplicadas em um modelo estrutural de alta hierarquia da ponte, dividido em elementos finitos de casca, sendo que em cada nó do modelo da ponte foram especificados os esforços obtidos da análise dinâmica do veículo. Para representar a passagem do comboio sobre a ponte, foram utilizadas funções que descrevem as forças de interação trem-ponte em cada nó do modelo da ponte, em cada intervalo de tempo, até que todo o trem tenha percorrido o comprimento da ponte. A consideração de tabuleiro rígido indeslocável foi corrigida por meio de um processo iterativo, de forma que os deslocamentos do tabuleiro obtidos para a primeira determinação dos esforços de interação foram somados às irregularidades do trilho (excitação de suporte aplicada nas rodas do trem). Com isso, foi possível identificar a resposta dinâmica proveniente da carga em movimento e das irregularidades geométricas nos trilhos, avaliando o conforto dos passageiros no interior do vagão. Por fim, realizou-se uma análise de distribuição estatística para avaliar a probabilidade de se ultrapassar os limites estabelecidos pelo Eurocode.

Palavra Chave: Dinâmica das Estruturas, Pontes Ferroviárias, Irregularidades Geométricas, Trens de Alta Velocidade. 


\begin{abstract}
AMARAL, P.G.C. Dynamic analysis of bridges for high-speed trains, 2017. Thesis (Science Doctor) - Escola Politécnica, Universidade de São Paulo, 2017.

This thesis resorts to a simplified methodology of dynamic analysis for the study of vibrations in railway bridges, produced by the passage of a high speed train, associated to the presence of irregularities in the rails. The study started from a vehicle model composed of fifteen degrees of freedom, namely, vertical and lateral displacements, and rotations about the longitudinal, lateral and vertical axes. The dynamic models of the train and the bridge were treated as uncoupled, yet being bound by the interaction train-bridge forces. Thus, the loads from the dynamic model of the train were calculated, adopting initially the hypothesis of rigid and fixed deck and also, considering the presence of geometric irregularities in the vertical track plane. In this work, we considered a case study using the Alfa Pendular vehicle model, evaluating the dynamic response of the train and the structure, considering the effect of the geometric irregularities at the tracks, as well as the presence of the ballast. The interaction forces obtained from the model of the vehicle were applied in a high hierarchy structural model of the bridge, divided into shell finite elements, specifying the forces obtained from the dynamic analysis of the vehicle at each node of the bridge model. To represent the train passage on the bridge, functions were used to describe the bridge-train interaction forces at each node of the bridge model at each time interval, until the entire train had travelled the bridge length. The consideration of rigid and fixed deck was corrected by means of an iterative process, so that the deck displacements obtained for a first determination of the interaction forces were added to the rail irregularities (excitation applied to the train wheels). Thus, it was possible to identify the dynamic response caused both by the moving loading and the geometrical irregularities of the tracks, evaluating the comfort of the passengers inside the wagon. Finally, a reliability study was carried out to evaluate the probability of exceeding the limits established by Eurocode.
\end{abstract}

Keywords: Dynamics of Structures, Railway Bridges, Geometric Irregularities, HighSpeed Trains. 


\section{ÍNDICE DE FIGURAS}

Figura 1.1: Linhas de alta velocidade na França. Fonte: http://www.uic.org/high-speeddatabase-maps\#\&gid $=1 \&$ pid $=7$.

Figura 1.2: Linhas de alta velocidade na Alemanha. Fonte: http://www.uic.org/high-speeddatabase-maps\#\&gid=1\&pid=8.

Figura 1.3: Linhas de alta velocidade em Portugal. Fonte: http://www.uic.org/high-speed-

database-maps\#\&gid=1\&pid=14.

Figura 1.4: Linhas de alta velocidade na Espanha. Fonte http://www.uic.org/high-speeddatabase-maps\#\&gid=1\&pid=15.

Figura 1.5: Instabilidade da via devido à flambagem dos trilhos. Fonte: FIGUEIREDO et al (2009).

Figura 2.1: Fluxograma proposto pelo Eurocode 1991-2. Fonte: EN 1991-2 (2003).

Figura 2.2: Limites da frequência natural da ponte em função do comprimento do vão (L) -

Figura 6.10 do Eurocode. Fonte: EN 1991-2 (2003). 11

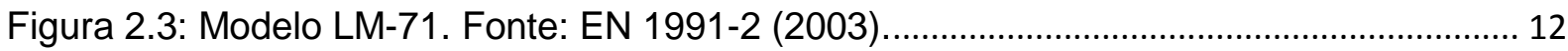

Figura 2.4: Modelos SW/0 e SW/2. Fonte: EN 1991-2 (2003) ............................................. 12

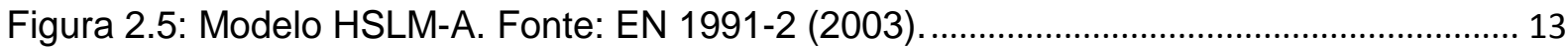

Figura 2.6: Modelo HSLM-B Fonte: Fonte: EN 1991-2 (2003) ............................................. 14

Figura 2.7: Definição do empenamento. Fonte: EN 1990 - ANNEX A2 (2005)....................... 16

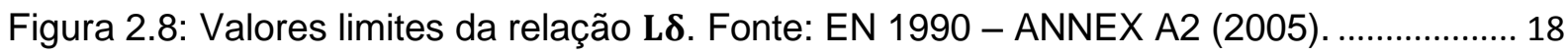

Figura 3.1: Configuração de eixos de comboios articulados. Fonte: FIGUEIREDO et al (2009).

Figura 3.2: Configuração de eixos de comboios convencionais. Fonte: FIGUEIREDO et al (2009).

Figura 3.3: Configuração de eixos de comboios regulares. Fonte: FIGUEIREDO et al (2009).

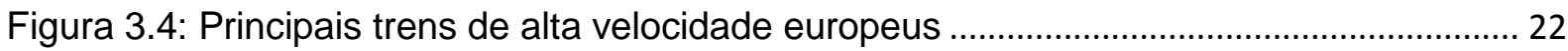

Figura 3.5: Geometria do trem Alfa Pendular. Fonte: COSTA et al (2012).............................. 23

Figura 3.6: Assinatura de comboios reais. Fonte FIGUEIREDO et al (2009).......................... 24

Figura 3.7: Assinatura do trem Alfa Pendular. Fonte: Autor....................................................... 24

Figura 4.1: Exemplos de comprimentos de expansão (LT). Fonte: EN 1991-2 (2003) adaptado.

Figura 4.2: Exemplo de utilização de tramos neutros em pontes. Fonte: MONTENEGRO E ALMEIDA et al (2012). 
Figura 4.3: Vias com lastro (a) e sem lastro (b). Fonte: http://kem-m-

akode.blogspot.com.br/2012/08/vamos-falar-de-tgv.html e

http://news.frbiz.com/china_railway_15_bureau_headquarters-397354.html.......................... 26

Figura 6.1: Modelo dinâmico do veículo. Fonte: CUNHA (2011) ............................................... 30

Figura 6.2: Modelo veicular do trem Alfa Pendular feito no ADINA. Fonte: Autor. ................... 32

Figura 6.3: Parâmetros do elemento de contato inseridos no ADINA. Fonte: Autor............... 33

Figura 6.4: Número de meias ondas no comprimento $\ell$. Fonte: CUNHA (2011) .................... 35

Figura 6.5: Irregularidades nas rodas. Fonte: CUNHA (2011) ................................................. 36

Figura 6.6: Séries espaciais de irregularidades. Fonte: Autor. .................................................. 37

Figura 6.7: Localização da Variante Alcácer do Sal. Fonte:

http://www.infraestruturasdeportugal.pt/rede/ferroviaria/mapa. 39

Figura 6.8: Ponte e viadutos da Variante de Alcácer do Sal. Fonte:

http://www.pengest.pt/Pontes-/-Viadutos/refer-ep-rede-ferroviaria-nacional-variante-entre-a-

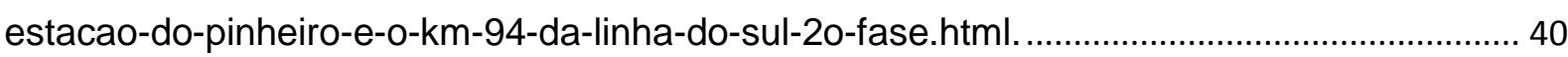

Figura 6.9: Seção transversal do Viaduto. Fonte: Rui Calçada (comunicação pessoal)........ 40

Figura 6.10: Seção no apoio do Viaduto. Fonte: Rui Calçada (comunicação pessoal).......... 41

Figura 6.11: Seção no diafragma do Viaduto. Fonte: Rui Calçada (comunicação pessoal). . 41

Figura 6.12: Seção transversal da Ponte. Fonte: Rui Calçada (comunicação pessoal)......... 42

Figura 6.13: Vista lateral da Ponte. Fonte: Rui Calçada (comunicação pessoal) .................... 43

Figura 6.14: Seções transversais do arco. Fonte: Rui Calçada (comunicação pessoal). ...... 43

Figura 6.15: Modelo do Viaduto no ADINA. Fonte: Autor......................................................... 45

Figura 6.16: Condições de contorno do viaduto. Fonte: Autor................................................... 46

Figura 6.17: Modelo da Ponte no ADINA. Fonte: Autor. ........................................................... 47

Figura 6.18: Condições de contorno da ponte. Fonte: Autor. ................................................. 47

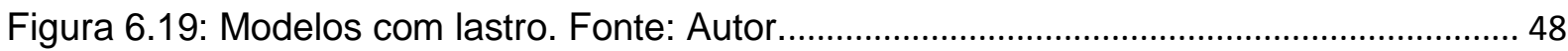

Figura 6.20: Propriedades do trilho. Fonte: http://www.trilhos.com.br/trilho-padrao-uic.html. 49

Figura 7.1: Modos de vibração do trem. Fonte: Autor. ............................................................. 52

Figura 7.2: Modos de vibração do viaduto. Fonte: Autor. .......................................................... 53

Figura 7.3: Modos de vibração da ponte. Fonte: Autor. .............................................................. 55

Figura 8.1: Irregularidades dos trilhos aplicadas em cada roda - Caso com viaduto sem lastro. Fonte: Autor.

Figura 8.2: Forças de interação para a 1 ${ }^{\mathrm{a}}$ iteração - Caso com viaduto sem lastro. Fonte:

Autor 57

Figura 8.3: Esquema de carregamento utilizado na análise dinâmica. Fonte: Autor. ............. 58

Figura 8.4: Funções aplicadas no nó central do viaduto. Fonte: Autor. 59 
Figura 8.5: Deslocamento vertical do tabuleiro no nó central. Fonte: Autor. 60

Figura 8.6: Irregularidades aplicadas no trem em cada iteração. Fonte: Autor. 60

Figura 8.7: Resposta dinâmica da força de interação no domínio da frequência - $1^{\underline{a}}$ Iteração. Fonte: Autor.

Figura 8.8: Resposta dinâmica da força de interação no domínio da frequência - $2^{\underline{a}}$ Iteração. Fonte: Autor.

Figura 8.9: Resposta dinâmica da força de interação no domínio da frequência - 3ª Iteração. Fonte: Autor. 62

Figura 9.1: Forças de interação na roda 1 para cada velocidade. Fonte: Autor. 66

Figura 9.2: Deslocamento vertical do tabuleiro - Trilho 1. Fonte: Autor. 69

Figura 9.3: Acelerações verticais no interior do vagão. Fonte: Autor. 71

Figura 9.4: Acelerações verticais no meio do tabuleiro - Trilho 1. Fonte: Autor. 74

Figura 9.5: Acelerações verticais no meio do tabuleiro - Trilho 2. Fonte: Autor. 76

Figura 9.6: Resultados considerando os deslocamentos do tabuleiro com a passagem do último vagão - Trilho 1. Fonte: Autor. 77

Figura 9.7: Forças de interação na roda 1 para cada velocidade. Fonte: Autor. 80

Figura 9.8: Deslocamento vertical do tabuleiro - Trilho 1. Fonte: Autor. 82

Figura 9.9: Acelerações verticais no interior do vagão. Fonte: Autor. 84

Figura 9.10: Acelerações verticais no meio do tabuleiro. Fonte: Autor. 88

Figura 10.1: Regra da distribuição normal. Fonte:

http://www.portalaction.com.br/probabilidades/62-distribuicao-normal. 90

Figura 10.2: Histograma e curva distribuição normal para a aceleração vertical no interior do primeiro vagão - Caso do Viaduto. Fonte: Autor.

Figura 10.3: Histograma e curva distribuição normal para a aceleração vertical no interior do primeiro vagão - Caso da Ponte. Fonte: Autor. 91

Figura 10.4: Histograma e curva distribuição normal para a aceleração vertical no tabuleiro Caso do Viaduto. Fonte: Autor.

Figura 10.5: Histograma e curva distribuição normal para a aceleração vertical no tabuleiro Caso da Ponte. Fonte: Autor.

Figura 11.1: Fluxograma aplicado para o estudo de caso do Viaduto. Fonte: EN 1991-2 (2003) - adaptado.

Figura 11.2: Figura 6.10 do Eurocode aplicada para o estudo de caso do Viaduto. Fonte: EN 1991-2 (2003) - adaptado.

Figura 11.3: Fluxograma aplicado para o estudo de caso da Ponte. Fonte: EN 1991-2 (2003) - adaptado. 


\section{ÍNDICE DE TABELAS}

Tabela 1.1: Níveis de conforto recomendado. Fonte: EN 1990 - ANNEX A2 (2005) .6

Tabela 2.1: Valores de amortecimento adotados pelo Eurocode (tabela 6.6). Fonte: EN 1991-2 (2003).

Tabela 2.2: Valores limites da torção. Fonte: EN 1990 - ANNEX A2 (2005).

Tabela 2.3: Valores limites do deslocamento e vibração transversal da ponte. Fonte: EN 1990 - ANNEX A2 (2005)

Tabela 3.1: Características dos principais trens europeus de alta velocidade. Fonte: ERRI D 214/RP 9 (1999).

Tabela 3.2: Parâmetros dos comboios ICE 2 e Eurostar. Fonte: ERRI D 214/RP 9 (1999). . 23

Tabela 5.1: Velocidades analisadas. Fonte: Autor. 28

Tabela 6.1: Parâmetros geométricos do veículo. Fonte: Autor. 30

Tabela 6.2: Propriedades mecânicas do trem Alfa Pendular. Fonte: MAGALHÃES (2013).. 31

Tabela 6.3: Propriedades dos materiais. Fonte: Autor. 44

Tabela 6.4: Propriedades do lastro. Fonte: CASAL (2010). 49

Tabela 7.1: Frequências naturais $(\mathrm{Hz})$. Fonte: Autor 50

Tabela 8.1: Passo do tempo prescrito no Eurocode. Fonte: Autor. 56

Tabela 8.2: Coeficientes de Rayleigh adotados nos modelos. Fonte: Autor. 59

Tabela 8.3: Desvios absolutos e relativos obtidos. Fonte: Autor. 63

Tabela 9.1: Valores máximos de aceleração vertical no interior do vagão. Fonte: Autor....... 72

Tabela 9.2: Valores máximos de aceleração vertical no interior do vagão. Fonte: Autor. 85

Tabela 10.1: Probabilidade de ultrapassar os limites estabelecidos no Eurocode - Estudo de caso do Viaduto. Fonte: Autor.

Tabela 10.2: Probabilidade de ultrapassar os limites estabelecidos no Eurocode - Estudo de caso da Ponte. Fonte: Autor. 


\section{ÍNDICE}

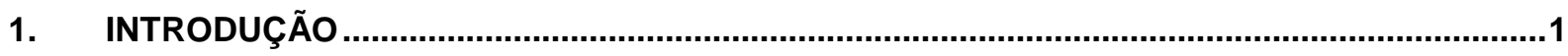

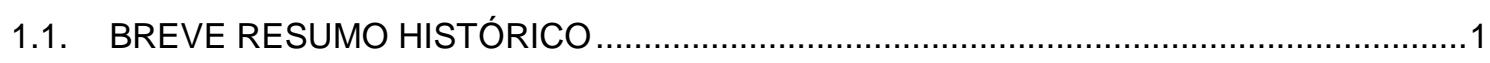

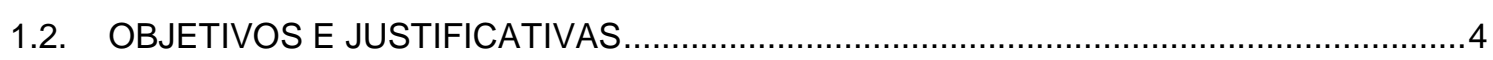

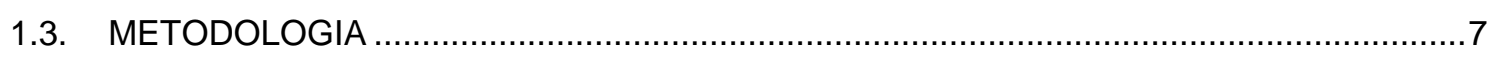

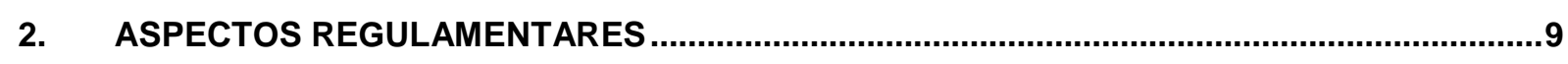

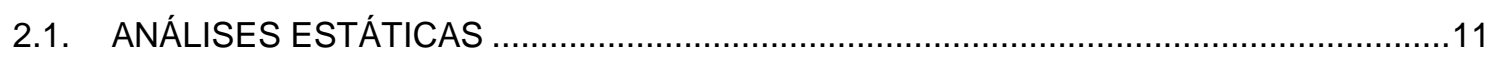

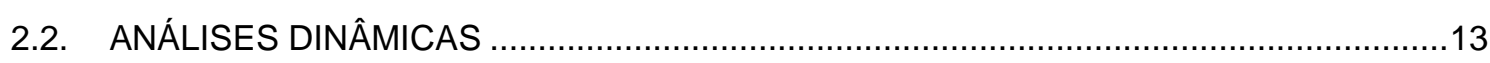

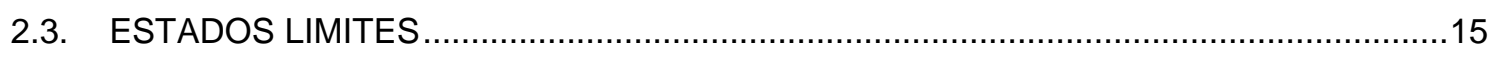

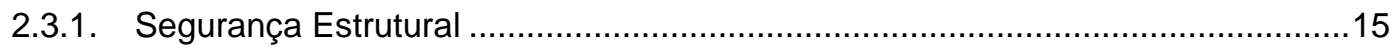

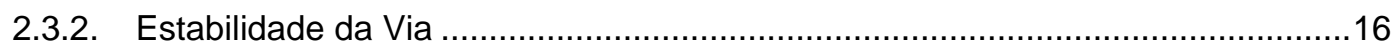

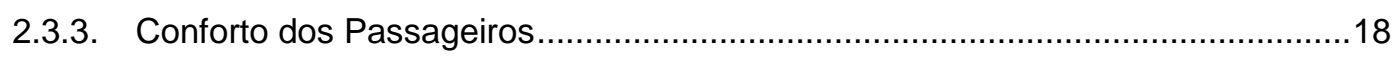

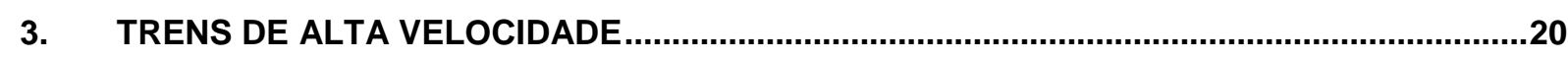

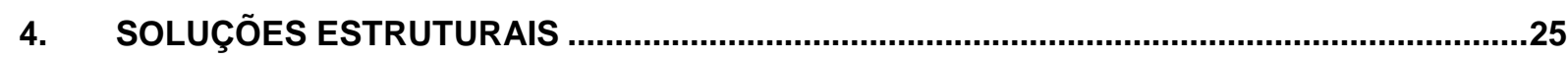

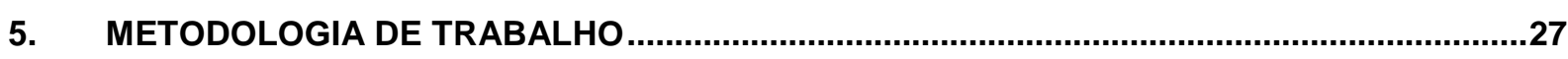

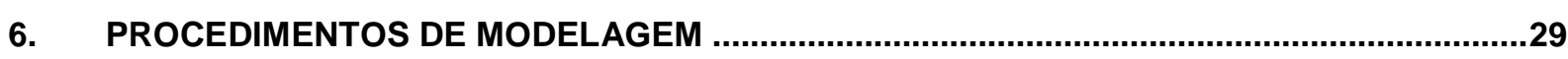

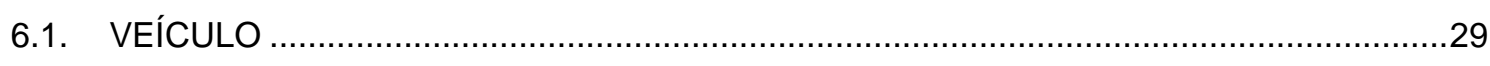

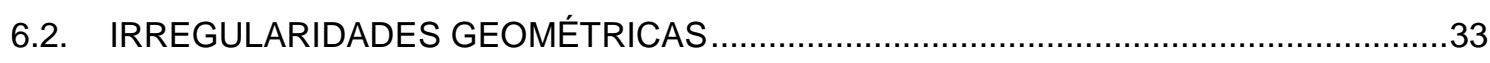

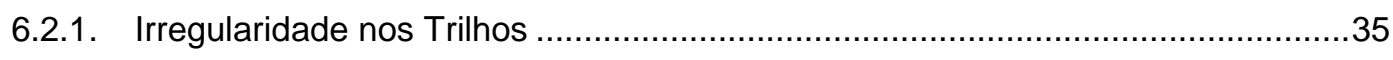

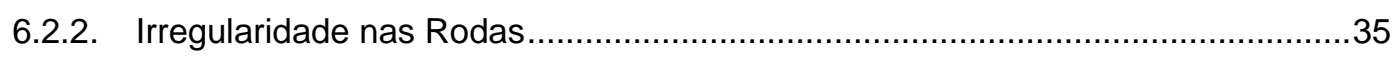

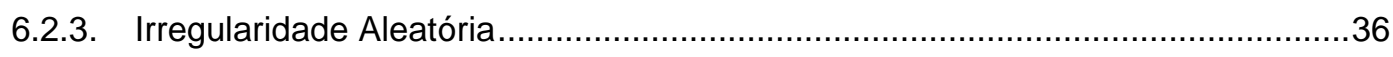

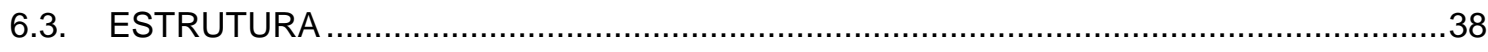

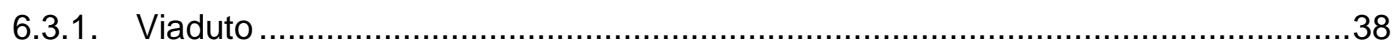

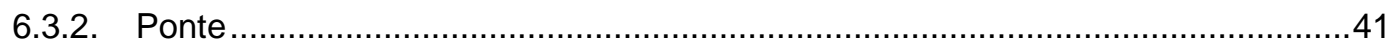

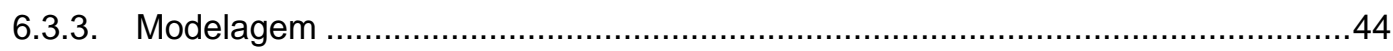

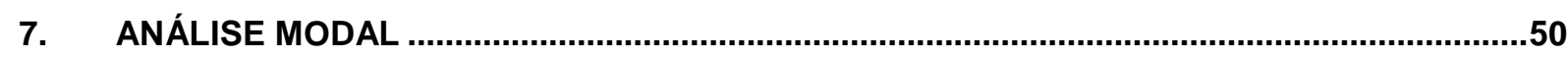

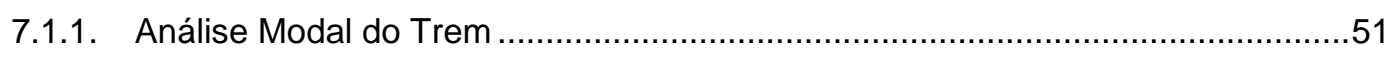

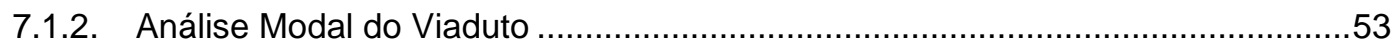

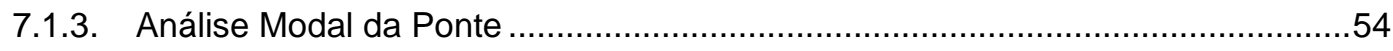

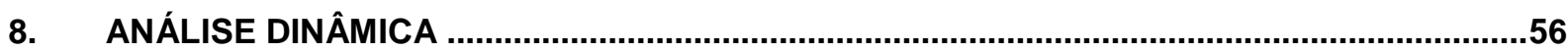

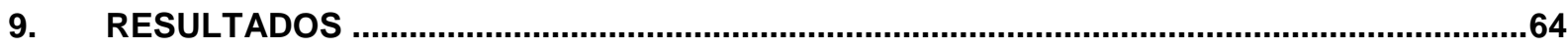

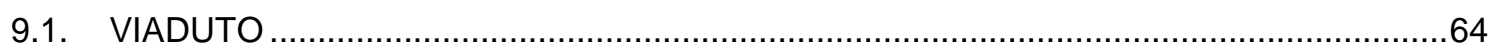




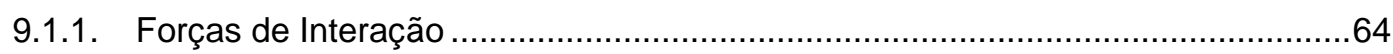

9.1.2. Deslocamentos do Tabuleiro …....................................................................66

9.1.3. Aceleração Vertical no Interior dos Vagões.....................................................69

9.1.4. Aceleração Vertical do Tabuleiro .................................................................. 72

9.1.5. Análise Considerando a Passagem do Último Vagão ........................................77

9.2. PONTE

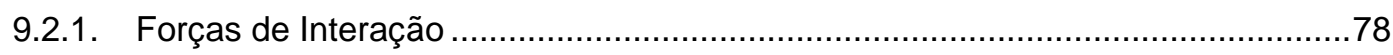

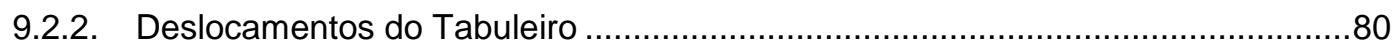

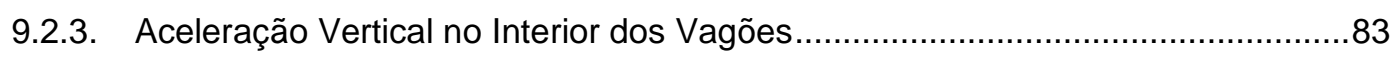

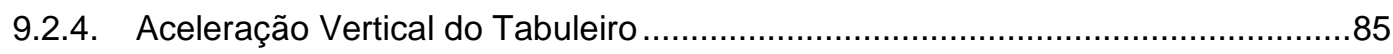

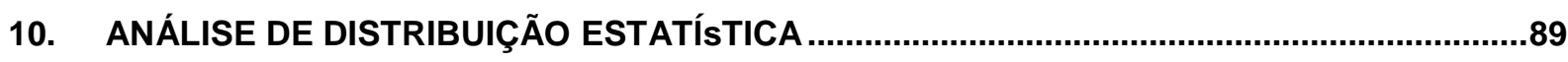

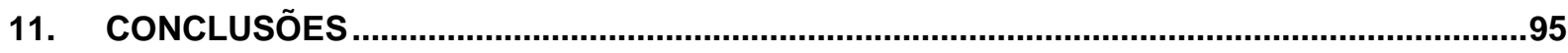

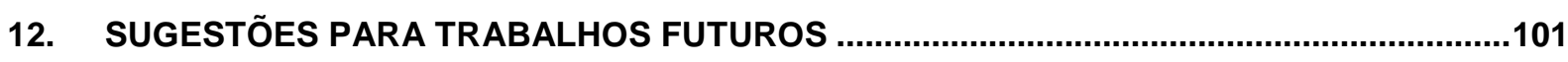

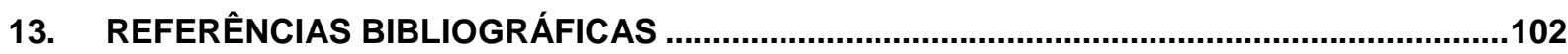

ANEXO 


\section{INTRODUÇÃO}

\subsection{BREVE RESUMO HISTÓRICO}

As linhas ferroviárias para alta velocidade são aquelas construídas para receberem trens com velocidades de operação superiores a $250 \mathrm{~km} / \mathrm{h}$. Também podem ser consideradas linhas de alta velocidade aquelas que foram especialmente adaptadas para operarem a velocidades acima de $200 \mathrm{~km} / \mathrm{h}$ (COUNCIL DIRECTIVE 96/48/EC).

A primeira linha de trem de alta velocidade foi inaugurada em 1964 no Japão, ligando as cidades de Tokyo e Osaka. Conhecida como Tokaido Shinkansen, o trem levava três horas e meia para percorrer a distância de $497 \mathrm{~km}$. O Japão foi pioneiro a dedicar-se a este transporte devido à sua alta densidade populacional e superfície montanhosa, que se torna imprópria para o modal rodoviário (O EMPREITEIRO, 2015).

Na Europa, a primeira linha de alta velocidade surgiu na França em 1981, ligando as cidades de Paris e Lyon. Em 1991, na Alemanha, foram inauguradas as linhas "Inter-City Express", ligando Hamburgo-Würzburg e Mannheim-Stuttgart. Em 1992, foi inaugurada a primeira linha na Itália, ligando as cidades de Roma e Florença, e na Espanha, ligando Madrid a Sevilha (CALÇADA, 2014).

A seguir, são apresentadas as linhas em serviço, em construção e previstas em alguns países da Europa. 


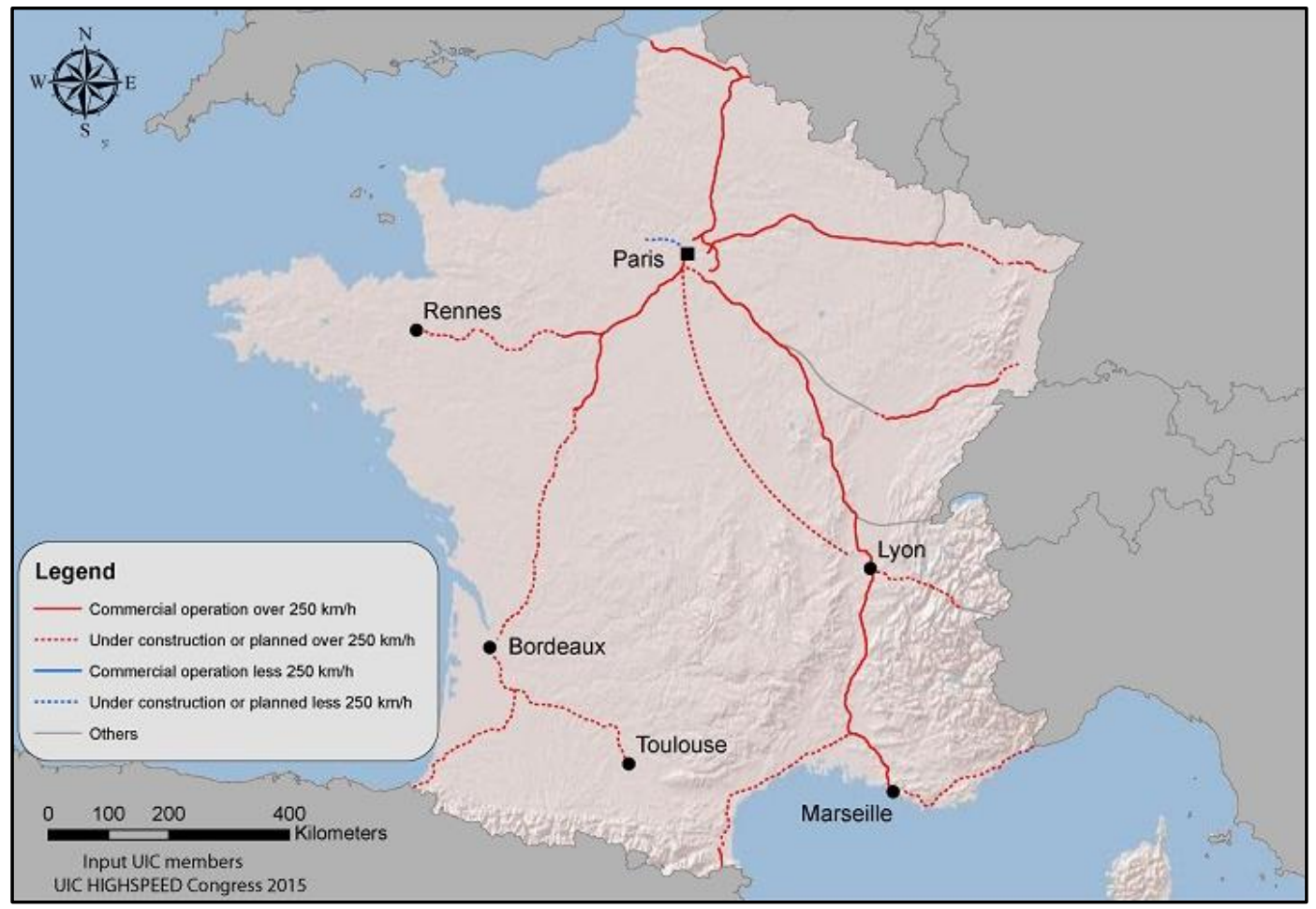

Figura 1.1: Linhas de alta velocidade na França. Fonte: http://www.uic.org/high-speeddatabase-maps\#\&gid=1\&pid=7.

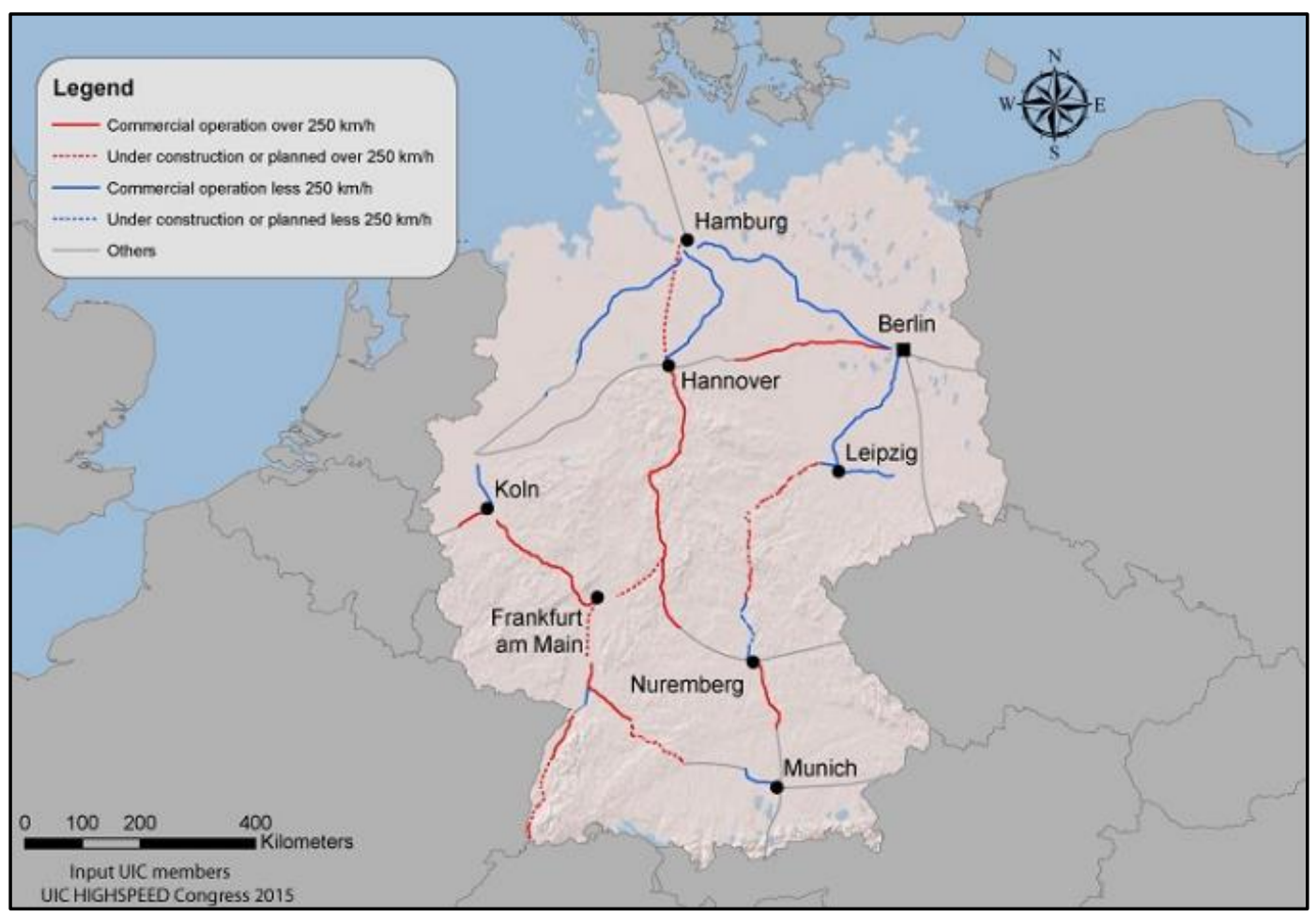

Figura 1.2: Linhas de alta velocidade na Alemanha. Fonte: http://www.uic.org/highspeed-database-maps\#\&gid=1\&pid=8. 


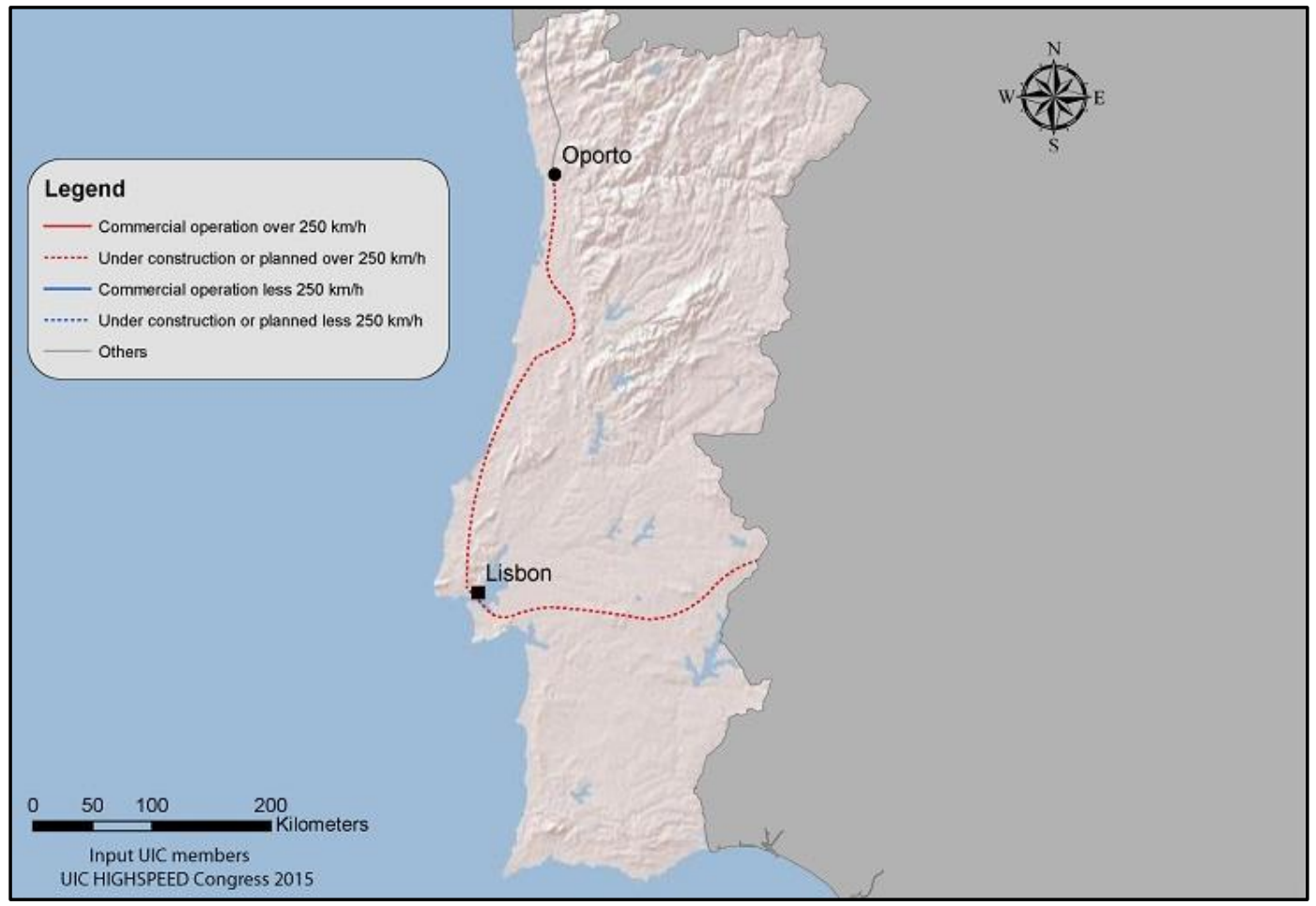

Figura 1.3: Linhas de alta velocidade em Portugal. Fonte: http://www.uic.org/highspeed-database-maps\#\&gid=1\&pid=14.

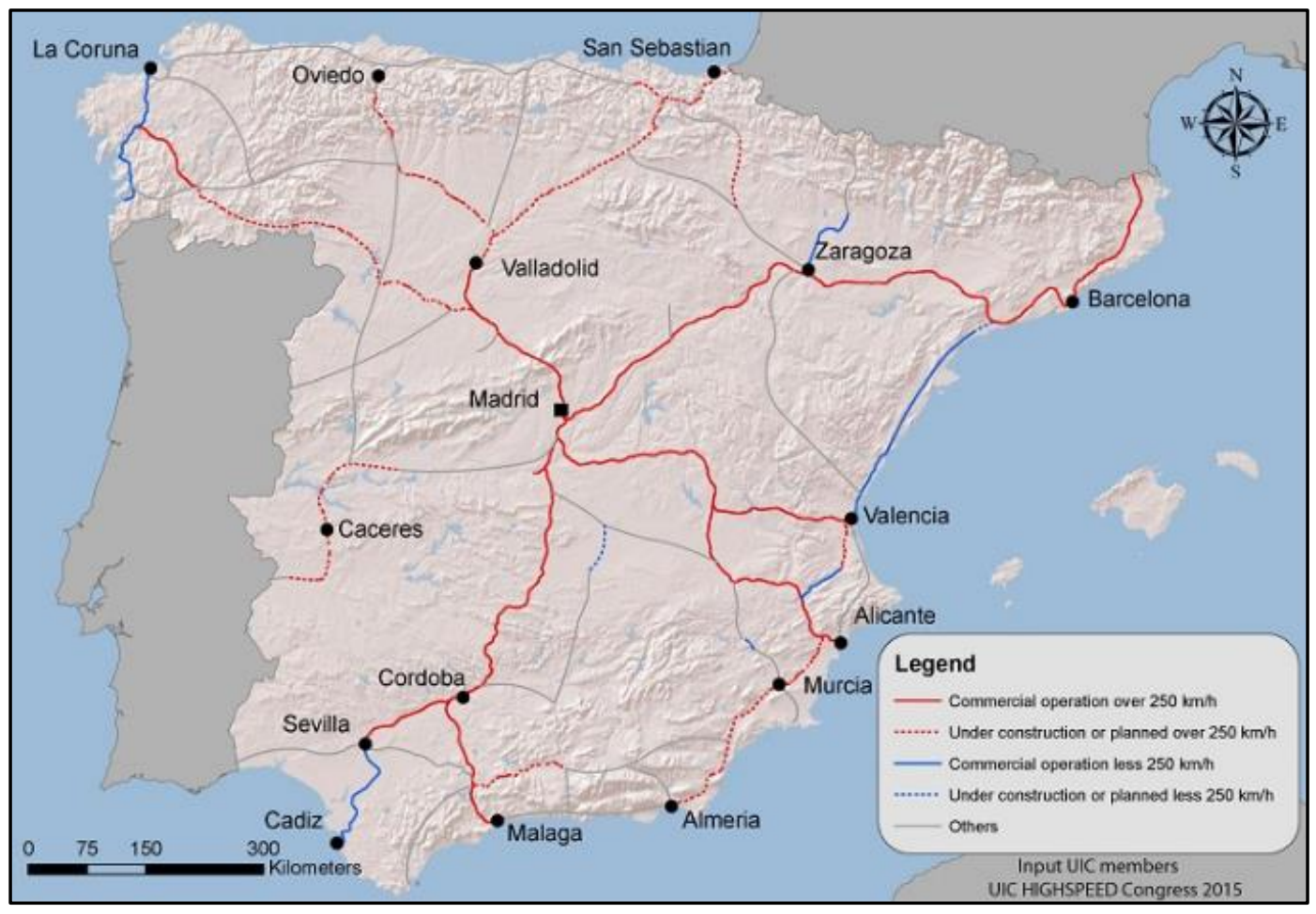

Figura 1.4: Linhas de alta velocidade na Espanha. Fonte http://www.uic.org/highspeed-database-maps\#\&gid=1\&pid=15. 
Hoje, na Europa, existe um conceito de "Interoperabilidade", que significa a capacidade do sistema ferroviário de alta velocidade europeu de permitir a circulação segura e sem interrupção dos comboios em vários países, atendendo aos critérios de conforto, operação e manutenção.

O país que se destaca hoje no setor de trem de alta velocidade é a China, com rede em operação de $4.576 \mathrm{~km}, 5.657 \mathrm{~km}$ de obras em expansão do sistema e $2.901 \mathrm{~km}$ de planejamento de extensão da rede. Além disso, a China também tem o trem mais veloz, atingindo cerca de $400 \mathrm{~km} / \mathrm{h}$, ligando as cidades de Wuhan e Guangzhou (MINISTÉRIO DO PLANEJAMENTO, 2015).

\subsection{OBJETIVOS E JUSTIFICATIVAS}

O trem de alta velocidade permite grande capacidade de transporte de massas, associada a uma elevada segurança e um tempo de viagem bastante competitivos. Além disso, apresenta os menores custos de transporte, com a redução de gastos energéticos, e as menores consequências em termos ambientais, devido às baixas emissões de gases nocivos para a atmosfera e ao pequeno número de acidentes verificados.

Especialmente no Brasil, devido à sua extensão e à dependência do modal rodoviário, a linha de alta velocidade também apresenta vantagens como viabilizar o desenvolvimento de polos regionais ao longo da ferrovia, estimulando a geração de empregos, possibilitando melhor distribuição da população e produção e diminuindo a aglomeração das grandes metrópoles, além de reduzir o tempo das viagens e o congestionamento nas rodovias.

A utilização do modal ferroviário exige, muitas vezes, a construção de obras de arte, como as pontes e os viadutos, a fim de vencer os obstáculos naturais e urbanos. Nesse texto, a referência a "pontes" deve ser entendida de forma genérica, ou seja, como obras de arte, incluindo os viadutos. As soluções estruturais a serem adotadas para pontes ferroviárias em vias de alta velocidade devem atender a um conjunto de exigências diferentes daquelas que normalmente são especificadas para pontes em vias convencionais. Neste caso, os efeitos dinâmicos decorrentes da passagem dos comboios em alta velocidade podem assumir uma grande relevância, como resultado essencialmente dos fenômenos de ressonância que tendem a se manifestar para velocidades superiores a $200 \mathrm{~km} / \mathrm{h}$. 
As pontes de vias de alta velocidade deverão atender a critérios técnicos específicos, de forma a garantir a circulação das composições com segurança e conforto para os passageiros. Estes critérios estão relacionados à segurança estrutural da ponte, à estabilidade da via e do contato trilho-roda e ao bem-estar dos passageiros, conforme Figueiredo et al (2009).

Com relação à segurança da estrutura, dois aspectos são importantes: os efeitos dinâmicos e o efeito da fadiga nos elementos estruturais. Os fenômenos dinâmicos surgem devido à passagem animada de velocidade das cargas do comboio e à existência de irregularidades nos trilhos e nas rodas dos veículos. Além disso, a passagem de comboios com grande número de veículos com espaçamento regular entre eixos $(d)$ pode levar ao efeito da ressonância da estrutura. Conforme apresentado em (FIGUEIREDO et al, 2009), simplificadamente, a carga do comboio pode ser assimilada a uma solicitação periódica de frequência $f$, dada por: $f=v / d$, sendo $v$ a velocidade de passagem do comboio.

Além das tipologias estruturais propostas para pontes de linhas de alta velocidade, vários fatores influenciam seu comportamento dinâmico, tais como:

- fatores inerentes à estrutura: massa, frequências naturais, amortecimento e continuidade da estrutura;

- fatores inerentes à via férrea: características dinâmicas da via (lastro, dormentes e trilhos), continuidade da via sobre as zonas adjacentes de aterro, forças de atrito desenvolvidas na camada de lastro (se existente), irregularidades do perfil dos trilhos, raios de curvatura e sobrelevação;

- fatores inerentes ao material circulante: composição do veículo, características dinâmicas das suspensões e irregularidades das rodas.

Com relação à estabilidade da via e do contato trilho-roda, devem ser analisadas a estabilidade do lastro (se existente), que garante a resistência lateral da via por meio de forças de atrito, e a estabilidade do trilho. Os esforços nos trilhos são devidos às variações térmicas ocorridas no tabuleiro da ponte e no próprio trilho, aos efeitos de aceleração e frenagem do comboio, às ações verticais devido ao tráfego e aos efeitos de fluência e retração do concreto. Segundo Figueiredo et al (2009), a perda de estabilidade do trilho é dada pela falta de capacidade resistente à tração ou à curvatura da via. A Figura 1.5 ilustra a instabilidade da via devido à flambagem do trilho. 


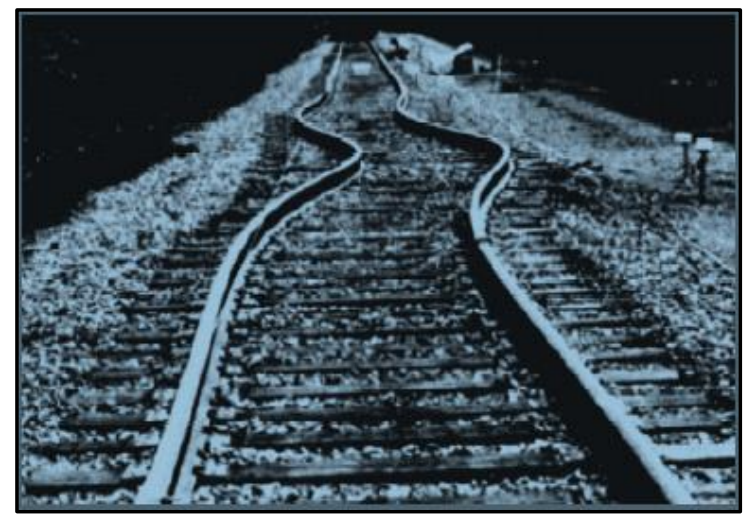

Figura 1.5: Instabilidade da via devido à flambagem dos trilhos. Fonte: FIGUEIREDO et al (2009).

Por fim, o conforto dos passageiros deve ser avaliado em função das acelerações obtidas no interior dos veículos durante sua passagem sobre a ponte. Segundo o Eurocode EN 1990 - Annex A2, os níveis de conforto estão indicados na Tabela A2.9, conforme apresentado na Tabela 1.1. Observa-se que a norma ISO 2631 também estabelece limites de conforto dos passageiros, porém, neste trabalho, serão adotados os critérios prescritos pelo Eurocode.

Tabela 1.1: Níveis de conforto recomendado. Fonte: EN 1990 - ANNEX A2 (2005)

\begin{tabular}{|c|c|}
\hline Nível de Conforto & Aceleração Vertical $\mathbf{b}_{\mathbf{v}}\left(\mathbf{m} / \mathbf{s}^{\mathbf{2}}\right)$ \\
\hline \hline Muito bom & 1,0 \\
\hline Bom & 1,3 \\
\hline Aceitável & 2,0 \\
\hline
\end{tabular}

Assim, este trabalho tem o objetivo de apresentar uma metodologia iterativa para o estudo da interação trem-ponte, tratando o trem e a ponte de forma desacoplada, mas conectando-os pelas forças de contato roda-trilho.

O estudo da interação dinâmica trem-ponte tem sido objeto de estudo por vários pesquisadores. Na Europa, destacam-se os trabalhos desenvolvidos na Universidade do Porto, em especial, o trabalho de Ribeiro (2012), em que o autor apresenta uma metodologia desacoplada com a utilização dos softwares MATLAB e ANSYS e integração direta no domínio da frequência. No Brasil, este assunto começou a ser desenvolvido na Universidade Federal do Rio de Janeiro, com os trabalhos de Correa (2003), para pontes ferroviárias, e de Santos (2007), para pontes rodoviárias; ambos os trabalhos utilizam uma metodologia acoplada com programação direta em software acadêmico e análise por integração direta no domínio do tempo. Ainda no Brasil, têm-se também os trabalhos 
desenvolvidos na Universidade de São Paulo: Moroz (2009), para pontes rodoviárias, e Cunha (2011), para pontes ferroviárias; estes trabalhos utilizam uma metodologia desacoplada-iterativa com software comercial ADINA e manipulação externa de arquivos de saída e análise por integração direta no domínio do tempo.

\subsection{METODOLOGIA}

Neste trabalho, serão estudadas as vibrações em pontes ferroviárias produzidas pela passagem de um trem de alta velocidade, sendo um aprofundamento aos estudos realizados por Cunha (2011).

Mantendo a abordagem adotada no trabalho referido, conforme já comentado, pretende-se realizar o estudo da interação trem-ponte considerando separadamente o trem e a ponte, mas conectando-os pelas forças de contato roda-trilho, dentro de um procedimento iterativo.

Para o modelo dinâmico do trem serão considerados quinze graus de liberdade, a saber: deslocamentos vertical e horizontal transversal e rotações em torno dos eixos vertical e horizontais (longitudinal e transversal), tanto para a massa suspensa, quanto para os dois truques. A excitação do modelo se dará devido à presença de irregularidades geométricas no plano vertical dos trilhos, que serão aplicadas na forma de deslocamentos impostos às rodas. Assim, as forças de interação obtidas nas rodas devem ser aplicadas no modelo estrutural da ponte, a fim de simular a passagem do comboio sobre a mesma. Como dito, nesta metodologia, os modelos estruturais do trem e da ponte são tratados de forma desacoplada, sendo conectados pelas forças de contato trem-ponte. Desta forma, são calculados os carregamentos provenientes da modelação dinâmica do trem, adotando-se inicialmente a hipótese de tabuleiro rígido e indeslocável e, ainda, considerando-se a presença de irregularidades geométricas no plano vertical dos trilhos. As forças de interação obtidas da modelação do veículo são aplicadas em um modelo estrutural da ponte em elementos finitos. Para representar a passagem do comboio sobre a ponte, são utilizadas funções que descrevem as forças de interação trem-ponte em cada nó do modelo da ponte, em cada instante de tempo, até que todo o trem tenha percorrido o comprimento da ponte. Por fim, é avaliada a influência na resposta dinâmica devida à adoção da hipótese de tabuleiro rígido e indeslocável, já que assumir esta condição leva a esforços de interação frequentemente, mas não sempre, superestimados. Desta forma, é feita a correção dos deslocamentos impostos na interface trilho-roda, por meio de um procedimento iterativo, de forma que se somem os deslocamentos do tabuleiro obtidos para a primeira determinação 
dos esforços de interação (com tabuleiro indeslocável) à excitação de suporte aplicada nas rodas do trem para simular a presença das irregularidades. Com isso, pode-se obter os novos esforços de interação, que são reaplicados ao modelo de elementos finitos do tabuleiro para determinar os novos deslocamentos, repetindo-se o procedimento até que os resultados sejam muito próximos aos do passo anterior. Observa-se que a consideração de tabuleiro rígido e indeslocável refere-se apenas à estrutura, sendo o lastro e trilho deformáveis. É oportuno mencionar que, na modelação estrutural do veículo, serão utilizados elementos finitos de contato nas rodas, de sorte a considerar eventual destacamento momentâneo entre roda e trilho.

O outro parâmetro de estudo deste trabalho, a saber, a influência do lastro na resposta dinâmica, é de grande interesse em função da tendência de eliminá-lo em vias de alta velocidade. A primeira versão de via sem lastro surgiu na Alemanha, em 1972, devido às crescentes exigências na estrutura da via. Este tipo de via leva a reduções substanciais dos custos e trabalhos de manutenção, além de redução do peso da via e a mitigação de problemas associados aos efeitos dinâmicos decorrentes da passagem do comboio, tais como a desestabilização do lastro no caso de vias tradicionais.

Assim, considerando os efeitos das irregularidades nos trilhos e efeito do lastro sobre a ponte, também será analisado o conforto dos passageiros no interior dos vagões. Nesse sentido, será realizado estudo de distribuição estatística, analisando-se a probabilidade de se ultrapassar os limites estabelecidos no Eurocode para o conforto dos passageiros e para a estabilidade da via.

Para a análise estrutural da ponte, serão considerados modelos de alta hierarquia. Os modelos de baixa hierarquia, como os unifilares, não apresentam uma boa correspondência das frequências de vibração para modos mais altos para certas tipologias estruturais. As forças de interação obtidas do modelo do trem serão aplicadas à ponte nos efetivos pontos de contato trem-ponte.

Os estudos realizados para os modelos do trem e da ponte serão realizados com a utilização do software de modelagem estrutural e análise dinâmica ADINA - Automatic Dynamic Incremental Nonlinear Analysis, disponibilizado no Laboratório de Mecânica Computacional da Escola Politécnica da Universidade de São Paulo. 


\section{ASPECTOS REGULAMENTARES}

Neste capítulo, serão apresentados alguns requisitos normativos existentes a respeito de projetos de pontes ferroviárias. Quanto a este assunto, conforme já dito, não temos referências brasileiras para estudos de análises dinâmicas de pontes de vias ferroviárias de alta velocidade. As normas brasileiras para projetos de pontes são a ABNT NBR 7187 - "Projetos de pontes de concreto armado e de concreto protendido" e a ABNT NBR-7189 "Cargas móveis para projeto estrutural de obras ferroviárias", embora esta última tenha sido recentemente cancelada (julho de 2015). A primeira especifica que o efeito dinâmico de cargas móveis pode ser considerado mediante análise quase-estática, multiplicando-se o valor considerado para carga vertical por um coeficiente de impacto, função apenas do comprimento do vão da ponte. Para as cargas horizontais, considera-se um valor correspondente a $20 \%$ da carga do eixo mais pesado.

Assim, devido à falta de referências nacionais sobre este tema, serão utilizados os critérios propostos pelo Eurocode EN 1991-2 para o desenvolvimento de projetos de pontes em vias de alta velocidade.

Segundo o Eurocode, os principais fatores que influenciam o comportamento dinâmico da ponte são: velocidade de tráfego, comprimento do vão da ponte, massa da estrutura, frequências naturais da estrutura, número e espaçamento de eixos das cargas, amortecimento da estrutura, irregularidades verticais nos trilhos, características das suspensões do veículo, presença de apoios na estrutura e de dormentes, imperfeições nas rodas e características dinâmicas da via.

A norma propõe um fluxograma em que é possível avaliar se realmente é necessária a realização de uma análise dinâmica. Segundo este fluxograma, dependendo dos dados de velocidade máxima de operação da linha, comprimento do vão da ponte, modelo estrutural, frequências dos primeiros modos de flexão e de torção da ponte e velocidade máxima nominal, é possível dispensar ou não a análise dinâmica. 


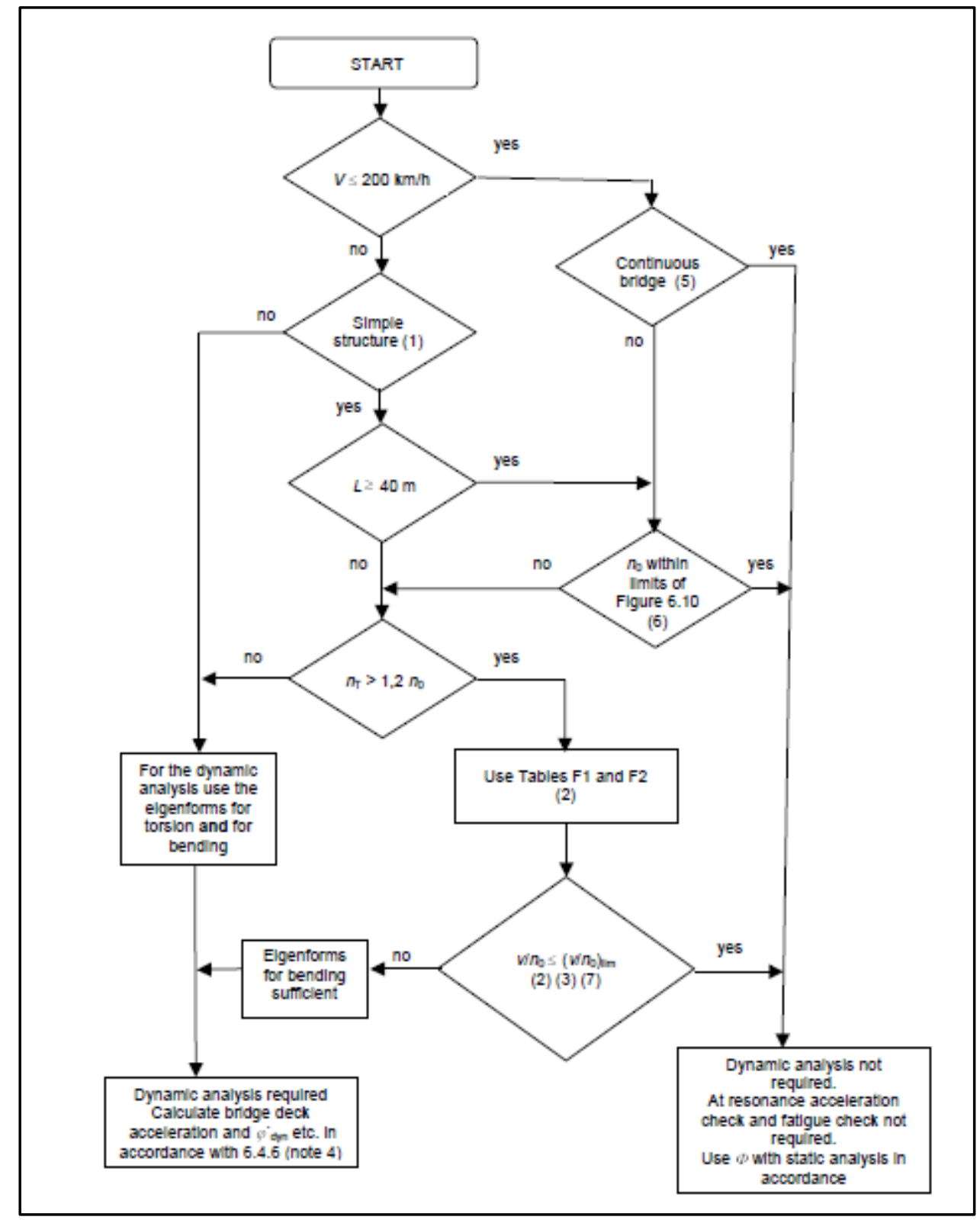

Figura 2.1: Fluxograma proposto pelo Eurocode 1991-2. Fonte: EN 1991-2 (2003).

Apesar de o fluxograma englobar uma série de caminhos em que não é necessário realizar uma análise dinâmica, existem numerosos casos em que isso não ocorre, como:

- $\quad$ nas pontes "não-simples" (em seção caixão, eixo curvo, suspensas, etc.);

- nas pontes em vigas contínuas em que a frequência do primeiro modo de flexão da ponte está fora dos limites indicados na Figura 6.10 do Eurocode EN 1991-2 (Figura 2.2) e a frequência do primeiro modo de torção da ponte é menor ou igual a 1,2 vezes o primeiro modo de flexão; 


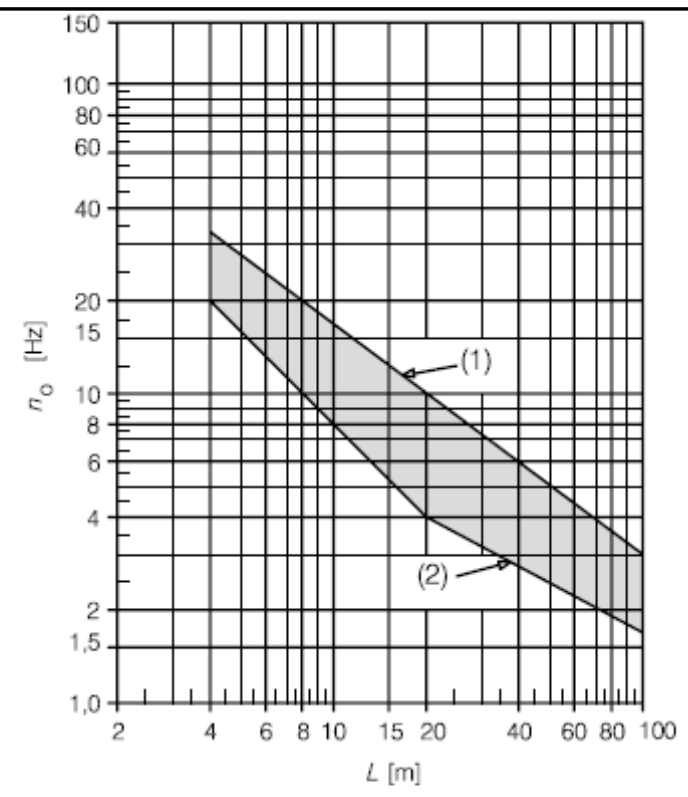

Key

(1) Upper limit of natural frequency

(2) Lower limit of natural frequency

Figura 2.2: Limites da frequência natural da ponte em função do comprimento do vão (L) - Figura 6.10 do Eurocode. Fonte: EN 1991-2 (2003).

- nas estruturas simplesmente apoiadas, com vão maior que $40 \mathrm{~m}$ de comprimento, mas frequência do primeiro modo de flexão fora dos limites estabelecidos pela norma;

- estruturas simplesmente apoiadas, com vão menor que $40 \mathrm{~m}$ de comprimento e frequência do primeiro modo de torção menor que 1,2 vezes o primeiro modo de flexão.

Com relação aos critérios normativos a serem considerados no projeto de pontes de vias de alta velocidade, serão apresentados alguns requisitos do Eurocode, tanto para as cargas a serem consideradas nas análises, quanto para as verificações a serem realizadas.

\subsection{ANÁLISES ESTÁTICAS}

O Eurocode propõe quatro modelos de carga para o tráfego de trens para consideração em análises estáticas, como apresentado a seguir:

- Modelo LM-71: este modelo representa o efeito estático de carregamento vertical devido ao tráfego normal do trem e é aplicável a qualquer tipo de ponte ferroviária. Os valores característicos de LM-71 devem ser multiplicados por um 
fator a nas linhas que transportam tráfego ferroviário mais pesado ou mais leve do que o tráfego normal.

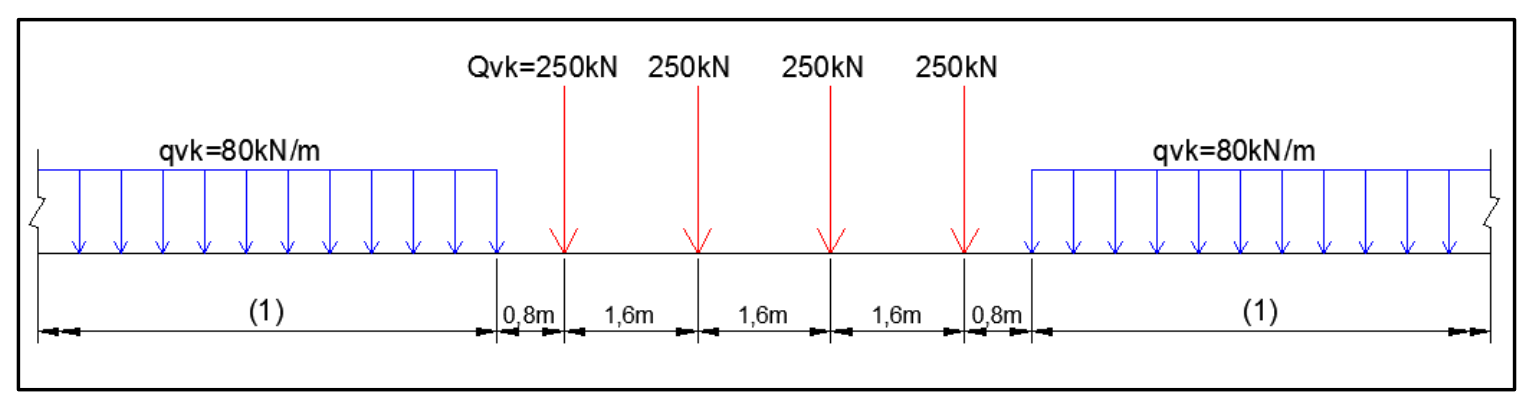

Figura 2.3: Modelo LM-71. Fonte: EN 1991-2 (2003).

- Modelo SW/0: este modelo representa o efeito estático de carregamento vertical devido ao tráfego normal do trem e é aplicável apenas em pontes com tabuleiro contínuo.

- Modelo SW/2: este modelo representa o efeito estático de carregamento vertical devido ao tráfego ferroviário pesado. Sua utilização deve ser restrita a tramos da via que possa circular tráfego pesado de mercadorias.

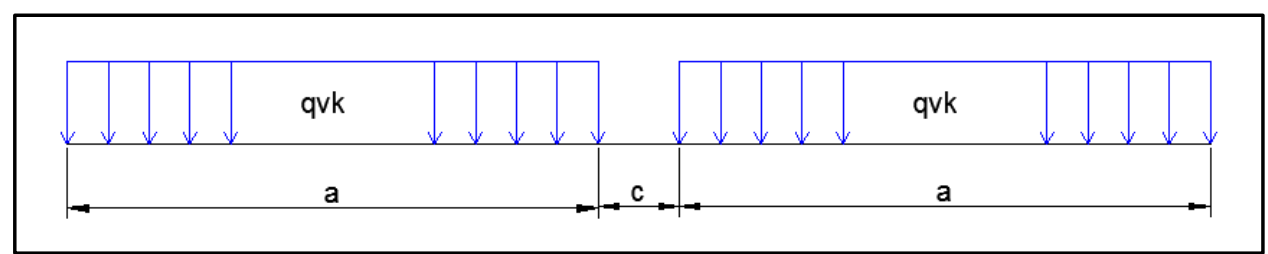

\begin{tabular}{|c|c|c|c|}
\hline Modelo de Carga & $\mathbf{q v k}[\mathbf{k N} / \mathbf{m}]$ & $\mathbf{a}$ [m] & $\mathbf{c}$ [m] \\
\hline \hline SW/0 & 133 & 15,0 & 5,3 \\
\hline SW/2 & 150 & 25,0 & 7,0 \\
\hline
\end{tabular}

Figura 2.4: Modelos SW/0 e SW/2. Fonte: EN 1991-2 (2003).

- Modelo "unloaded": modelo utilizado para a consideração do comboio descarregado por meio de uma carga uniformemente distribuída de $10 \mathrm{kN} / \mathrm{m}$. Este modelo deve ser aplicado quando for mais desfavorável, em conjunto com outras ações, como o vento lateral sobre o comboio, especialmente para estudo de levantamento da estrutura em apoios.

Nos casos em que a análise dinâmica não é requerida, a norma exige a consideração dos efeitos dinâmicos nas análises estáticas por meio de dois fatores corretivos $\varphi$ e $\Phi$. O primeiro leva em conta as amplificações devidas à carga do comboio e 
das irregularidades nos trilhos e rodas. O segundo leva em conta os efeitos dinâmicos associados à passagem do tráfego normal do comboio.

\subsection{ANÁLISES DINÂMICAS}

Nos casos em que o cálculo dinâmico é requerido, as análises deverão ser realizadas considerando os valores característicos das cargas por eixo dos comboios de alta velocidade.

Para a realização de análises dinâmicas, a norma propõe o modelo de carga HSLM, que é utilizado para trens de passageiros que operam a velocidades superiores a $200 \mathrm{~km} / \mathrm{h}$. Este modelo deve ser utilizado no cálculo dinâmico de pontes em linhas internacionais em que sejam aplicáveis os critérios técnicos de interoperabilidade. Existem dois modelos, dependendo do comprimento dos veículos, HSLM-A e HSLM-B, os quais representam os efeitos dinâmicos de comboios articulados, convencionais e regulares. $A$ seguir são apresentados os modelos de carga do HSLM.

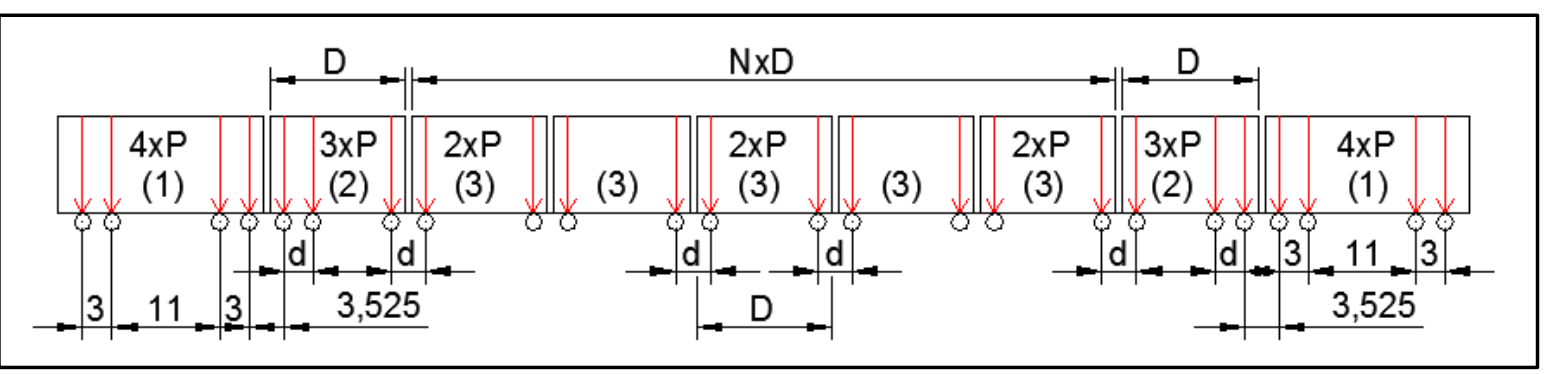

\begin{tabular}{|c|c|c|c|c|}
\hline $\begin{array}{c}\text { Trem } \\
\text { Universal }\end{array}$ & $\begin{array}{c}\text { Número de Carros } \\
\text { Intermediários (N) }\end{array}$ & $\begin{array}{c}\text { Comprimento } \\
\text { do Carro (D) }\end{array}$ & $\begin{array}{c}\text { Espaçamento do Eixo } \\
\text { do Truque (d) [m] }\end{array}$ & $\begin{array}{c}\text { Força Concentrada } \\
\text { (P) [kN] }]\end{array}$ \\
\hline \hline A1 & 18 & 18 & 2,0 & 170 \\
\hline A2 & 17 & 19 & 3,5 & 200 \\
\hline A3 & 16 & 20 & 2,0 & 180 \\
\hline A4 & 15 & 21 & 3,0 & 190 \\
\hline A5 & 14 & 22 & 2,0 & 170 \\
\hline A6 & 13 & 23 & 2,0 & 180 \\
\hline A7 & 13 & 24 & 2,0 & 190 \\
\hline A8 & 12 & 25 & 2,5 & 190 \\
\hline A9 & 11 & 26 & 2,0 & 210 \\
\hline A10 & 11 & 27 & 2,0 & 210 \\
\hline
\end{tabular}

Figura 2.5: Modelo HSLM-A. Fonte: EN 1991-2 (2003). 

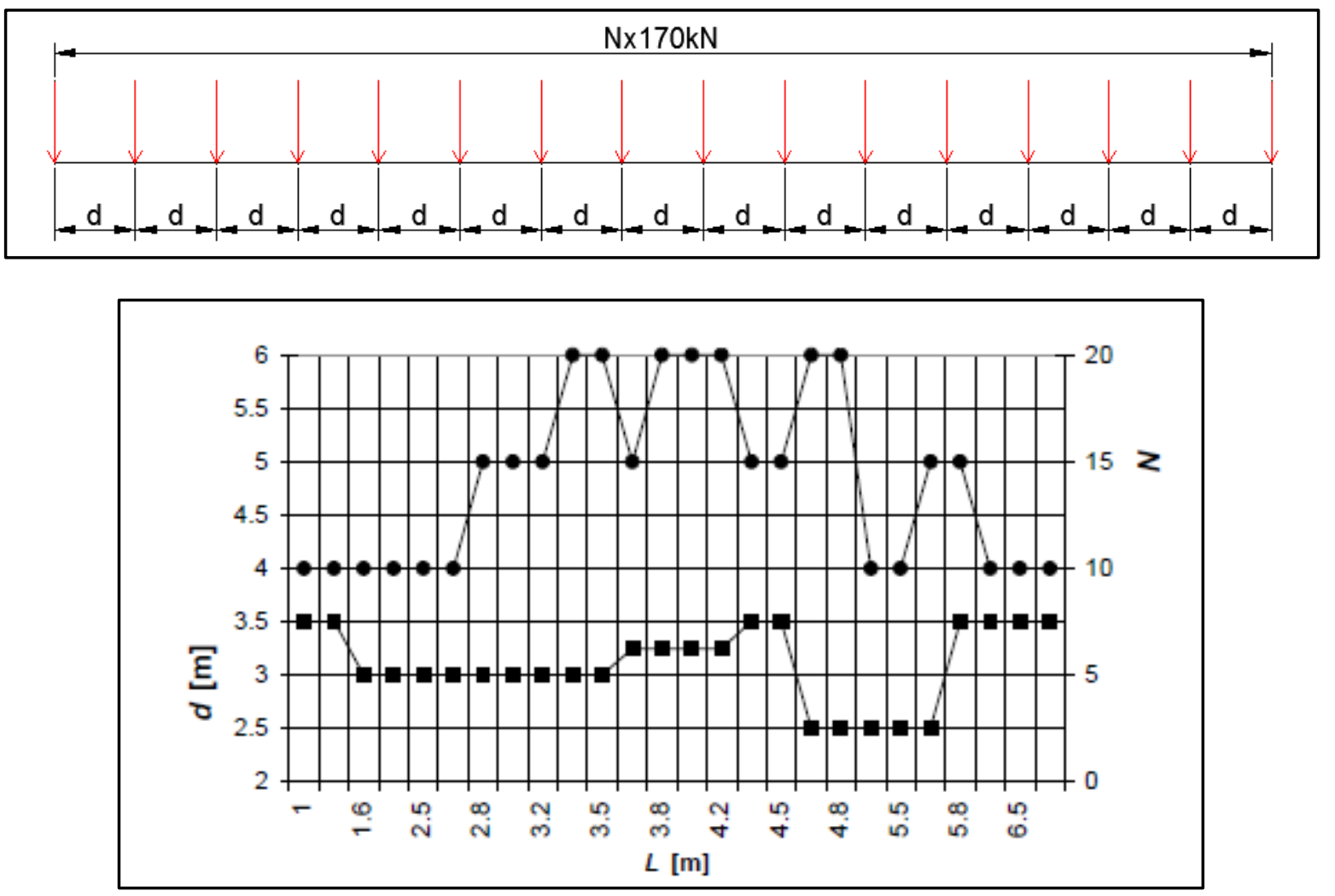

Figura 2.6: Modelo HSLM-B Fonte: Fonte: EN 1991-2 (2003).

onde:

$L$ é o comprimento do vão.

$\mathrm{Na}$ realização das análises dinâmicas, deverá ser considerada uma gama de velocidades variando de $40 \mathrm{~m} / \mathrm{s}$ até 1,2 vezes a velocidade de projeto da via, conforme a expressão a seguir:

$$
v_{i}=n_{0} \times \lambda_{i}
$$

onde:

$v_{i}$ é a velocidade de ressonância, em $\mathrm{m} / \mathrm{s}$;

$n_{0}$ é a primeira frequência natural da estrutura;

$\lambda_{i}$ é o comprimento de onda da frequência de excitação e pode ser estimado por:

$$
\lambda_{i}=\frac{d}{i}
$$

em que $d$ é o espaçamento regular dos eixos do veículo e $i=1,2,3$ ou 4 . 
Para os parâmetros de amortecimento, o Eurocode especifica na Tabela 6.6 os valores a serem adotados, que é função do comprimento do vão da ponte $(L)$ e do material da ponte. Esses valores estão reproduzidos na Tabela 2.1.

Tabela 2.1: Valores de amortecimento adotados pelo Eurocode (tabela 6.6). Fonte: EN 1991-2 (2003).

\begin{tabular}{|c|c|c|}
\hline \multirow{2}{*}{ Tipo de Ponte } & \multicolumn{2}{|c|}{ Limite inferior da porcentagem de amortecimento crítico [\%] } \\
\cline { 2 - 3 } & Vão $\mathbf{L}<\mathbf{2 0 m}$ & Vão $\mathbf{L} \geq \mathbf{2 0 m}$ \\
\hline \hline Aço e estrutura mista & $\zeta=0,5+0,125(20-\mathrm{L})$ & $\zeta=0,5$ \\
\hline Concreto Prontendido & $\zeta=1,0+0,07(20-\mathrm{L})$ & $\zeta=1,0$ \\
\hline Perfil preenchido e concreto armado & $\zeta=1,5+0,07(20-\mathrm{L})$ & $\zeta=1,5$ \\
\hline
\end{tabular}

\subsection{ESTADOS LIMITES}

Com relação às verificações a serem feitas no projeto de pontes ferroviárias, o Eurocode especifica que devem ser analisadas a segurança estrutural, a estabilidade da via e o conforto dos passageiros.

\subsubsection{Segurança Estrutural}

A segurança estrutural deve ser verificada considerando os valores característicos das sobrecargas ferroviárias como sendo o mais crítico entre:

- o cálculo estático do modelo de cálculo LM71, e SW/0 no caso de estruturas contínuas, multiplicado pelo fator dinâmico $\Phi$ :

$$
\Phi \times(L M 71 "+" S W / 0)
$$

- o cálculo dinâmico dos comboios reais (RT) de alta velocidade ou dos modelos do HSLM:

$$
\left(1+\phi_{d y n}^{\prime}+\frac{\phi^{\prime \prime}}{2}\right) \times(H S L M \text { ou } R T)
$$

onde e $\phi "$ representa o efeito das irregularidades dos trilhos e das rodas do veículo e $\phi_{d y n}^{\prime}$ representa o fator de amplificação dinâmica, obtido pela seguinte expressão

$$
\phi_{\text {dyn }}^{\prime}=\text { máx }\left|\frac{y_{d y n}}{y_{\text {stat }}}\right|-1
$$

sendo que $\mathrm{y}_{\mathrm{dyn}}$ representa o valor máximo da resposta dinâmica num determinado ponto da estrutura devido à passagem dos comboios HSLM ou RT e $\mathrm{y}_{\text {stat }}$ representa o valor máximo da resposta estática. 


\subsubsection{Estabilidade da Via}

Com relação à garantia de estabilidade da via, devem ser analisados os parâmetros: aceleração vertical da ponte, rotação de torção e das extremidades em torno dos eixos vertical e transversal da ponte e deslocamentos vertical, transversal e longitudinal da ponte, conforme apresentado no Eurocode (EN 1990-ANNEX A2, 2005).

\subsubsection{Aceleração vertical da ponte}

O parâmetro da aceleração vertical da ponte está relacionado à possibilidade de ocorrência de instabilidade na camada de lastro, no caso de vias com lastro, levando à perda de resistência lateral da via e, no caso de vias sem lastro, à perda de contato entre a roda e o trilho. Desta forma, o item A2.4.4.2.1 do Anexo A do Eurocode (EN 1990-ANNEX $A 2,2005)$ especifica um limite máximo para a aceleração vertical da ponte, em função da existência ou não de lastro na ponte, sendo de $3,5 \mathrm{~m} / \mathrm{s}^{2}$ para pontes com lastro e $5 \mathrm{~m} / \mathrm{s}^{2}$ para pontes sem lastro.

$\mathrm{Na}$ análise dinâmica, para a verificação da aceleração vertical da ponte devem ser consideradas as contribuições de modos com frequências até o máximo de $30 \mathrm{~Hz}, 1,5$ vezes a frequência do primeiro modo de vibração da ponte (no plano vertical) ou a frequência do terceiro modo de vibração da ponte (no plano vertical).

\subsubsection{Rotação de torção}

A verificação de torção da ponte deverá ser feita com os valores característicos dos modelos LM71, SW/0 ou SW/2, multiplicados pelos fatores $\Phi$ e a (sendo a o fator de classificação para cargas verticais, conforme item 6.3.2 do Eurocode (EN 1991-2, 2003)), ou com os modelos HSLM, caso seja mais desfavorável, e com a força centrífuga.

Segundo o item A2.4.4.2.2 do Anexo A2 do Eurocode (EN 1990 - ANNEX A2, 2005), o empenamento máximo " $t$ " medido em $\mathrm{mm}$ a cada $3 \mathrm{~m}$ entre duas seções transversais (Figura 2.7) não deverá exceder os limites indicados na Tabela 2.2.

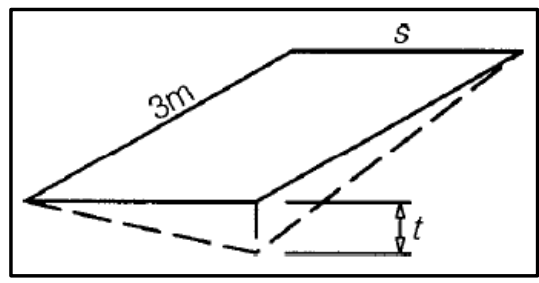

Figura 2.7: Definição do empenamento. Fonte: EN 1990 - ANNEX A2 (2005). 
Tabela 2.2: Valores limites da torção. Fonte: EN 1990 - ANNEX A2 (2005).

\begin{tabular}{|c|c|}
\hline Faixa de Velocidade $\mathbf{V}(\mathbf{k m} / \mathbf{h})$ & Torção Máxima $\mathbf{t}(\mathbf{m m} / \mathbf{3 m})$ \\
\hline \hline $\mathrm{V} \leq 120$ & $\mathrm{t} \leq \mathrm{t}_{1}$ \\
\hline $120<\mathrm{V} \leq 200$ & $\mathrm{t} \leq \mathrm{t}_{2}$ \\
\hline $\mathrm{V}>200$ & $\mathrm{t} \leq \mathrm{t}_{3}$ \\
\hline
\end{tabular}

Os valores de " $t$ ", de acordo com o Eurocode, são correspondentes a $t_{1}=4,5$, $t_{2}=3,0$ e $t_{3}=1,5$.

\subsubsection{Deslocamento vertical da ponte}

Os deslocamentos verticais da ponte devem ser avaliados considerando modelos de carga LM71, SW/0 ou SW/2 e não deverá exceder o limite de L/600.

\subsubsection{Deslocamento e vibração transversal da ponte}

O deslocamento e vibração transversal devem ser verificados considerando os modelos de carga LM71, SW/0 ou SW/2, afetados pelos fatores $\Phi$ e $\alpha$, com a ação das cargas de vento e efeito térmico entre as superfícies laterais da ponte.

Estes parâmetros são limitados por meio da rotação transversal da ponte nos apoios e encontros $\left(\delta_{h}\right)$ e por meio do raio de curvatura transversal $\left(r=L^{2} / 8 \delta_{h}\right)$, sendo $L$ o vão do tabuleiro.

A Tabela 2.3, extraída da Tabela A2.8 do Anexo A2 do Eurocode apresenta uma recomendação para esses limites.

Tabela 2.3: Valores limites do deslocamento e vibração transversal da ponte. Fonte: EN 1990 ANNEX A2 (2005)

\begin{tabular}{|c|c|c|c|}
\hline Faixa de Velocidade & \multirow{2}{*}{$\begin{array}{c}\text { Rotação Horizontal } \\
\mathbf{V}(\mathbf{k m} / \mathbf{h})\end{array}$} & \multicolumn{2}{|c|}{ Variação máxima do raio de curvatura $(\mathbf{m})$} \\
\cline { 3 - 4 } & Máxima (rad) & Único vão & Vários vãos \\
\hline \hline $\mathrm{V} \leq 120$ & 0,0035 & 1.700 & 3.500 \\
\hline $120<\mathrm{V} \leq 200$ & 0,0020 & 6.000 & 9.500 \\
\hline $\mathrm{V}>200$ & 0,0015 & 14.000 & 17.500 \\
\hline
\end{tabular}

Observa-se que, a fim de evitar efeitos de ressonância lateral dos veículos, a primeira frequência referente a um modo transversal de um tramo da ponte deve ser superior a $1,2 \mathrm{~Hz}$. 


\subsubsection{Conforto dos Passageiros}

Com relação ao nível de conforto dos passageiros, este critério deve ser avaliado em função da aceleração vertical medida no interior dos vagões durante a passagem do veículo sobre a ponte. O Eurocode estabelece três níveis de conforto, conforme apresentado na Tabela 1.1, sendo "muito bom" para acelerações até 1,0 m/s², "bom" para até $1,3 \mathrm{~m} / \mathrm{s}^{2}$ e "aceitável", para valores até $2,0 \mathrm{~m} / \mathrm{s}^{2}$.

Para a verificação da aceleração no interior dos vagões, é necessária a realização de análises dinâmicas considerando a interação veículo-estrutura. Devido à dificuldade e gasto computacional para estas análises, o Eurocode propõe um procedimento simplificado, com base num valor limite do deslocamento vertical da ponte $(\delta)$ ao longo do eixo de cada via, que é função do vão da ponte $(L)$, da velocidade do trem $(v)$, do número de vãos e da configuração da ponte. $\mathrm{O}$ valor de $\delta$ deve ser determinado com o modelo de carga LM71 multiplicado pelo fator dinâmico $\Phi$.

A Figura 2.8, extraída do Eurocode, apresenta os valores limites da relação $(L / \delta)$ para pontes com três ou mais vãos simplesmente apoiados e aceleração no interior dos vagões de $1,0 \mathrm{~m} / \mathrm{s}^{2}$ (nível de conforto "muito bom"). Para níveis de conforto "bom" e "aceitável", deve-se dividir os valores de $(L / \delta)$ pela aceleração correspondente a cada nível de conforto $\left(b_{v}\right)$. No caso de pontes com número de vãos inferior a três, os valores limites deverão ser multiplicados por 0,7 e para pontes com mais de três vãos contínuos, deverão ser multiplicados por 0,9.

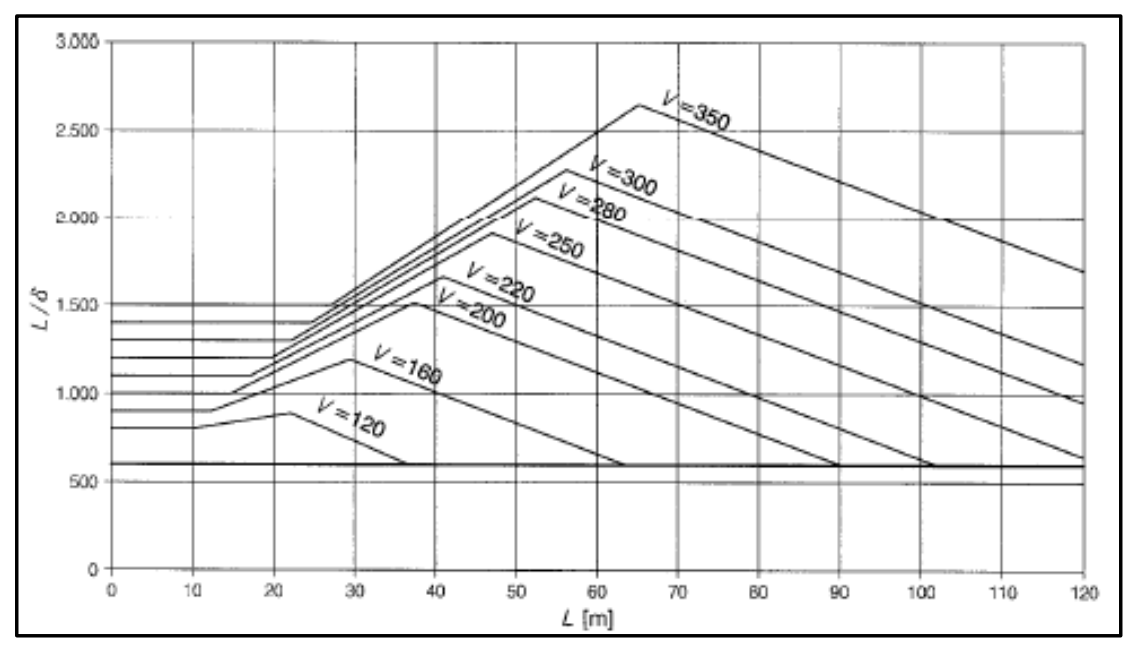

Figura 2.8: Valores limites da relação (L/ס). Fonte: EN 1990 - ANNEX A2 (2005). 
Observa-se na Figura 2.8 que o limite superior para o deslocamento vertical do tabuleiro tende a $L / 600$, sendo este reduzido com o aumento da velocidade. 


\section{TRENS DE ALTA VELOCIDADE}

Existem hoje na Europa três tipos de comboios de alta velocidade, a saber: comboios articulados, em que os truques dos vagões são partilhados pelos vagões adjacentes, comboios convencionais, em que cada vagão possui dois truques independentes, e comboio regular, em que os truques apresentam apenas um eixo partilhado pelos vagões adjacentes. As figuras a seguir apresentam essas configurações, extraídas de (FIGUEIREDO et al, 2009).

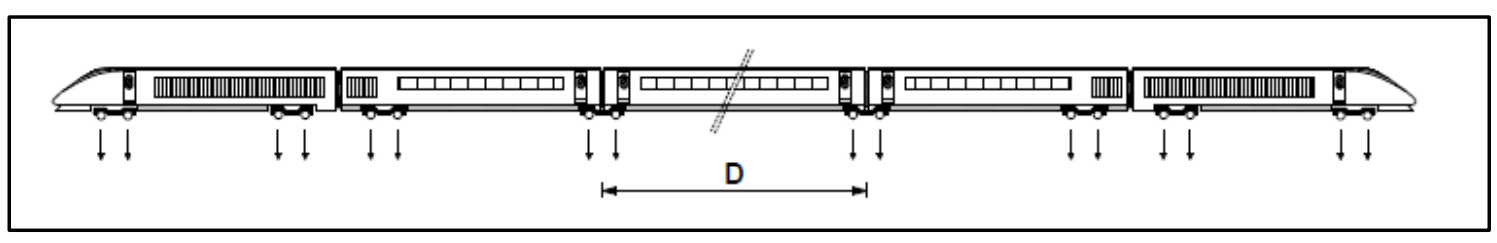

Figura 3.1: Configuração de eixos de comboios articulados. Fonte: FIGUEIREDO et al (2009).

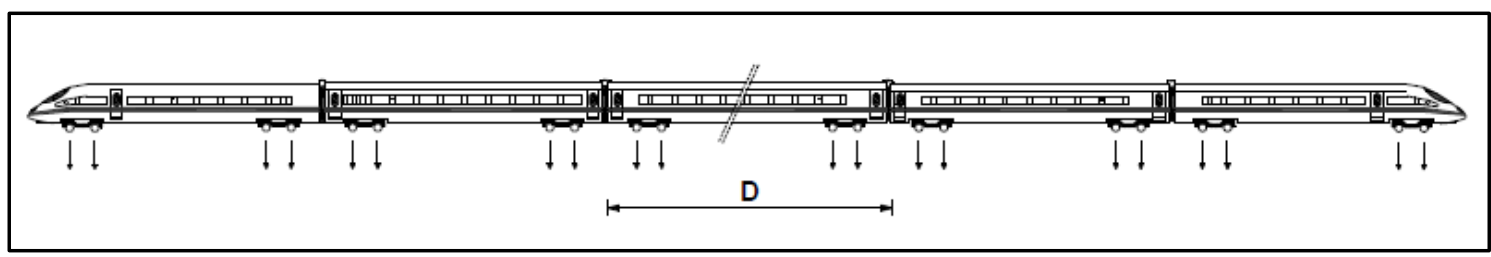

Figura 3.2: Configuração de eixos de comboios convencionais. Fonte: FIGUEIREDO et al (2009).

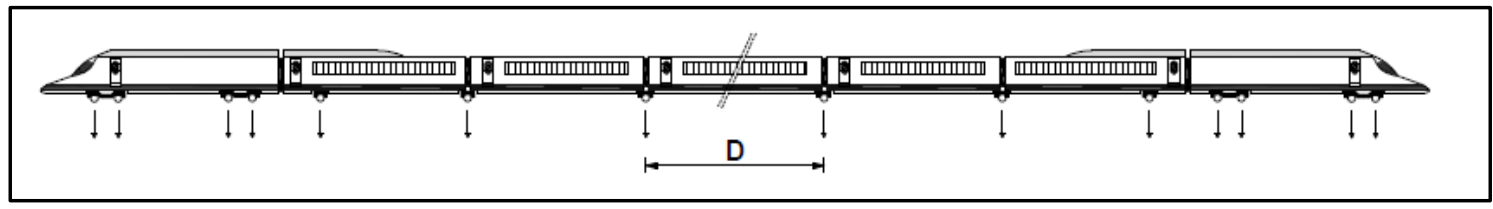

Figura 3.3: Configuração de eixos de comboios regulares. Fonte: FIGUEIREDO et al (2009).

Na Figura 3.4, são apresentados os principais trens de alta velocidade europeus. 


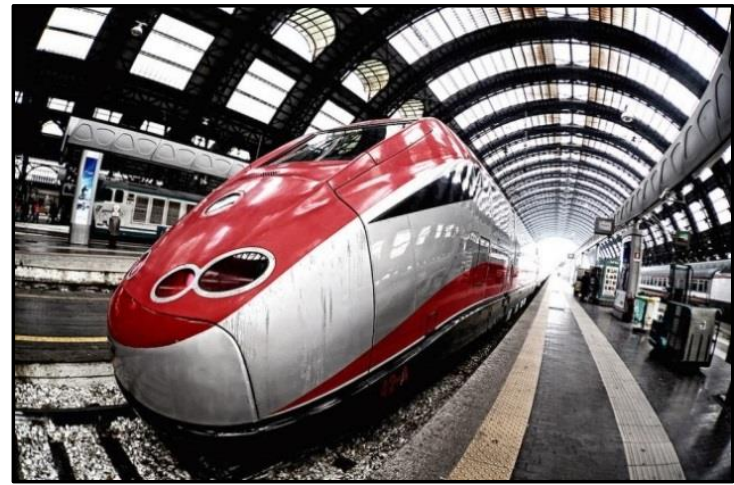

a) ETR Y500. Fonte:

http://viajedetrem.blogspot.com.br/.

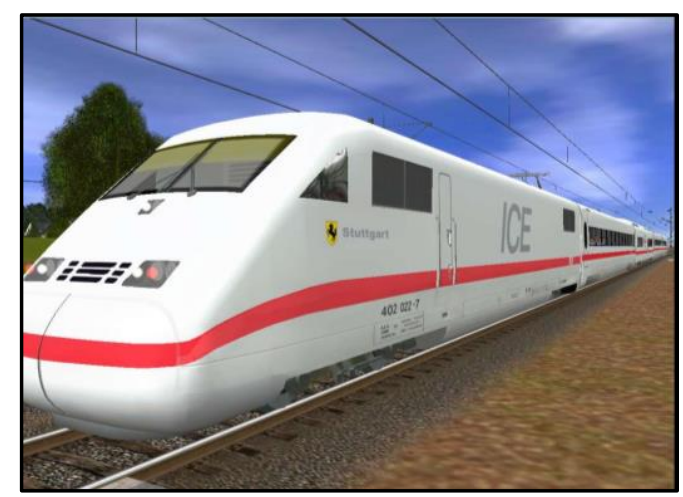

c) ICE 2. Fonte:

http://www.snipview.com/q/ICE\%202.

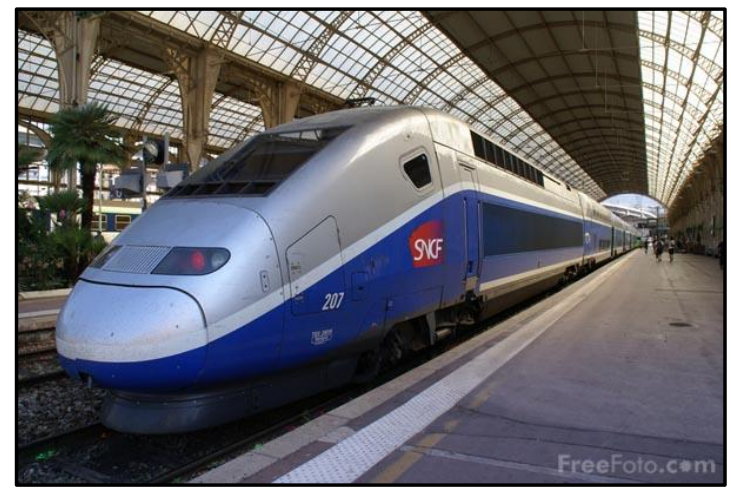

e) TGV. Fonte:

http://www.freefoto.com/preview/25-10-2/TGVDuplex-train.

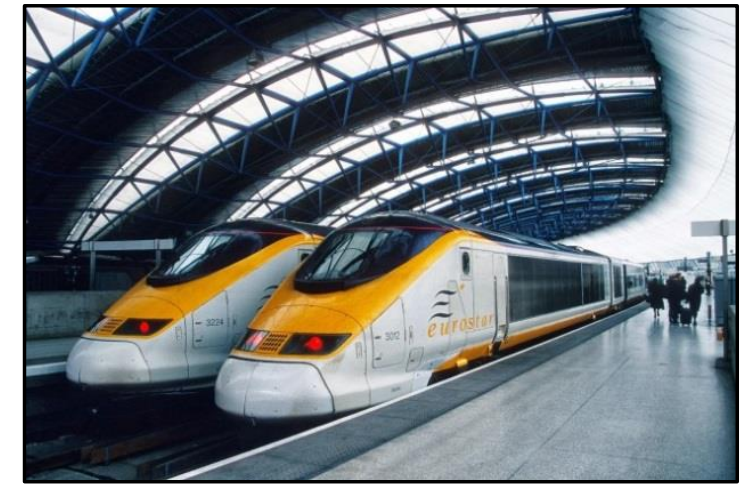

b) Eurostar. Fonte:

http://viajedetrem.blogspot.com.br/.

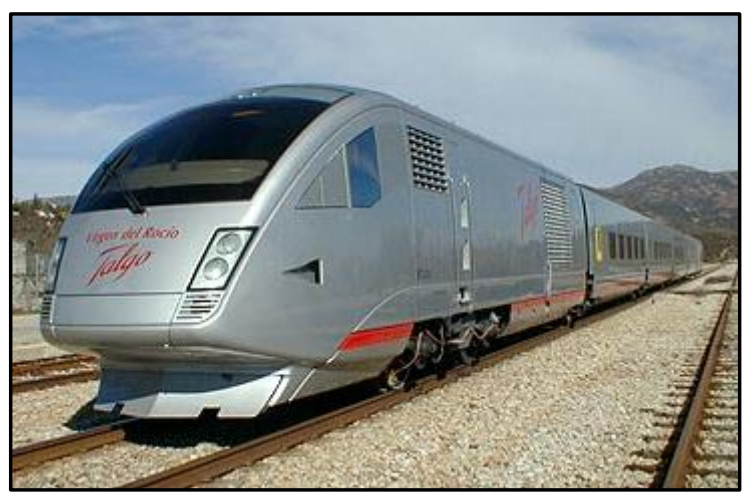

d) Talgo. Fonte:

http://www.talgoamerica.com/history.aspx.

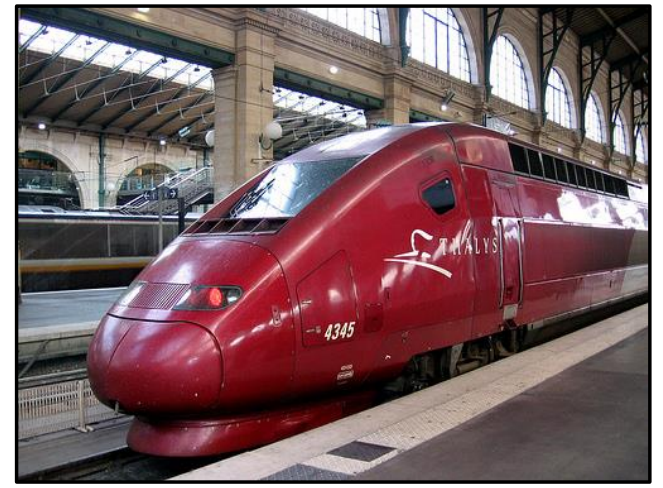

f) Thalys 2. Fonte:

https://blogostoso.wordpress.com/tag/thalys 


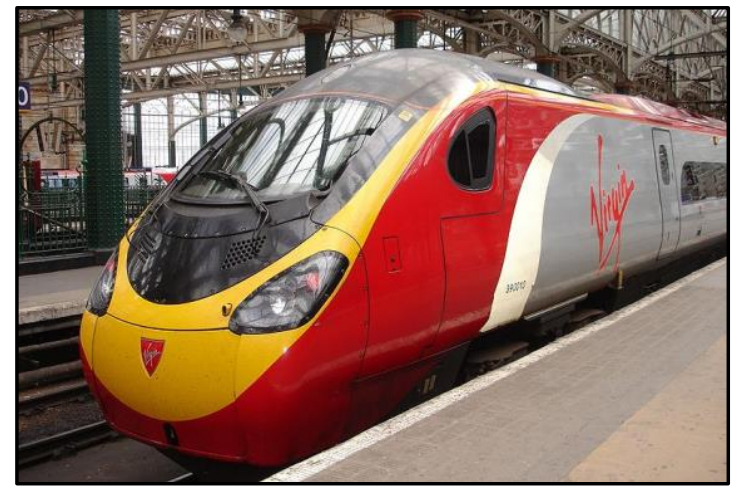

g) Virgin. Fonte:

http://www.lancashirebusinessview.co.uk/virgi n-wins-rail-services-rights-promises-linkblackpool-london-42927/.

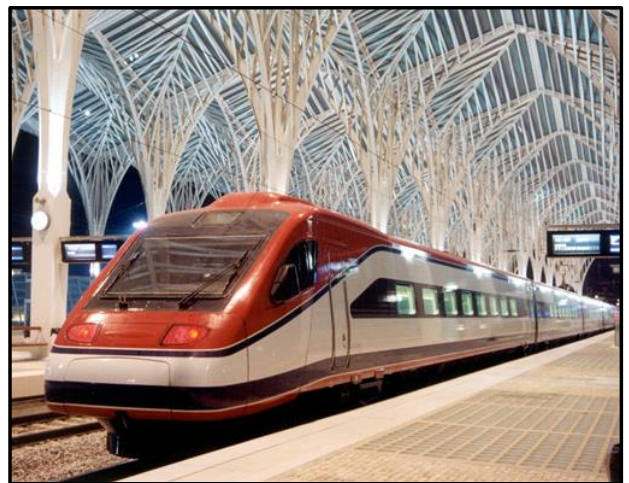

h) Alfa Pendular. Fonte: http://kem-makode.blogspot.com.br/2012/08/vamos-falarde-tgv.html.

Figura 3.4: Principais trens de alta velocidade europeus

As características dos comboios indicados na Figura 3.4 ("a" a "g"), extraídas do ERRI D 214/RP 9 (1999), são apresentadas a seguir.

Tabela 3.1: Características dos principais trens europeus de alta velocidade. Fonte: ERRI D 214/RP 9 (1999).

\begin{tabular}{|c|c|c|c|c|c|}
\hline Comboio & $\begin{array}{c}\text { Tipo de } \\
\text { comboio }\end{array}$ & $\begin{array}{c}\text { Número de } \\
\text { eixos }\end{array}$ & $\begin{array}{c}\text { Comprimento } \\
\text { total }(\mathbf{m})\end{array}$ & $\begin{array}{c}\text { Afastamento médio } \\
\text { entre truques }(\mathbf{m})\end{array}$ & $\begin{array}{c}\text { Carga média } \\
\text { por eixo }(\mathbf{k N})\end{array}$ \\
\hline \hline ETR Y500 & Convencional & 48 & 295,7 & 26,1 & 131 \\
\hline Eurostar & Articulado & 48 & 387,67 & 18,7 & 170 \\
\hline ICE2 & Convencional & 56 & 350,52 & 26,4 & 124 \\
\hline Talgo AV2 & Regular & 40 & 356,05 & 13,14 & 170 \\
\hline TGV & Articulado & 60 & 468,14 & 18,7 & 169 \\
\hline Thalys 2 & Articulado & 52 & 393,34 & 18,7 & 169 \\
\hline Virgin & Convencional & 44 & 258,7 & 23,9 & 170 \\
\hline
\end{tabular}

A Tabela 3.2 apresenta os parâmetros dos comboios ICE 2 e Eurostar utilizados para análise dinâmica com interação veículo-estrutura, conforme indica o documento ERRI D 214/RP 9, 1999. 
Tabela 3.2: Parâmetros dos comboios ICE 2 e Eurostar. Fonte: ERRI D 214/RP 9 (1999).

\begin{tabular}{|c|c|c|c|c|c|c|}
\hline \multicolumn{2}{|c|}{ Propriedades mecânicas do trem } & \multicolumn{2}{|c|}{ ICE 2 } & \multicolumn{3}{c|}{ Eurostar } \\
\cline { 3 - 7 } & & Locomotiva & Carro & Locomotiva & Carro R1 & Carros R2-R8 \\
\hline \hline \multirow{2}{*}{ Corpo do carro } & $\mathrm{Mc}(\mathrm{kg})$ & 60.768 & 33.930 & 51.500 & 35.860 & 22.525 \\
\cline { 2 - 7 } & $\mathrm{Jc}\left(\mathrm{kg} \cdot \mathrm{m}^{2}\right)$ & 1.344 .000 & 2.115 .000 & 1.050 .000 & 1.658 .000 & 810.000 \\
\hline \multirow{2}{*}{ Truque } & $\mathrm{Mc}(\mathrm{kg})$ & 5.600 & 2.373 & 2.200 & 2.200 & 2.900 \\
\cline { 2 - 7 } & $\mathrm{Jc}\left(\mathrm{kg} \cdot \mathrm{m}^{2}\right)$ & 21.840 & 1.832 & 1.900 & 1.900 & 2.508 \\
\hline Rodas & $\mathrm{Mw}(\mathrm{kg})$ & 2.003 & 1.728 & 1.700 & 1.700 & 1.900 \\
\hline Carga nas rodas & $\mathrm{Pw}(\mathrm{N})$ & 196.200 & 112.000 & 170.000 & 170.000 & 170.000 \\
\hline $\begin{array}{c}\text { Suspensão } \\
\text { secundária }\end{array}$ & $\mathrm{Kp} \mathrm{(N/m)}$ & 1.760 .000 & 300.000 & 3.260 .000 & 90.000 & 580.000 \\
\cline { 2 - 7 } & $\mathrm{Cp}(\mathrm{N} . \mathrm{s} / \mathrm{m})$ & 152.000 & 6.000 & 90.000 & 20.000 & - \\
\hline $\begin{array}{c}\text { Suspensão } \\
\text { primária }\end{array}$ & $\mathrm{Kp}(\mathrm{N} / \mathrm{m})$ & 4.800 .000 & 1.600 .000 & 2.600 .000 & 2.600 .000 & 2.000 .000 \\
\cline { 2 - 7 } & $\mathrm{Cp}(\mathrm{N} . \mathrm{s} / \mathrm{m})$ & 108.000 & 20.000 & 12.000 & 12.000 & 12.000 \\
\hline Comprimento & $\mathrm{L}(\mathrm{m})$ & 20,9 & 26,4 & 22,5 & 21,845 & 18,7 \\
\hline
\end{tabular}

O trem Alfa Pendular é um modelo muito utilizado em Portugal e será objeto de estudo neste trabalho, por disponibilidade das informações sobre as características geométricas e parâmetros necessários para a modelagem dinâmica do trem.

A seguir, são apresentados a geometria e os parâmetros considerados para o trem Alfa Pendular.

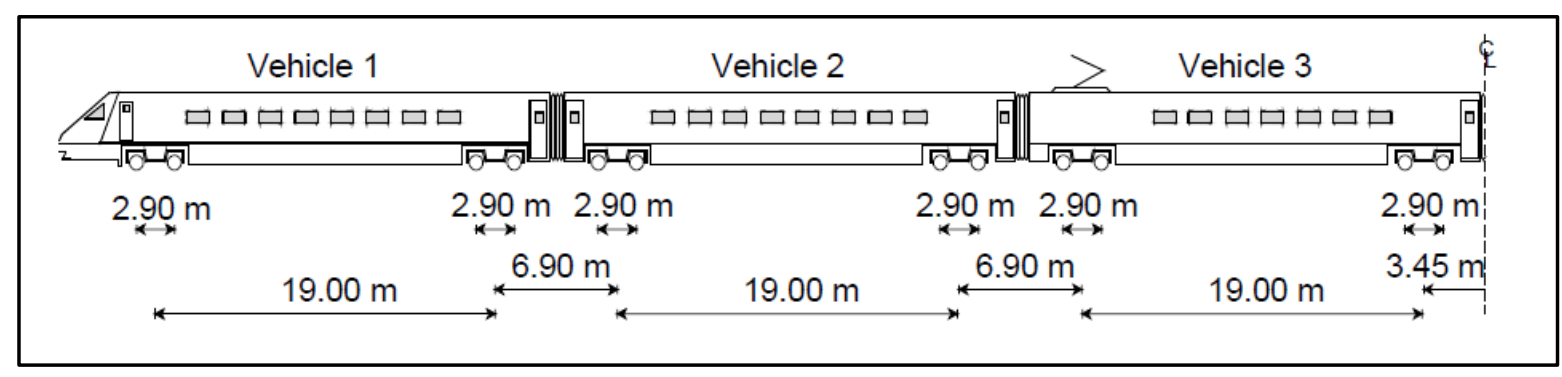

Figura 3.5: Geometria do trem Alfa Pendular. Fonte: COSTA et al (2012).

Para avaliar o efeito dinâmico correspondente a um trem específico, é calculada a assinatura do trem $\left(S_{0}\right)$. Este parâmetro permite determinar os efeitos de diferentes trens para uma mesma estrutura, bem como a resposta dinâmica para uma determinada ponte, conforme indica o documento ERRI D 214/RP 9, 1999.

A expressão a seguir, extraída de (FIGUEIREDO et al, 2009), apresenta o cálculo da assinatura de um comboio, onde $\lambda$ indica o comprimento de onda da excitação, $M$ é o número de eixos do comboio e $P_{k}$ corresponde à carga aplicada no eixo $k$ a uma distância $x_{k}$ do primeiro eixo $\left(P_{1}\right)$.

$$
S_{0}(\lambda)=\operatorname{MAX} X_{i=1 a M} \sqrt{\left[\sum_{k=1}^{i} P_{k} \cos \left(\frac{2 \pi x_{k}}{\lambda}\right)\right]^{2}+\left[\sum_{k=1}^{i} P_{k} \operatorname{sen}\left(\frac{2 \pi x_{k}}{\lambda}\right)\right]^{2}}
$$


De acordo com Figueiredo et al (2009), a determinação de assinatura do comboio refere-se a uma medida de comparação da agressividade do material rolante existente e futuro e pode ser entendida como uma transformada de Fourier da ação induzida por um conjunto de cargas, indicando os comprimentos de onda nas quais este conjunto produz os maiores efeitos.

A Figura 3.6 apresenta a assinatura de comboios reais e a Figura 3.7 mostra a assinatura para o trem Alfa Pendular.

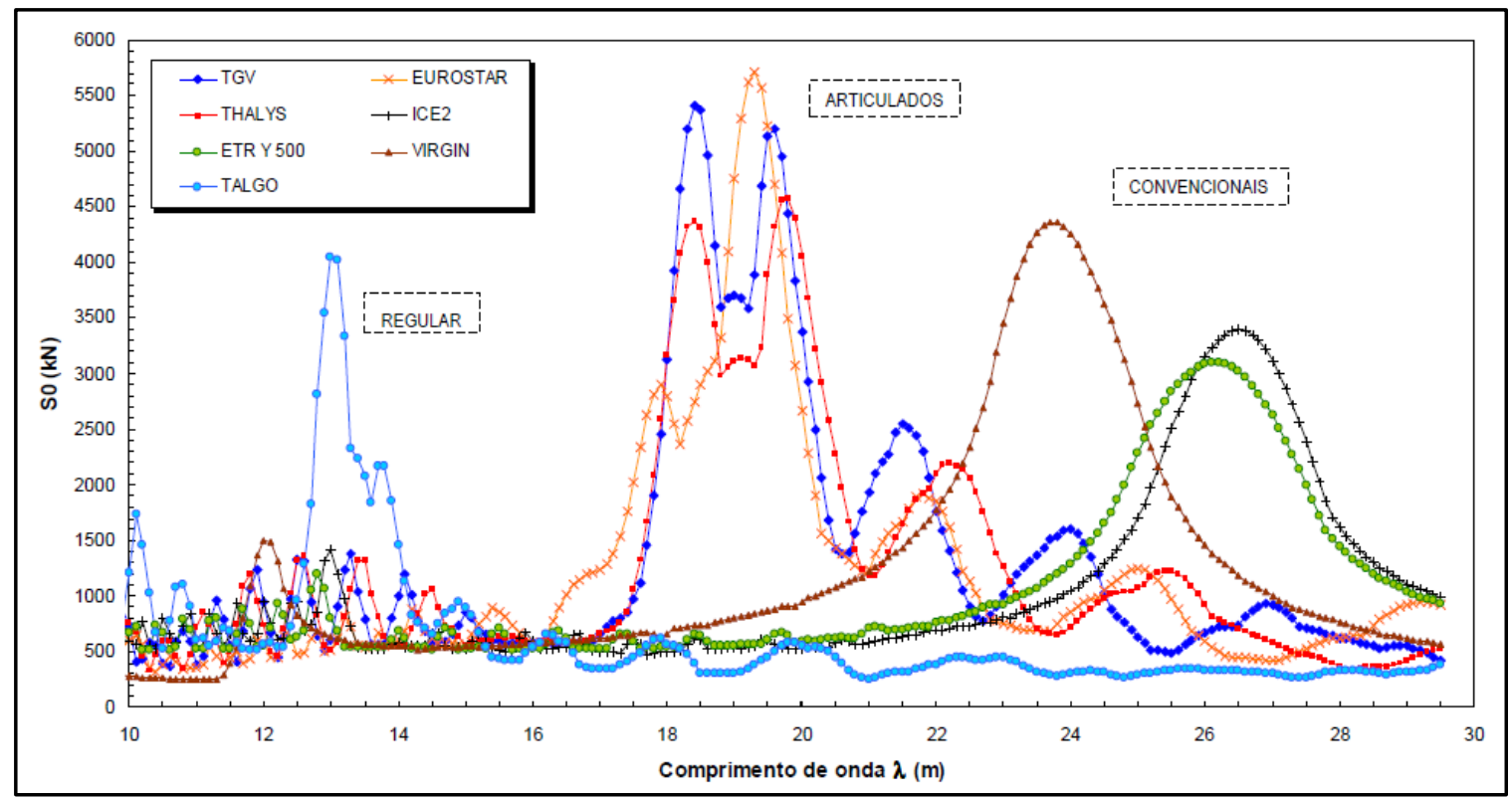

Figura 3.6: Assinatura de comboios reais. Fonte FIGUEIREDO et al (2009).

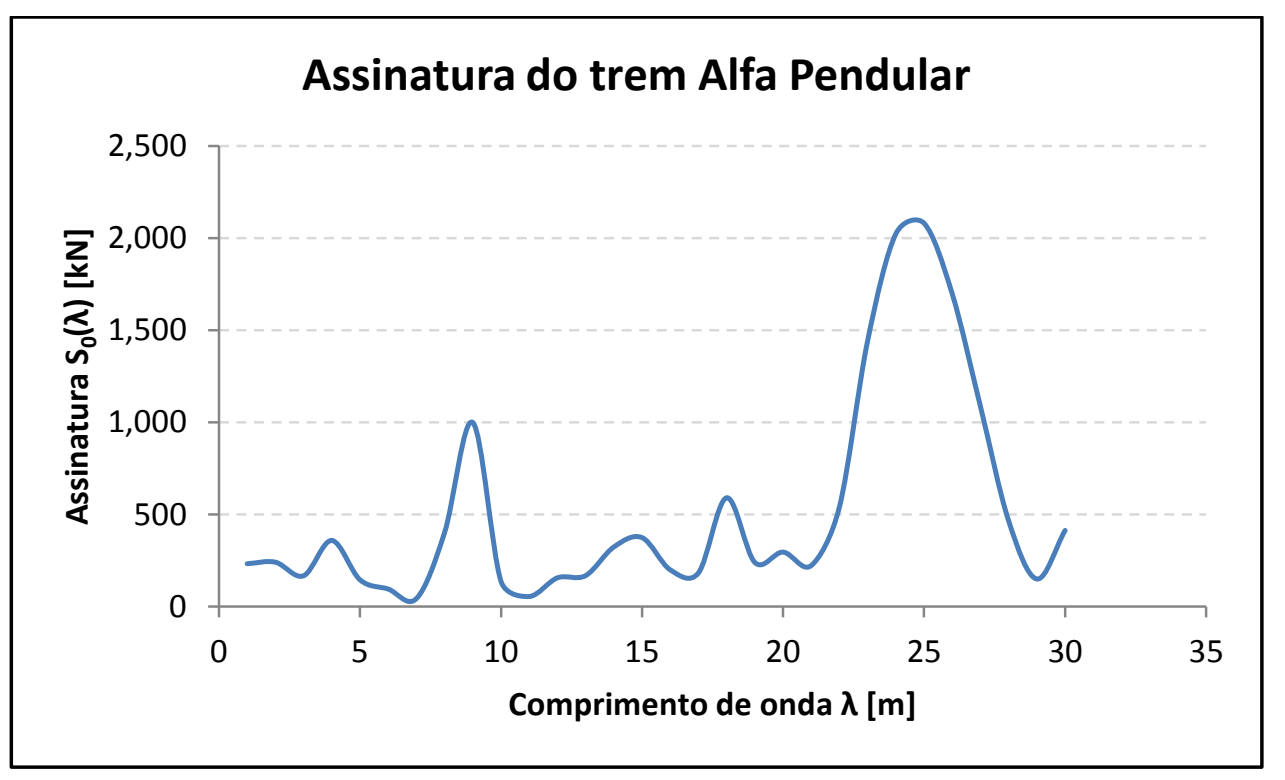

Figura 3.7: Assinatura do trem Alfa Pendular. Fonte: Autor. 


\section{SOLUÇÕES ESTRUTURAIS}

Conforme apresentado em Figueiredo et al (2009), durante a elaboração de projetos estruturais de pontes ferroviárias de vias de alta velocidade, alguns aspectos são relevantes na escolha do esquema estrutural longitudinal da estrutura, pois este deve ser capaz de garantir a segurança, bem como o funcionamento da via. Além disso, o esquema estrutural está relacionado com a condição de continuidade dos trilhos, que não devem estar expostos à ruptura devido ao esgotamento de sua capacidade resistente ou à instabilidade.

Neste sentido, o esquema estrutural longitudinal deve conter pontos fixos, localizados sobre os pilares ou encontros das pontes, capazes de absorver os efeitos de aceleração, frenagem e dilatação térmica. Estes esforços podem ser aliviados mediante a instalação de aparelhos de dilatação da via, porém, este tipo de junta pode constituir uma zona frágil e sujeita a grandes amplificações, além do custo elevado e necessidade de manutenção na via.

Assim, o Eurocode limita o comprimento entre o ponto fixo e a extremidade do vão $\left(L_{T}\right)$ como sendo igual a $60 \mathrm{~m}$ para estruturas metálicas e $90 \mathrm{~m}$ para estruturas mistas e de concreto.

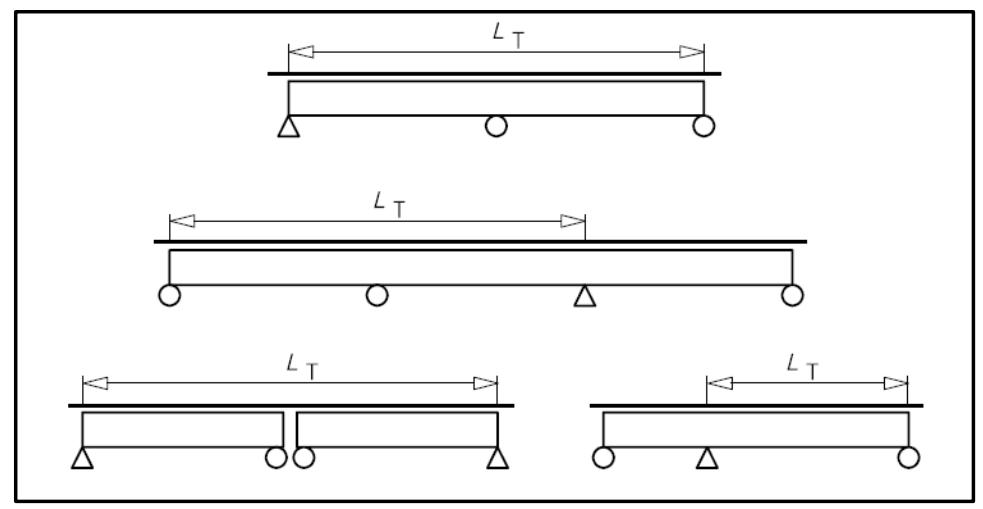

Figura 4.1: Exemplos de comprimentos de expansão $\left(L_{T}\right)$. Fonte: EN 1991-2 (2003) adaptado.

Desta forma, o esquema estrutural adotado em projetos de pontes ferroviária pode ser formado por vãos simplesmente apoiados com trilho contínuo, cujo comprimento máximo do vão deve atender aos limites indicados $\left(L_{T}\right)$, ou ser formado por vãos contínuos com a utilização dos aparelhos de dilatação. No caso de pontes contínuas extensas, podem ainda serem utilizadas estruturas de transição entre os tramos contínuos, por meio de tramos isostáticos, chamados de tramos "neutros", sobre os quais são instalados os aparelhos de dilatação da via. A Figura 4.2 ilustra a utilização de tramos neutros. 


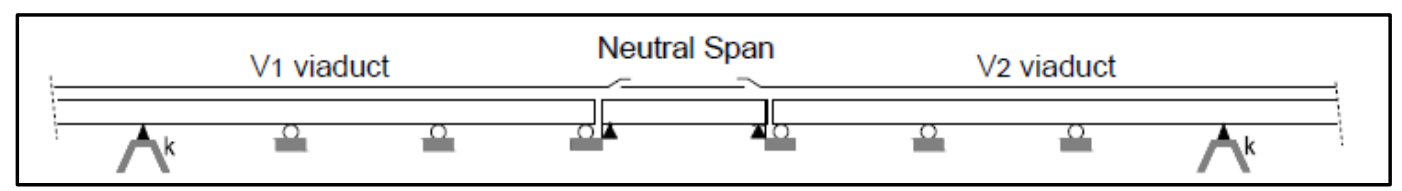

Figura 4.2: Exemplo de utilização de tramos neutros em pontes. Fonte: MONTENEGRO E ALMEIDA et al (2012).

Outro aspecto importante na solução estrutural adotada em projetos é a utilização ou não de lastro. Segundo Casal (2010), a utilização de vias sem lastro tem apresentado grandes vantagens em linhas de alta velocidade que se caracterizam por apresentarem maiores exigências em nível funcional e construtivo. Pontes onde o lastro não é utilizado apresentam redução da manutenção da via, aumento significativo da vida útil da via, maior estabilidade da via e maior resistência lateral, além de ser uma solução para o problema de sucção do lastro devido à passagem do trem. Por outro lado, a via sem lastro apresenta elevados custos de construção, elevado ruído, dificuldade de alterações na via e grandes exigências à fundação da ponte, uma vez que os recalques podem danificar a estrutura.

Casal também destaca o problema de interação via-ponte em vias sem lastro localizado nas transições, devido a este tipo de via ser mais sensível às deformações ocorridas na estrutura, podendo gerar forças de levantamento ou deformações por flexão nos trilhos. No caso dos encontros, este problema é agravado devido aos assentamentos que podem ocorrer no nível do solo e à diferença de rigidez entre a ponte e o solo.

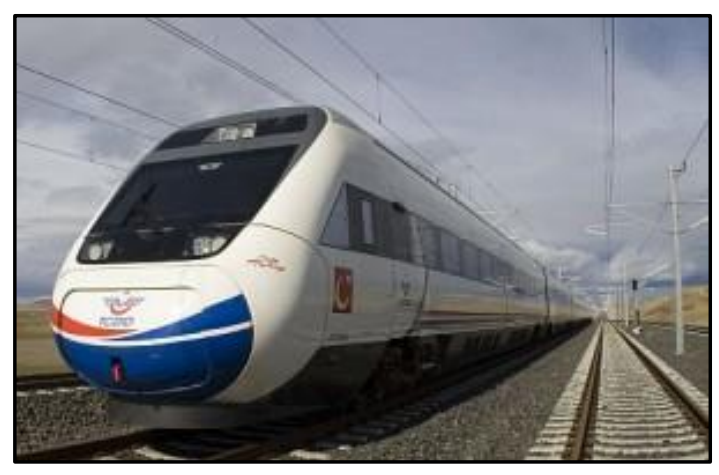

(a)

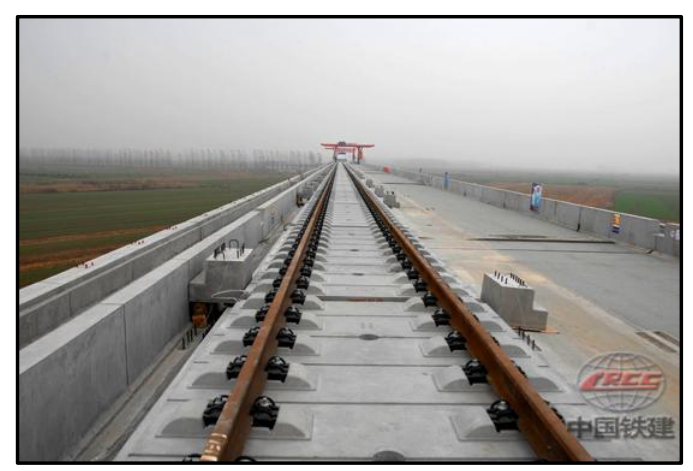

(b)

Figura 4.3: Vias com lastro (a) e sem lastro (b). Fonte: http://kem-makode.blogspot.com.br/2012/08/vamos-falar-de-tgv.html e http://news.frbiz.com/china_railway_15_bureau_headquarters-397354.html. 


\section{METODOLOGIA DE TRABALHO}

Este trabalho apresenta um aprimoramento da metodologia proposta por Cunha (2011) para a realização de análise dinâmica de pontes ferroviárias. Aqui são consideradas análises em pontes de vias de alta velocidade, utilizando modelos de alta hierarquia para a ponte. Além disso, são estudadas características como velocidade do comboio e imperfeições geométricas no plano vertical dos trilhos, o efeito do lastro na ponte, o contato entre as rodas e os trilhos e o conforto dos passageiros. Também é realizada uma análise de distribuição estatística, a fim de se obter a probabilidade de se garantir o conforto dos passageiros e a estabilidade da via, conforme os limites estabelecidos pelo Eurocode.

$\mathrm{Na}$ metodologia proposta para a realização das análises dinâmicas, avalia-se o comportamento do veículo e da estrutura de forma desacoplada. Assim, realiza-se, inicialmente, a análise do modelo veicular, com os quinze graus de liberdade já mencionados, considerando elementos de contato em cada roda do trem. A excitação é introduzida mediante deslocamentos impostos no plano vertical, representando as irregularidades existentes nos trilhos. Admite-se, numa primeira análise, que o tabuleiro da ponte é rígido e indeslocável, porém este pressuposto é corrigido por meio de um processo iterativo, de forma a somar os deslocamentos do tabuleiro, obtidos para a primeira determinação dos esforços de interação (com tabuleiro indeslocável) à excitação de suporte aplicada nas rodas do trem. Com isso, obtêm-se novos esforços de interação, que são reaplicados ao modelo do tabuleiro para determinar novos deslocamentos, repetindo-se o procedimento até que os resultados sejam muito próximos aos do passo anterior.

A análise dinâmica do veículo foi realizada para velocidades de $144 \mathrm{~km} / \mathrm{h}$ até $350 \mathrm{~km} / \mathrm{h}$. De acordo com o Eurocode (EN 1991-2, 2003), devem ser analisadas velocidades até 1,2 vezes a velocidade máxima prevista para a via (de $220 \mathrm{~km} / \mathrm{h}$ ), que, neste caso, corresponderia a $264 \mathrm{~km} / \mathrm{h}$. A análise para esta variação de velocidades é importante, pois a frequência de excitação do trem pode ser estimada em função da velocidade, $f=v / d$, onde $v$ é a velocidade do trem e $d$ é a distância regular entre os eixos. Desta forma, a frequência obtida para a velocidade máxima de tráfego pode não ser próxima a uma frequência natural da ponte, mas pode-se encontrar esta proximidade para outra velocidade, causando o efeito de ressonância. Observa-se que, apesar de a norma especificar a análise de velocidades até $264 \mathrm{~km} / \mathrm{h}$ para este estudo de caso, optou-se por avaliar o comportamento para velocidades superiores a este limite, como $300 \mathrm{~km} / \mathrm{h}$ e $350 \mathrm{~km} / \mathrm{h}$. A Tabela 5.1 apresenta as velocidades adotadas para análise estrutural. 
Tabela 5.1: Velocidades analisadas. Fonte: Autor.

\begin{tabular}{|c|c|}
\hline Velocidades [m/s] & Velocidades [km/h] \\
\hline \hline 40,00 & 144 \\
\hline 41,67 & 150 \\
\hline 44,44 & 160 \\
\hline 47,22 & 170 \\
\hline 50,00 & 180 \\
\hline 52,78 & 190 \\
\hline 55,56 & 200 \\
\hline 58,33 & 210 \\
\hline 61,11 & 220 \\
\hline 63,89 & 230 \\
\hline 66,67 & 240 \\
\hline 69,44 & 250 \\
\hline 72,22 & 260 \\
\hline 73,33 & 264 \\
\hline 83,33 & 300 \\
\hline 97,22 & 350 \\
\hline
\end{tabular}

As forças de interação obtidas no modelo veicular, para cada roda, são aplicadas no modelo de alta hierarquia da ponte, em elementos finitos, de forma a simular o tráfego do trem sobre a ponte.

As forças de interação são aplicadas em cada nó da malha do modelo da estrutura, na posição dos trilhos. Desta forma, para não ser necessário interpolar as forças nodais, a discretização da estrutura deve estar compatível com o passo de tempo adotado, de forma a atender a um dos critérios a seguir (CALÇADA, 2014 apud ERRI D 214/RP 9):

$$
\Delta t=\frac{T_{n}}{8} \approx \frac{T_{n}}{10} \text { ou } \Delta t=\frac{L}{4 n v_{\text {máx }}}
$$

onde:

$T_{n}$ : é o menor período de vibração da estrutura considerado na análise;

n: é o número de modos a ser incluído nas análises;

$L$ : é o vão da ponte;

$v_{\text {máx }}:$ é a velocidade máxima do trem.

Observa-se que a escolha do incremento do tempo deverá também atender a requisitos análogos à Equação 5.1, agora referentes aos menores períodos naturais dos veículos e aos menores períodos da excitação induzidos pelas irregularidades.

Cabe observar que, para a realização das análises dinâmicas, a análise transiente feita no ADINA utiliza o método de Newmark, cujos parâmetros de estabilidade adotados são $\gamma=0,5$ e $\beta=0,25$. 


\section{PROCEDIMENTOS DE MODELAGEM}

\subsection{VEÍCULO}

Para a modelagem veicular, considerou-se o modelo de trem Alfa Pendular devido à disponibilidade de informações sobre a geometria e parâmetros mecânicos deste veículo. Os dados geométricos utilizados foram extraídos de Costa et al (2012) e são apresentados na Figura 3.5 e na Tabela 6.2.

$\mathrm{Na}$ análise do veículo, foram considerados quinze graus de liberdade, sendo três graus referentes ao deslocamento vertical (bounce), três de deslocamento horizontal transversal (sway), três graus de rotação em torno do eixo transversal (pitch), três de rotação em torno do eixo longitudinal (roll) e três de rotação em torno do eixo vertical (yaw), todos os graus analisados para o vagão e os dois truques.

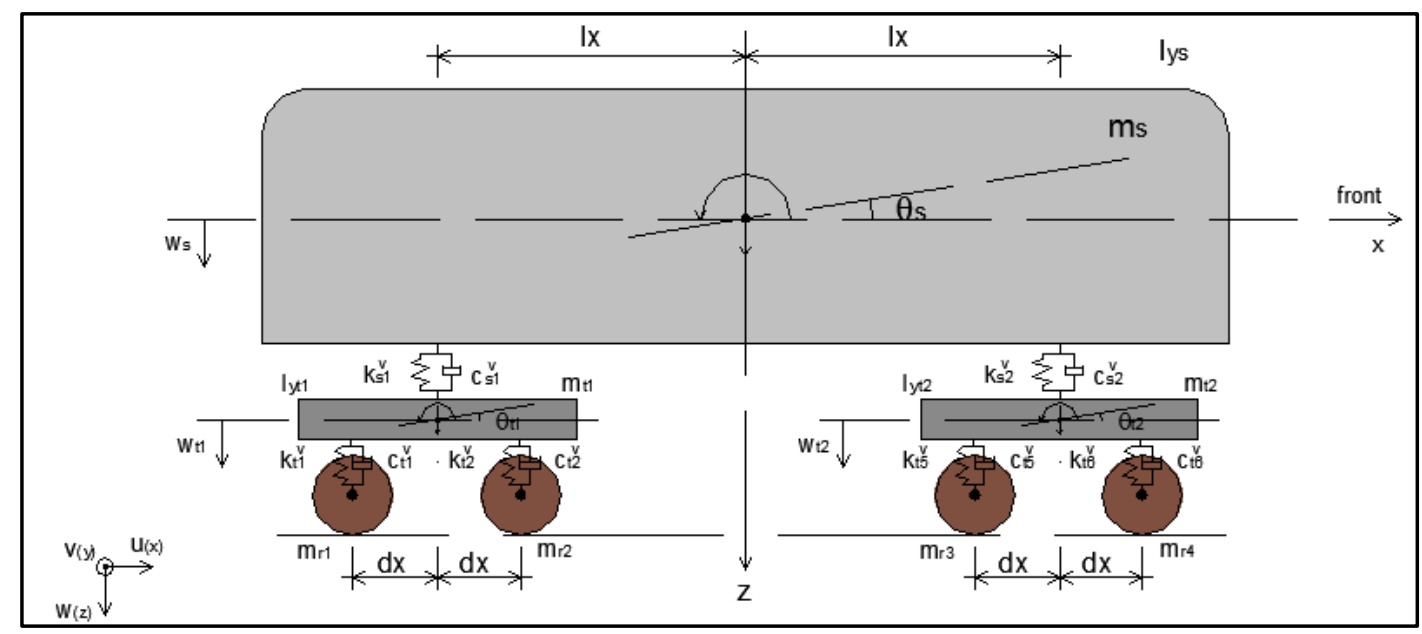

a) Seção longitudinal

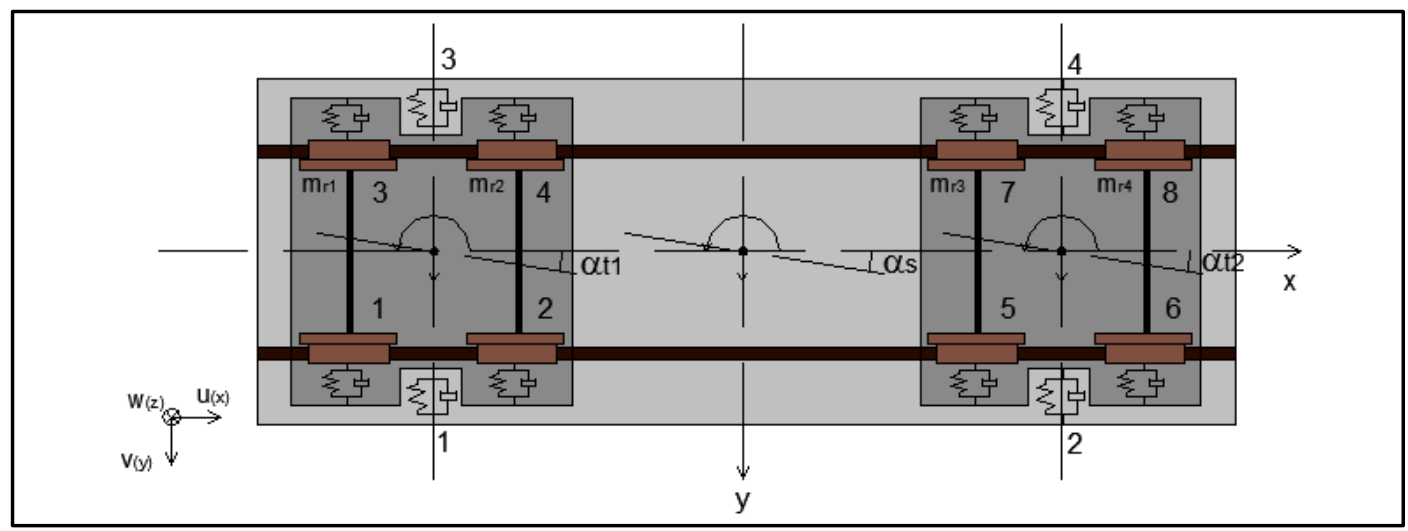

b) Planta 


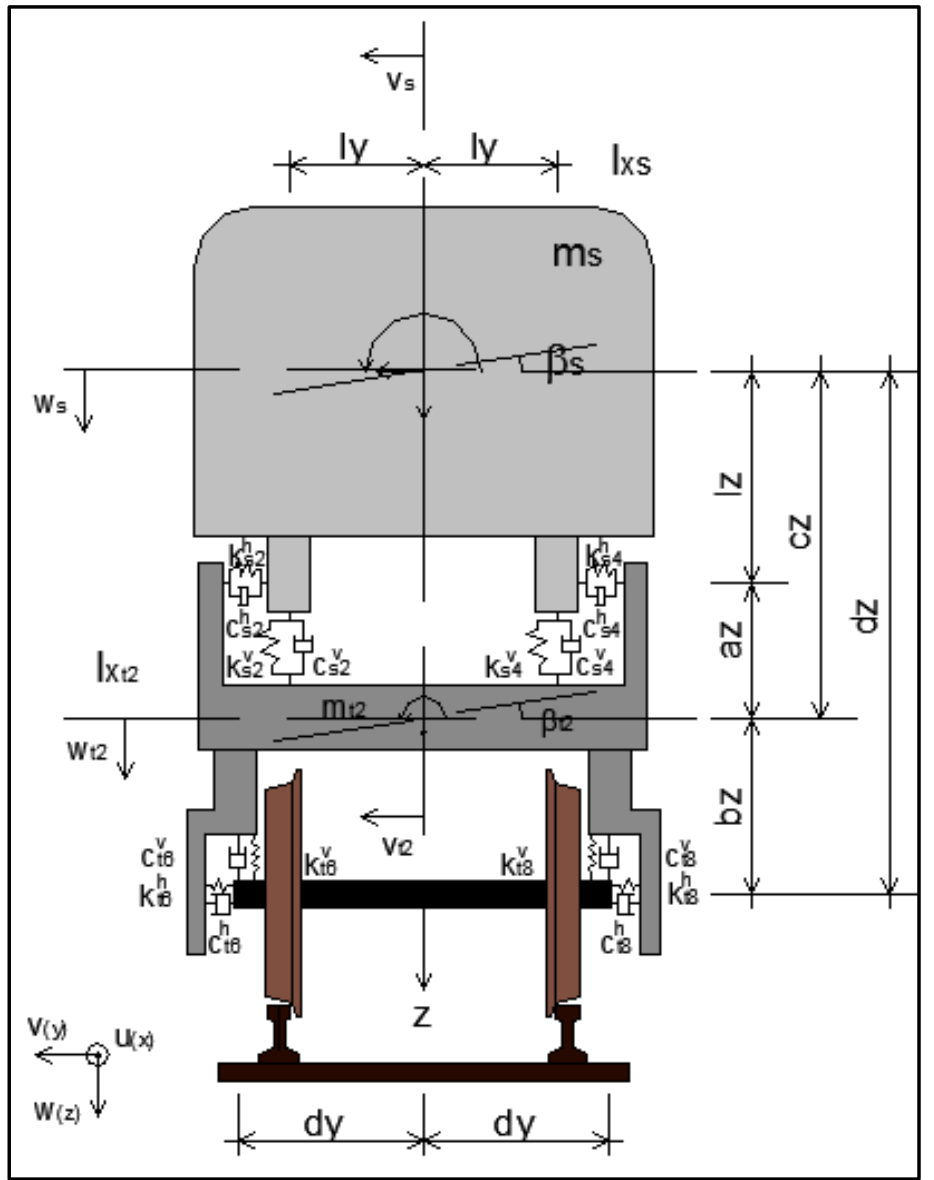

c) Seção transversal

Figura 6.1: Modelo dinâmico do veículo. Fonte: CUNHA (2011).

Tabela 6.1: Parâmetros geométricos do veículo. Fonte: Autor.

\begin{tabular}{|c|c|}
\hline Dimensão & Medida (m) \\
\hline \hline $\mathrm{Ix}$ & 9,5 \\
\hline $\mathrm{ly}$ & 1,55 \\
\hline $\mathrm{dx}$ & 1,35 \\
\hline $\mathrm{d} y$ & 1,07 \\
\hline $\mathrm{Iz}$ & 1,2 \\
\hline $\mathrm{az}$ & 0,52 \\
\hline $\mathrm{bz}$ & 0,52 \\
\hline $\mathrm{cz}$ & 1,72 \\
\hline $\mathrm{d} z$ & 2,24 \\
\hline
\end{tabular}


Tabela 6.2: Propriedades mecânicas do trem Alfa Pendular. Fonte: MAGALHÃES (2013).

\begin{tabular}{|c|c|c|}
\hline \multirow{4}{*}{ Corpo do carro } & $\mathrm{m}_{\mathrm{s}}(\mathrm{kg})$ & 46.200 \\
\hline & $\mathrm{I}_{\mathrm{xs}}\left(\mathrm{kg} \cdot \mathrm{m}^{2}\right)$ & 78.000 \\
\hline & $\mathrm{I}_{\mathrm{ys}}\left(\mathrm{kg} \cdot \mathrm{m}^{2}\right)$ & 2.600 .000 \\
\hline & $\mathrm{I}_{\mathrm{zs}}\left(\mathrm{kg} \cdot \mathrm{m}^{2}\right)$ & 2.600 .000 \\
\hline \multirow{4}{*}{ Suspensão secundária } & $\mathrm{k}_{\mathrm{sv}}(\mathrm{N} / \mathrm{m})$ & 273.250 \\
\hline & $\mathrm{k}_{\mathrm{sh}}(\mathrm{N} / \mathrm{m})$ & 815.000 \\
\hline & $\mathrm{C}_{\mathrm{sv}}(\mathrm{N} . \mathrm{s} / \mathrm{m})$ & 26.900 \\
\hline & $\mathrm{c}_{\mathrm{sh}}(\mathrm{N} . \mathrm{s} / \mathrm{m})$ & 428.000 \\
\hline \multirow{8}{*}{ Truques } & $\mathrm{m}_{\mathrm{t} 1}(\mathrm{~kg})$ & 3.000 \\
\hline & $\mathrm{I}_{\mathrm{xt1}}\left(\mathrm{kg} \cdot \mathrm{m}^{2}\right)$ & 2.100 \\
\hline & $\mathrm{I}_{\mathrm{yt1}\left(\mathrm{kg} \cdot \mathrm{m}^{2}\right)}$ & 2.600 \\
\hline & $I_{z t 1}\left(k g \cdot m^{2}\right)$ & 4.800 \\
\hline & $\mathrm{m}_{\mathrm{t} 2}(\mathrm{~kg})$ & 3.000 \\
\hline & $\mathrm{I}_{\mathrm{xt2} 2}\left(\mathrm{~kg} \cdot \mathrm{m}^{2}\right)$ & 2.100 \\
\hline & $\mathrm{I}_{\mathrm{yt2} 2}\left(\mathrm{~kg} \cdot \mathrm{m}^{2}\right)$ & 2.600 \\
\hline & $\mathrm{I}_{\mathrm{zt} 2}\left(\mathrm{~kg} \cdot \mathrm{m}^{2}\right)$ & 4.800 \\
\hline \multirow{4}{*}{ Suspensão primária } & $\mathrm{k}_{\mathrm{tv}}(\mathrm{N} / \mathrm{m})$ & 706.050 \\
\hline & $\mathrm{k}_{\mathrm{th}}(\mathrm{N} / \mathrm{m})$ & 5.000 .000 \\
\hline & $\mathrm{c}_{\mathrm{tv}}(\mathrm{N} . \mathrm{s} / \mathrm{m})$ & 17.700 \\
\hline & $\mathrm{c}_{\mathrm{th}}(\mathrm{N} . \mathrm{s} / \mathrm{m})$ & 100 \\
\hline \multirow{4}{*}{ Eixos } & $\mathrm{m}_{\mathrm{r} 1}(\mathrm{~kg})$ & 1.800 \\
\hline & $\mathrm{m}_{\mathrm{r} 2}(\mathrm{~kg})$ & 1.800 \\
\hline & $\mathrm{m}_{\mathrm{r} 3}(\mathrm{~kg})$ & 1.800 \\
\hline & $m_{r 4}(k g)$ & 1.800 \\
\hline
\end{tabular}

O trem foi modelado com a utilização do software ADINA - Automatic Dynamic Incremental Nonlinear Analysis. O modelo foi realizado considerando elementos de viga de Euler-Bernoulli com seis graus de liberdade em cada nó (tipo beam, conforme terminologia do ADINA) e elementos rígidos (rigid link) para garantir o comportamento de corpo rígido entre as barras de uma mesma estrutura, vagão ou truque. As molas e os amortecedores foram representados por elementos de barra do tipo spring (na terminologia do ADINA), aos quais é possível atribuir propriedades de rigidez e amortecimento, cujos valores são apresentados na Tabela 6.2. Na Figura 6.2 apresenta-se o modelo veicular. 


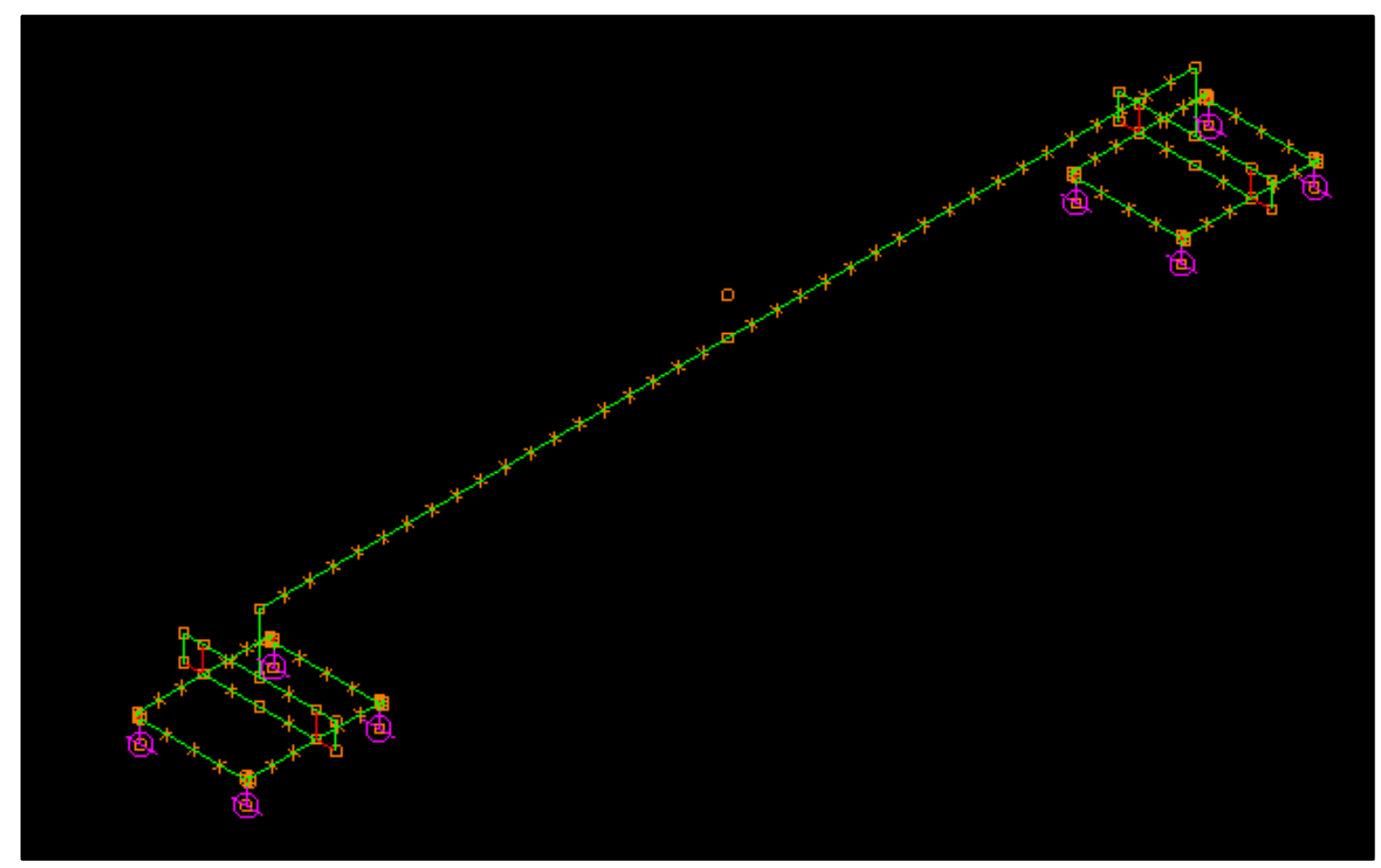

Figura 6.2: Modelo veicular do trem Alfa Pendular feito no ADINA. Fonte: Autor.

Uma preocupação relevante é a perda de contato entre o trem e a via, podendo ocorrer devido à presença de irregularidades nas rodas e nos trilhos. Esta perda de contato pode ocasionar um descarrilamento do trem, além de poder gerar forças de interação consideráveis para a estrutura. Este contato é de difícil caracterização, pois apresenta um comportamento não linear e exige o conhecimento das tensões geradas pelo veículo e estrutura.

Para a representação deste contato, utilizou-se o elemento finito de contato disponível no ADINA que, neste caso, corresponde a um contato do tipo nó a nó. O contato foi considerado em cada roda do trem, onde são aplicadas as irregularidades existentes nos trilhos. Realizou-se uma análise de sensibilidade nos parâmetros solicitados pelo ADINA, a fim de se obter uma melhor resposta.

No caso de um elemento de contato do tipo nó a nó, devem ser fornecidos os parâmetros " $w$ " (que está relacionado à força no contato) e a tolerância da penetração, ambos dependentes do módulo de elasticidade do material. A Figura 6.3 apresenta os parâmetros adotados no ADINA para caracterização do contato. 


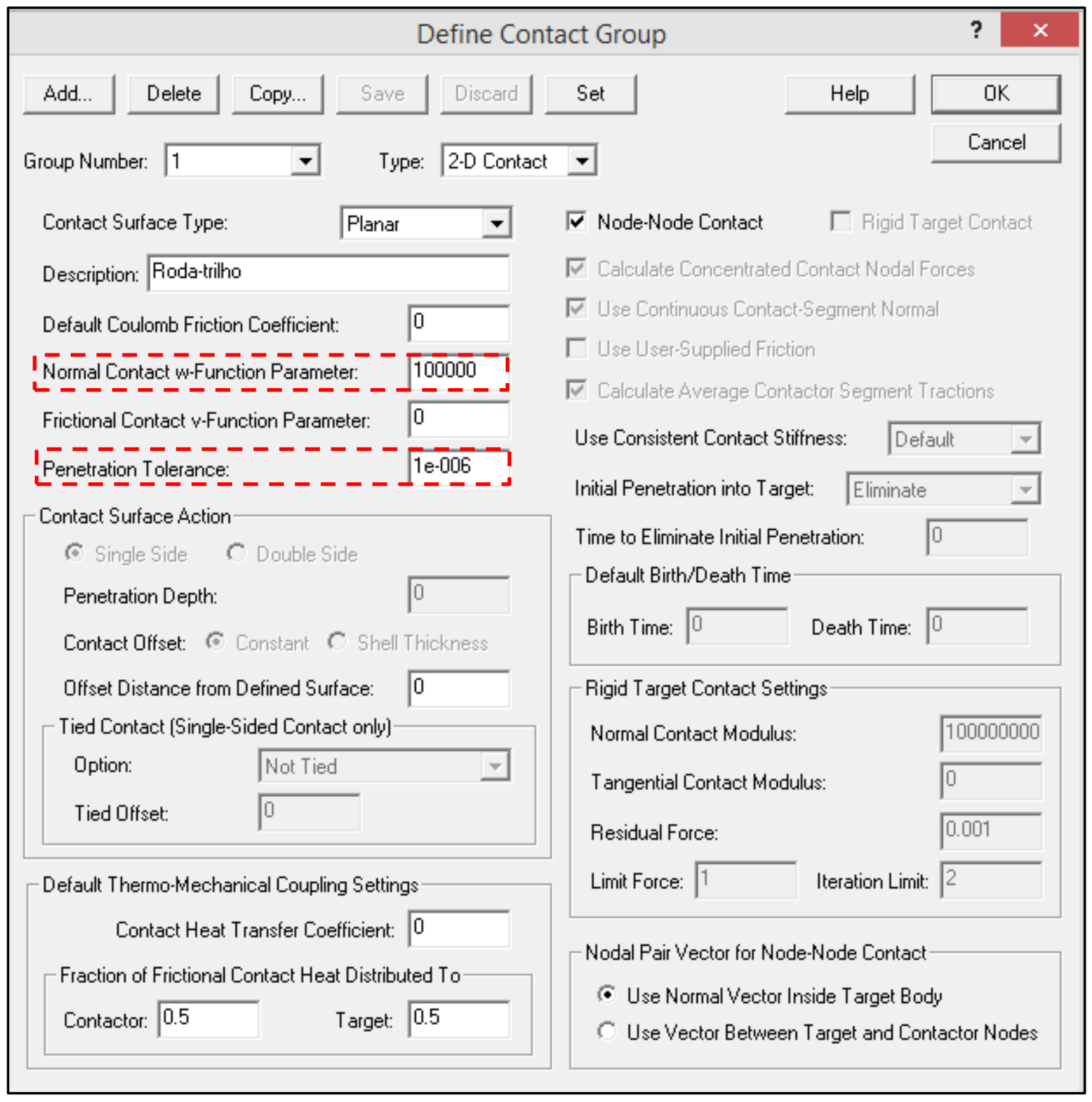

Figura 6.3: Parâmetros do elemento de contato inseridos no ADINA. Fonte: Autor.

\subsection{IRREGULARIDADES GEOMÉTRICAS}

Segundo Frýba (1996), as irregularidades representam uma importante fonte de excitação de pontes durante a passagem de veículos. As irregularidades consistem de desvios nos trilhos na faixa de contorno da geometria ideal e podem ocorrer em uma posição carregada e em uma posição descarregada (desvios da posição geométrica mesmo durante a passagem do veículo numa velocidade muito baixa).

As irregularidades dependem principalmente das folgas entre elementos individuais da via permanente e a ponte, e de suas propriedades elásticas. 
O autor especifica quatro tipos de irregularidades nos trilhos, a saber:

- $\quad$ irregularidade da elevação (perfil vertical), sendo a média da elevação de dois trilhos:

$$
\frac{1}{2}\left(y_{1}+y_{2}\right)
$$

- irregularidade do alinhamento, que é a média da posição lateral de dois trilhos:

$$
\frac{1}{2}\left(z_{1}+z_{2}\right)
$$

- irregularidade da superelevação (seção transversal), que é a média entre a diferença em elevação de dois trilhos:

$$
\frac{1}{2}\left(y_{1}-y_{2}\right)
$$

- $\quad$ irregularidade da bitola, que é a distância horizontal entre a borda interna de dois trilhos, medida perpendicularmente entre eles e $14 \mathrm{~mm}$ abaixo do topo dos trilhos:

$$
\frac{1}{2}\left(z_{1}-z_{2}\right)
$$

A elevação e superelevação das irregularidades influenciam principalmente as vibrações verticais dos veículos e das pontes, enquanto que os alinhamentos, bitola e superelevação das irregularidades desencadeiam vibrações horizontais transversais de veículos e pontes, além de torção nas pontes.

A distribuição das irregularidades ao longo dos trilhos pode ser periódica (descrita por série trigonométrica de Fourier), com ondulações nas superfícies dos trilhos, ou estocástica, descrita estatisticamente geralmente por meio de uma função de densidade espectral.

Segundo Cunha (2011), as irregularidades periódicas podem causar vibrações significantes no veículo, principalmente quando a frequência de excitação da irregularidade coincidir com alguma frequência natural do veículo. As irregularidades no plano vertical nos trilhos são originadas pela ação das rodas, ação da corrosão causada pelas intempéries e pela deformação plástica da superfície de rodagem dos trilhos, além dos defeitos do assentamento sobre a estrutura, especialmente se não houver lastro. As irregularidades no plano horizontal são causadas pela dificuldade em manter o alinhamento dos trilhos durante sua fase de construção e devido à flambagem lateral de um trecho da via ou de desvios de traçado no assentamento dos trilhos. 


\subsubsection{Irregularidade nos Trilhos}

Para as irregularidades periódicas longitudinais nos trilhos, tanto no plano vertical quanto horizontal, pode-se considerar a expressão 6.5, extraída de Cunha (2011):

$$
r(x)=A_{n} \operatorname{sen}\left(\omega_{n} t+\Phi\right)
$$

onde:

A: amplitude da irregularidade;

$\Phi:$ ângulo de fase;

$n$ : número de meias ondas em $\ell$;

$\omega_{n}$ : frequência da irregularidade $\left(\omega_{n}=\frac{2 \pi V}{\lambda_{n}}=\frac{n \pi V}{\ell}\right)$

$\ell$ : comprimento da irregularidade;

$\lambda_{n}$ : comprimento de onda

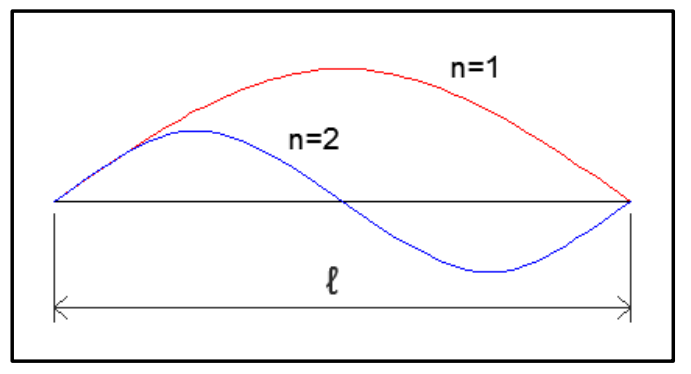

Figura 6.4: Número de meias ondas no comprimento $\ell$. Fonte: CUNHA (2011).

As irregularidades nos trilhos também podem ser definidas de forma aleatória, determinadas a partir de tratamento estatístico de várias medidas em linhas férreas. Conforme Frýba (1996), estas irregularidades podem ser definidas conforme a expressão [6.6].

$$
G(\omega)=\frac{A \omega_{2}^{2}\left(\omega^{2}+\omega_{1}^{2}\right)}{\omega^{4}\left(\omega^{2}+\omega_{2}^{2}\right)}
$$

As constantes $A, \omega_{1}$ e $\omega_{2}$ dependem do estado de conservação da via e podem ser obtidas em (FRÝBA, 1996), enquanto que $\omega$ corresponde a frequência circular.

\subsubsection{Irregularidade nas Rodas}

As irregularidades nas rodas podem ser descritas pela função: 


$$
r(x)=\left\{\begin{array}{ccc}
\frac{1}{2} a_{i}\left[1-\cos \frac{2 \pi}{b_{i}}\left(x-k A_{i}-B_{i}\right)\right], & \text { se } & B_{i}+k A_{i} \leq x \leq B_{i}+k A_{i}+b_{i} \\
0, & \text { se } & B_{i}+k A_{i}+b_{i}<x<B_{i}+(k+1) A_{i}
\end{array}\right.
$$

onde:

$A_{i}, B_{i}, a_{i}$ e $b_{i}$ : estão indicados na Figura 6.5;

$i$ : a i-ésima roda com achatamento;

$k: 0,1,2, \ldots$
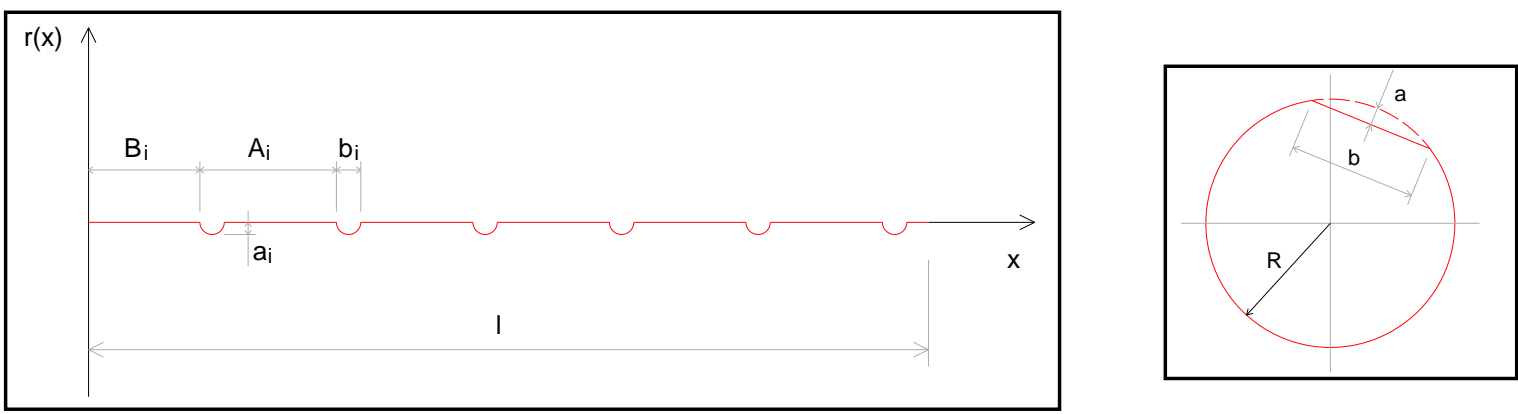

Figura 6.5: Irregularidades nas rodas. Fonte: CUNHA (2011).

\subsubsection{Irregularidade Aleatória}

Neste trabalho, será considerado como dado de entrada da análise um espectro padronizado utilizado para definir o perfil de irregularidades no plano vertical dos trilhos de forma estocástica. Partir-se-á de uma densidade espectral de potência $S(\omega)$ que define as irregularidades aleatórias nos trilhos, obtida a partir de expressões existentes na literatura (Equação 6.6) ajustadas em função de medições experimentais, sendo $\omega$ a frequência angular. Como a análise dinâmica a ser realizada será não linear, será necessária a obtenção da série espacial da irregularidade definida no tempo. Assim, a relação entre a densidade espectral de potência e o espectro de amplitude $A(\omega)$ de cada componente de frequência é dada por:

$$
S(\omega)=\frac{A^{2}(\omega)}{\Delta \omega}
$$

onde $\Delta \omega$ é o intervalo da frequência.

Como a função $S(\omega)$ foi construída a partir de valores discretos de frequências $\omega$, é natural que tanto $S(\omega)$ quanto $A(\omega)$ também sejam dados em valores discretos. 
Desta forma, considerando os valores da amplitude de oscilação para cada frequência, a série espacial de irregularidade aleatória pode ser dada por:

$$
\mathrm{r}(\mathrm{x})=\sum_{\mathrm{i}=1}^{\mathrm{N}} \mathrm{A}\left(\omega_{\mathrm{i}}\right) \cos \left(\omega_{\mathrm{i}} \mathrm{x}+\phi_{\mathrm{i}}\right)
$$

Observa-se que $\phi_{\mathrm{i}}$ é uma fase aleatória distribuída entre 0 e $2 \pi$. Desta forma, é possível gerar uma infinidade de séries espaciais que possuam a mesma densidade espectral de potência.

Assim, foram geradas duas séries espaciais de irregularidades, uma para cada trilho da via, conforme apresenta a Figura 6.6.

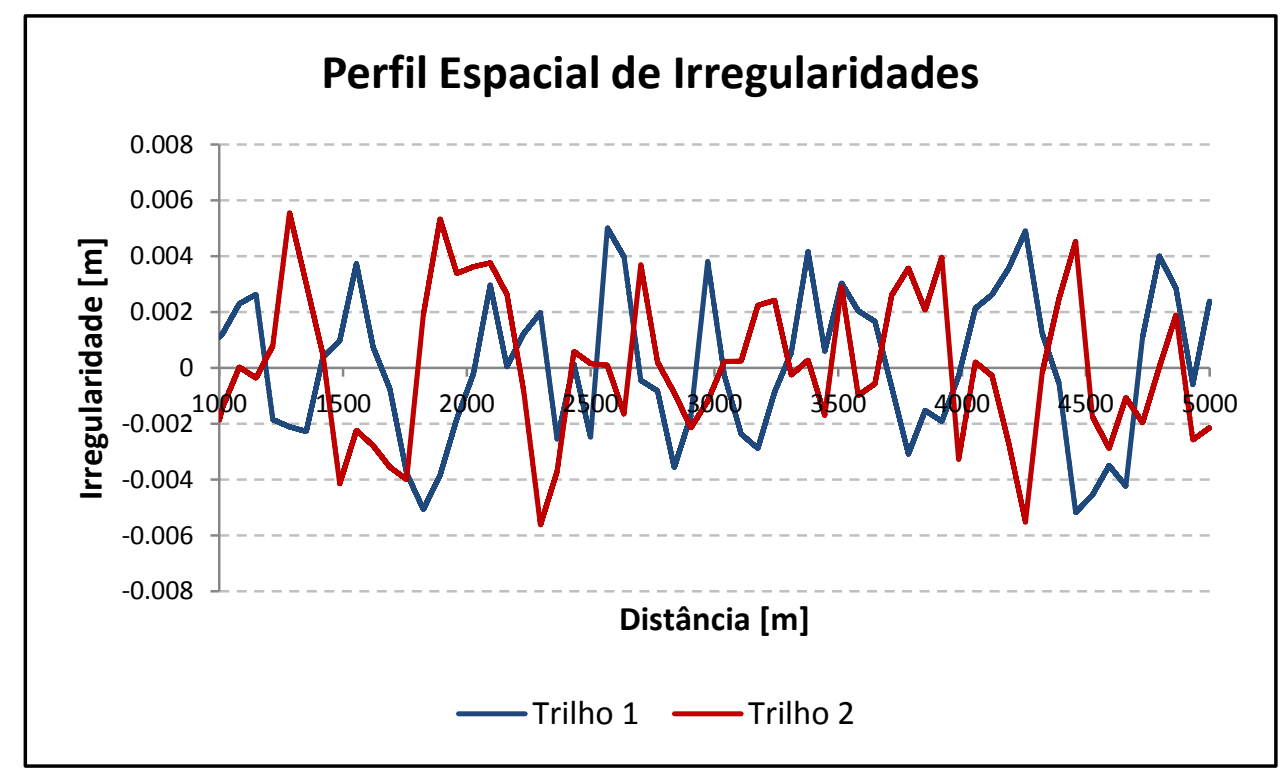

Figura 6.6: Séries espaciais de irregularidades. Fonte: Autor.

Observa-se que o perfil de irregularidade foi gerado a partir de um espectro de grande energia em baixa frequência, resultando em grande comprimento de onda. Como o objetivo deste trabalho é o desenvolvimento da metodologia iterativa para análises dinâmicas com interação veículo-estrutura, não será feito um estudo paramétrico com a alteração desses parâmetros. Porém, é importante salientar que a escolha do perfil de irregularidades interfere diretamente nos resultados das análises e que comprimentos de onda menores devem ser esperados na geração de perfis de irregularidade típicos de trilhos.

Conforme comentado, a série espacial da irregularidade é aplicada no modelo veicular em forma de deslocamentos impostos, para cada roda do trem, e com isso, são 
extraídos os históricos das forças de interação vertical em função do tempo. Essas forças serão aplicadas num modelo de alta hierarquia da ponte, de modo a simular o tráfego do trem sobre a ponte.

\subsection{ESTRUTURA}

Este trabalho tem como objetivo avaliar o comportamento dinâmico de pontes para trens de alta velocidade e o conforto dos passageiros no interior dos vagões, considerando o efeito das irregularidades geométricas no plano vertical dos trilhos e a presença (ou não) do lastro.

Neste trabalho, são considerados dois estudos de caso correspondentes à Linha do Sul da malha ferroviária portuguesa, especificamente à Variante Alcácer do Sal, ligando a Estação do Pinheiro ao km 94 da Linha do Sul. Segundo Martins (2008), esta ligação é importante para a melhoria da oferta ferroviária no trecho Lisboa - Algarve, uma vez que o corredor anterior apresentava limitações em relação às características geotécnicas e às velocidades devido à presença de curvas. A Figura 6.7 apresenta a locação desta variante.

O projeto da Variante de Alcácer do Sal apresenta uma extensão total de $29 \mathrm{~km}$ (Figura 6.8), incluindo uma ponte e os viadutos de acesso, do lado Norte e Sul. O sistema estrutural é do tipo ponte estaiada em arco (bowstring)" com três vãos de $160 \mathrm{~m}$ de comprimento, em estrutura mista aço-concreto, numa extensão total de $480 \mathrm{~m}$. Os viadutos também são em estrutura mista aço-concreto, sendo o trecho do lado Norte com desenvolvimento de $1.114,75 \mathrm{~m}$ composto por 26 tramos, enquanto que o trecho do lado Sul tem extensão de $1.140 \mathrm{~m}$ com 27 tramos.

\subsubsection{Viaduto}

Os viadutos de acesso apresentam vãos de $37,5 \mathrm{~m}$ e $45 \mathrm{~m}$, feitos em estrutura mista aço-concreto. Os tabuleiros são constituídos de dois perfis metálicos de alma cheia, com diafragmas sobre os apoios e espaçados ao longo do vão, e com uma laje de concreto armado sobre os perfis metálicos com uma espessura de $0,35 \mathrm{~m}$ na zona central. As vigas têm altura de $2.600 \mathrm{~mm}$ e estão afastadas $5.800 \mathrm{~mm}$ entre si. No trecho alargado, a distância entre os perfis passa para $7.000 \mathrm{~mm}$ e a largura do tabuleiro aumenta de 13,0 m para $15,7 \mathrm{~m}$. 


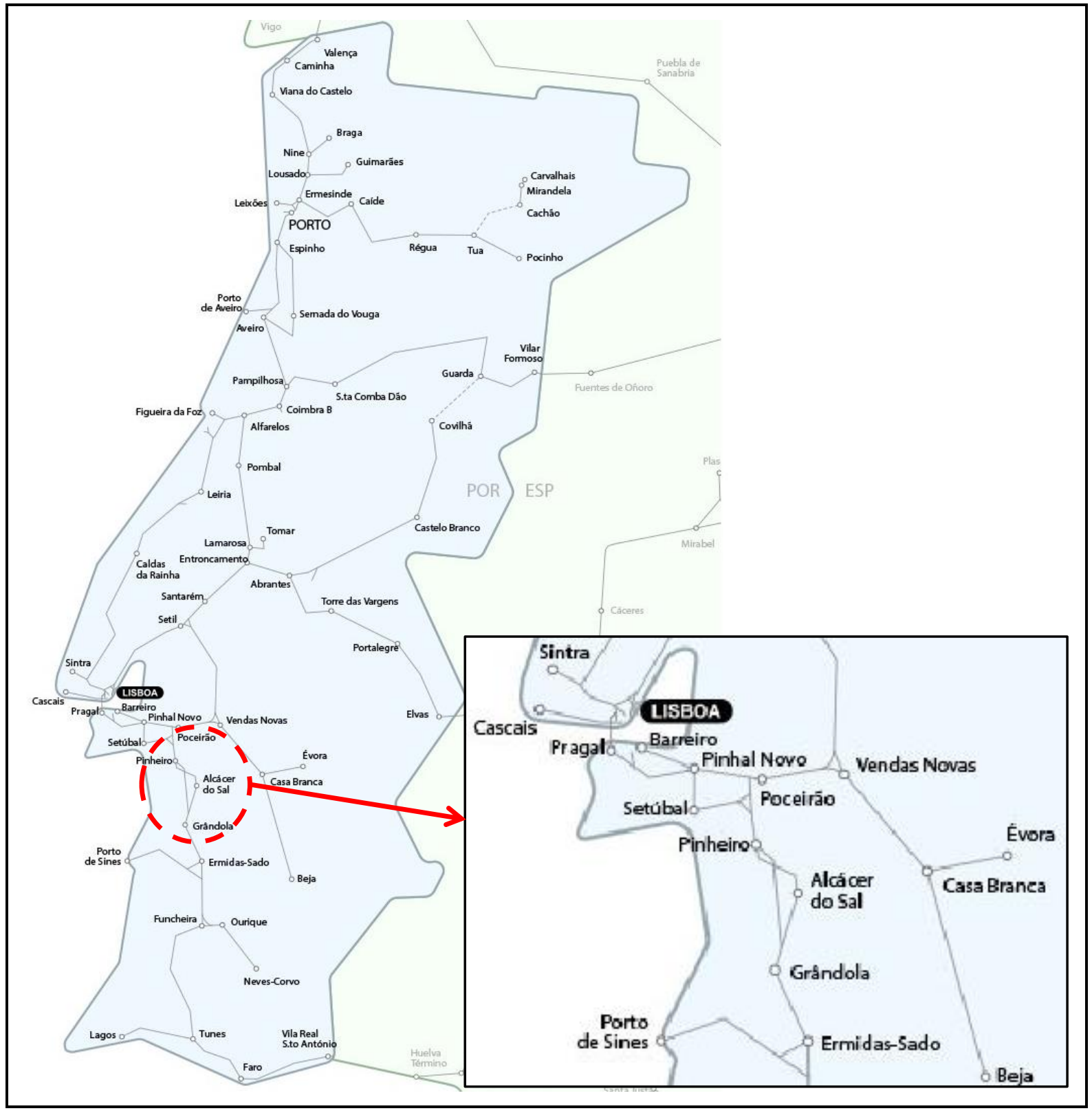

Figura 6.7: Localização da Variante Alcácer do Sal. Fonte: http://www.infraestruturasdeportugal.pt/rede/ferroviaria/mapa. 


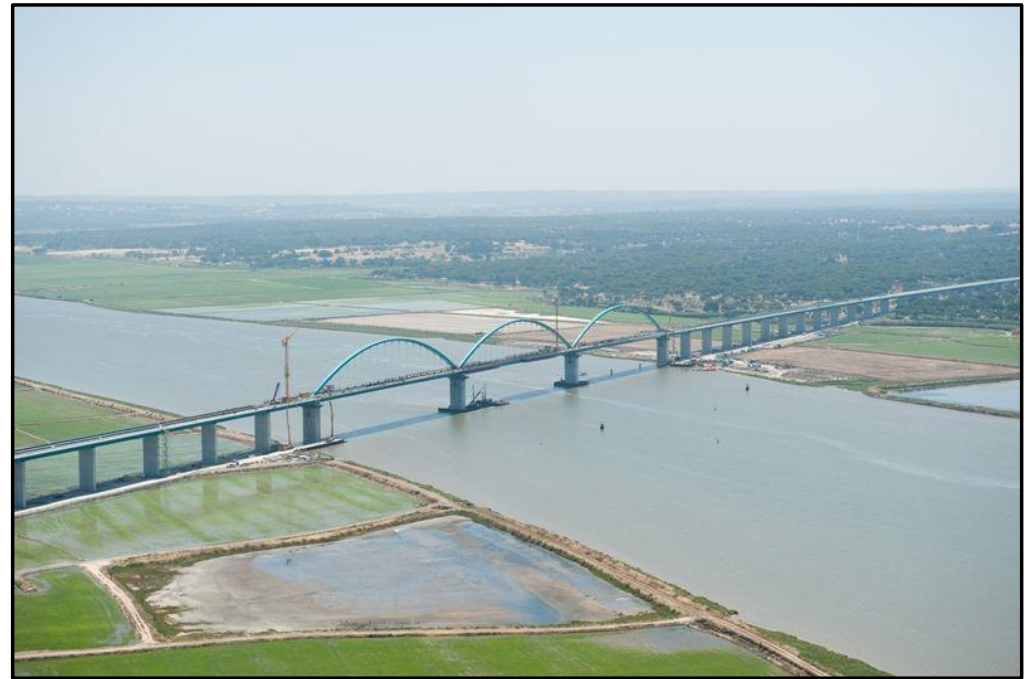

Figura 6.8: Ponte e viadutos da Variante de Alcácer do Sal. Fonte:

http://www.pengest.pt/Pontes-/-Viadutos/refer-ep-rede-ferroviaria-nacional-varianteentre-a-estacao-do-pinheiro-e-o-km-94-da-linha-do-sul-2o-fase.html.

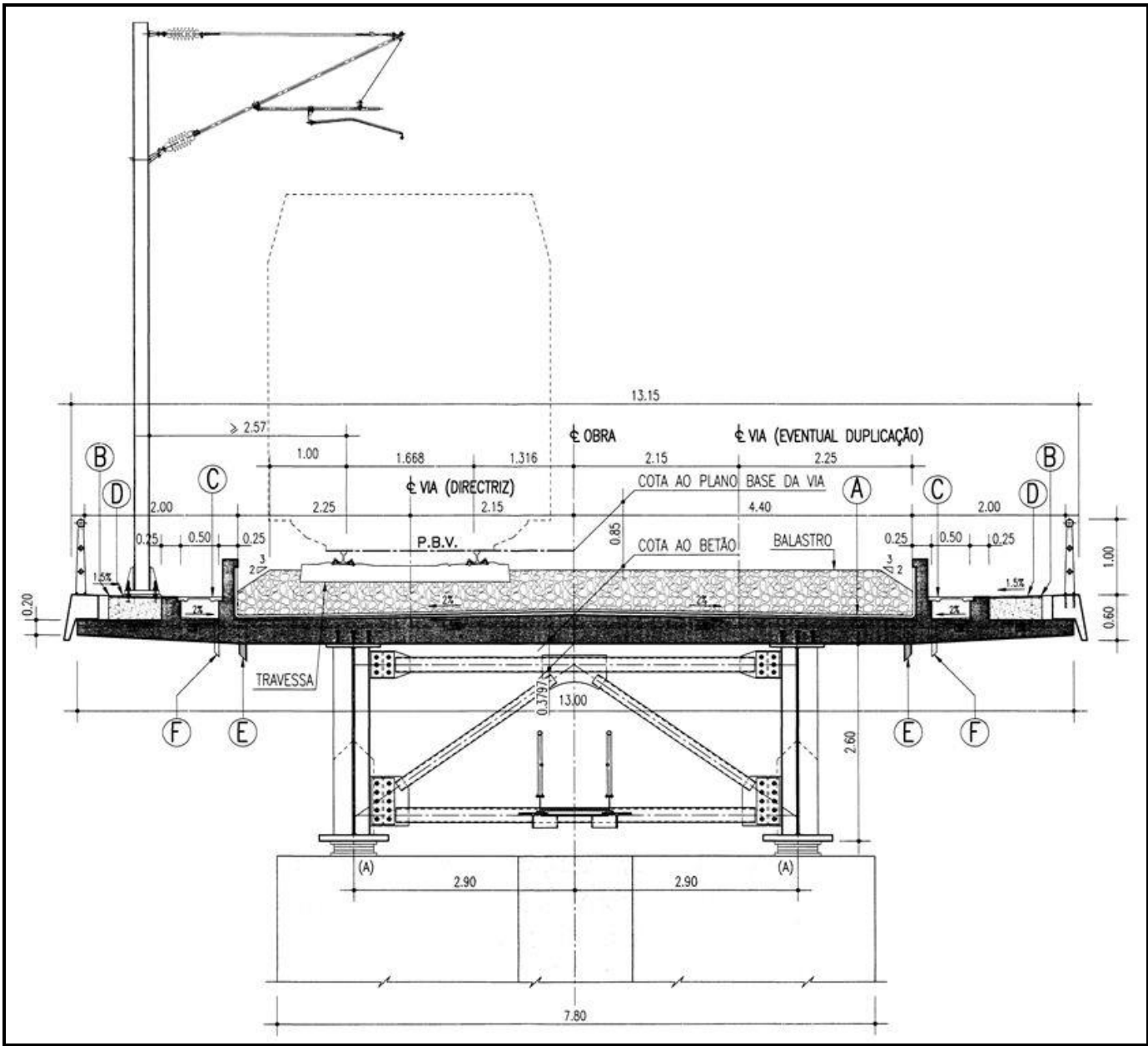

Figura 6.9: Seção transversal do Viaduto. Fonte: Rui Calçada (comunicação pessoal). 


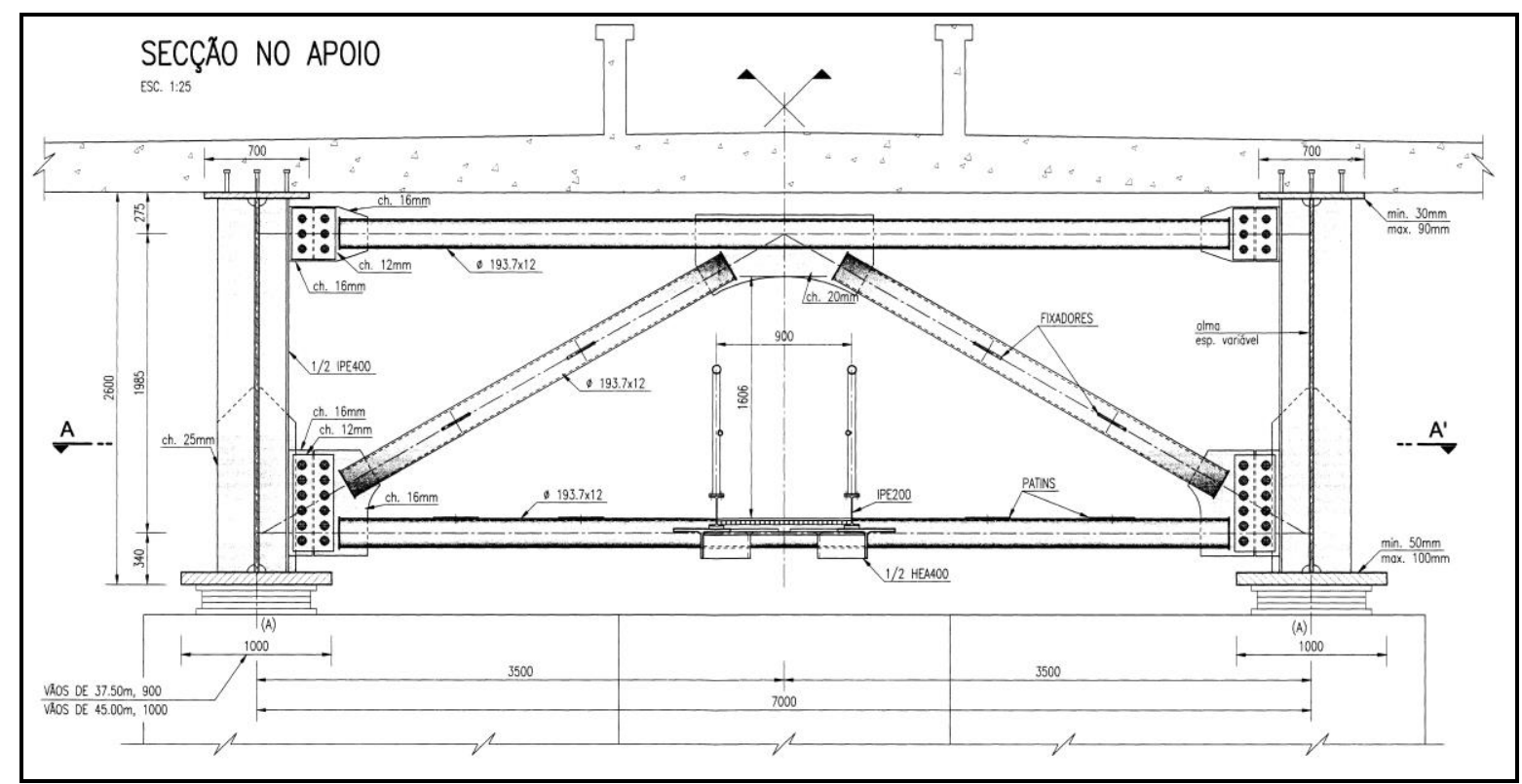

Figura 6.10: Seção no apoio do Viaduto. Fonte: Rui Calçada (comunicação pessoal).

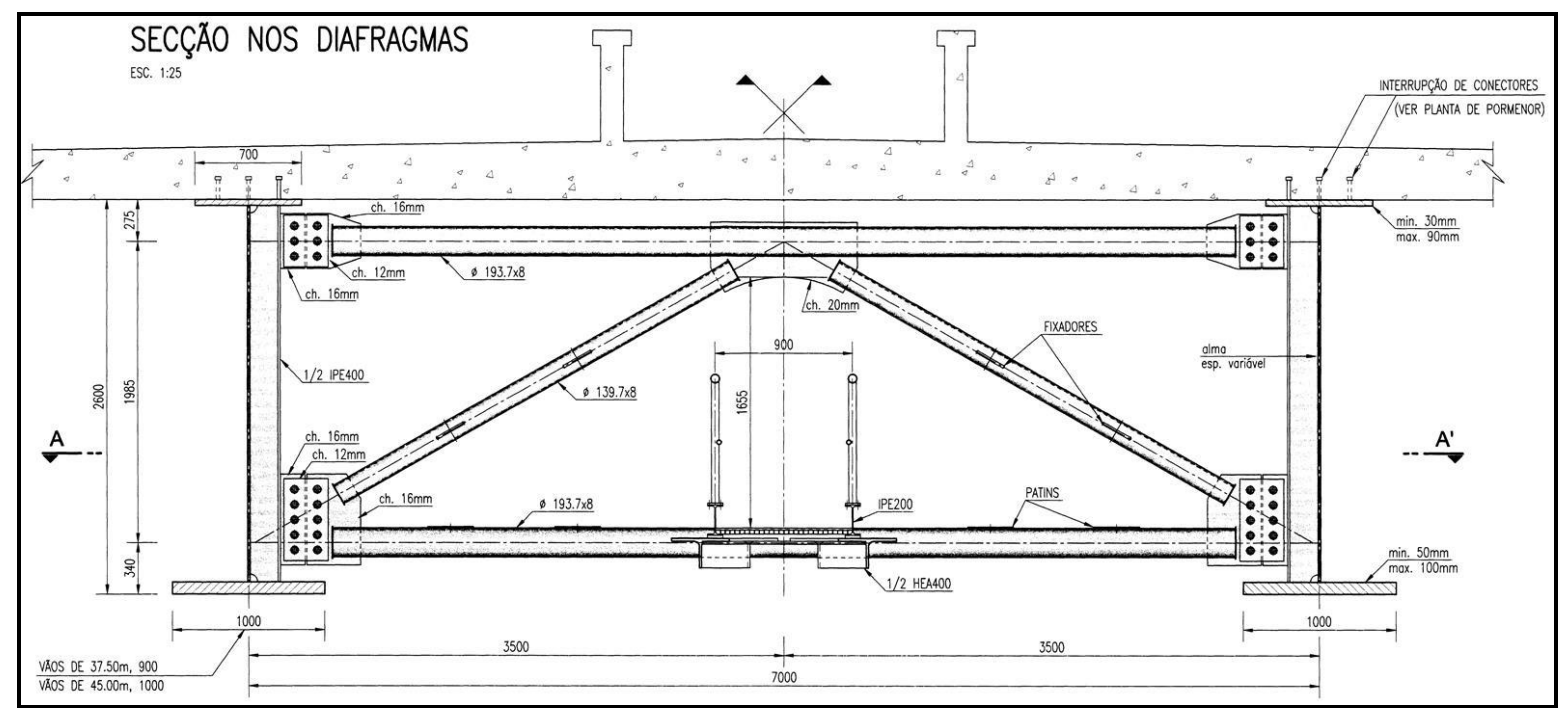

Figura 6.11: Seção no diafragma do Viaduto. Fonte: Rui Calçada (comunicação pessoal).

\subsubsection{Ponte}

Conforme já mencionado, a ponte apresenta três vãos de 160 m, numa extensão total de $480 \mathrm{~m}$. O sistema estrutural é do tipo "bowstring", sendo o tabuleiro um caixão misto aço-concreto com suspensão axial a partir de 18 pendurais. A estrutura constitui uma viga hiperestática, com seção caixão feita com chapas metálicas e laje de concreto armado com uma espessura de $0,43 \mathrm{~m}$ na região central. $\mathrm{O}$ arco centrado sobre o tabuleiro é formado 
por uma seção tubular feito por chapas metálicas, conforme apresentado na Figura 6.13. Os pendurais são constituídos de barras de aço $S 355$ NL de $200 \mathrm{~mm}$ de diâmetro sendo articulados nas ligações com 0 arco e o tabuleiro. As figuras a seguir apresentam a geometria da ponte.

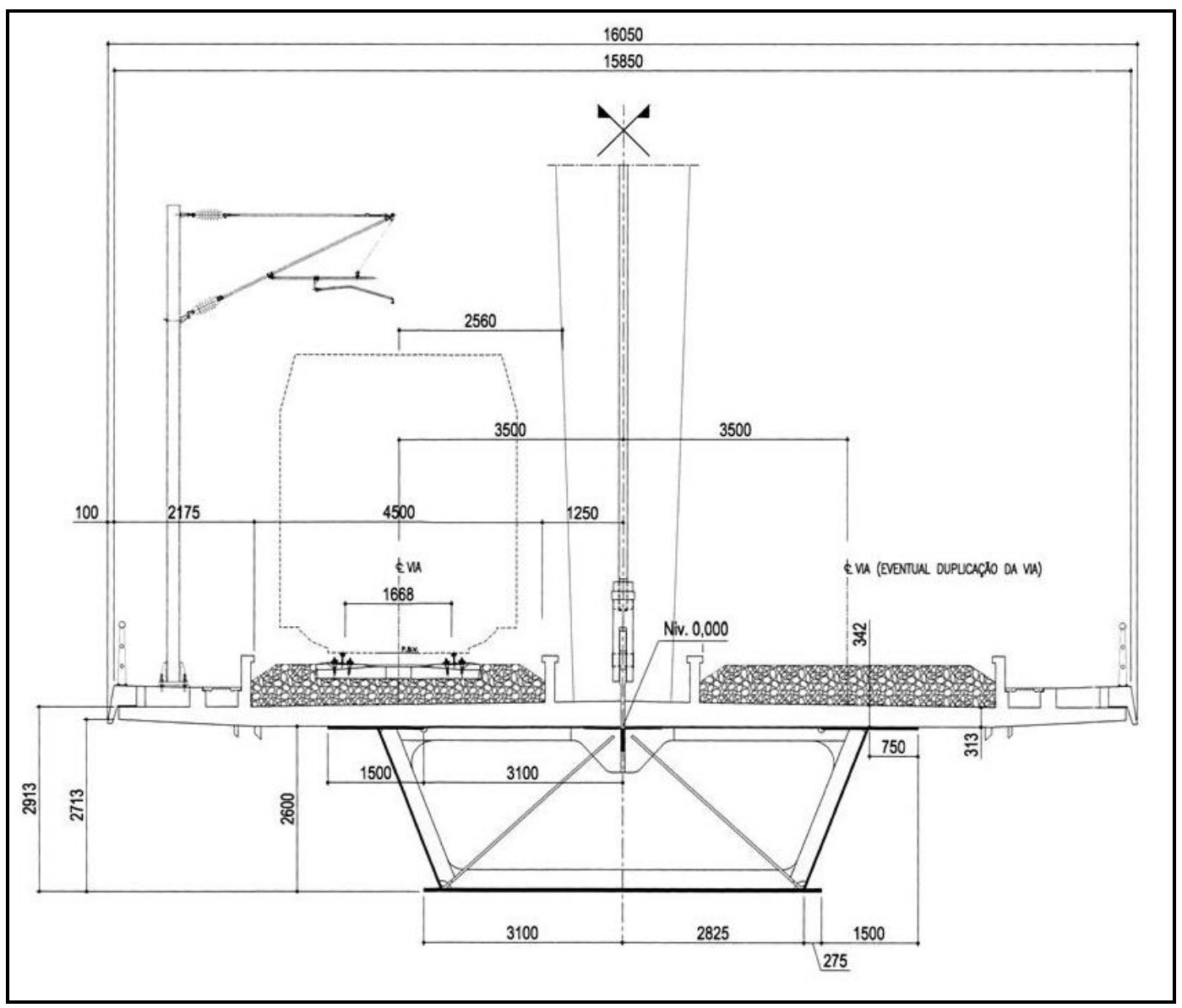

Figura 6.12: Seção transversal da Ponte. Fonte: Rui Calçada (comunicação pessoal). 


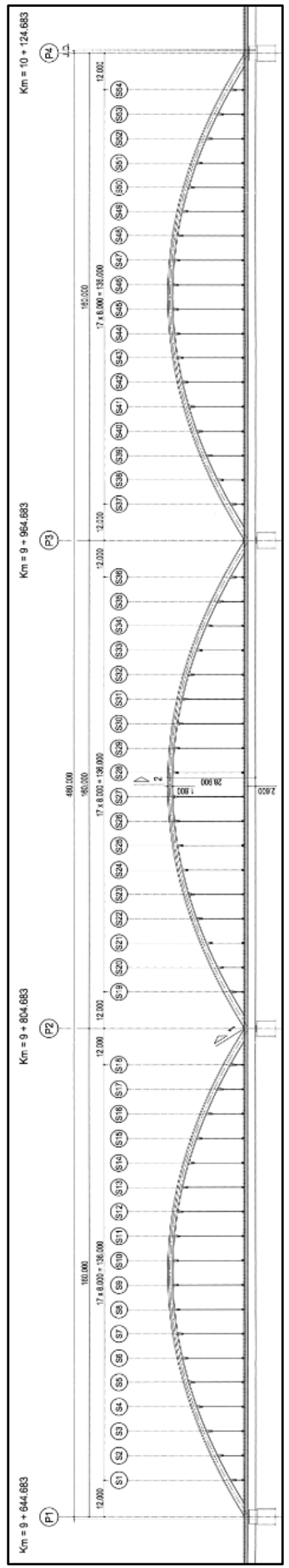

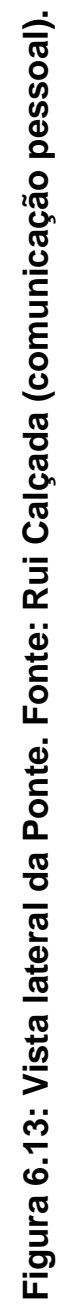

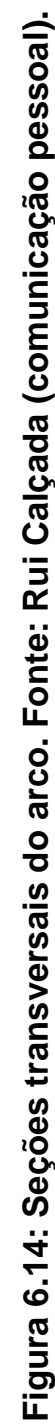




\subsubsection{Modelagem}

Neste trabalho, foram considerados dois estudos de caso para aplicação da metodologia proposta, sendo um para o viaduto com vão de $45 \mathrm{~m}$ e largura de $13,0 \mathrm{~m}$ e outro para a ponte, considerando os três vãos. Observa-se que, de acordo com o fluxograma proposto pelo Eurocode (Figura 2.1), para os dois casos considerados exige-se a realização da análise dinâmica para velocidades acima de $200 \mathrm{~km} / \mathrm{h}$ por não se configurarem como uma estrutura simples, especialmente no caso do sistema estrutural da ponte suspensa em arco.

Os modelos estruturais do viaduto e da ponte foram realizados no ADINA, mediante a utilização de elementos de casca e de barra, considerando o eixo da geometria dos elementos estruturais.

As propriedades dos materiais aço e concreto foram as mesmas para os modelos do viaduto e da ponte e são apresentadas na Tabela 6.3.

Tabela 6.3: Propriedades dos materiais. Fonte: Autor.

\begin{tabular}{|c|c|c|}
\hline Material & $\mathbf{Y}\left[\mathbf{k N} / \mathbf{m}^{\mathbf{3}}\right]$ & $\mathbf{E}[\mathbf{G P a}]$ \\
\hline \hline Concreto & 25,0 & 35 \\
\hline Aço & 78,0 & 210 \\
\hline
\end{tabular}

\subsubsection{Modelo do viaduto}

A Figura 6.15 apresenta o modelo do viaduto realizado no ADINA. Foram utilizados elementos de casca do tipo "shell" (elemento isoparamétrico de 4 nós) para a modelagem do tabuleiro e das vigas metálicas e elementos de barra do tipo "beam" para a modelagem dos demais perfis da seção transversal.

Observa-se que a meso- e infraestrutura não foram avaliadas neste modelo, sendo adotados apoios rígidos nas extremidades do tabuleiro. A consideração dos pilares e da fundação da estrutura torna relevante a aplicação das irregularidades nos trilhos também no plano horizontal, visto que esta excitação pode gerar amplificações nos esforços e deslocamentos para o dimensionamento destas estruturas. 


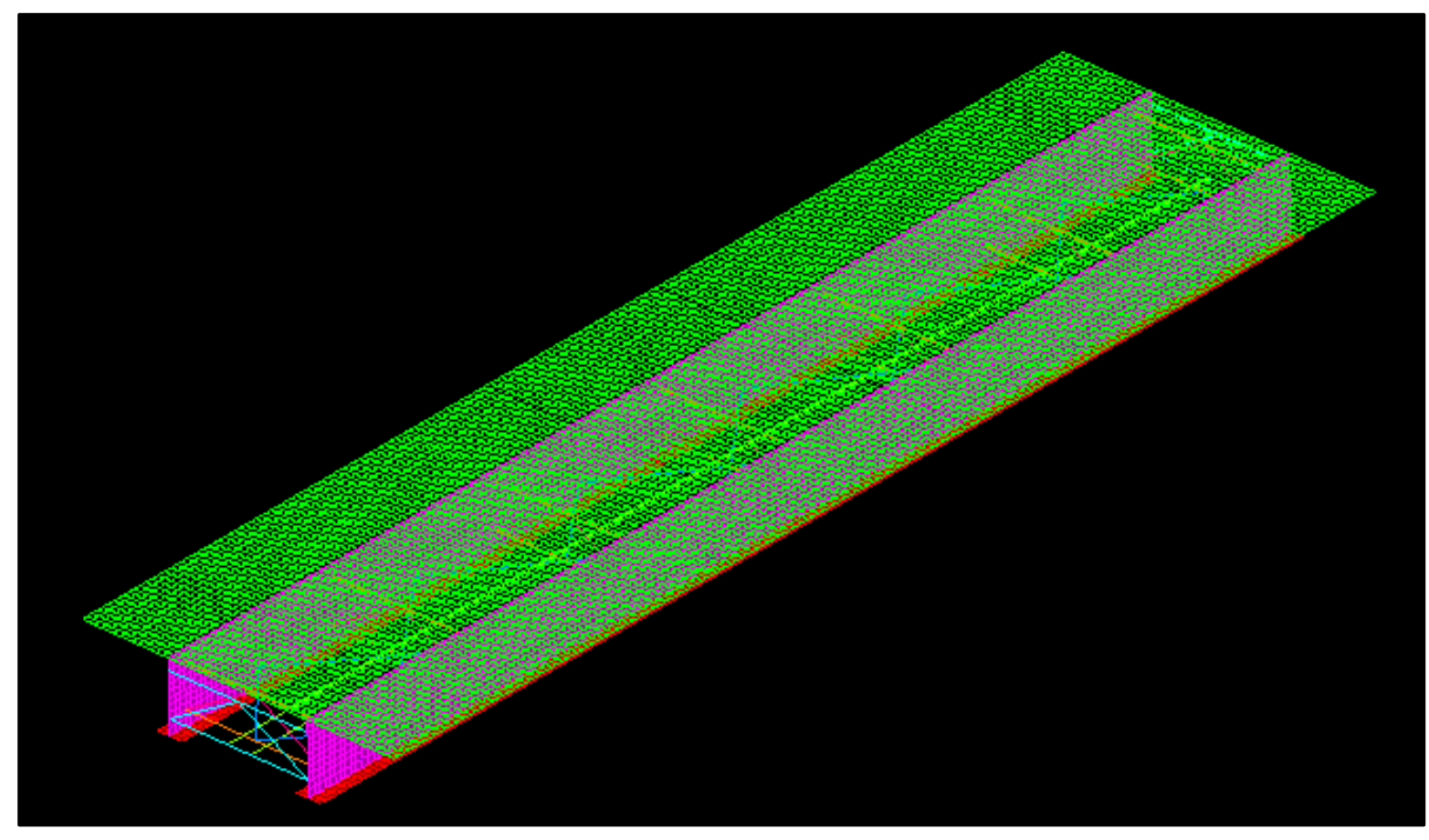

Figura 6.15: Modelo do Viaduto no ADINA. Fonte: Autor.

A discretização da malha de elementos finitos foi feita com elementos regulares de quatro nós, com dimensões de aproximadamente $0,25 \mathrm{~m}$ de lado. Apesar do alto custo computacional, a malha refinada contribui para uma melhor precisão do modelo, uma vez que as cargas que descrevem a passagem do trem são aplicadas a cada um dos nós ao longo da posição do trilho.

Neste modelo estrutural não foram incluídos os pilares e respectivas fundações. Desta forma, como condições de contorno do tabuleiro adotou-se vinculação "B" de um lado do viaduto, com o travamento dos deslocamentos nas direções vertical e horizontal transversal, e vinculação "C" do outro lado, restringindo os deslocamentos nas três direções, conforme indicado na Figura 6.16. 


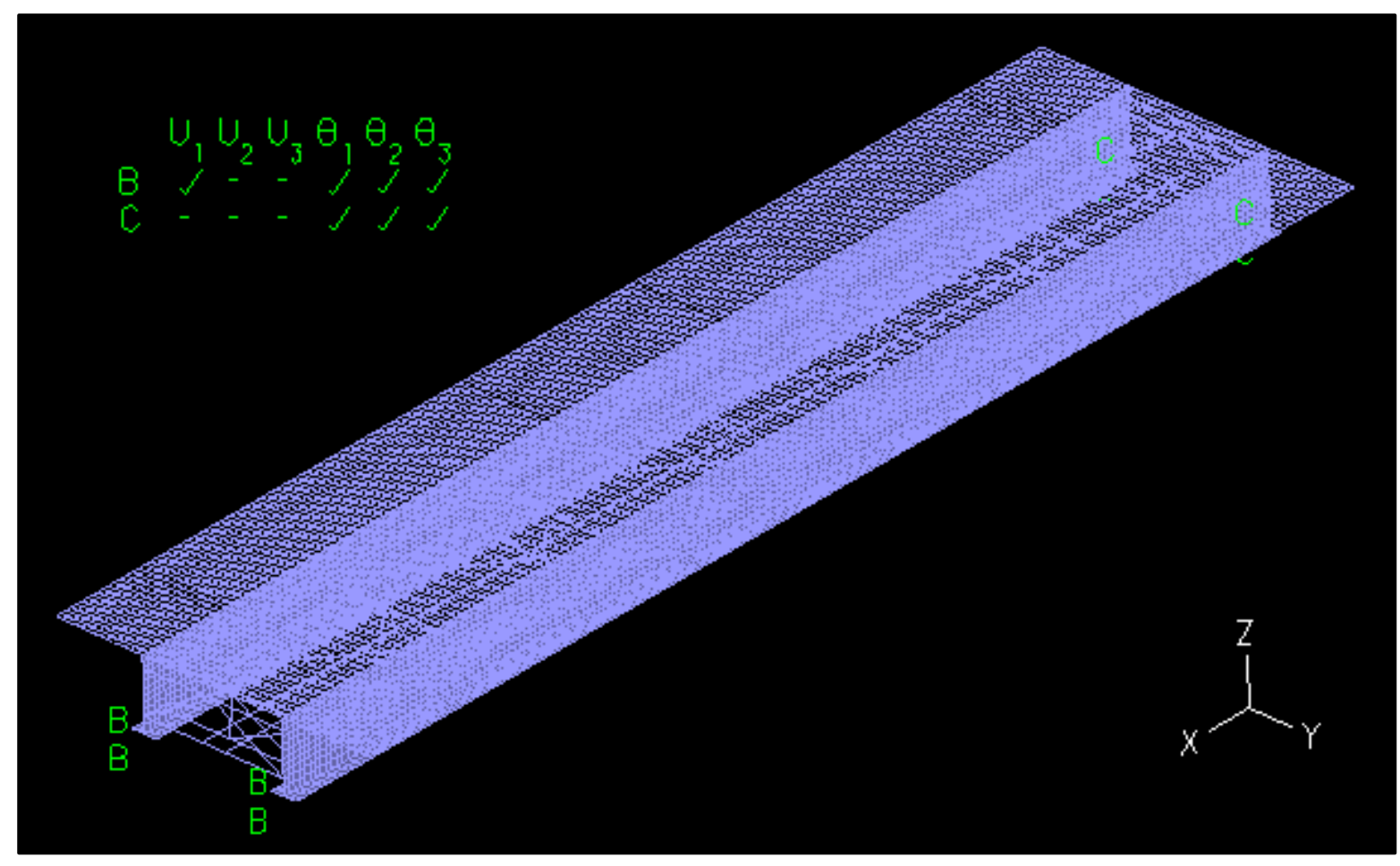

Figura 6.16: Condições de contorno do viaduto. Fonte: Autor.

\subsubsection{Modelo da ponte}

A ponte também foi modelada utilizando elementos de casa do tipo "shell" para a laje de concreto e para as chapas metálicas, enquanto que o arco, pendurais e demais elementos da seção transversal foram modelados utilizando elementos de barra do tipo "beam". Assim como feito no modelo do viaduto, na análise da ponte também não foram consideradas a meso- e infraestrutura.

Os pendurais foram considerados articulados nas ligações com o arco e o tabuleiro, sendo liberadas as restrições de momentos fletores nessas ligações. Em relação à modelagem do arco, como ele apresenta uma geometria variável, considerou-se uma seção média em cada trecho. A Figura 6.17 apresenta o modelo da ponte realizado no ADINA. 


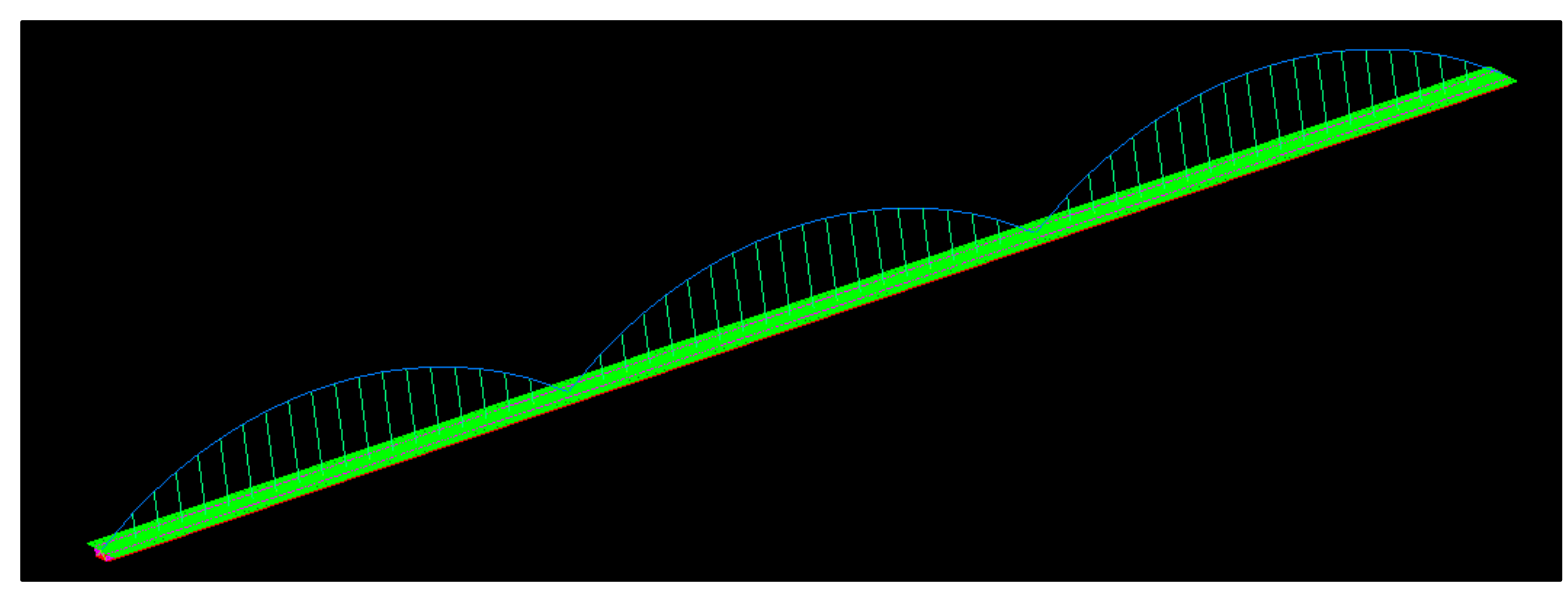

Figura 6.17: Modelo da Ponte no ADINA. Fonte: Autor.

A malha de elementos finitos foi realizada também com elementos regulares de quatro nós, com dimensões de aproximadamente 1,0 m de lado. Neste caso, em função do comprimento da ponte, optou-se por adotar uma malha menos refinada devido ao custo computacional na realização das análises dinâmicas.

As restrições de apoio são as mesmas utilizadas para o viaduto, conforme indicadas na Figura 6.18. Observa-se que a continuidade entre os tramos da ponte foi garantida mantendo-se a ligação entre os elementos da malha.

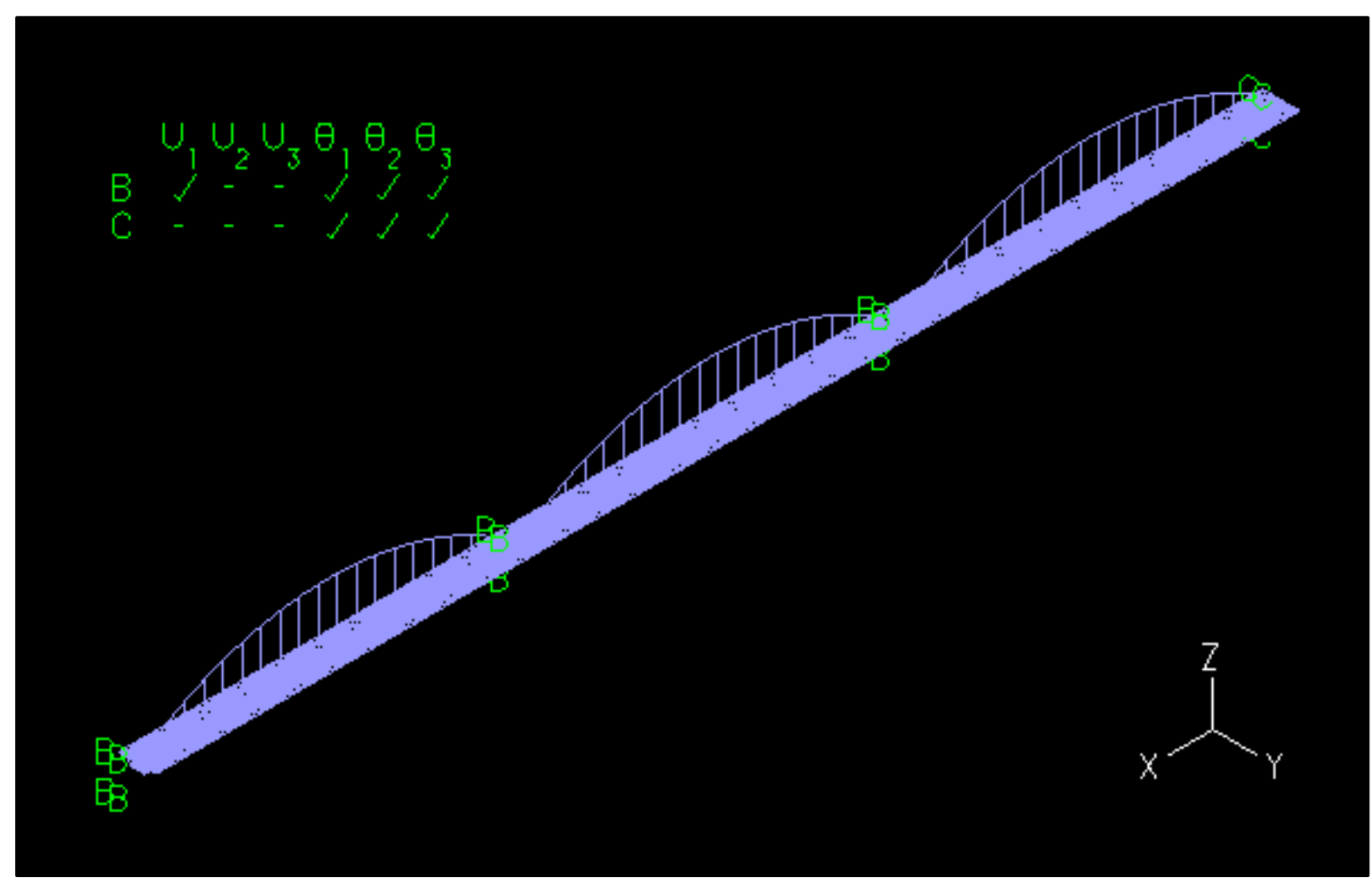

Figura 6.18: Condições de contorno da ponte. Fonte: Autor. 


\subsubsection{Trilho e lastro}

Tanto para o viaduto quanto para a ponte, analisou-se também a influência do lastro na resposta para o conforto dos passageiros no interior dos vagões. Apesar de o estudo de caso adotado na metodologia apresentar o lastro, foram realizadas duas análises, sendo uma com presença do lastro, conforme o projeto, e outra sem o lastro, aplicando as cargas diretamente sobre o tabuleiro. Para os casos sem a presença do lastro, os modelos utilizados são os apresentados anteriormente. Para os casos com o lastro, os modelos foram ajustados inserindo o trilho e a lastro, como apresenta a Figura 6.19.

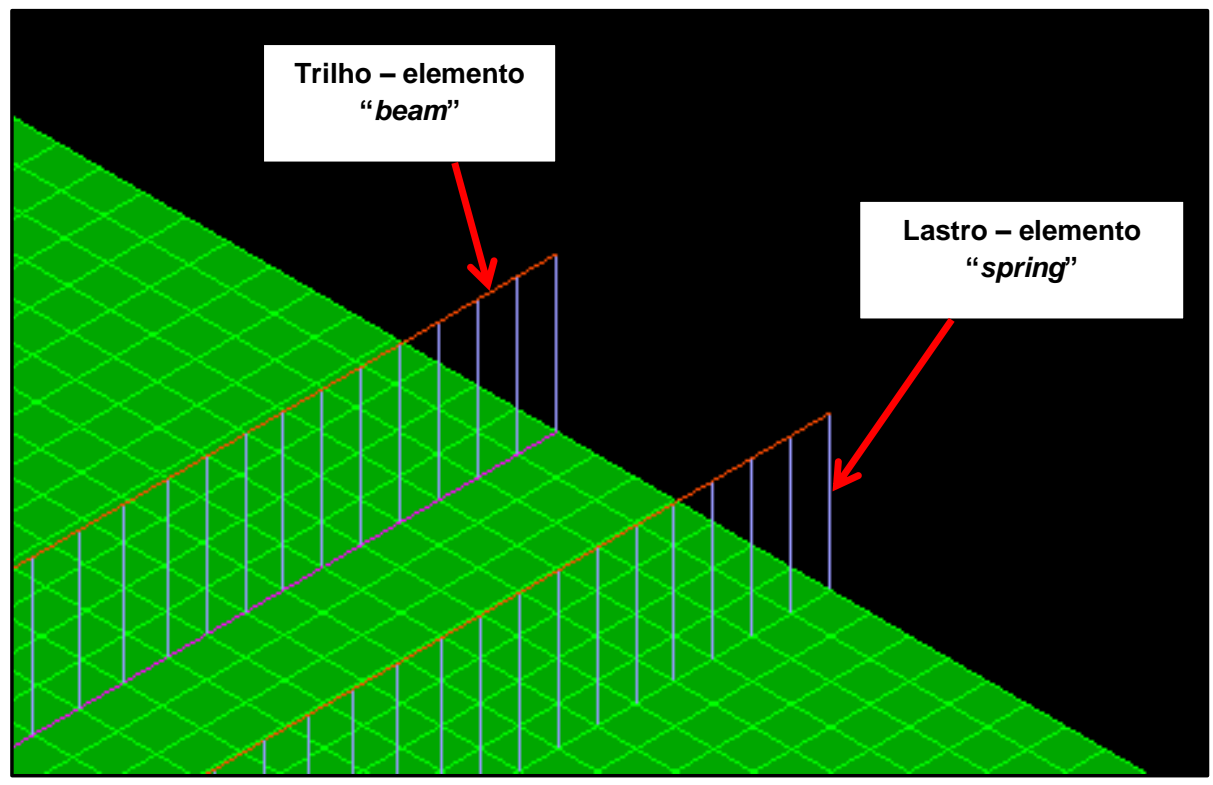

Figura 6.19: Modelos com lastro. Fonte: Autor.

Os trilhos foram modelados no ADINA utilizando elementos de barra do tipo "beam", sendo conectados em cada nó do tabuleiro por meio de elementos de barra do tipo "spring", com especificação das propriedades de rigidez e amortecimento do lastro. O trilho indicado neste projeto foi o UIC 60, cuja geometria e parâmetros encontram-se indicados na Figura 6.20. Os parâmetros do lastro são apresentados na Tabela 6.4. 


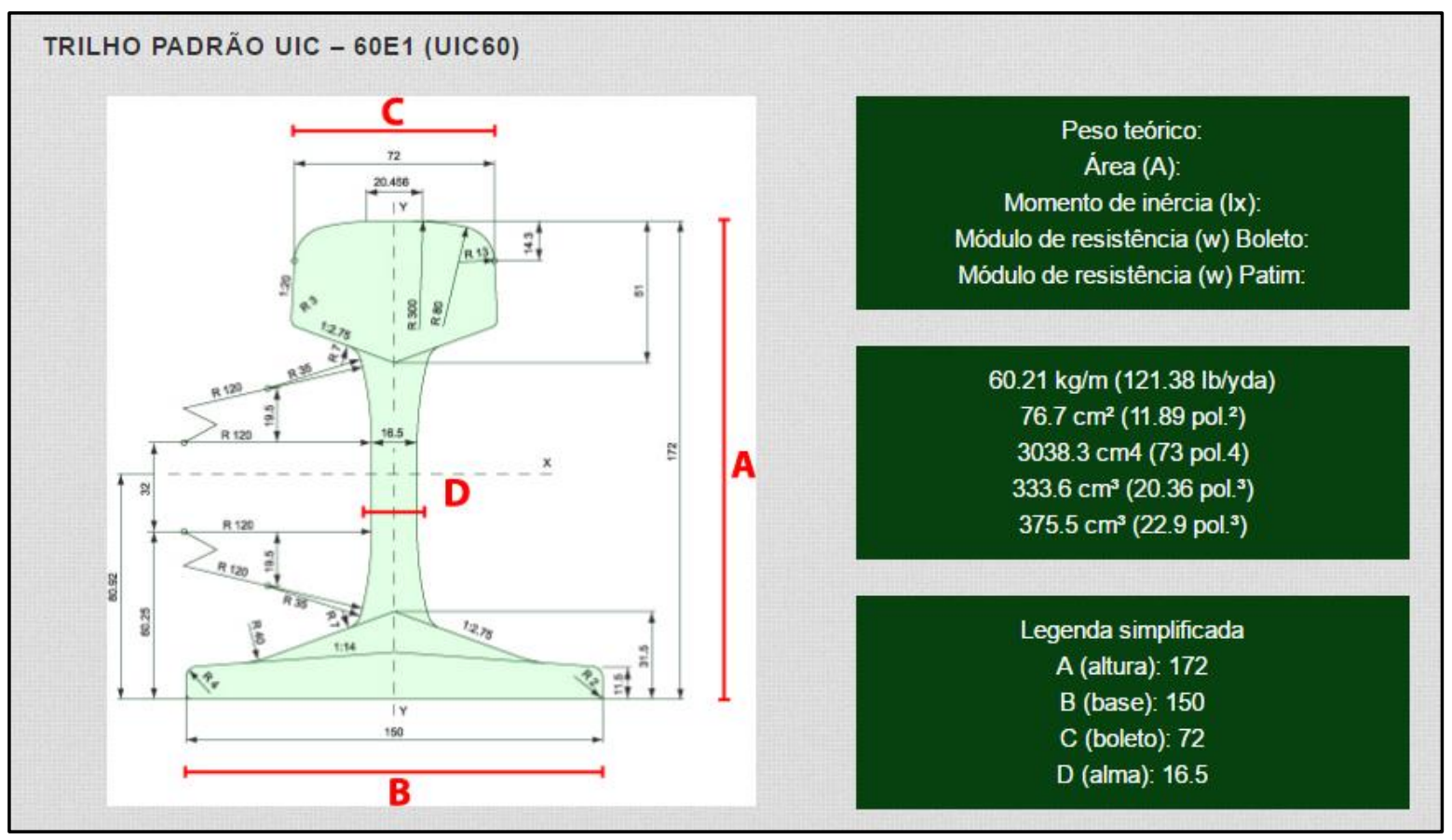

Figura 6.20: Propriedades do trilho. Fonte: http://www.trilhos.com.br/trilho-padraouic.html.

Tabela 6.4: Propriedades do lastro. Fonte: CASAL (2010).

\begin{tabular}{|c|c|}
\hline $\mathrm{k}_{\text {lastro }}$ & $100.000 \mathrm{kN} / \mathrm{m}$ \\
\hline $\mathrm{c}_{\text {lastro }}$ & $15 \mathrm{kNs} / \mathrm{m}$ \\
\hline
\end{tabular}




\section{ANÁLISE MODAL}

Iniciou-se o estudo a partir da análise modal do veículo e das estruturas do viaduto e da ponte, realizadas no ADINA. A Tabela 7.1 apresenta uma comparação entre as frequências obtidas para os quinze primeiros modos de vibração. As frequências indicadas com hachura cinza não serão analisadas, pois correspondem a modos locais de vibração que não estão relacionados ao tabuleiro, como por exemplo, dos elementos estruturais dos contraventamentos e no arco e pendurais da ponte.

Tabela 7.1: Frequências naturais $(\mathrm{Hz})$. Fonte: Autor.

\begin{tabular}{|c|c|c|c|}
\hline Modo & Veículo & Viaduto & Ponte \\
\hline 10 Modo & 0,361 & 1,967 & 0,188 \\
\hline 2o Modo & 0,707 & 3,078 & 0,250 \\
\hline 3 Modo & 0,895 & 3,549 & 0,358 \\
\hline 4\% Modo & 1,625 & 4,605 & 0,920 \\
\hline 5 Modo & 2,197 & 5,277 & 0,975 \\
\hline 6 Modo & 5,344 & 5,292 & 0,992 \\
\hline $7^{\circ}$ Modo & 5,350 & 5,331 & 1,059 \\
\hline 8 Modo & 6,891 & 5,416 & 1,082 \\
\hline 9 Modo & 6,894 & 6,167 & 1,215 \\
\hline 10 Modo & 7,081 & 6,192 & 1,267 \\
\hline $11^{\circ}$ Modo & 7,081 & 7,024 & 1,345 \\
\hline $12^{\circ}$ Modo & 13,580 & 7,222 & 1,477 \\
\hline 13음odo & 13,590 & 7,295 & 1,627 \\
\hline $14^{\circ}$ Modo & 13,870 & 7,357 & 1,643 \\
\hline 15 Modo & 13,870 & 7,434 & 1,644 \\
\hline
\end{tabular}

Observa-se que algumas frequências do veículo estão muito próximas a frequências naturais do viaduto e da ponte. $O$ primeiro modo de vibração do viaduto $(1,967 \mathrm{~Hz})$ corresponde ao deslocamento no plano horizontal do tabuleiro e distorção das transversinas no apoio e apresenta frequência próxima ao quinto modo do trem $(2,197 \mathrm{~Hz})$, referente à rotação em torno do eixo longitudinal e deslocamento horizontal transversal. $\mathrm{O}$ quarto modo da ponte $(0,920 \mathrm{~Hz})$ corresponde ao primeiro modo de vibração do tabuleiro, sendo de flexão no plano vertical, e apresenta proximidade com o terceiro modo do veículo $(0,895 \mathrm{~Hz})$, que é de rotação em torno do eixo horizontal transversal. A proximidade entre as frequências e a relação entre os modos poderão resultar em amplificações da resposta dinâmica.

A seguir, serão apresentados os modos de vibração para o trem, viaduto e ponte. 


\subsubsection{Análise Modal do Trem}

A Figura 7.1 apresenta as dez primeiras frequências obtidas para o vagão típico do trem Alfa Pendular com os respectivos modos de vibração.

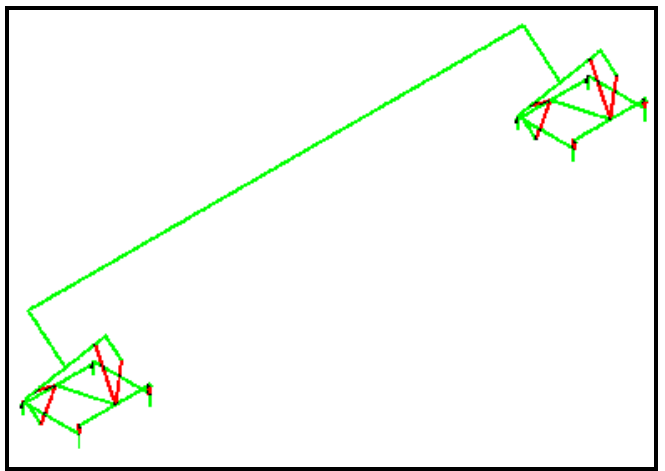

$1^{\circ}$ Modo de vibração - Modo de roll

$$
f=0,36 \mathrm{~Hz}
$$

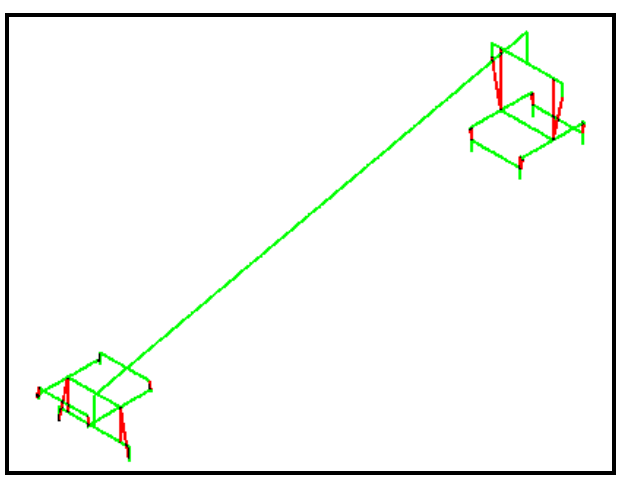

$3^{\circ}$ Modo de vibração - Modo de pitch

$$
f=0,89 \mathrm{~Hz}
$$

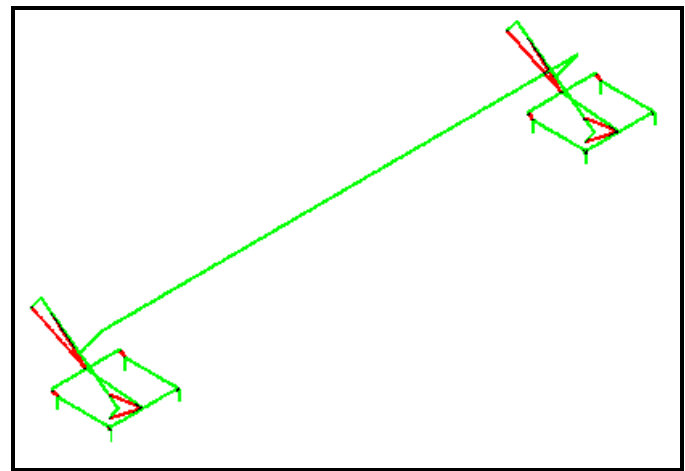

$5^{\circ}$ Modo de vibração - Modo de roll e sway

$$
f=2,20 \mathrm{~Hz}
$$

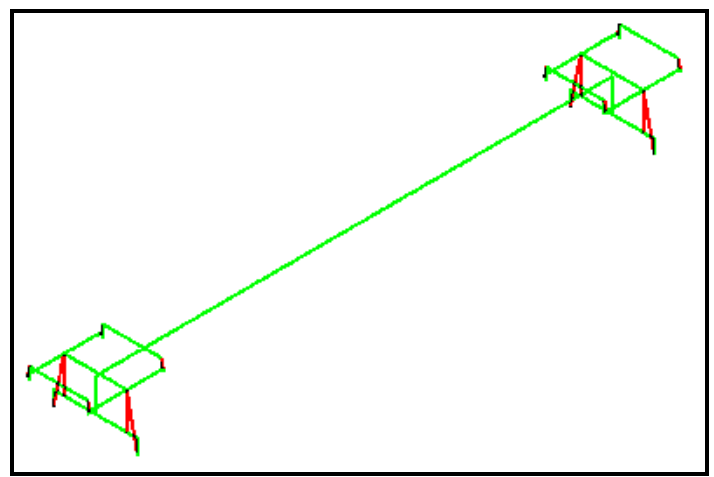

$2^{\circ}$ Modo de viração - Modo de bounce

$f=0,71 \mathrm{~Hz}$

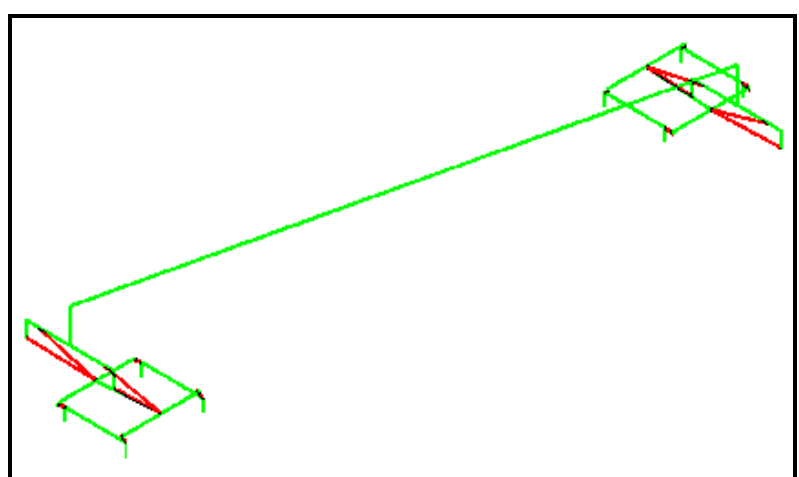

$4^{\circ}$ Modo de vibração - Modo de yaw

$f=1,63 \mathrm{~Hz}$

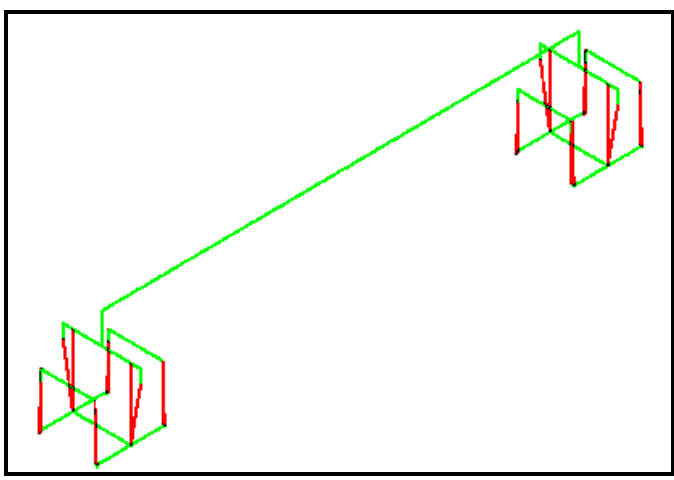

$6^{\circ}$ Modo de vibração - Modo de bounce

$$
f=5,34 \mathrm{~Hz}
$$




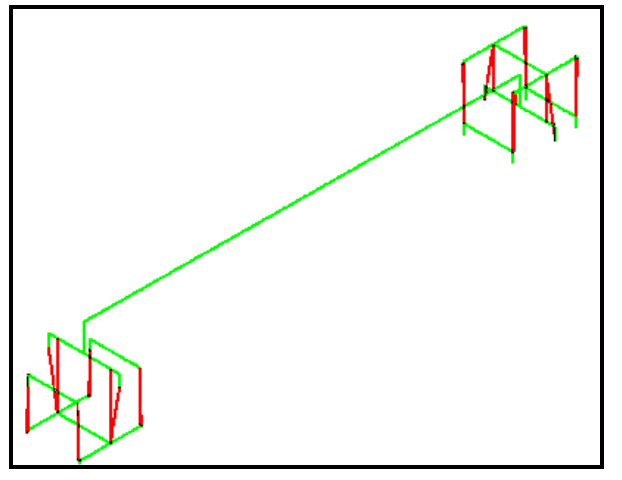

$7^{\circ}$ Modo de vibração - Modo de bounce

$$
f=5,35 \mathrm{~Hz}
$$

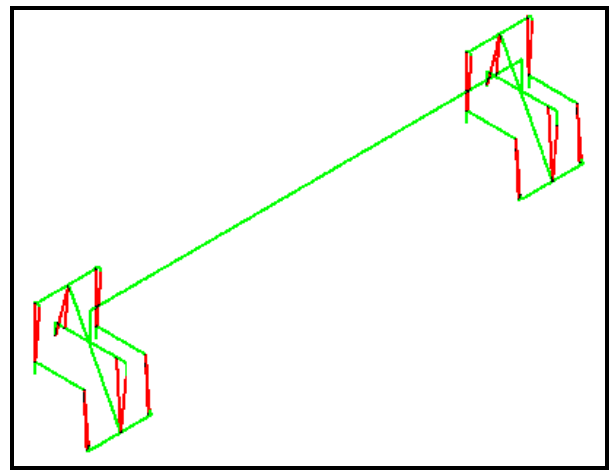

$9^{\circ}$ Modo de vibração - Modo do roll

$$
f=6,89 \mathrm{~Hz}
$$

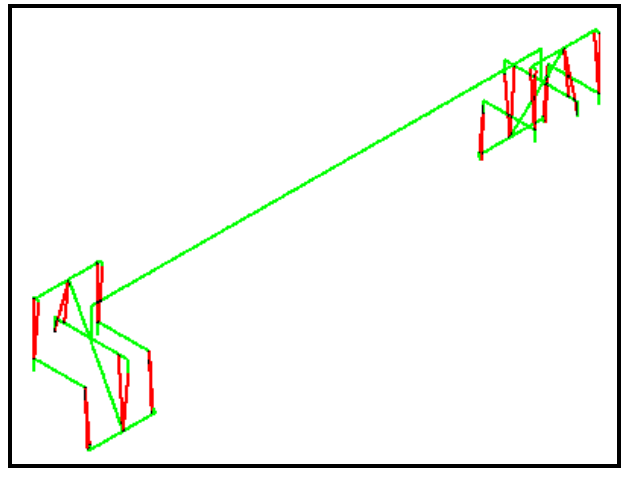

$8^{\circ}$ Modo de vibração - Modo de roll

$$
f=6,89 \mathrm{~Hz}
$$

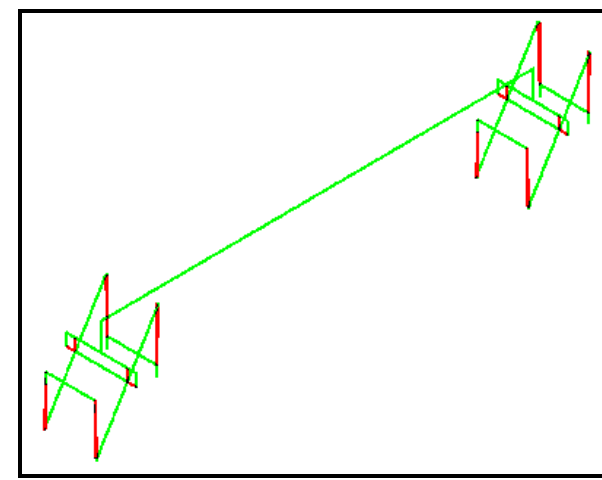

$10^{\circ}$ Modo - Modo de pitch

$$
f=7,08 \mathrm{~Hz}
$$

Figura 7.1: Modos de vibração do trem. Fonte: Autor. 


\subsubsection{Análise Modal do Viaduto}

A Figura 7.2 apresenta as quatro primeiras frequências obtidas para o viaduto com os respectivos modos de vibração.

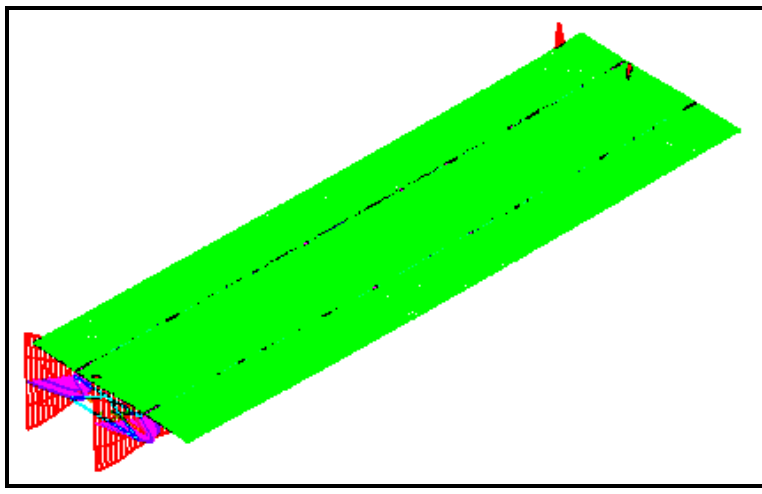

$1^{\circ}$ Modo de vibração - Modo de deslocamento no plano horizontal do tabuleiro e distorção das transversinas no apoio $-f=1,97 \mathrm{~Hz}$

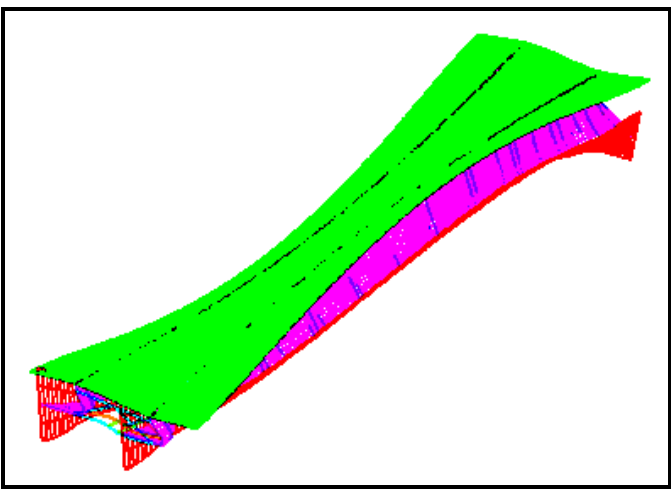

$3^{\circ}$ Modo de vibração - Modo de torção

$$
f=3,55 \mathrm{~Hz}
$$

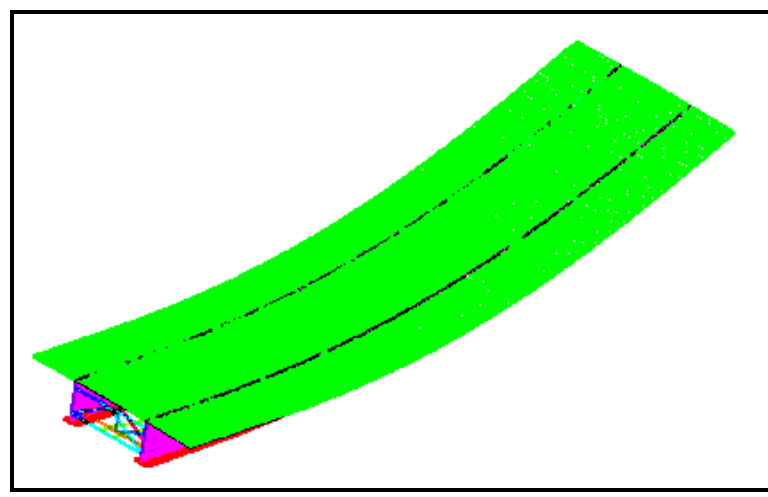

$2^{\circ}$ Modo de vibração - Modo de flexão vertical -

$$
f=3,08 \mathrm{~Hz}
$$

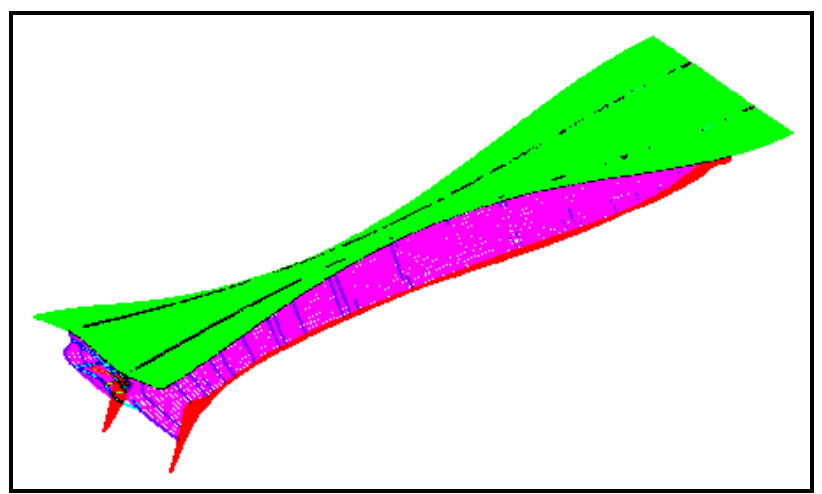

$4^{\circ}$ Modo de vibração - Modo de torção

$$
f=4,61 \mathrm{~Hz}
$$

Figura 7.2: Modos de vibração do viaduto. Fonte: Autor. 


\subsubsection{Análise Modal da Ponte}

A Figura 7.3 apresenta as duas primeiras frequências de flexão obtidas para o tabuleiro da ponte com os respectivos modos de vibração.

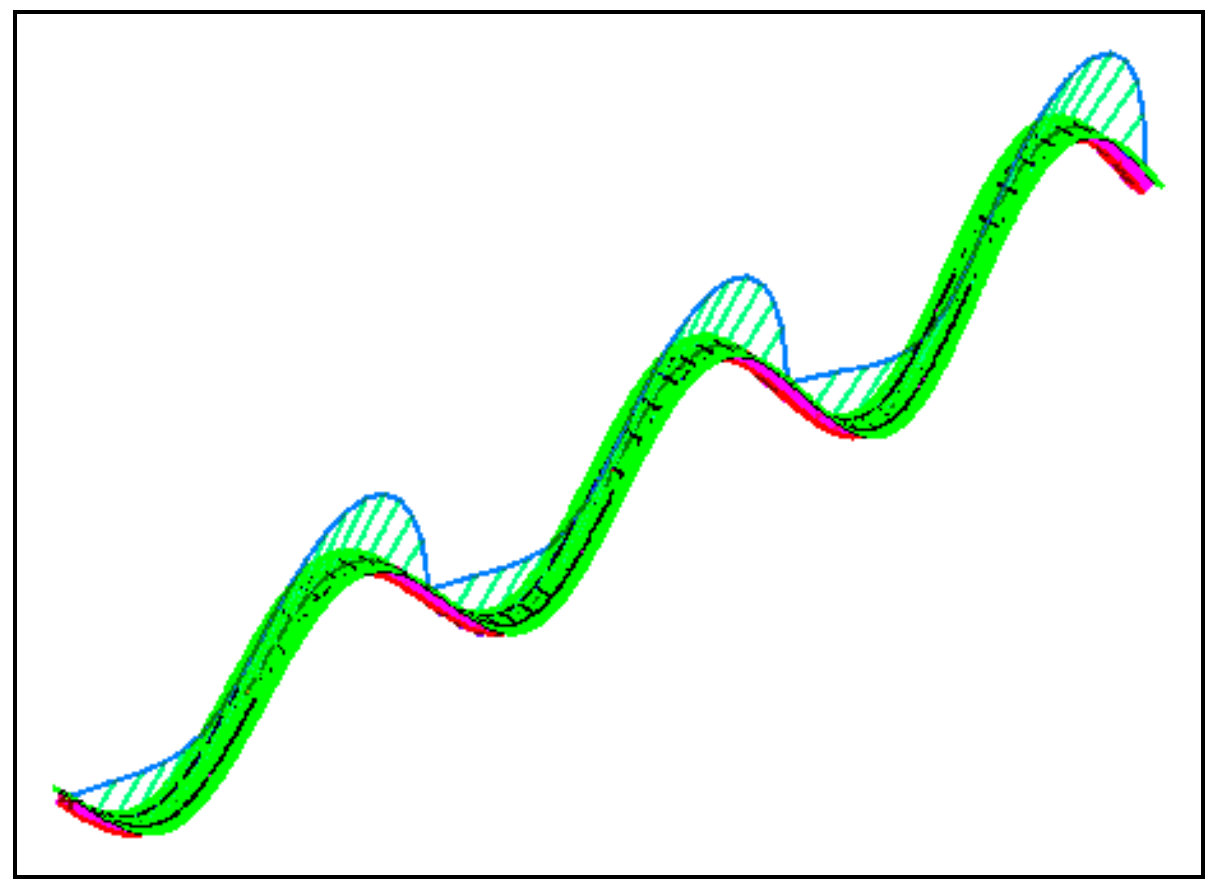

$4^{\circ}$ Modo de vibração - Modo de flexão no plano vertical $-f=0,92 \mathrm{~Hz}$

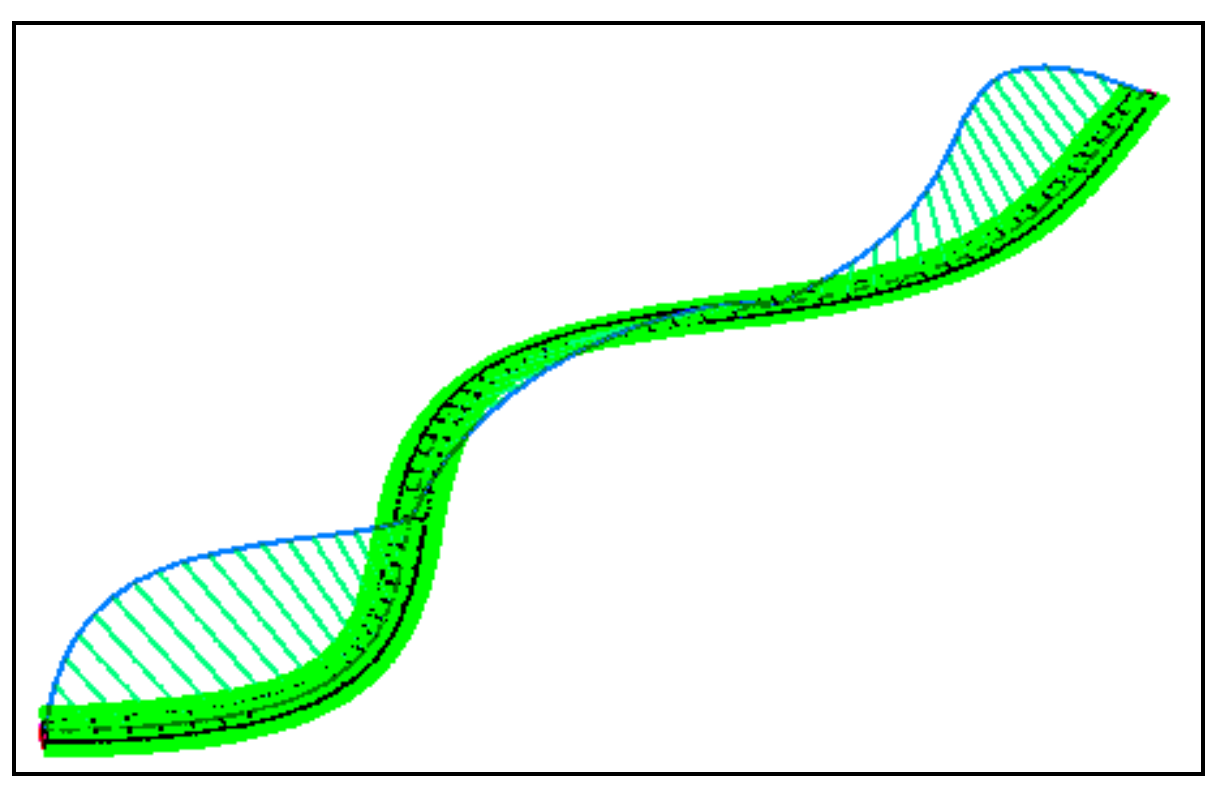

$5^{\circ}$ Modo de vibração - Modo de flexão no plano horizontal $-f=0,97 \mathrm{~Hz}$ 


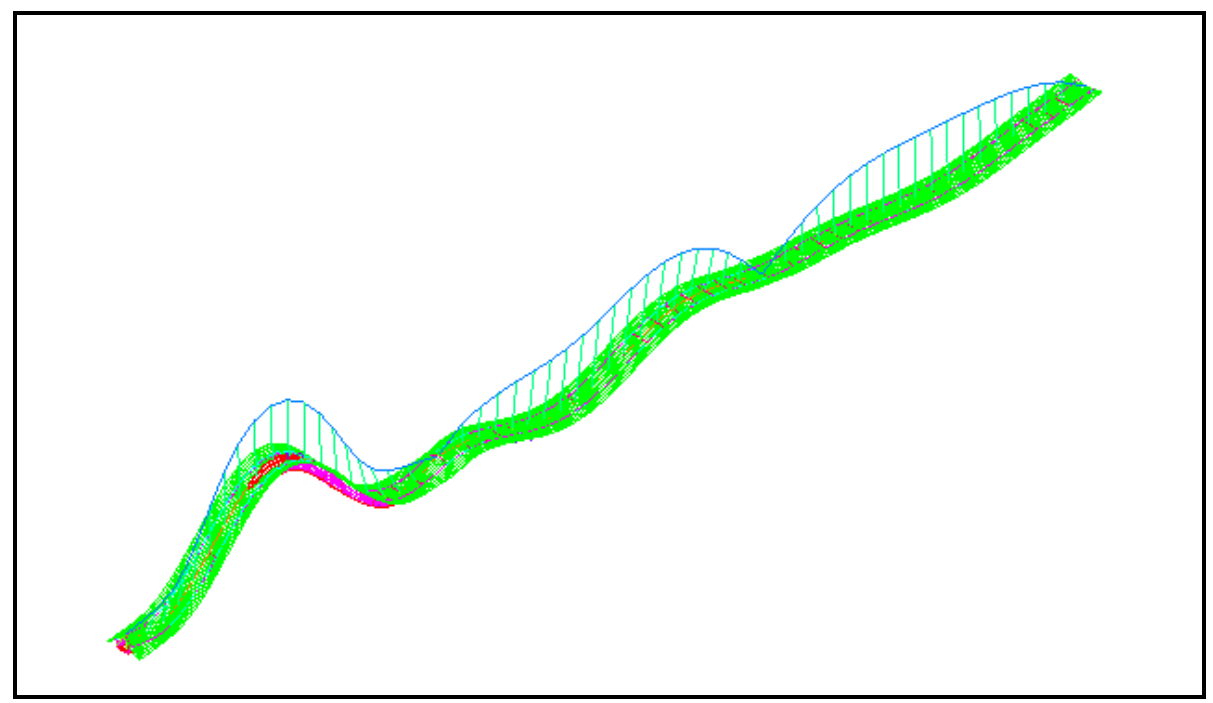

$13^{\circ}$ Modo de vibração - Modo de flexão no plano vertical $-f=1,63 \mathrm{~Hz}$

Figura 7.3: Modos de vibração da ponte. Fonte: Autor. 


\section{ANÁLISE DINÂMICA}

Uma vez realizadas as análises modais do trem e das estruturas, procedeu-se à análise dinâmica. Para isto, verificou-se inicialmente a discretização da malha adotada nos modelos das estruturas, pois deve estar compatível com o passo considerado do tempo (expressão [5.1]).

Tabela 8.1: Passo do tempo prescrito no Eurocode. Fonte: Autor.

\begin{tabular}{|c|c|c|c|}
\hline Estrutura & $\mathbf{f}[\mathbf{H z}]$ & $\mathbf{T}[\mathbf{s}]$ & $\mathbf{\Delta t}[\mathbf{s}]$ \\
\hline \hline Viaduto & 4,605 & 0,217 & 0,022 \\
\hline Ponte & 1,644 & 0,608 & 0,061 \\
\hline
\end{tabular}

Conforme indicado na Tabela 8.1, o passo deve ser de no mínimo 0,022 s para o viaduto e de $0,061 \mathrm{~s}$ para a ponte. Considerando a menor velocidade analisada $144 \mathrm{~km} / \mathrm{h}$, o passo do espaço deve ser de $0,87 \mathrm{~m}$ para o viaduto e de 2,43 $\mathrm{m}$ para a ponte. Estas dimensões são muito grandes para representar a passagem do trem sobre a estrutura, além de o valor obtido para o passo da ponte ser grande também para a representação da malha em elementos finitos. Desta forma, optou-se por adotar uma discretização mais fina para melhorar a precisão do modelo, apesar do alto custo computacional. Assim, conforme já descrito no item 5.3.3, a discretização da malha adotada foi de aproximadamente $0,25 \mathrm{~m}$ para o viaduto e $1,0 \mathrm{~m}$ para a ponte.

Conforme já comentado, a análise dinâmica inicia-se com o estudo do veículo sob a consideração de tabuleiro rígido e indeslocável. Assim, as séries espaciais de irregularidades apresentadas na Figura 6.6 são aplicadas em cada uma das rodas do modelo do trem por meio de deslocamentos impostos, considerando o trecho em que o trem se encontra sobre a estrutura. Observa-se que as irregularidades são as mesmas em cada uma das rodas, porém defasadas para o instante em que cada roda entra na ponte.

A fim de ilustrar a metodologia proposta, serão apresentados aqui o procedimento e as análises realizadas para o caso de trem trafegando sobre o viaduto com velocidade de $200 \mathrm{~km} / \mathrm{h}$ sem o efeito do lastro. Posteriormente, no capítulo 9, serão apresentados os resultados para todas as análises realizadas. A Figura 8.1 apresenta a primeira iteração (tabuleiro rígido e indeslocável) das irregularidades aplicadas no modelo do veículo. 


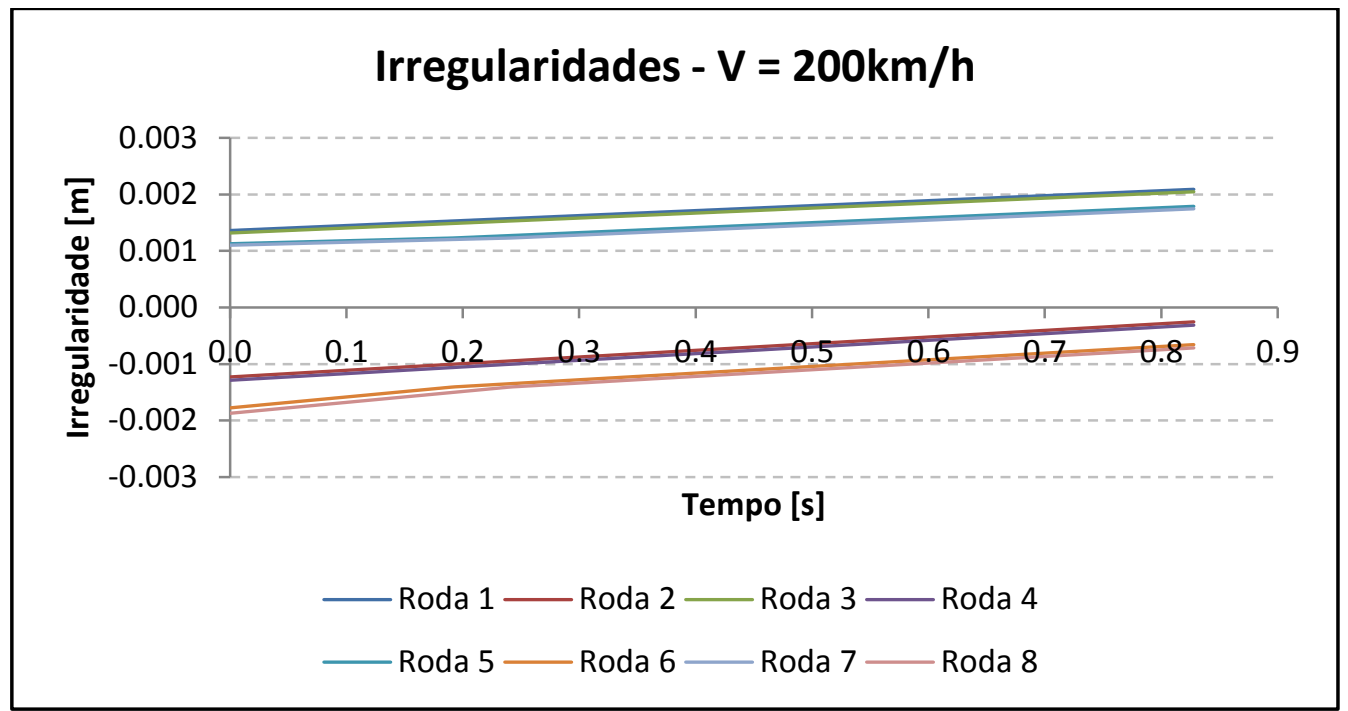

Figura 8.1: Irregularidades dos trilhos aplicadas em cada roda - Caso com viaduto sem lastro. Fonte: Autor.

Para a análise dinâmica da estrutura, são extraídas as forças de interação obtidas da análise do veículo e aplicadas em cada nó da estrutura ao longo do comprimento do trilho. A Figura 8.2 apresenta as forças de interação obtidas para a primeira iteração.

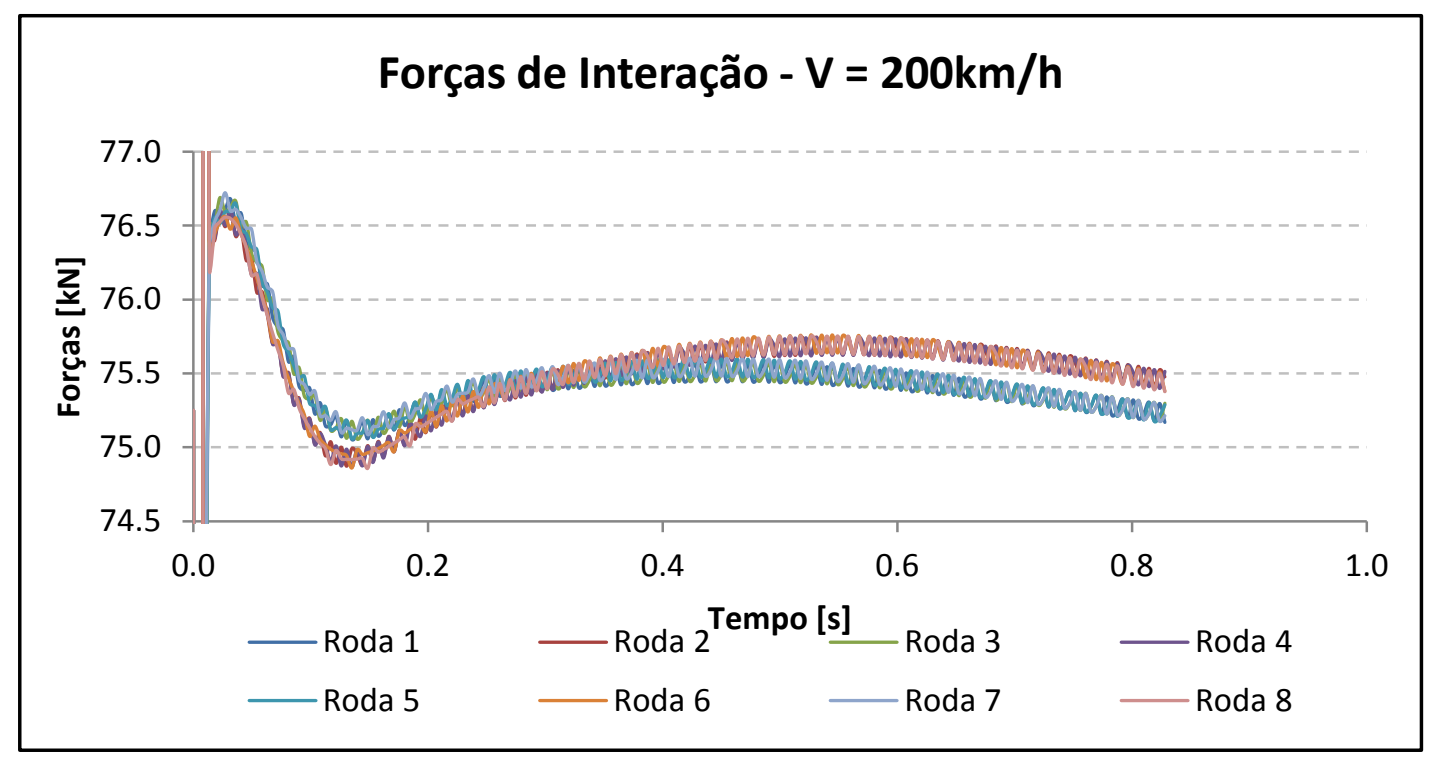

Figura 8.2: Forças de interação para a $1^{\mathrm{a}}$ iteração - Caso com viaduto sem lastro. Fonte: Autor.

O valor da força aplicada no nó equivale à força de interação no instante em que o trem se encontra sobre aquela posição e igual à zero para os demais instantes, como indica a equação a seguir. 


$$
P_{i}=P_{k} N_{i}\left(x_{k}\right)
$$

onde $N_{i}$ é igual a um para os instantes em que o trem estiver sobre aquela posição e zero para os demais.

A Figura 8.3 ilustra o esquema de carregamento considerado.

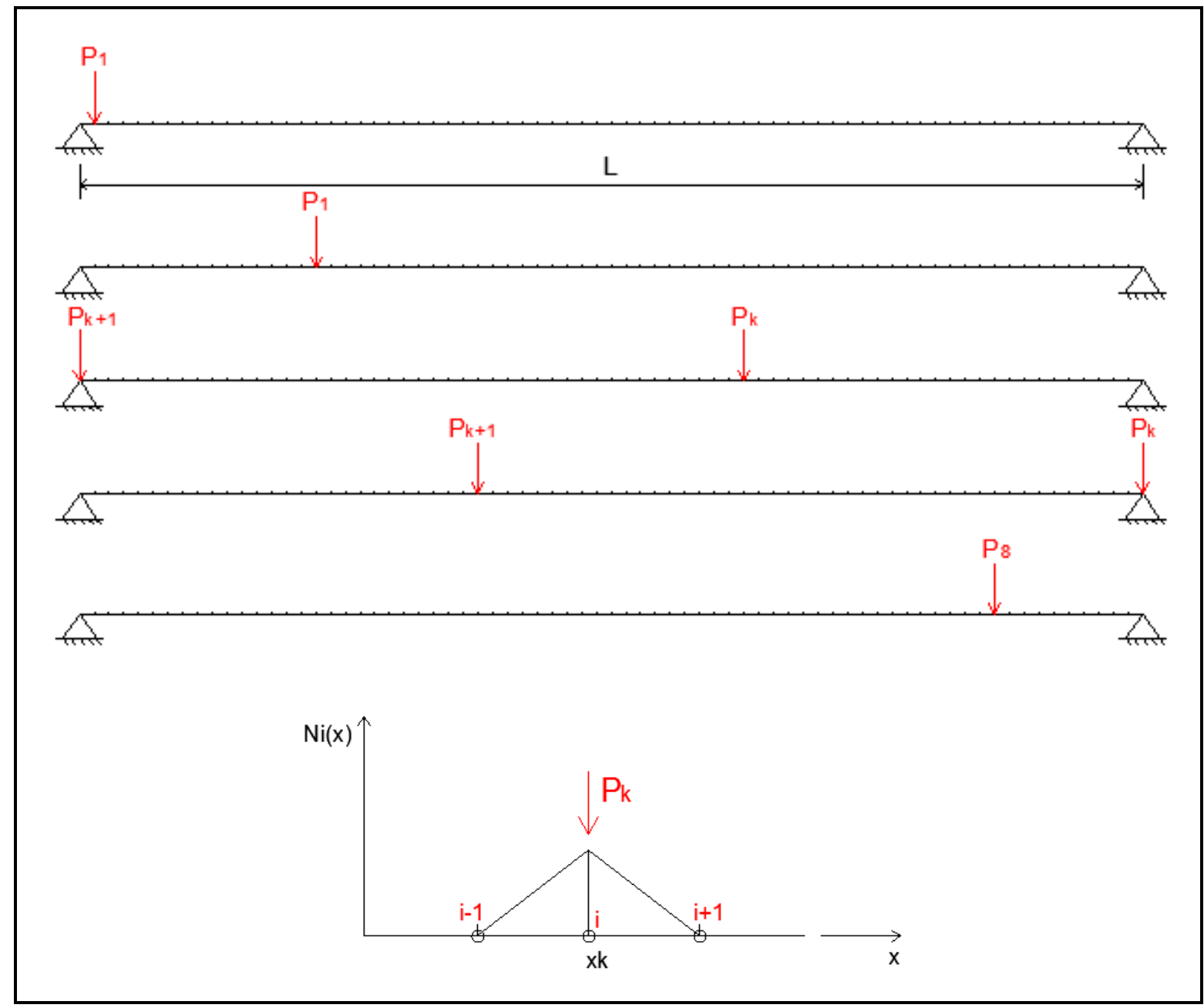

Figura 8.3: Esquema de carregamento utilizado na análise dinâmica. Fonte: Autor.

A Figura 8.4 apresenta o carregamento aplicado no nó central do viaduto para o caso sem lastro e velocidade de $200 \mathrm{~km} / \mathrm{h}$. Como se pode perceber, a primeira roda passa sobre este ponto no instante de $0,414 \mathrm{~s}$ e a última roda do sexto vagão no instante de $3,056 \mathrm{~s}$. Os valores aplicados são da ordem de $75 \mathrm{kN}$, referentes ao peso do veículo distribuído em cada roda. 


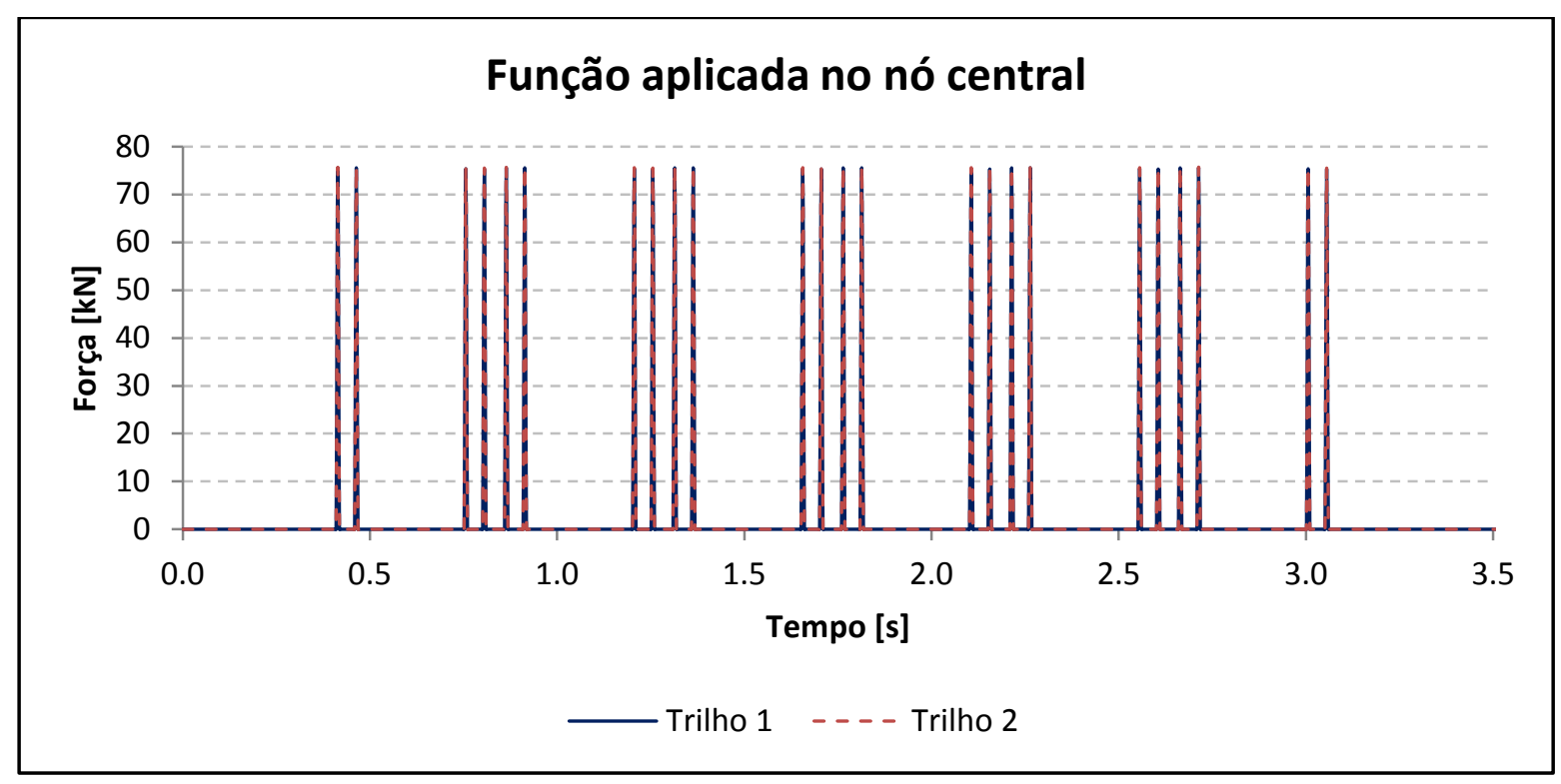

Figura 8.4: Funções aplicadas no nó central do viaduto. Fonte: Autor.

Considerou-se também uma taxa de amortecimento de $0,5 \%$ correspondente ao especificado na Tabela 2.1, por se tratar de estrutura mista e vãos superiores a $20 \mathrm{~m}$. 0 amortecimento foi inserido nos modelos por meio dos coeficientes de Rayleigh, sendo que, para o viaduto, considerou-se a influência dos dois primeiros modos de flexão no plano vertical $(3,078 \mathrm{~Hz}$ e $8,569 \mathrm{~Hz})$ e, para a ponte, considerou-se a do $4^{\circ}$ e do $23^{\circ}$ modos de vibração, também referentes à flexão no plano vertical $(0,920 \mathrm{~Hz}$ e 2,668 Hz). A Tabela 8.2 apresenta os coeficientes de Rayleigh adotados nos modelos do viaduto e da ponte.

Tabela 8.2: Coeficientes de Rayleigh adotados nos modelos. Fonte: Autor.

\begin{tabular}{|c|c|c|}
\hline Estrutura & $\boldsymbol{\alpha}\left[\mathrm{s}^{-1}\right]$ & $\boldsymbol{\beta}[\mathrm{s}]$ \\
\hline \hline Viaduto & $1,42.10^{-1}$ & $1,36.10^{-4}$ \\
\hline Ponte & $4,95.10^{-2}$ & $4,44.10^{-4}$ \\
\hline
\end{tabular}

Para a correção do pressuposto de tabuleiro rígido e indeslocável, somou-se o deslocamento do tabuleiro equivalente ao instante em que o trem se encontra sobre cada posição às irregularidades previamente consideradas. Na Figura 8.5 apresenta-se o deslocamento vertical do tabuleiro do viaduto para o caso sem lastro e velocidade de $200 \mathrm{~km} / \mathrm{h}$. É possível perceber a contribuição de cada vagão trafegando sobre o nó, bem como a influência do número de vagões sobre a estrutura. 


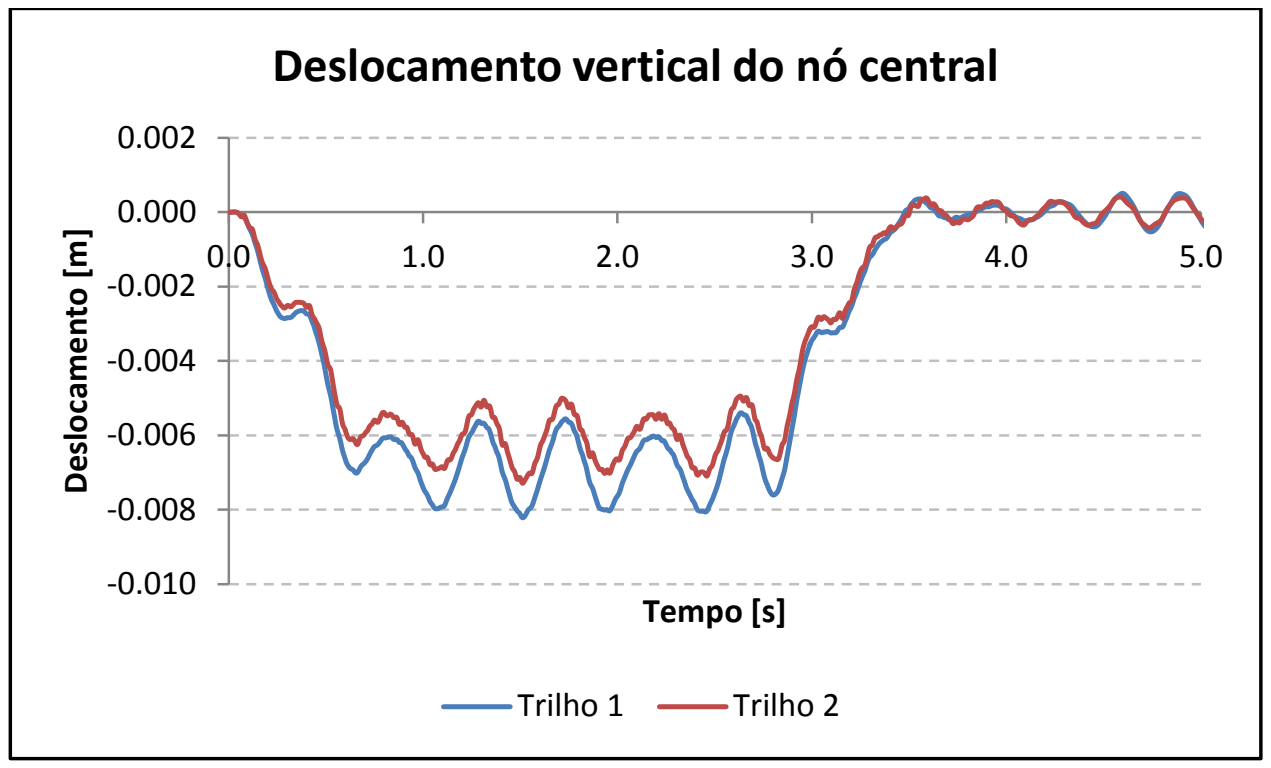

Figura 8.5: Deslocamento vertical do tabuleiro no nó central. Fonte: Autor.

Observa-se também que o trilho 2 corresponde ao trilho interno da via em relação ao eixo do viaduto. Desta forma, os deslocamentos obtidos neste trilho são inferiores ao trilho 1 , já que na região do trilho 2 a influência dos modos de torção do tabuleiro é menor.

A Figura 8.6 apresenta um comparativo entre as irregularidades aplicadas no trem na primeira, segunda e terceira iteração. Observa-se que, de acordo com a Figura 6.6, em que se apresentam as irregularidades aplicadas no trem para a primeira iteração, para uma distância muito pequena, a função que caracteriza a irregularidade é praticamente linear.

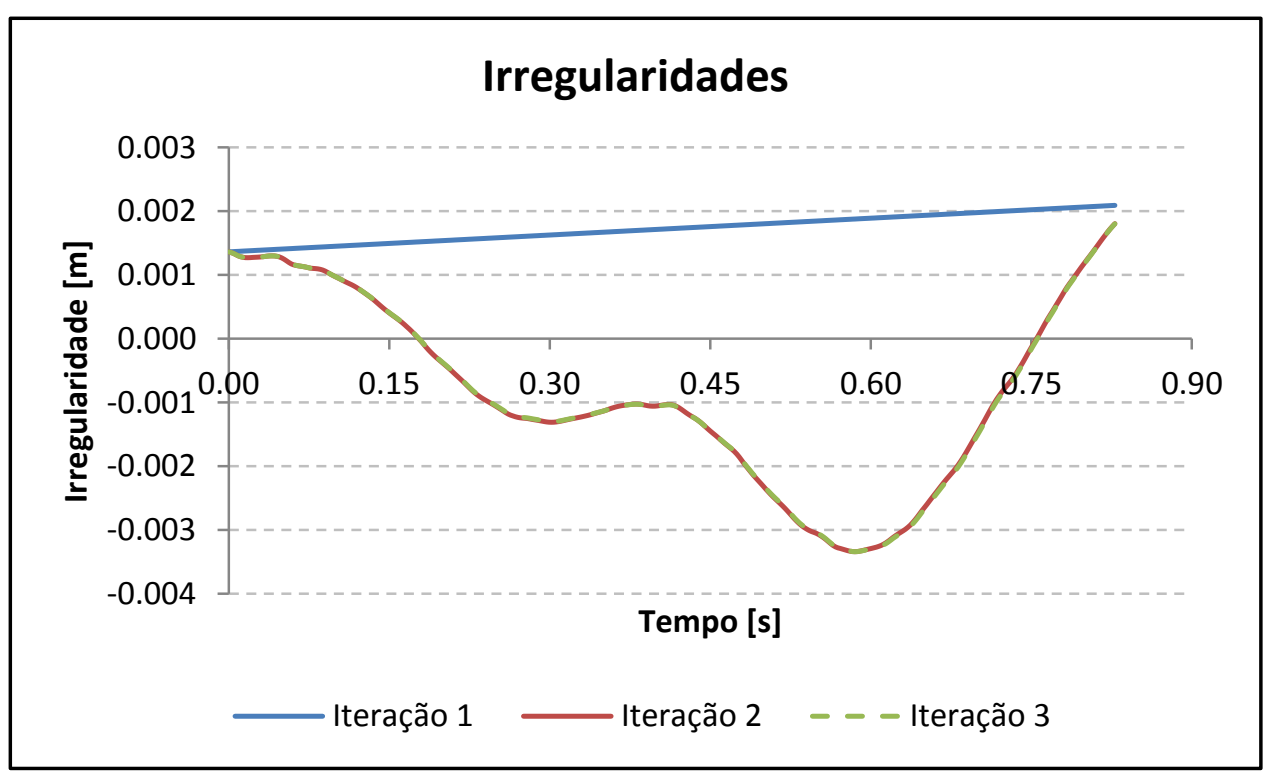

Figura 8.6: Irregularidades aplicadas no trem em cada iteração. Fonte: Autor. 
Com a correção dos deslocamentos, o procedimento é repetido até que os resultados da última iteração sejam muito próximos aos da iteração anterior. Ao final deste trabalho, no capítulo de anexo, é apresentado um fluxograma para ilustração da metodologia proposta, com a apresentação sucinta das planilhas e rotinas desenvolvidas.

A verificação da convergência do método foi avaliada a partir das transformadas de Fourier para a força de interação entre o veículo e o tabuleiro de cada iteração pelo método SRSS - Square Root of the Sum of Squares - que corresponde à raiz quadrada da soma dos quadrados das máximas amplitudes das forças, no intervalo de frequência analisado, conforme a expressão [8.2].

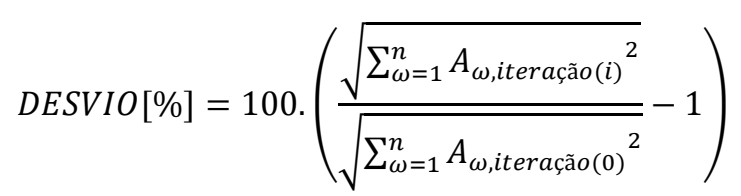

Onde:

n: o número de frequências consideradas para o cálculo das amplitudes;

$\omega$ : a frequência angular;

$A_{\omega, \text { iteração(0) }}:$ amplitude da força para a frequência angular $\omega$ na primeira iteração;

$A_{\omega, \text { iteração(i) }}:$ amplitude da força para a frequência angular $\omega$ na última iteração.

Para a verificação de convergência do método, utilizou-se o estudo de caso do trem trafegando sobre o viaduto para a velocidade de $200 \mathrm{~km} / \mathrm{h}$ sem a presença do lastro. Neste caso, foram obtidas as transformadas de Fourier com o auxílio do ADINA para as forças de interação obtidas para a roda 1 , cujos diagramas de resposta dinâmica no domínio da frequência são apresentados a seguir para casa iteração.

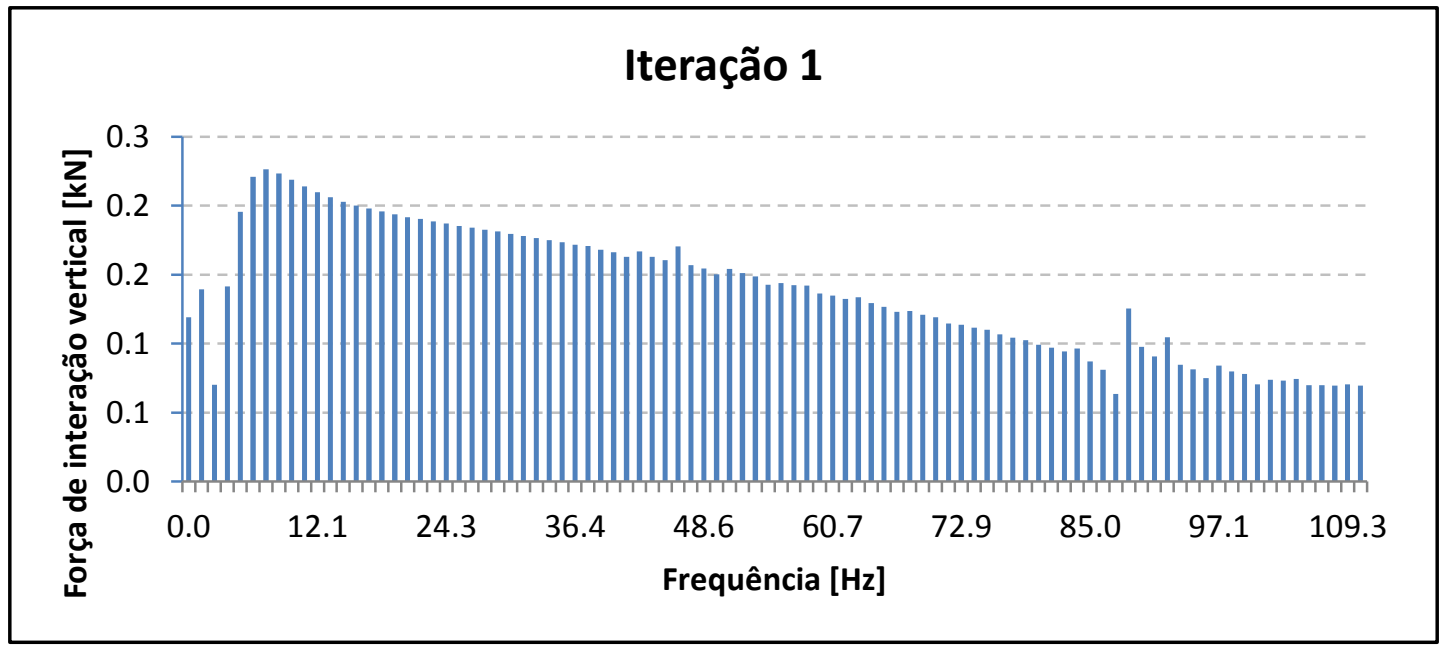


Figura 8.7: Resposta dinâmica da força de interação no domínio da frequência 1를 Iteração. Fonte: Autor.

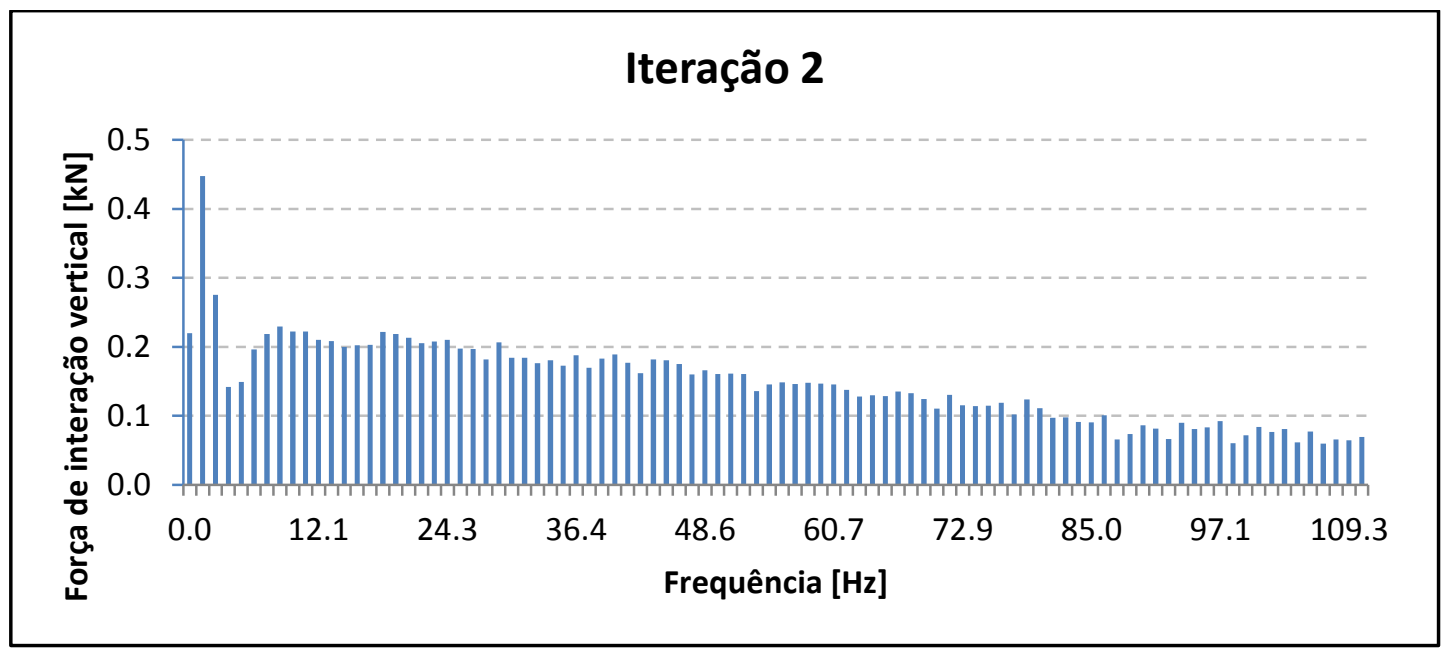

Figura 8.8: Resposta dinâmica da força de interação no domínio da frequência 2ª Iteração. Fonte: Autor.

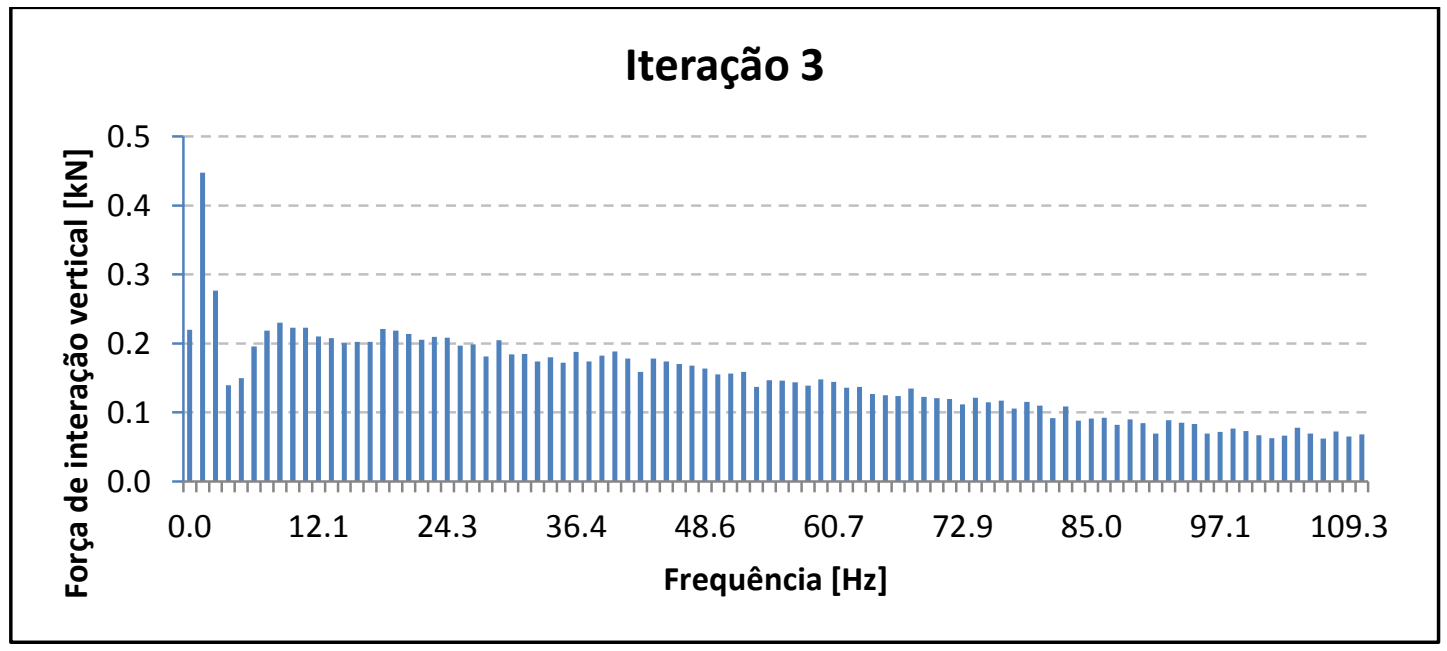

Figura 8.9: Resposta dinâmica da força de interação no domínio da frequência $3^{\text {a }}$ Iteração. Fonte: Autor.

A Tabela 8.3 apresenta os desvios absolutos e relativos verificados para as iterações. Nota-se que a força de interação vertical apresenta uma boa convergência na $3^{\circ}$ iteração (desvio relativo de $-0,361 \%$ ). Com relação à adoção da hipótese de tabuleiro rígido e indeslocável, a análise mostra que é necessário fazer pelo menos duas iterações, visto que os deslocamentos do tabuleiro são de importante relevância na resposta dinâmica. 
Tabela 8.3: Desvios absolutos e relativos obtidos. Fonte: Autor.

\begin{tabular}{|l|l|l|l|}
\hline Iteração & Desvio abs.(\%) & Iteração & Desvio rel.(\%) \\
\hline
\end{tabular}

\begin{tabular}{|c|c|c|c|}
\hline $1-2$ & 9,803 & $1-2$ & 9,803 \\
\hline $1-3$ & 9,407 & $2-3$ & $-0,361$ \\
\hline
\end{tabular}




\section{RESULTADOS}

Este trabalho estuda o comportamento de pontes ferroviárias para trens de alta velocidade, avaliando a influência do lastro na resposta dinâmica. Para isso, serão analisadas as respostas de forças de interação, aceleração vertical no interior dos vagões e a aceleração e o deslocamento vertical do tabuleiro. Os valores serão comparados com os limites estabelecidos pelo Eurocode. Observa-se que, apesar de este trabalho ter foco nos estados limites de serviço, conforto dos passageiros e estabilidade da via, a metodologia pode ser aplicada para o dimensionamento no estado limite último, com a análise dos esforços nos elementos estruturais, já que os resultados podem ser extraídos do ADINA e tratados de forma análoga aos aqui apresentados.

Conforme já mencionado, o processo iterativo correspondente à metodologia proposta mostra boa convergência na segunda iteração. Desta forma, devido ao alto custo computacional, os resultados apresentados aqui se referem a esta iteração.

\subsection{VIADUTO}

\subsubsection{Forças de Interação}

A seguir, são apresentados os diagramas das forças de interação para cada velocidade no estudo de caso do viaduto, para as análises com e sem o lastro. Como se pode perceber, a presença do lastro praticamente não altera os valores das forças de interação. Os resultados apresentados referem-se às forças de interação obtidas para uma das rodas do veículo.

De acordo com a Figura 9.1, as forças de interação tendem a ser um pouco mais elevadas para velocidades maiores, bem como se nota o aumento da oscilação das forças.
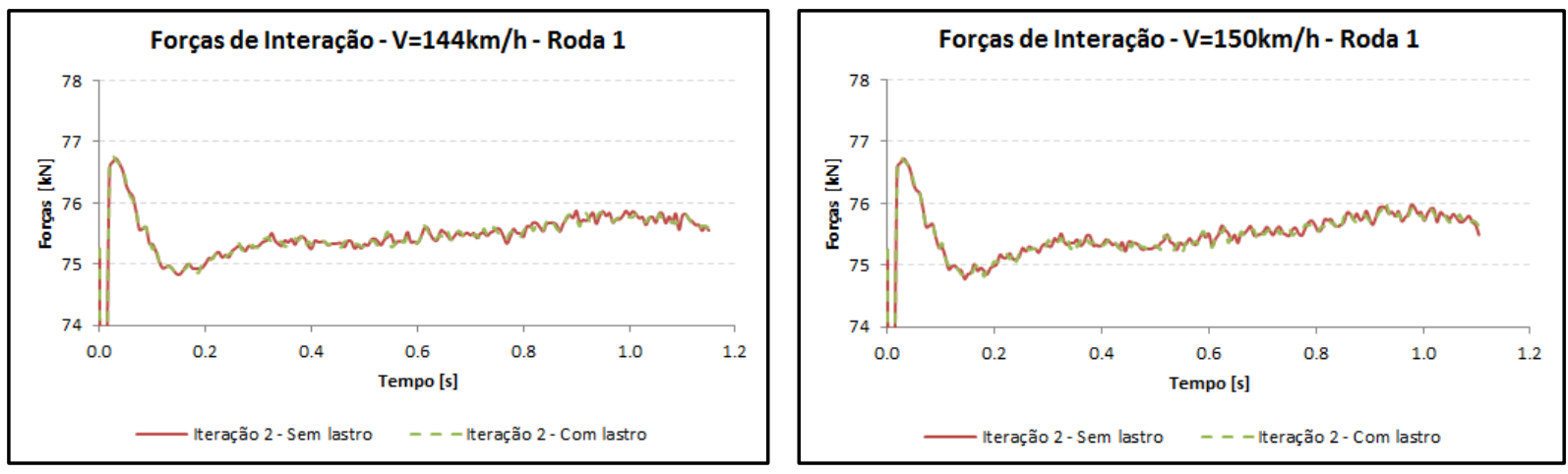

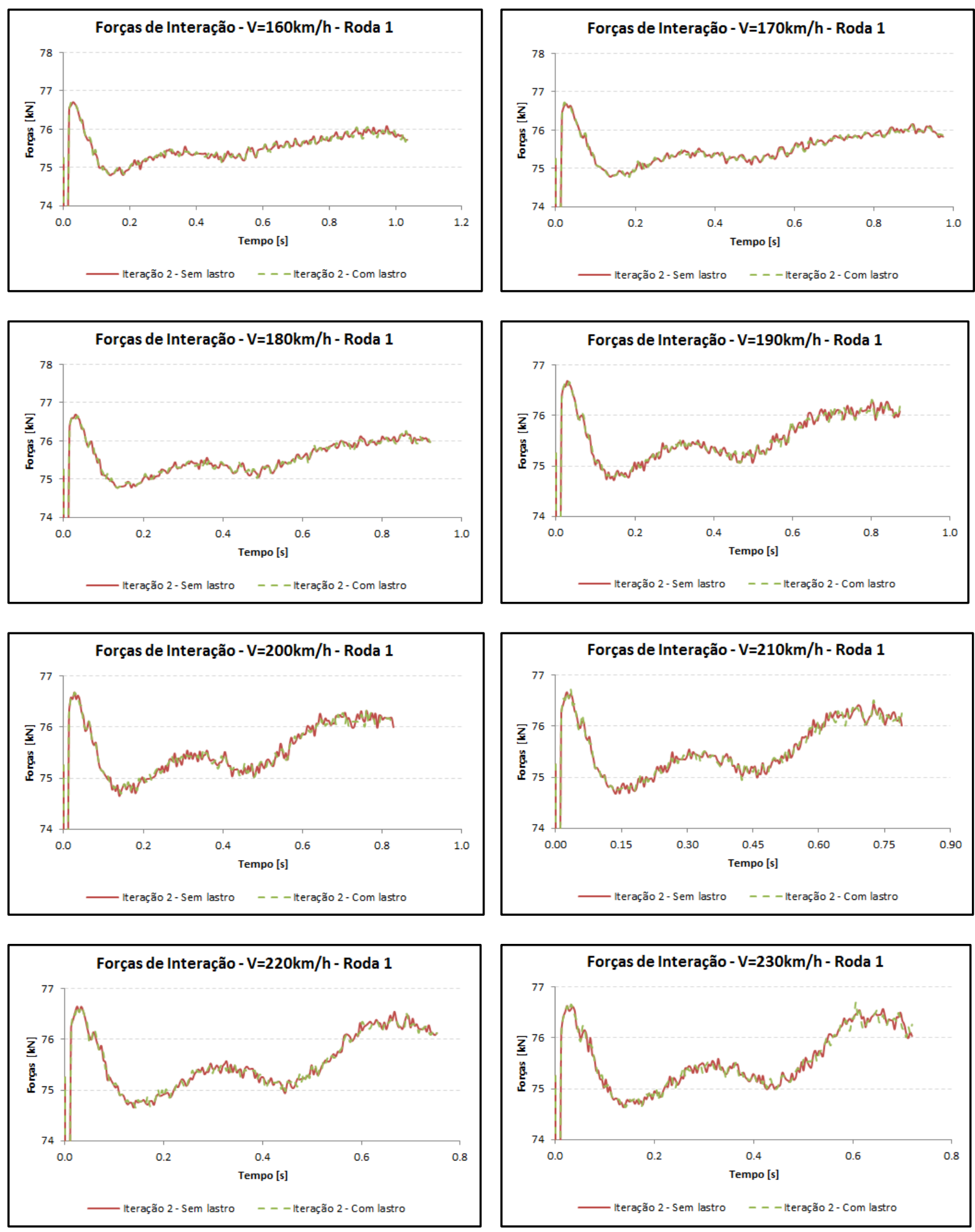

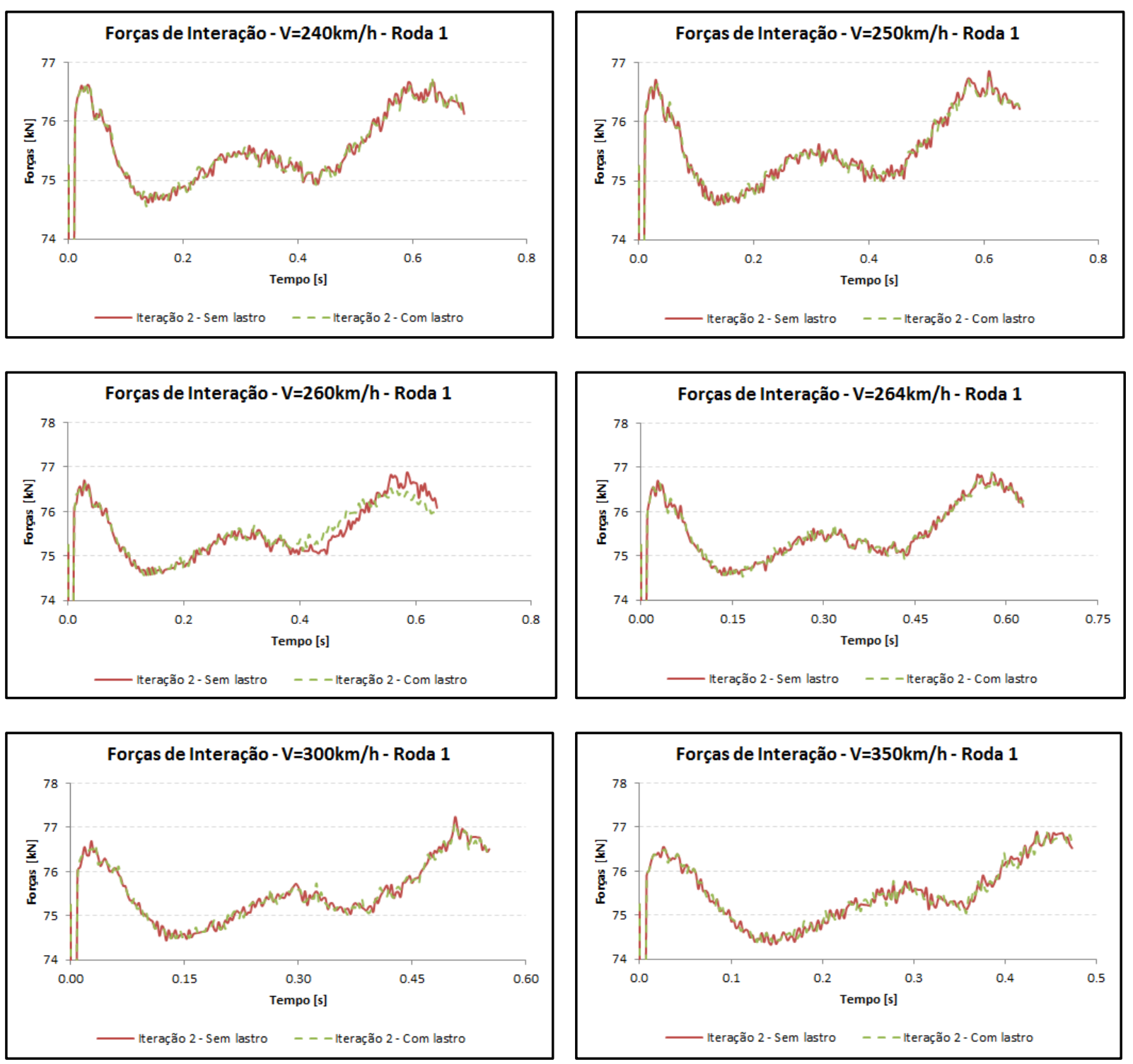

Figura 9.1: Forças de interação na roda 1 para cada velocidade. Fonte: Autor.

\subsubsection{Deslocamentos do Tabuleiro}

Entre as respostas analisadas, apresenta-se aqui a referente ao deslocamento vertical do tabuleiro. Este valor foi obtido no meio do comprimento do vão, avaliado no nó correspondente ao trilho 1 da via, sendo este o mais externo em relação ao eixo da seção transversal.

Conforme prescrito no Eurocode, o deslocamento vertical do tabuleiro não deve exceder $L / 600$, sendo que, no caso do viaduto, este limite é de $0,075 \mathrm{~m}$. Para todos os casos analisados, o deslocamento encontrado é inferior a este limite, sendo o valor máximo 
correspondente à análise com velocidade de $264 \mathrm{~km} / \mathrm{h}$, equivalente a $14 \mathrm{~mm}$ para o caso sem o lastro e 13,9 mm para o caso com o lastro.

Observa-se que existe uma amplificação do deslocamento vertical do tabuleiro para velocidades mais altas, sendo de $8 \mathrm{~mm}$ para a velocidade de $144 \mathrm{~km} / \mathrm{h}$ e de $15 \mathrm{~mm}$ para a velocidade de $264 \mathrm{~km} / \mathrm{h}$. Observa-se também que houve uma maior oscilação da resposta, sendo que, no caso da velocidade de $144 \mathrm{~km} / \mathrm{h}$, a amplitude da oscilação é em torno de $2 \mathrm{~mm}$, enquanto que para a velocidade de $264 \mathrm{~km} / \mathrm{h}$ este valor é da ordem de $10 \mathrm{~mm}$.

Para as velocidades entre $260 \mathrm{~km} / \mathrm{h}$ e $300 \mathrm{~km} / \mathrm{h}$ os deslocamentos verticais no tabuleiro aumentaram com o número de vagões sobre a estrutura, havendo uma amplificação destes valores mesmo com a saída do trem. Neste caso, evidencia-se um caso ressonante entre o veículo e a estrutura.

Em relação ao lastro, houve uma boa correspondência entre os valores para os casos sem e com a presença do lastro para todas as velocidades analisadas.
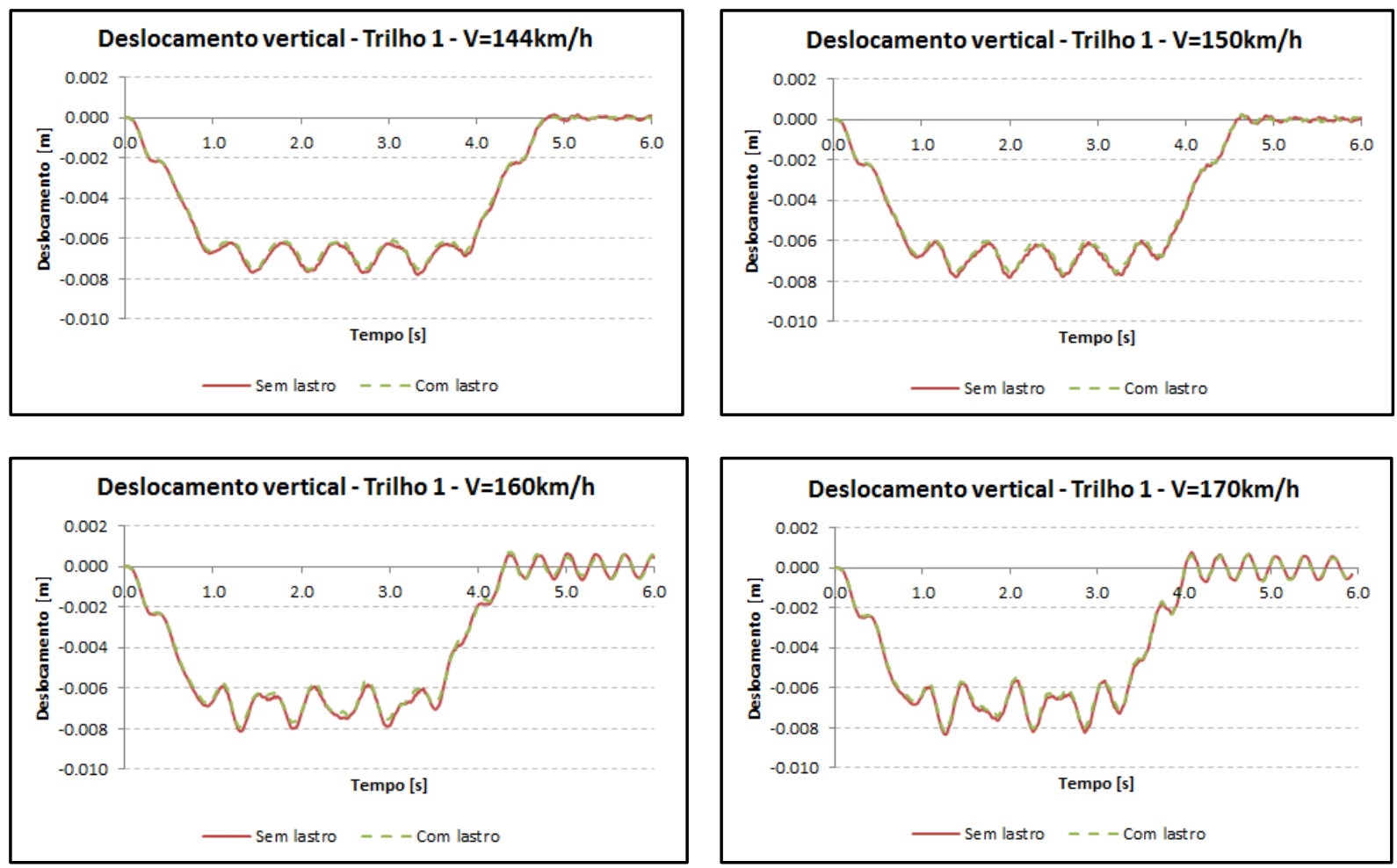

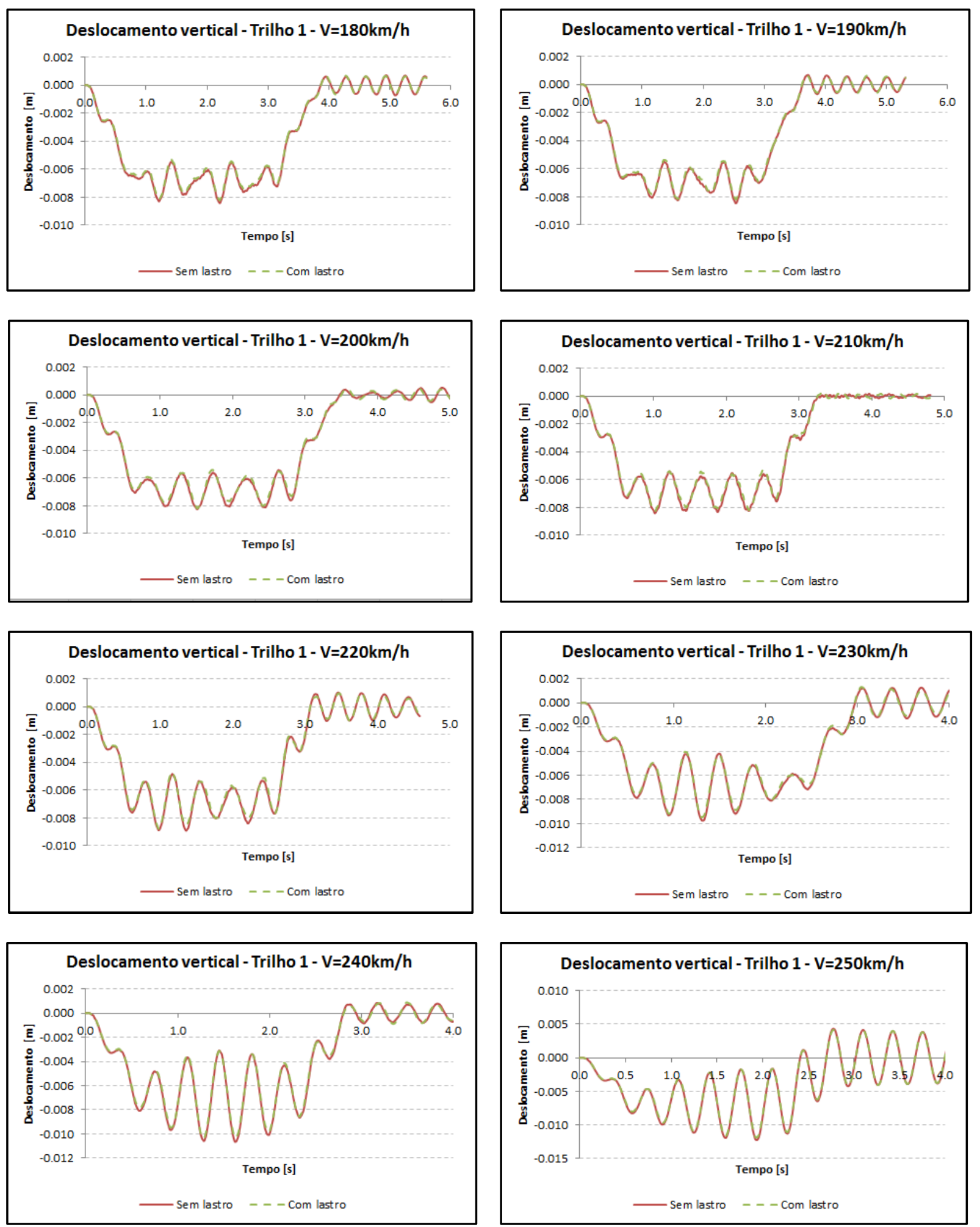

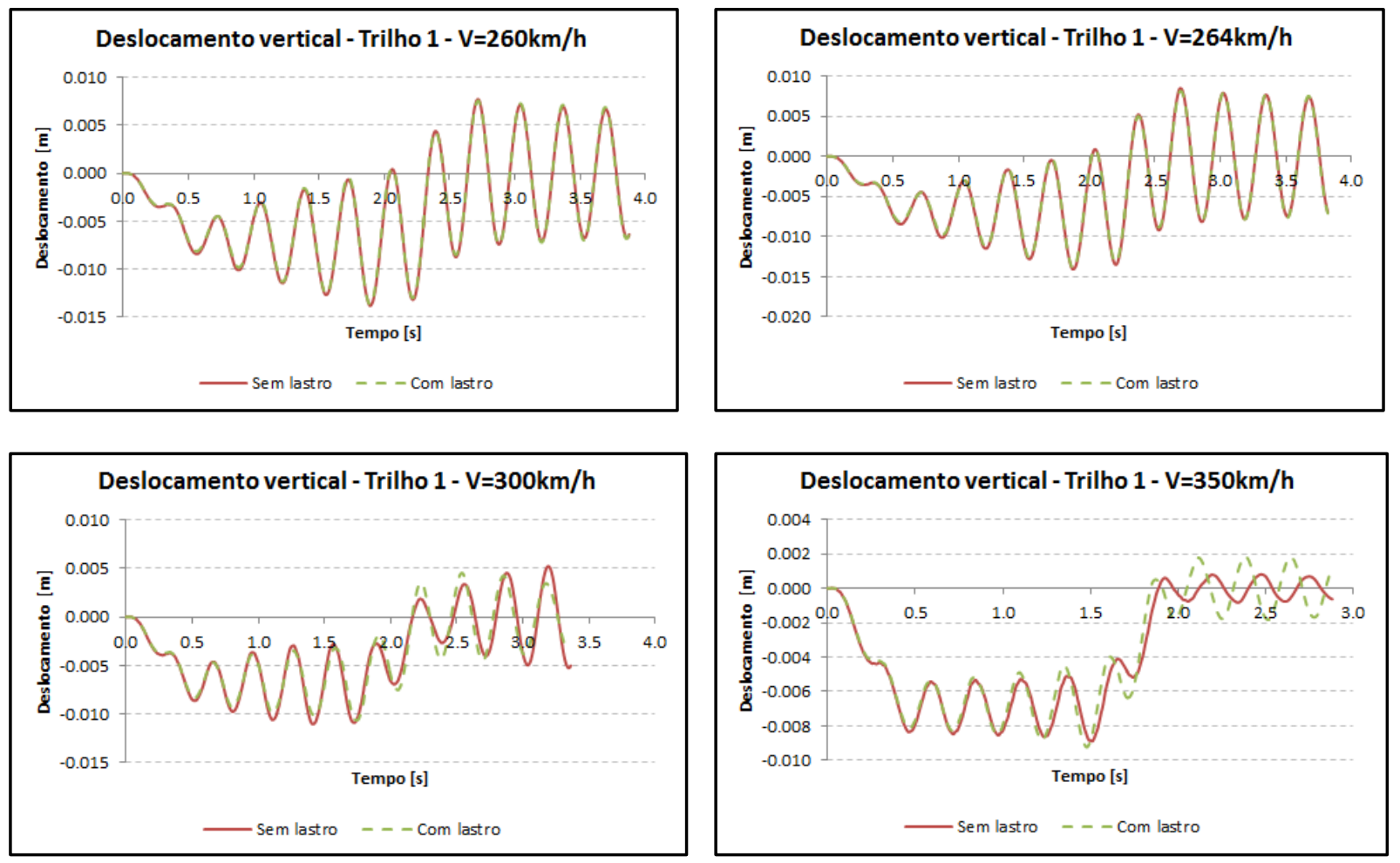

Figura 9.2: Deslocamento vertical do tabuleiro - Trilho 1. Fonte: Autor.

\subsubsection{Aceleração Vertical no Interior dos Vagões}

A seguir, são apresentados os diagramas de aceleração vertical no interior do vagão para cada velocidade, para as análises com e sem o lastro. Observa-se que os diagramas apresentados correspondem ao efeito do primeiro vagão trafegando sobre a estrutura.
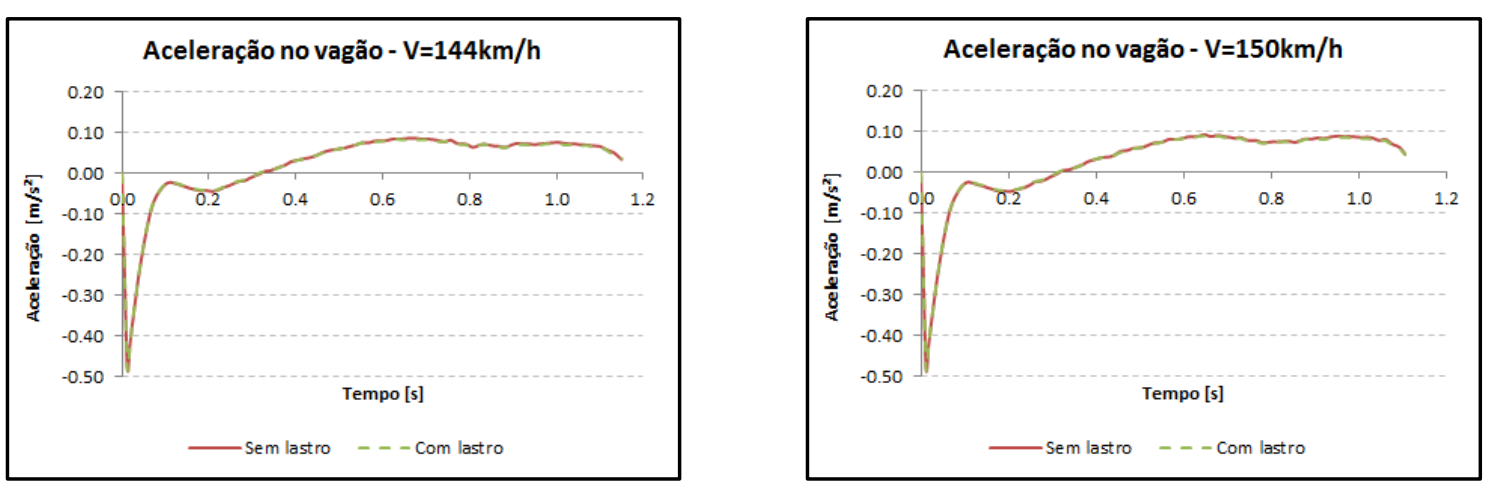

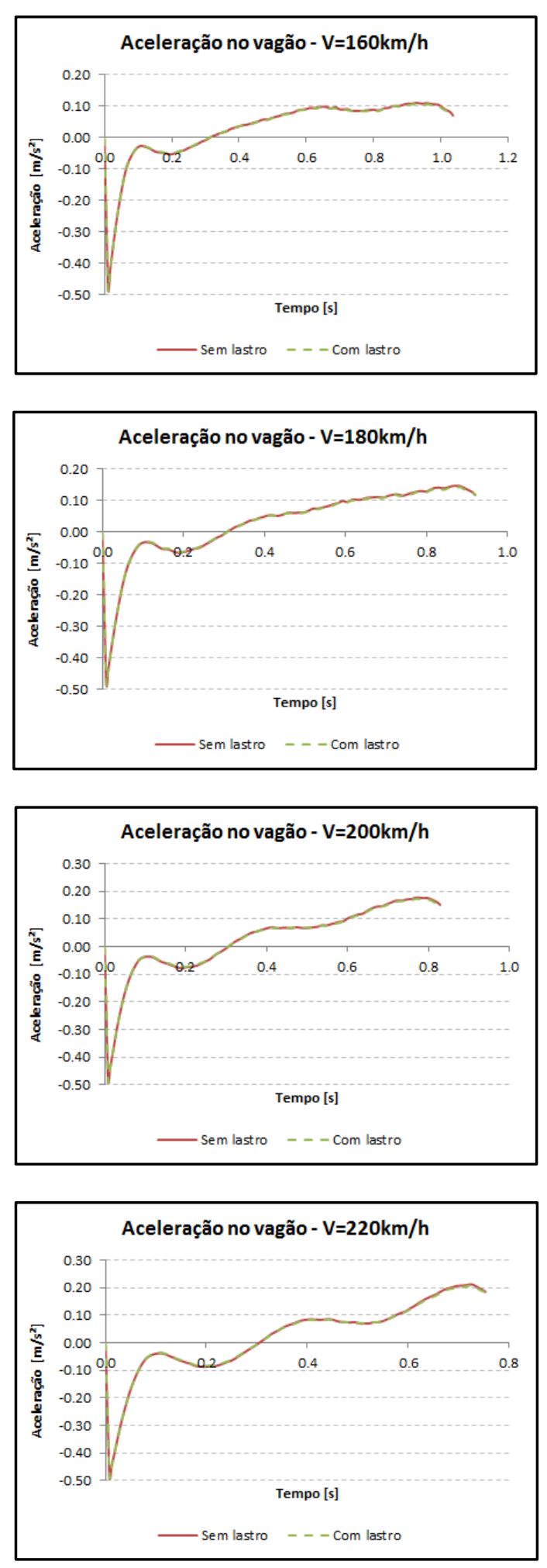
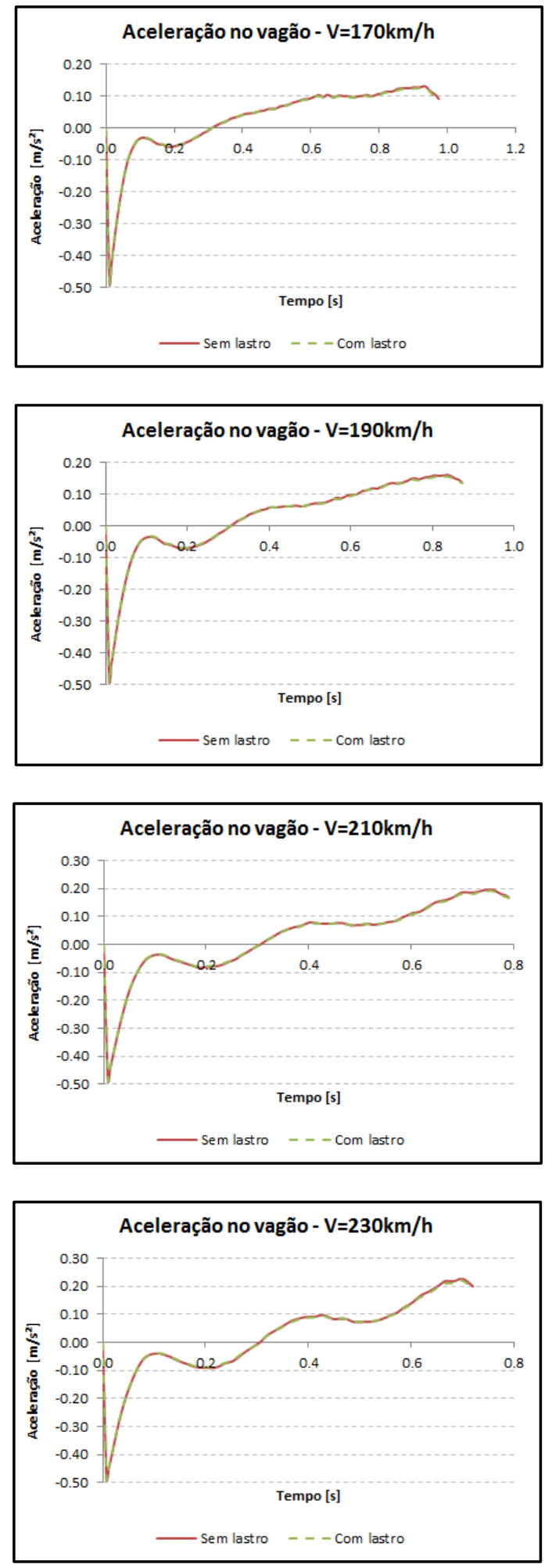

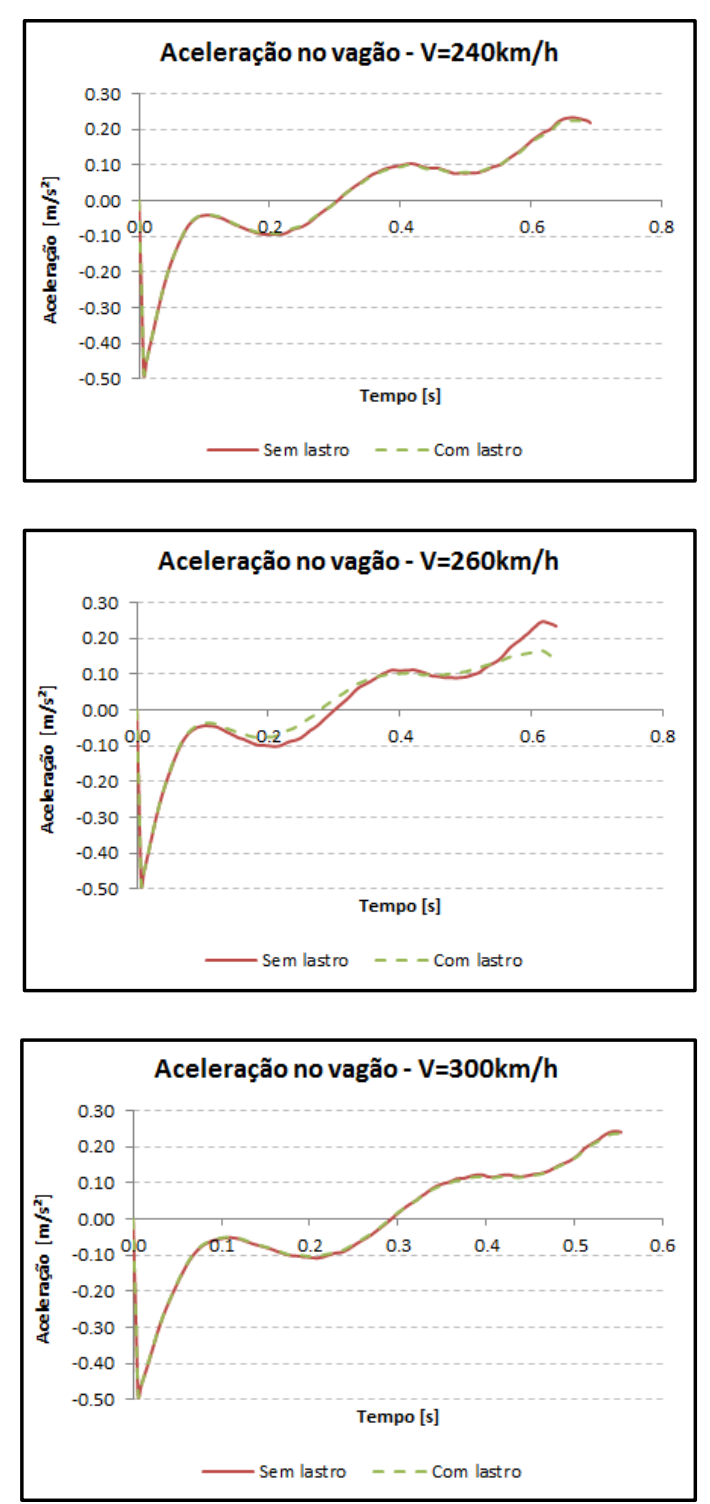
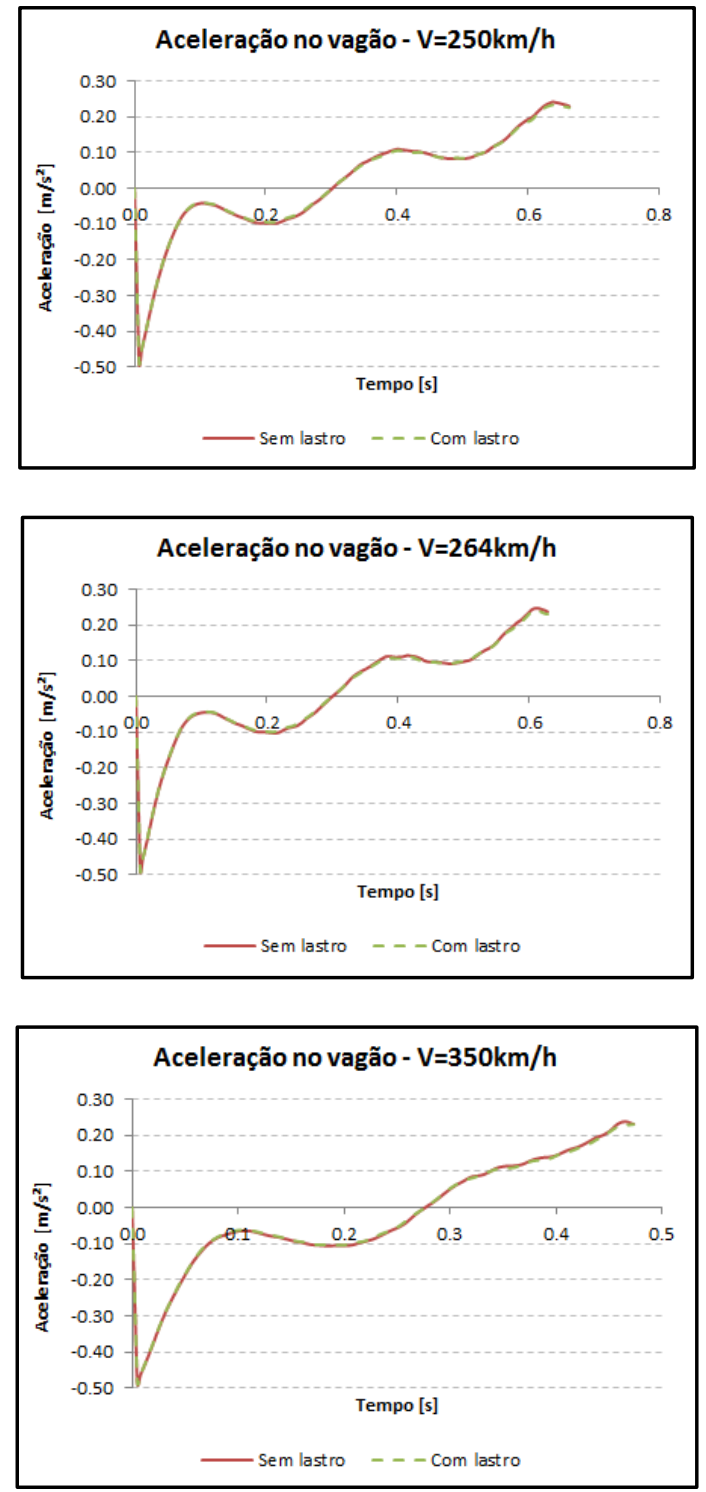

Figura 9.3: Acelerações verticais no interior do vagão. Fonte: Autor.

Para todos os casos analisados as acelerações obtidas são menores do que $1,0 \mathrm{~m} / \mathrm{s}^{2}$, correspondente ao nível de conforto "muito bom" conforme os limites estabelecidos pelo Eurocode (Tabela 1.1). Observa-se na Figura 9.3 que ocorre um pico de aceleração vertical no instante em que o trem entra no viaduto, porém, este valor ainda se encontra inferior ao limite indicado e tende a reduzir à medida que o trem trafega sobre a estrutura.

Apesar de graficamente não ser perceptível a influência do lastro na resposta, a Tabela 9.1 apresenta os valores máximos obtidos para a aceleração vertical no interior do vagão para os casos com e sem lastro. Como se pode perceber, para todos os casos, a aceleração vertical para o caso sem lastro é ligeiramente maior que o caso com lastro, 
sendo o maior valor encontrado de $0,248 \mathrm{~m} / \mathrm{s}^{2}$ para o caso sem lastro e velocidade de $264 \mathrm{~km} / \mathrm{h}$, desconsiderado o pico de aceleração na entrada do trem no viaduto.

Tabela 9.1: Valores máximos de aceleração vertical no interior do vagão. Fonte: Autor.

\begin{tabular}{|c|c|c|}
\hline Velocidade $[\mathbf{k m} / \mathbf{h}]$ & $\mathbf{b}_{\mathbf{v}, \text { sem lastro }}\left[\mathbf{m} / \mathbf{s}^{\mathbf{2}}\right]$ & $\mathbf{b}_{\mathbf{v}, \text { com lastro }}\left[\mathbf{m} / \mathbf{s}^{\mathbf{2}}\right]$ \\
\hline \hline 144 & 0,087 & 0,085 \\
\hline 150 & 0,092 & 0,089 \\
\hline 160 & 0,110 & 0,107 \\
\hline 170 & 0,131 & 0,127 \\
\hline 180 & 0,146 & 0,143 \\
\hline 190 & 0,161 & 0,156 \\
\hline 200 & 0,178 & 0,173 \\
\hline 210 & 0,197 & 0,192 \\
\hline 220 & 0,213 & 0,209 \\
\hline 230 & 0,227 & 0,223 \\
\hline 240 & 0,234 & 0,225 \\
\hline 250 & 0,242 & 0,234 \\
\hline 260 & 0,247 & 0,168 \\
\hline 264 & 0,248 & 0,241 \\
\hline 300 & 0,243 & 0,238 \\
\hline 350 & 0,239 & 0,230 \\
\hline
\end{tabular}

\subsubsection{Aceleração Vertical do Tabuleiro}

Analisou-se também a resposta da aceleração vertical no tabuleiro do viaduto, num ponto posicionado no meio do comprimento do vão e no afastamento correspondente às posições dos trilhos 1 ou 2, sendo o trilho 1 o mais externo em relação ao eixo da seção transversal, para os casos sem e com a presença do lastro.

Nas duas posições analisadas, as acelerações são maiores para velocidades mais altas e os picos representam a passagem de cada truque sobre o ponto analisado. Como se pode perceber, as acelerações obtidas para o caso com o lastro são inferiores àquelas para o caso sem o lastro, além de a maioria dos registros estarem dentro dos limites estabelecidos pelo Eurocode $\left(3,5 \mathrm{~m} / \mathrm{s}^{2}\right)$. Em relação às acelerações para o caso sem o lastro, elas ultrapassam o limite de $5,0 \mathrm{~m} / \mathrm{s}^{2}$, porém, ressalta-se que este projeto refere-se a uma via com a presença do lastro e que esta análise foi realizada apenas a fim de ilustração e comparação.

Em relação às respostas obtidas para a aceleração vertical do tabuleiro na posição equivalente ao trilho 2 , os resultados foram bem maiores na comparação com os obtidos na posição do trilho 1 , chegando a aproximadamente $50 \mathrm{~m} / \mathrm{s}^{2}$ para o caso sem lastro e velocidade de $350 \mathrm{~km} / \mathrm{h}$. Isso se deve à contribuição da laje, já que o trilho 1 se posiciona 
praticamente sobre a transversina da seção, enquanto que o trilho 2 se posiciona sobre o vão da laje.
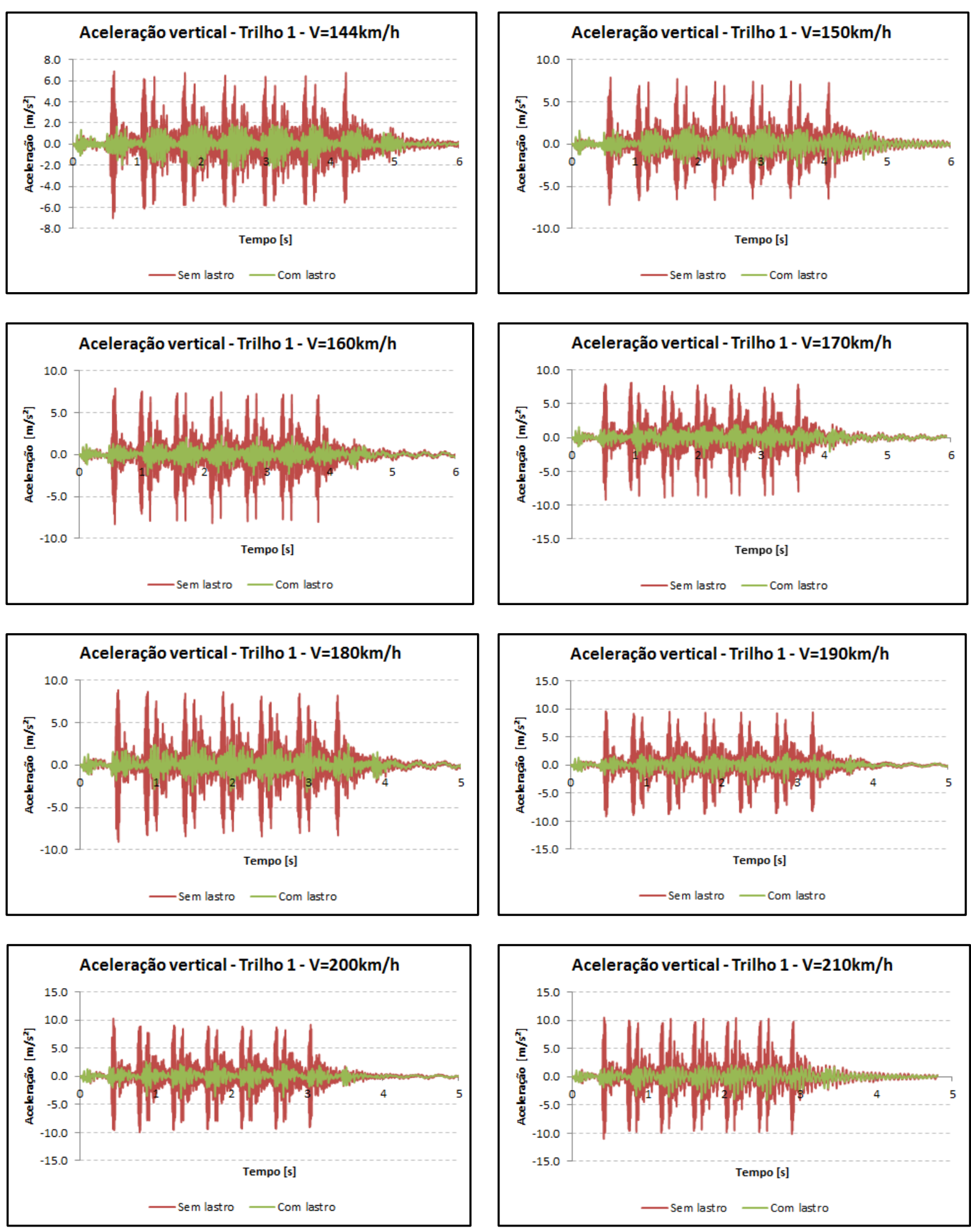

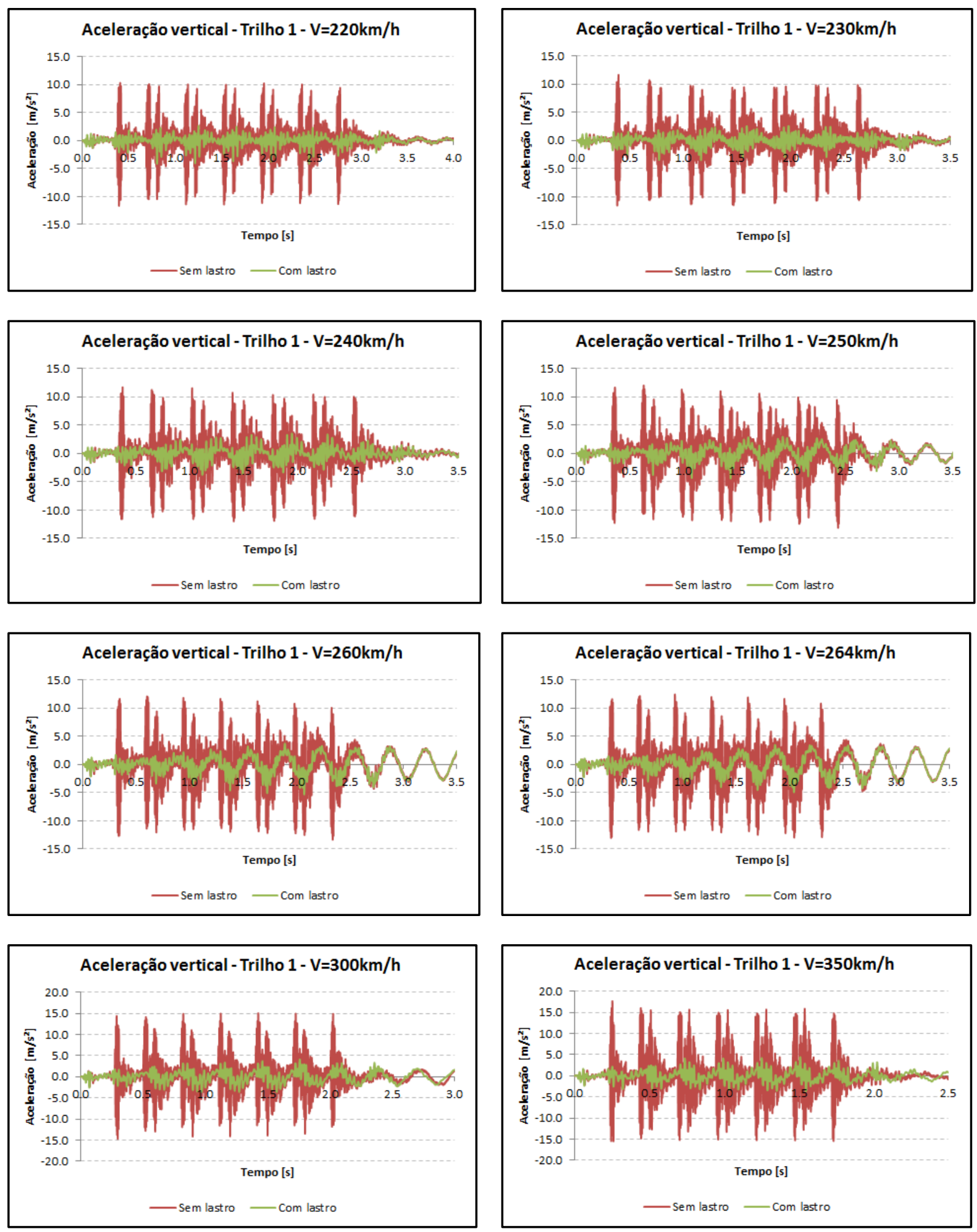

Figura 9.4: Acelerações verticais no meio do tabuleiro - Trilho 1. Fonte: Autor. 

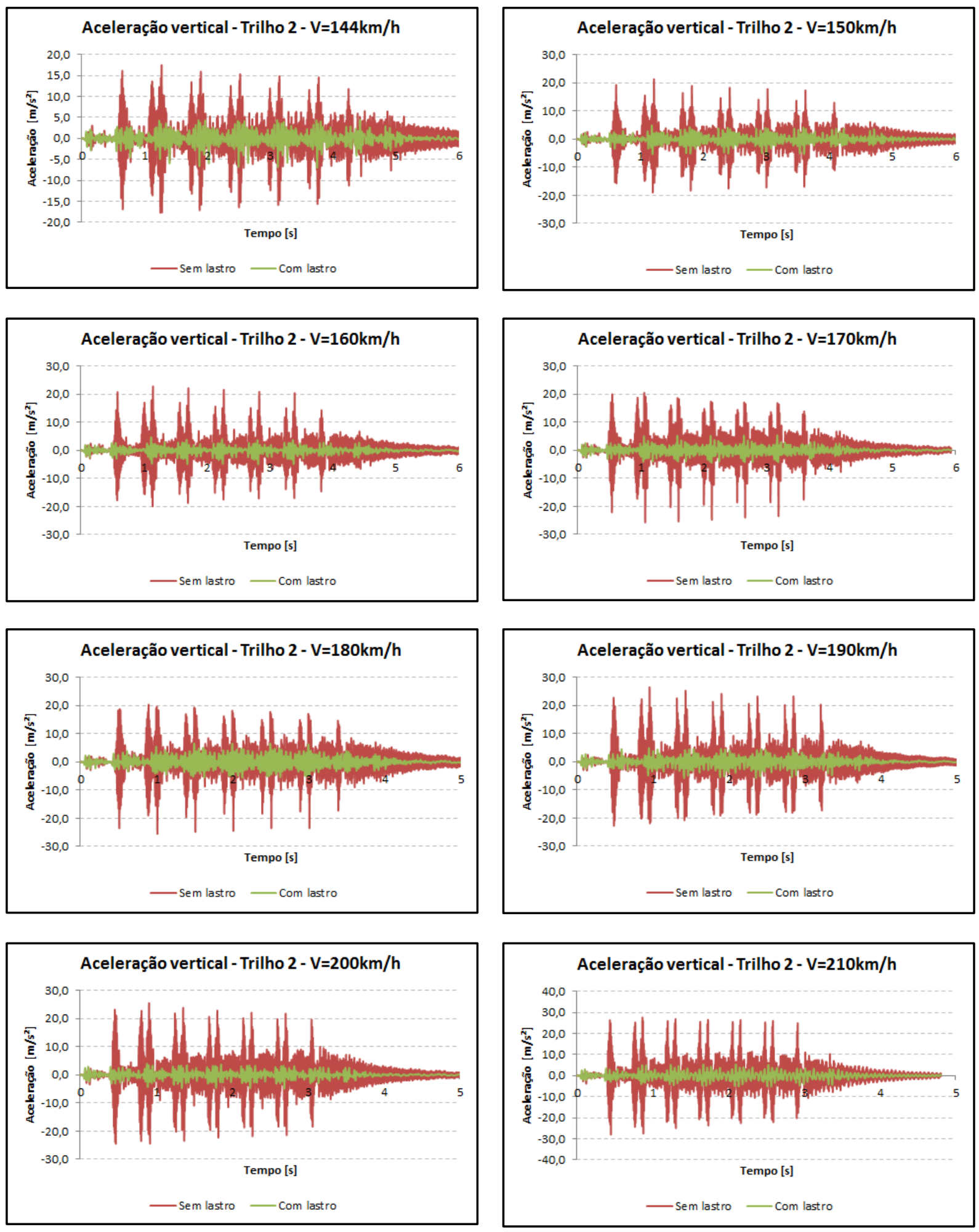

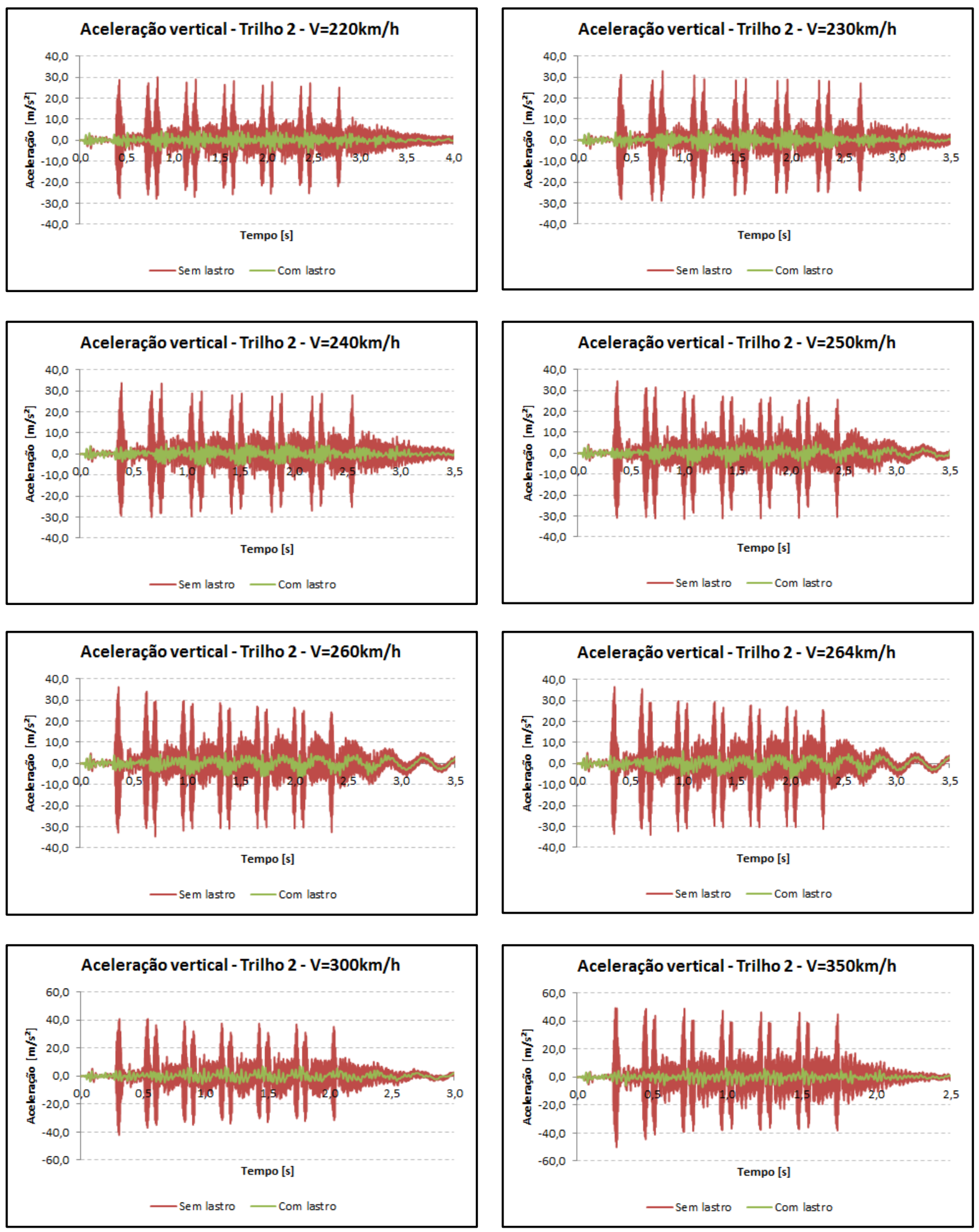

Figura 9.5: Acelerações verticais no meio do tabuleiro - Trilho 2. Fonte: Autor. 


\subsubsection{Análise Considerando a Passagem do Último Vagão}

Conforme indicado no item 9.1.2, para a velocidade de $264 \mathrm{~km} / \mathrm{h}$ percebe-se um caso ressonante entre o trem e o viaduto, em que se observa uma amplificação dos deslocamentos verticais do tabuleiro após a passagem do trem sobre a estrutura. Como a modelagem do trem foi feita apenas para um vagão e a correção do pressuposto de tabuleiro rígido e indeslocável considerando os deslocamentos verticais da estrutura com a passagem do primeiro vagão, optou-se por verificar os resultados para este caso, com velocidade de $264 \mathrm{~km} / \mathrm{h}$, considerando os deslocamentos do tabuleiro com a passagem do último vagão. A seguir, são apresentados os resultados obtidos.
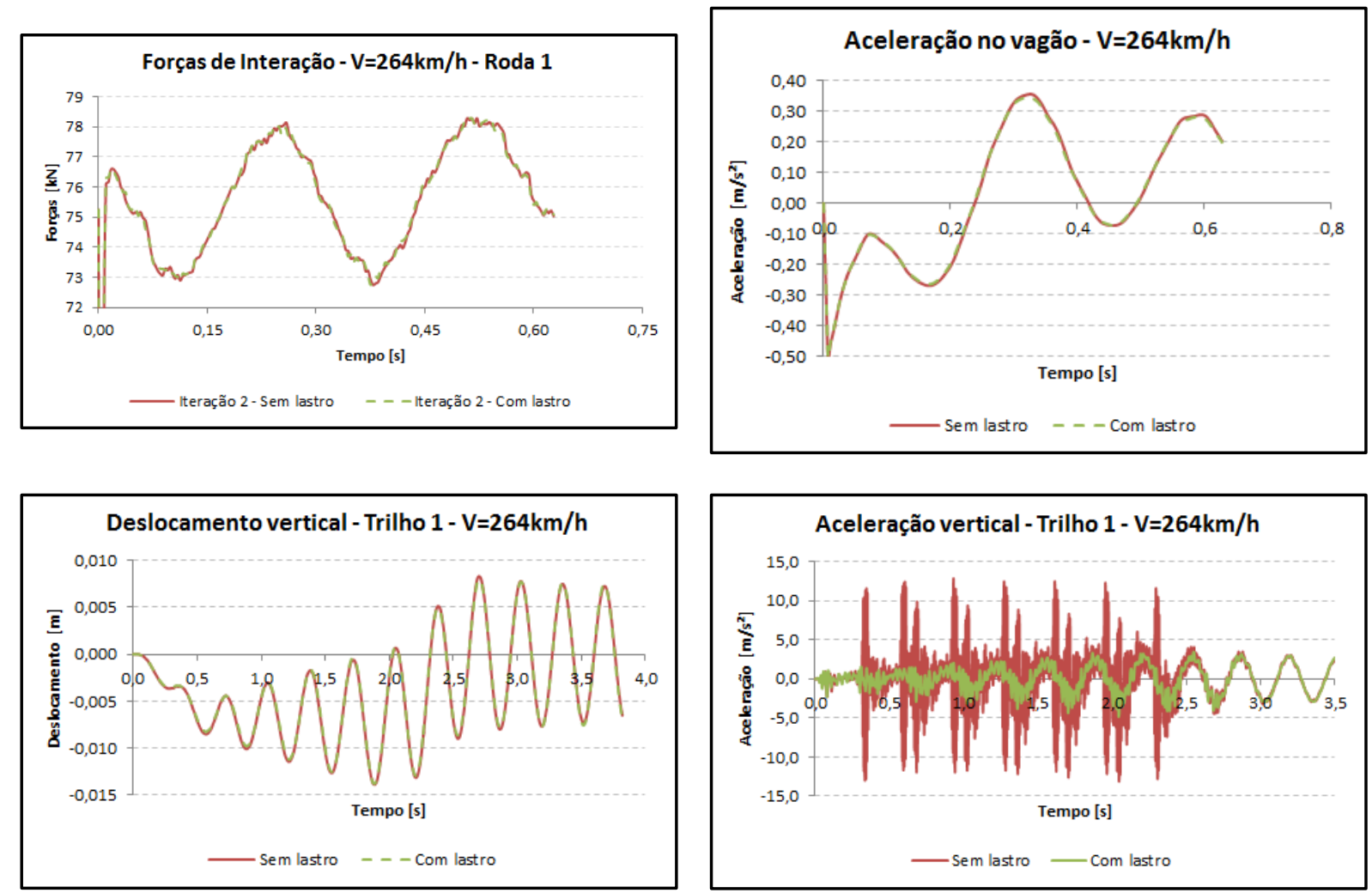

Figura 9.6: Resultados considerando os deslocamentos do tabuleiro com a passagem do último vagão - Trilho 1. Fonte: Autor.

Como se pode perceber na Figura 9.6, há uma amplificação da resposta para as forças de interação e para a aceleração vertical no interior do vagão. As forças de interação apresentaram uma amplitude de oscilação de $\pm 2,5 \mathrm{kN}$, sendo os valores máximos obtidos de aproximadamente 78 kN. Para a aceleração vertical no interior do vagão, a oscilação da resposta, bem como sua amplitude, foram superiores ao caso considerando o primeiro vagão, sendo o valor máximo obtido de aproximadamente $0,35 \mathrm{~m} / \mathrm{s}^{2}$. Para os casos de 
deslocamento vertical e aceleração vertical do tabuleiro, os valores obtidos considerando a passagem do primeiro vagão e do último vagão foram praticamente iguais. Assim, ressaltase a importância para a análise da resposta considerando também a passagem do último vagão sobre a estrutura.

\subsection{PONTE}

\subsubsection{Forças de Interação}

A seguir, são apresentados os diagramas das forças de interação para cada velocidade no estudo de caso da ponte, para as análises com e sem o lastro. Como se pode perceber, a presença do lastro, como no estudo de caso do viaduto, praticamente não altera os valores das forças de interação. Os resultados apresentados referem-se às forças de interação para uma das rodas do veículo.

Os diagramas a seguir apresentam as forças de interação obtidas na segunda iteração para todas as velocidades analisadas, para os estudos de caso com e sem o lastro.
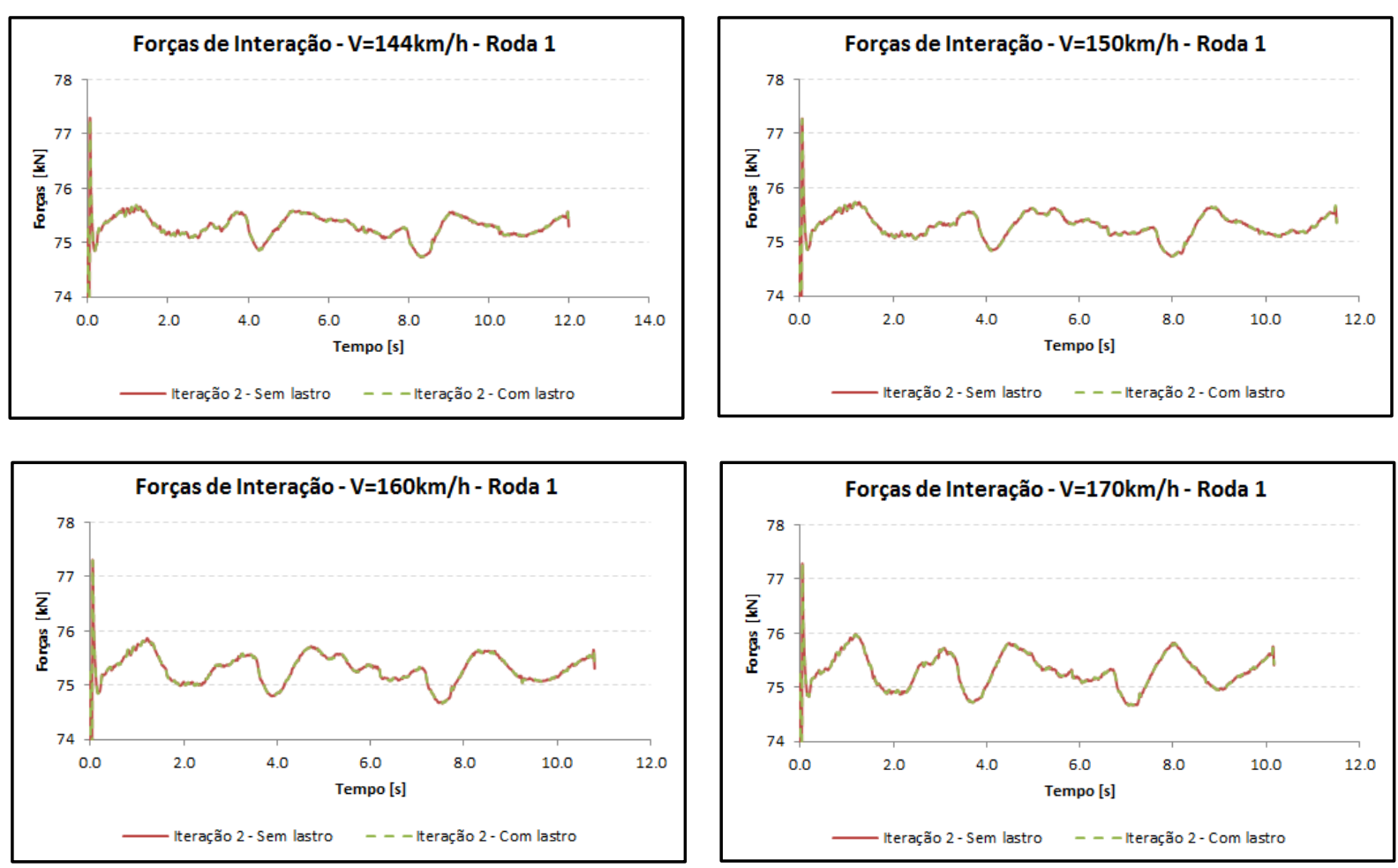

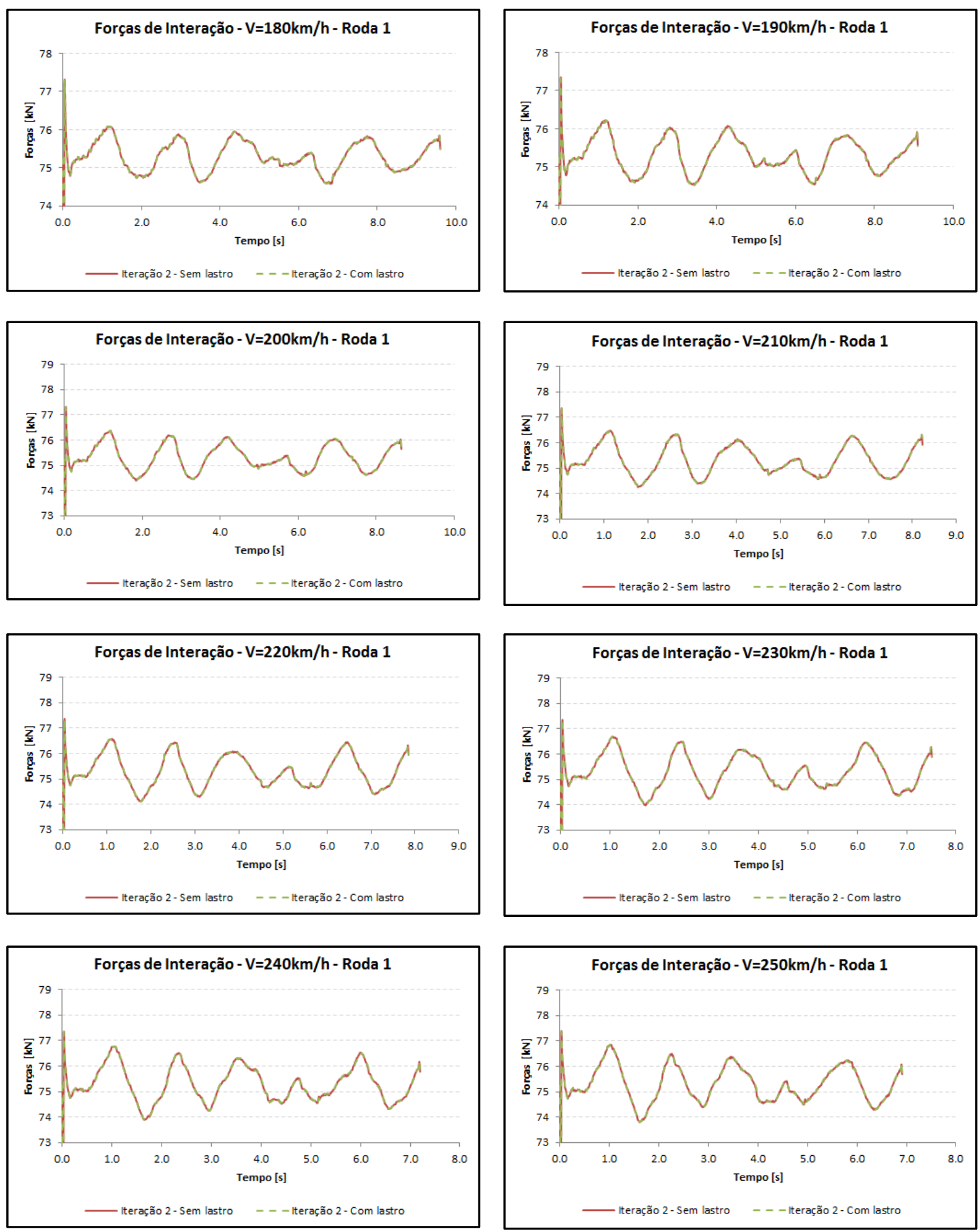

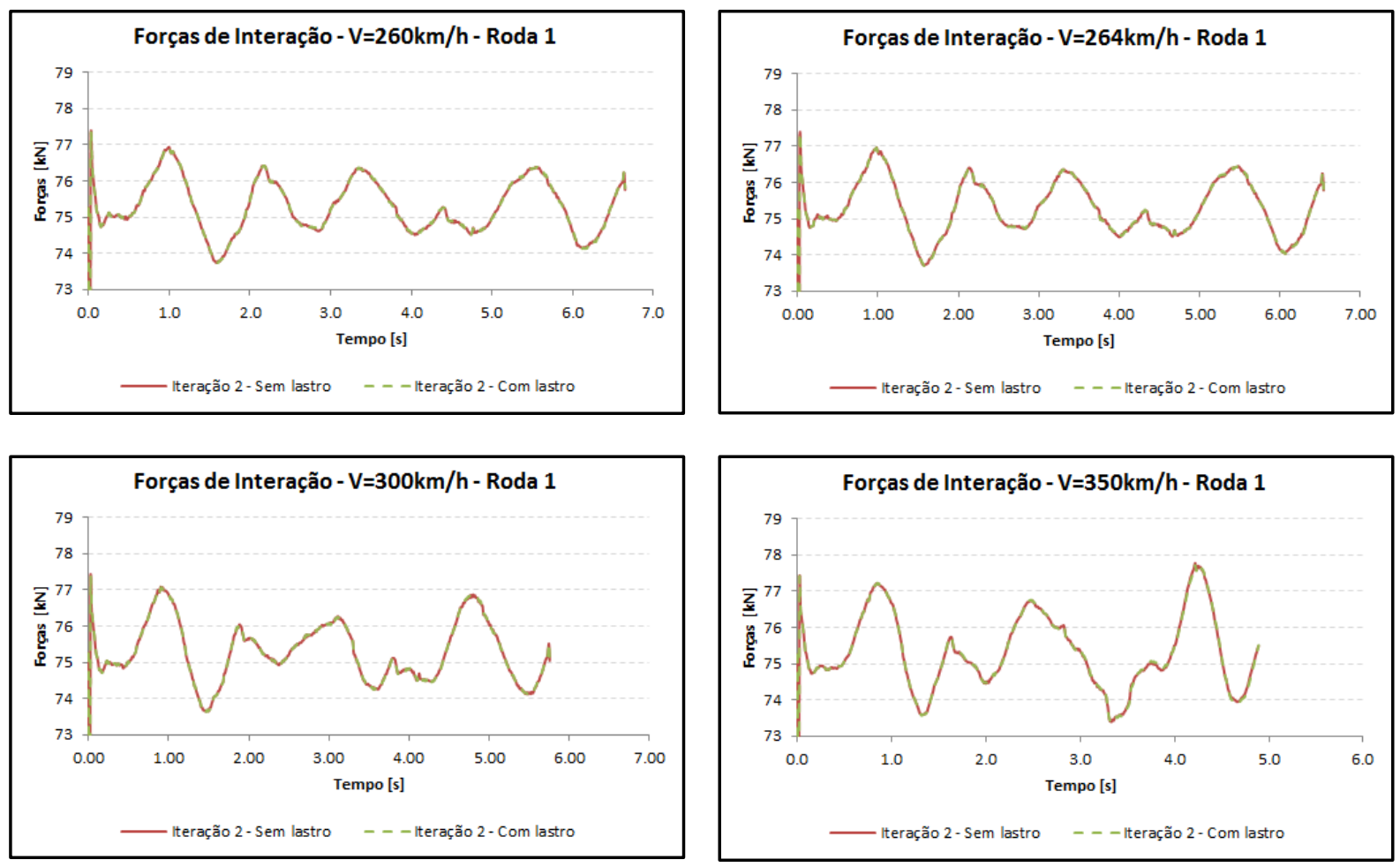

Figura 9.7: Forças de interação na roda 1 para cada velocidade. Fonte: Autor.

\subsubsection{Deslocamentos do Tabuleiro}

Apresentam-se aqui os resultados referentes ao deslocamento vertical do tabuleiro. Este valor foi obtido no meio do comprimento do vão, avaliado no nó correspondente ao trilho 1 da via, sendo este o mais externo em relação ao eixo da seção transversal.

Conforme já citado no item 9.1.2, de acordo com as prescrições do Eurocode o deslocamento vertical do tabuleiro não deve exceder $L / 600$, sendo que, no caso da ponte que apresenta um vão de $160 \mathrm{~m}$, este limite é de 0,267 m. Para todos os casos analisados, o deslocamento encontrado é inferior a este limite, sendo o valor máximo equivalente a $0,02 \mathrm{~m}$ praticamente em todas as análises.

Observa-se que, para algumas velocidades, existe uma oscilação maior dos deslocamentos, a saber, de $180 \mathrm{~km} / \mathrm{h}$ para o primeiro e segundo vãos e de $240 \mathrm{~km} / \mathrm{h}$ para o terceiro vão.

Em relação ao lastro, houve uma boa correspondência entre os valores para os casos sem e com a presença do lastro para todas as velocidades analisadas. 

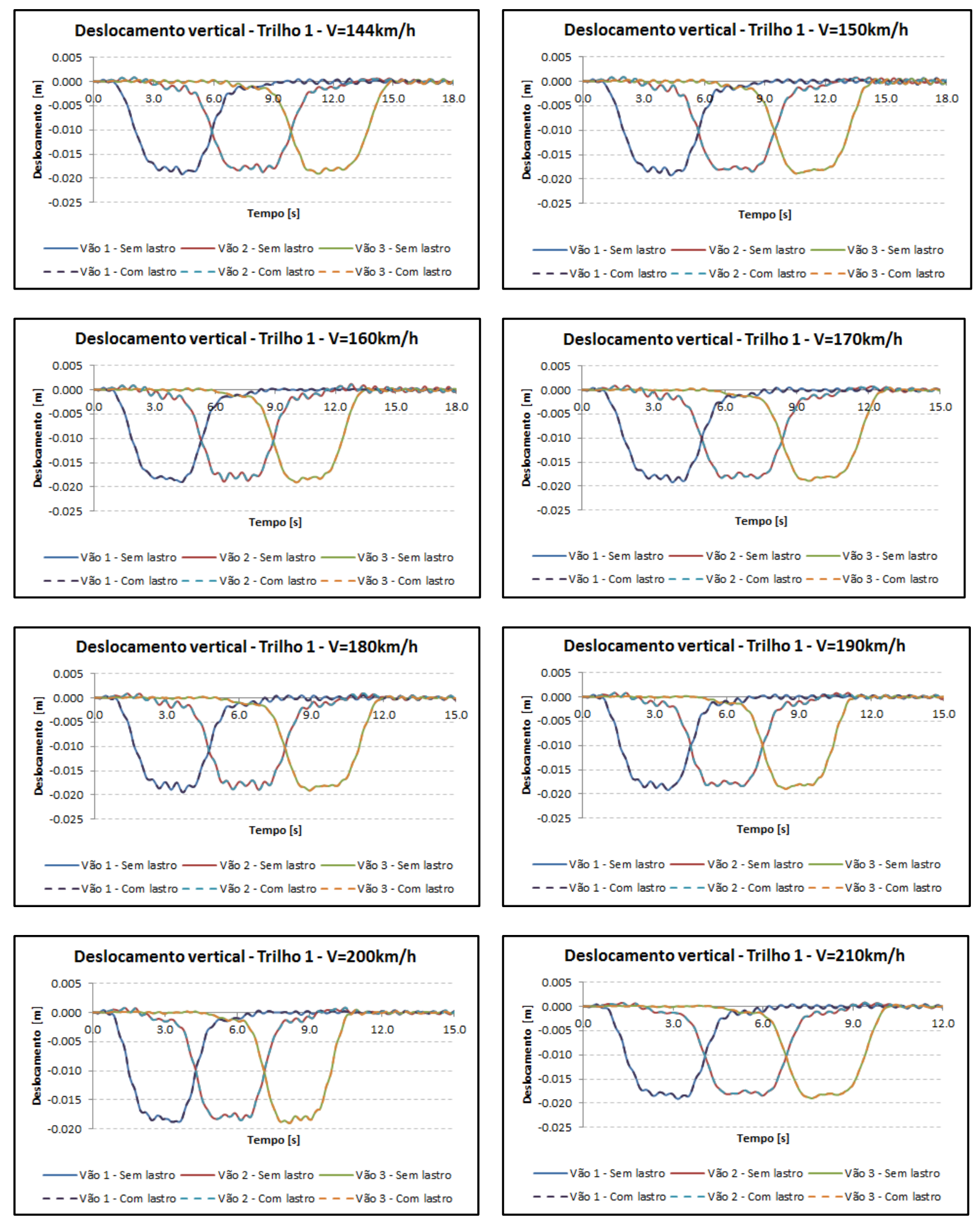

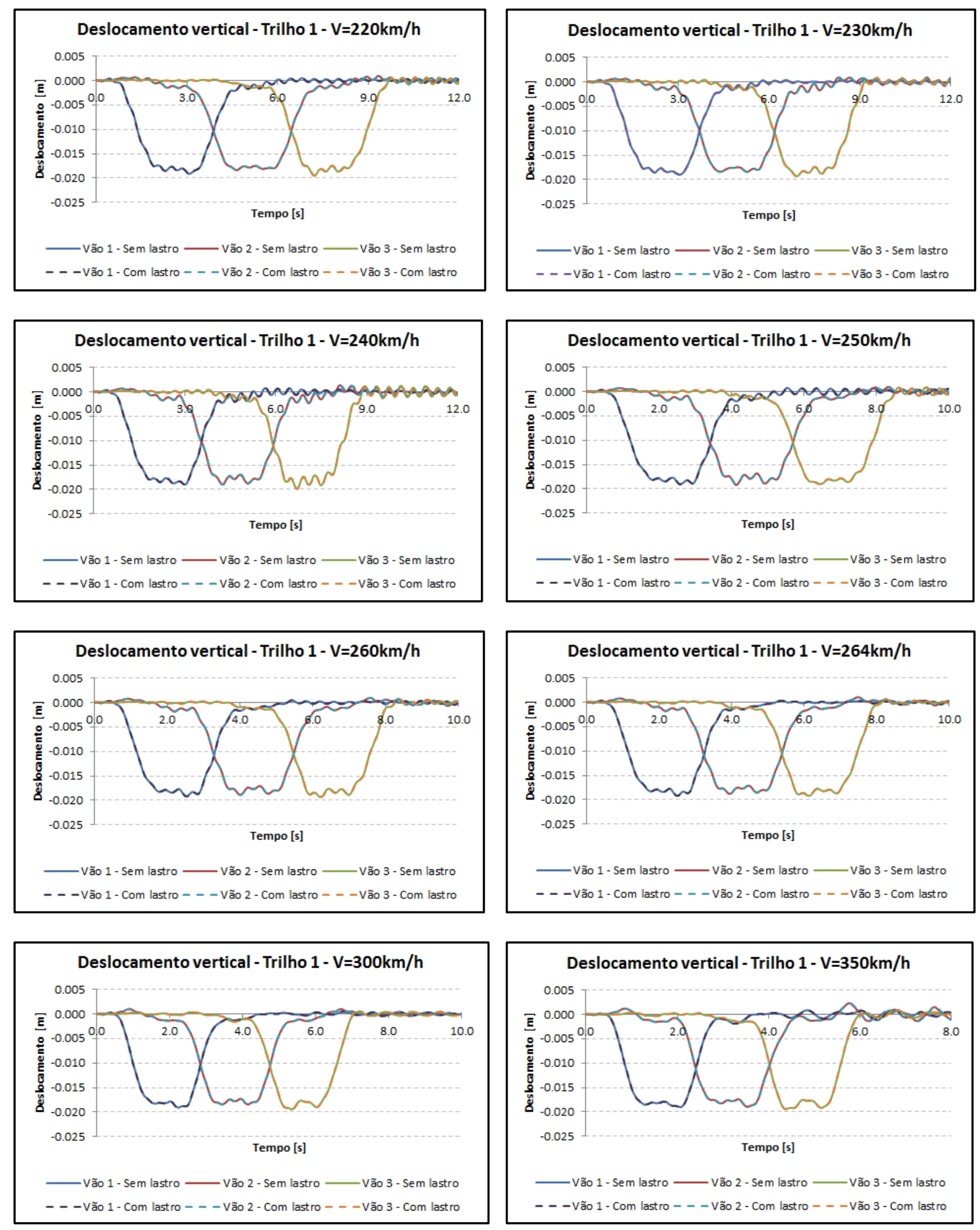

Figura 9.8: Deslocamento vertical do tabuleiro - Trilho 1. Fonte: Autor. 


\subsubsection{Aceleração Vertical no Interior dos Vagões}

A seguir, são apresentados os diagramas de aceleração vertical no interior do vagão para cada velocidade, para as análises com e sem o lastro.
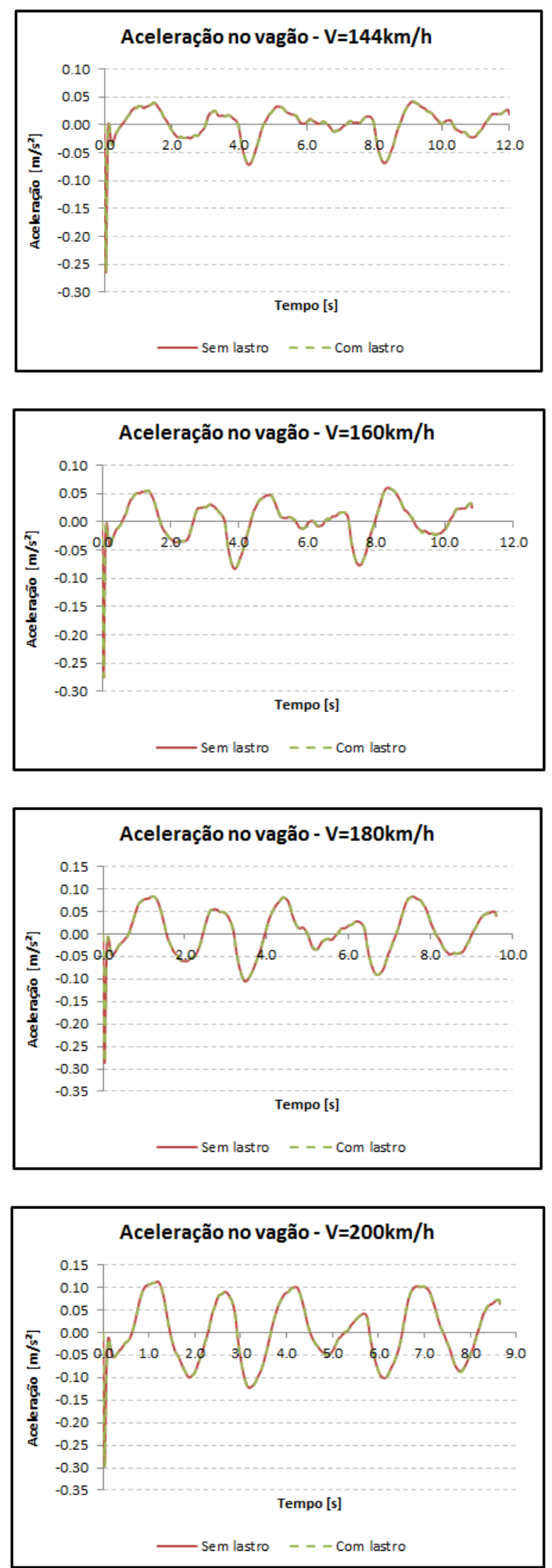
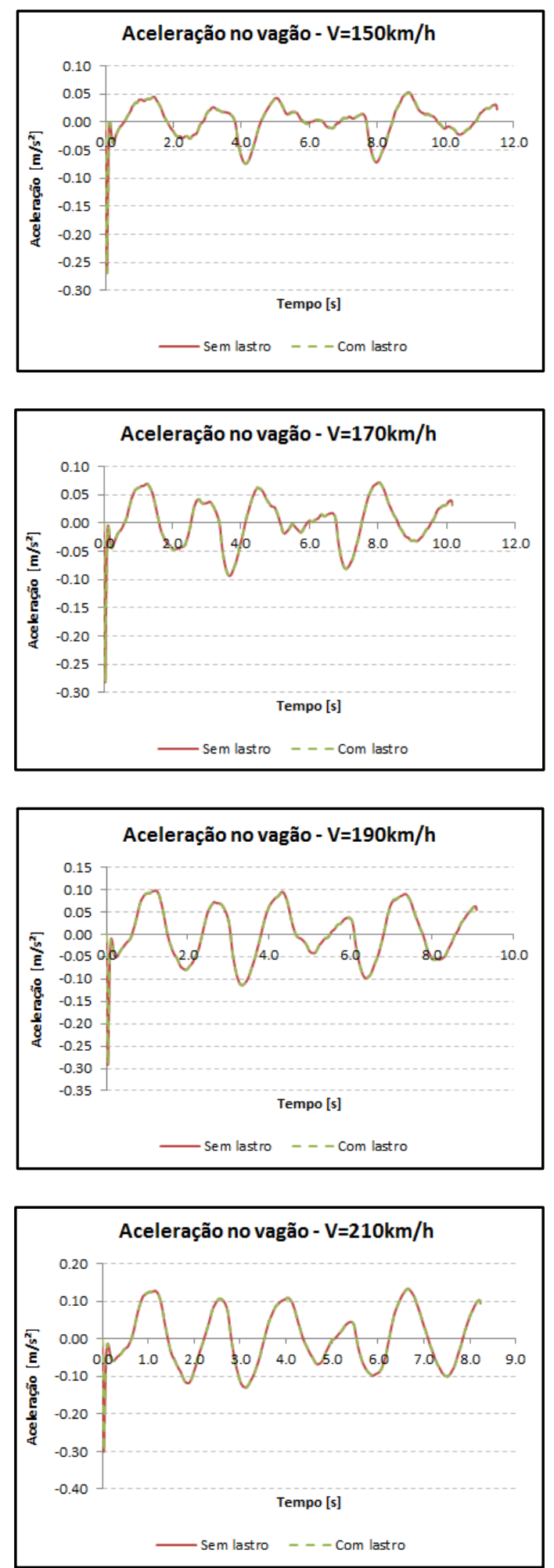

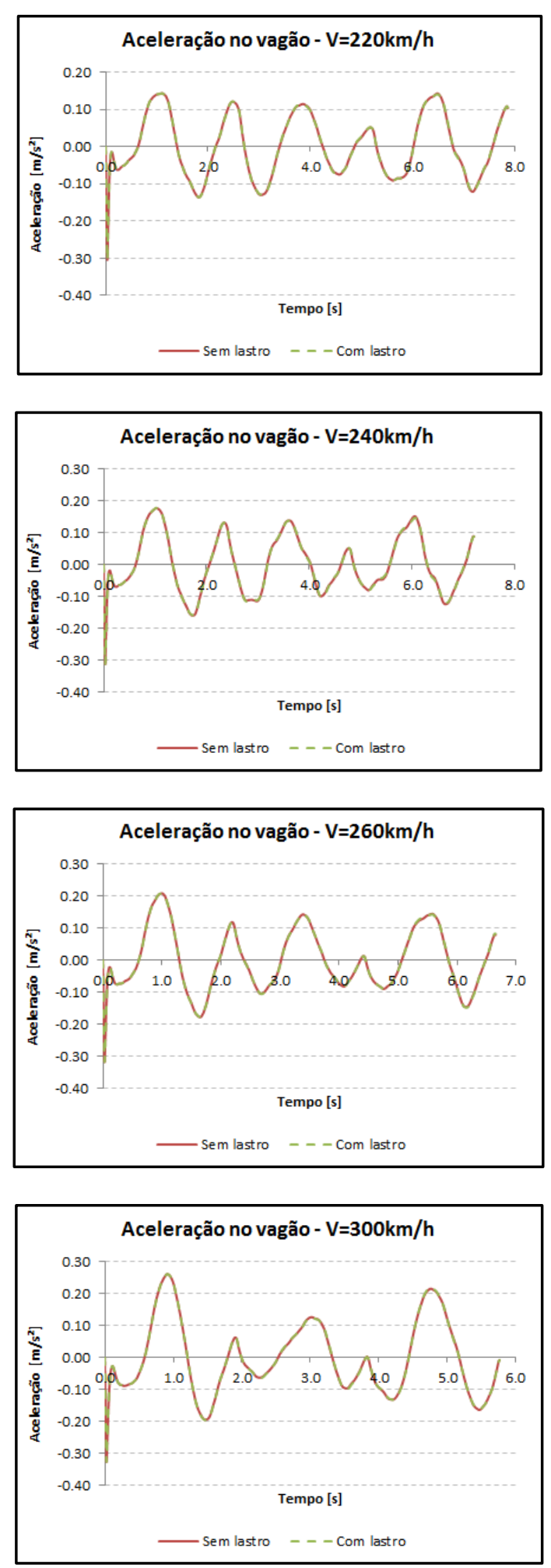
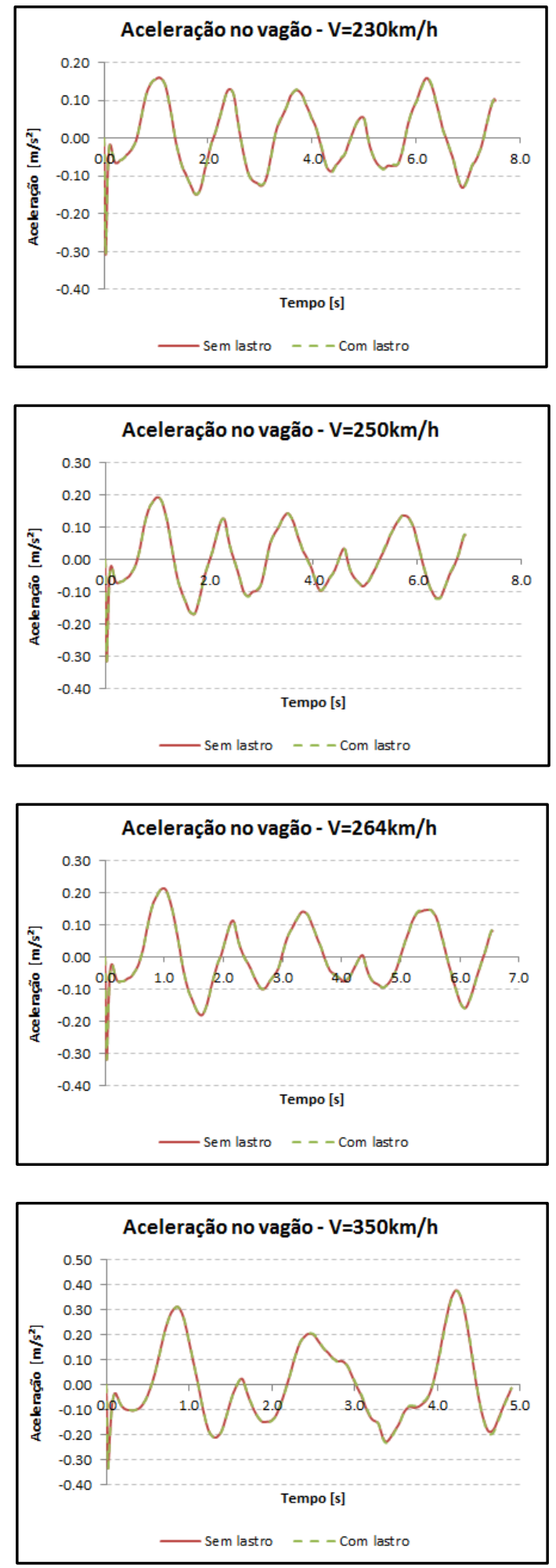

Figura 9.9: Acelerações verticais no interior do vagão. Fonte: Autor.

Assim como nas análises realizadas para o viaduto, para todos os casos analisados, as acelerações obtidas atendem aos requisitos do Eurocode, que classifica o 
conforto dos passageiros no interior do vagão como "muito bom" (Tabela 1.1), ou seja, a aceleração vertical é inferior a $1,0 \mathrm{~m} / \mathrm{s}^{2}$. Observa-se também o pico de aceleração vertical no instante em que o trem entra na ponte, cujo valor ainda se encontra inferior ao limite indicado e tende a reduzir a medida que o trem trafega sobre a estrutura.

A Tabela 9.2 apresenta os valores máximos obtidos para a aceleração vertical no interior do vagão para os casos com e sem lastro. Apesar de não ser possível avaliar o efeito do lastro nas figuras, a tabela mostra que, para todos os casos, a aceleração vertical para o caso sem lastro é ligeiramente maior que o caso com lastro, com valor máximo encontrado de $0,378 \mathrm{~m} / \mathrm{s}^{2}$ para o caso sem lastro e velocidade de $350 \mathrm{~km} / \mathrm{h}$, desconsiderado o pico de aceleração na entrada do trem no viaduto.

Tabela 9.2: Valores máximos de aceleração vertical no interior do vagão. Fonte: Autor.

\begin{tabular}{|c|c|c|}
\hline Velocidade $[\mathbf{k m} / \mathbf{h}]$ & $\mathbf{b}_{\mathbf{v}, \text { sem lastro }}\left[\mathbf{m} / \mathbf{s}^{\mathbf{}}\right]$ & $\mathbf{b}_{\mathbf{v}, \text { com lastro }}\left[\mathbf{m} / \mathbf{s}^{\mathbf{2}}\right]$ \\
\hline \hline 144 & $-0,071$ & $-0,071$ \\
\hline 150 & $-0,074$ & $-0,074$ \\
\hline 160 & $-0,083$ & $-0,083$ \\
\hline 170 & $-0,093$ & $-0,093$ \\
\hline 180 & $-0,105$ & $-0,106$ \\
\hline 190 & $-0,114$ & $-0,114$ \\
\hline 200 & $-0,123$ & $-0,124$ \\
\hline 210 & 0,133 & 0,134 \\
\hline 220 & 0,143 & 0,143 \\
\hline 230 & 0,160 & 0,161 \\
\hline 240 & 0,177 & 0,178 \\
\hline 250 & 0,193 & 0,193 \\
\hline 260 & 0,209 & 0,209 \\
\hline 264 & 0,214 & 0,215 \\
\hline 300 & 0,261 & 0,262 \\
\hline 350 & 0,378 & 0,376 \\
\hline & &
\end{tabular}

\subsubsection{Aceleração Vertical do Tabuleiro}

Em relação à resposta da aceleração vertical no tabuleiro da ponte, esta foi analisada num ponto posicionado no meio do comprimento do vão e no afastamento do trilho 1, ou seja, o trilho mais externo com relação ao eixo da seção transversal, para os casos sem e com a presença do lastro.

Conforme a Figura 9.10, as acelerações são maiores para velocidades mais altas e os picos correspondem à passagem de cada truque sobre o ponto analisado. Da mesma 
forma que o observado no estudo de caso do viaduto, as acelerações obtidas para as análises com o lastro são inferiores àquelas para o caso sem o lastro. Porém, para o estudo de caso da ponte, todos os resultados obtidos estão dentro dos limites estabelecidos pelo Eurocode, sendo de $3,5 \mathrm{~m} / \mathrm{s}^{2}$ para o tabuleiro com a presença do lastro e $5,0 \mathrm{~m} / \mathrm{s}^{2}$ para o tabuleiro sem o lastro. Salienta-se que o projeto referente a esta ponte contempla a existência do lastro, mas o estudo de caso sem o lastro foi realizado apenas a fim de ilustração e comparação dos resultados.
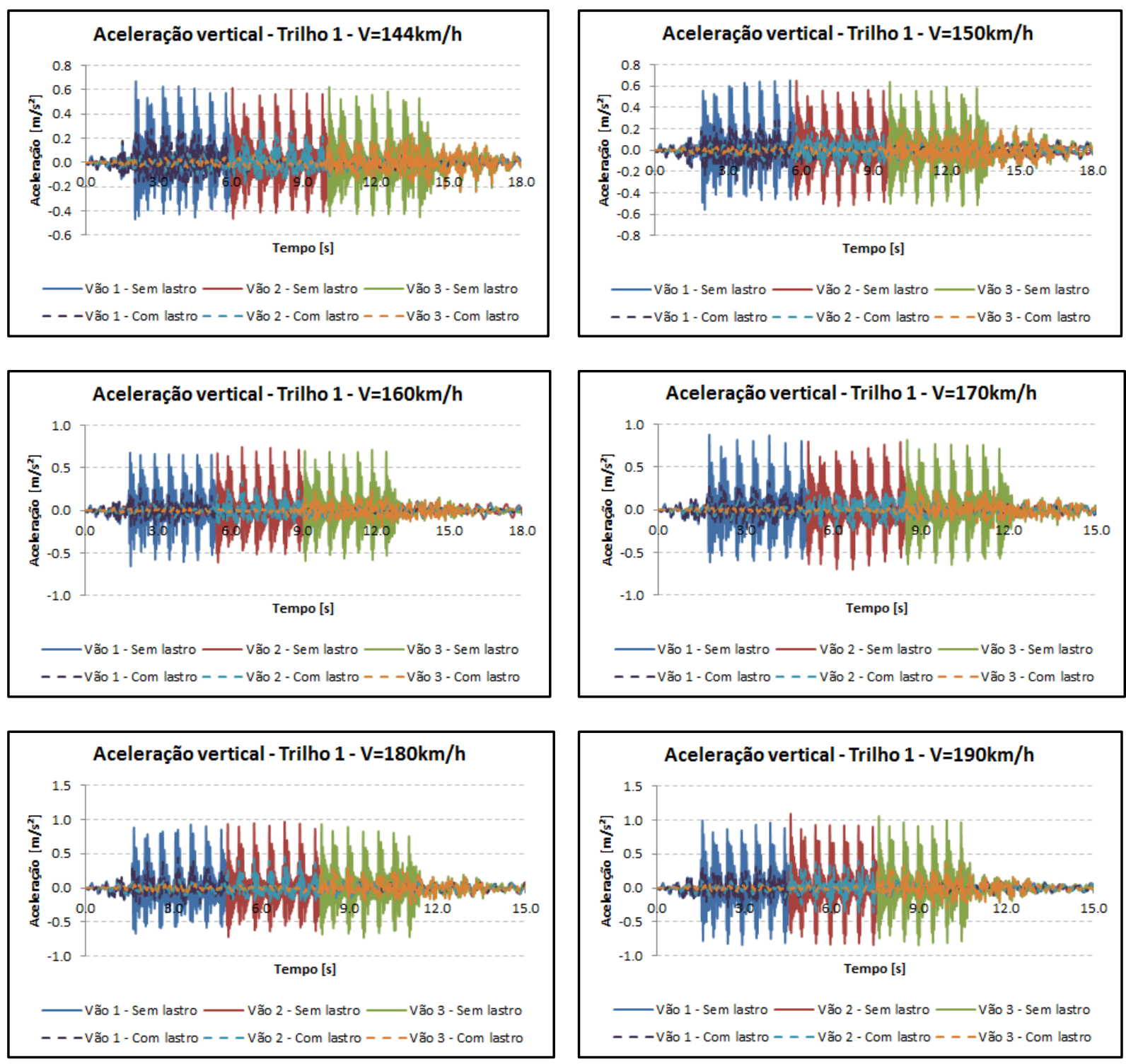

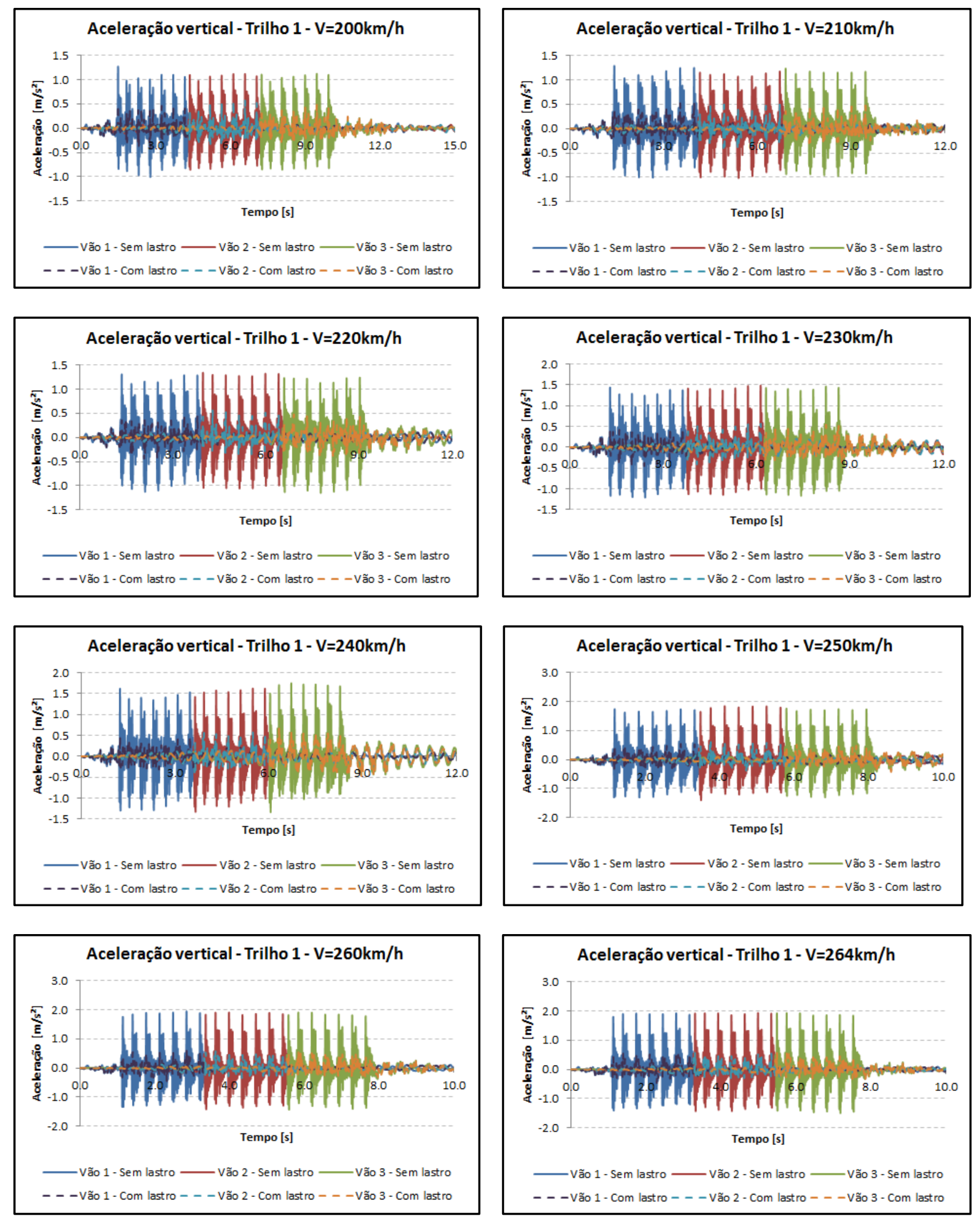

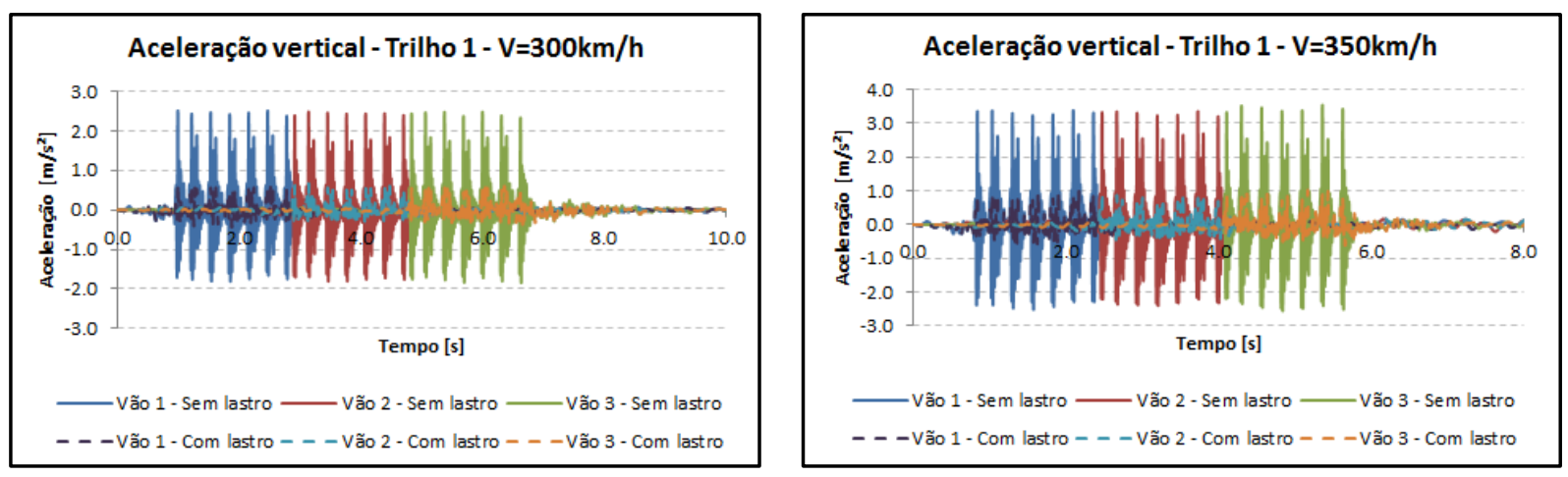

Figura 9.10: Acelerações verticais no meio do tabuleiro. Fonte: Autor. 


\section{ANÁLISE DE DISTRIBUIÇÃO ESTATÍSTICA}

A análise de distribuição estatística a ser realizada tem o objetivo de avaliar a probabilidade de se ultrapassar os limites estabelecidos pelo Eurocode para o conforto do passageiro no interior do vagão e para as acelerações verticais do tabuleiro.

Conforme apresentado no item 6.2.3, será considerado como dado de entrada da análise um espectro padronizado, utilizado para definir o perfil de irregularidades nos trilhos de forma aleatória, e que, aplicado em um "módulo processador determinístico", permitirá analisar a resposta em relação aos estados limites de conforto dos passageiros e estabilidade da via.

Para isso, as acelerações verticais no interior do vagão e no tabuleiro são organizadas em forma de histograma, o qual fornece uma ideia da forma de distribuição de probabilidade da variável aleatória, aqui suposta como sendo a distribuição normal ou Gaussiana. Assim, a densidade de probabilidade de distribuição normal das acelerações pode ser estabelecida no entorno de um valor médio $(\mu)$, mediante a seguinte expressão:

$$
f(x)=\frac{1}{\sigma \sqrt{2 \pi}} e^{\left(-\frac{(x-\mu)^{2}}{2 \sigma^{2}}\right)}
$$

onde $\sigma$ corresponde ao desvio padrão e mede a dispersão em torno do valor médio.

Desta forma, a probabilidade de ocorrência de um determinado valor é obtida por meio de:

$$
P[-\lambda \sigma \leq z \leq \lambda \sigma]=\frac{1}{\sigma \sqrt{2 \pi}} \int_{-\lambda \sigma}^{\lambda \sigma} e^{-\frac{z^{2}}{2}} d z
$$

sendo $z=\frac{x-\mu}{\sigma}$.

Uma regra utilizada para a distribuição normal de valor médio $\mu=0$ indica que $68,26 \%$ dos valores estão no intervalo de uma vez o desvio padrão $(-\sigma, \sigma), 95,44 \%$ no intervalo de duas vezes o desvio padrão $(-2 \sigma, 2 \sigma), 99,73 \%$ no intervalo de três vezes o desvio padrão $(-3 \sigma, 3 \sigma)$ e 99,994\% no intervalo de quatro vezes o desvio padrão $(-4 \sigma, 4 \sigma)$, conforme mostra a Figura 10.1. 


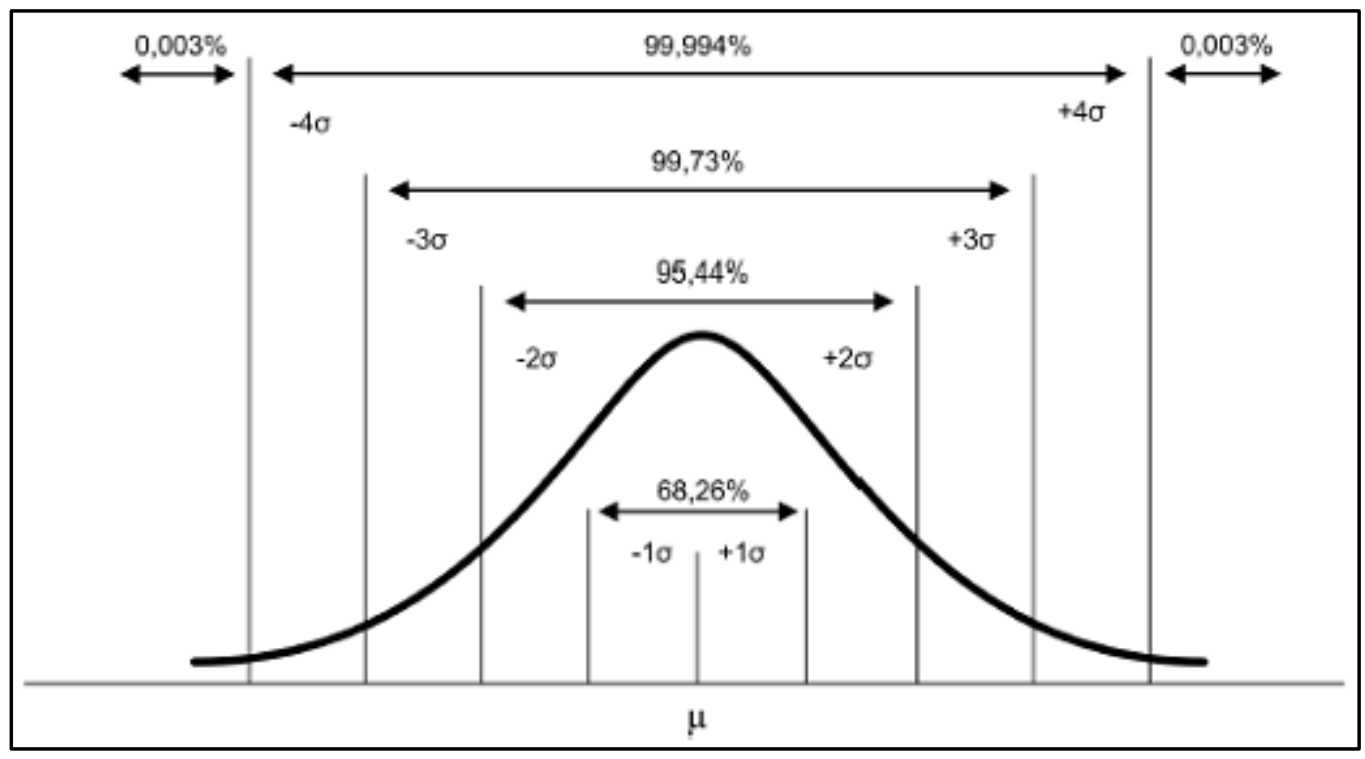

Figura 10.1: Regra da distribuição normal. Fonte:

http://www.portalaction.com.br/probabilidades/62-distribuicao-normal.

Como o foco de análise deste trabalho será o estado limite de conforto dos passageiros e estabilidade da via, as variáveis de saída de interesse serão as acelerações máximas no interior de um vagão do trem e no tabuleiro. Assim, será construído o histograma da resposta, a fim de se ajustar a função densidade de probabilidade. Com isso, serão determinados os parâmetros que definem a distribuição, calculando-se, portanto, a probabilidade de as variáveis aleatórias ultrapassarem os valores de referência indicados pelo Eurocode.

Observa-se que as análises de distribuição estatística aqui realizadas correspondem ao estudo de caso do viaduto e da ponte com o lastro, compatível com o projeto de referência.

A seguir, são apresentados o histograma e a curva de distribuição normal para a aceleração vertical no interior do primeiro vagão. 


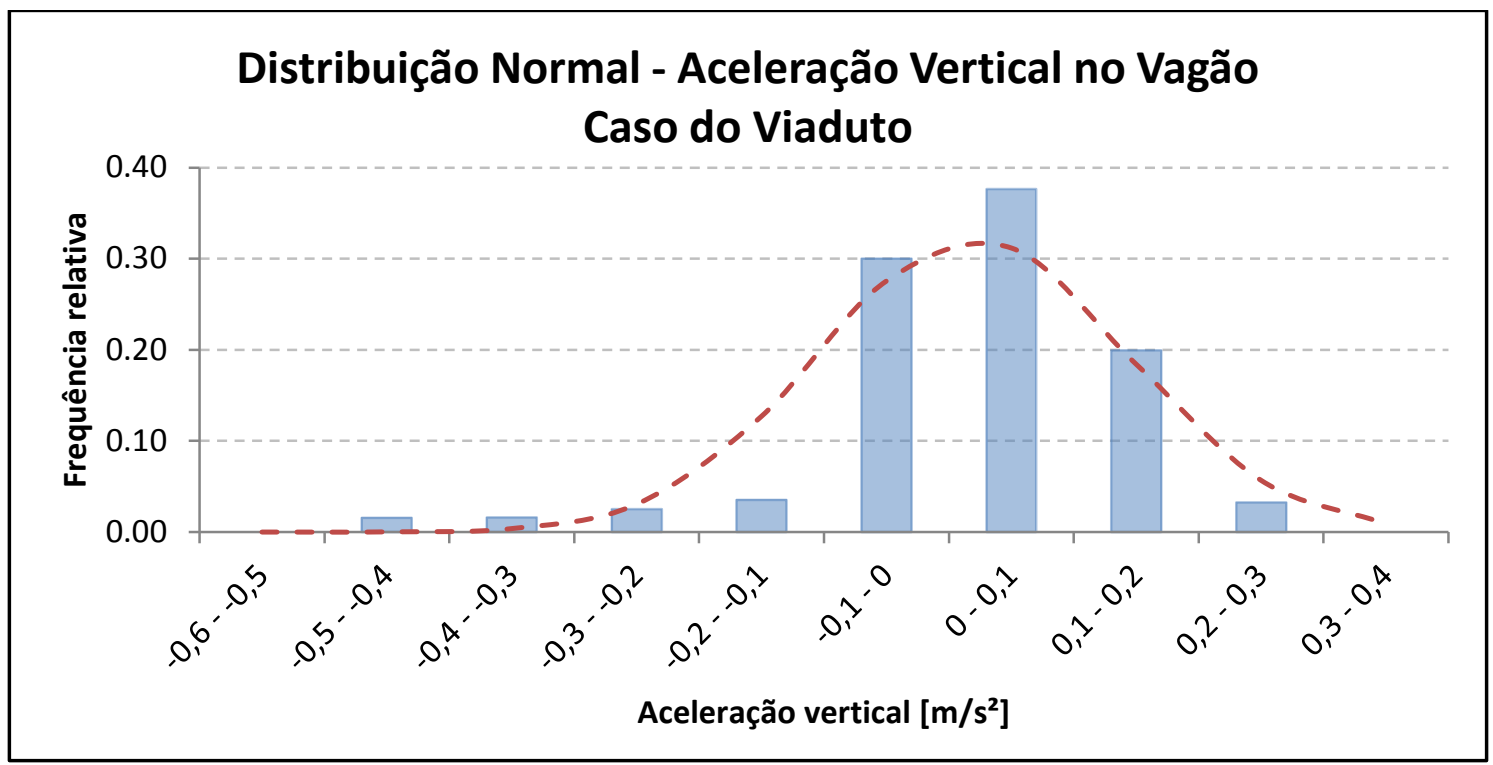

Figura 10.2: Histograma e curva distribuição normal para a aceleração vertical no interior do primeiro vagão - Caso do Viaduto. Fonte: Autor.

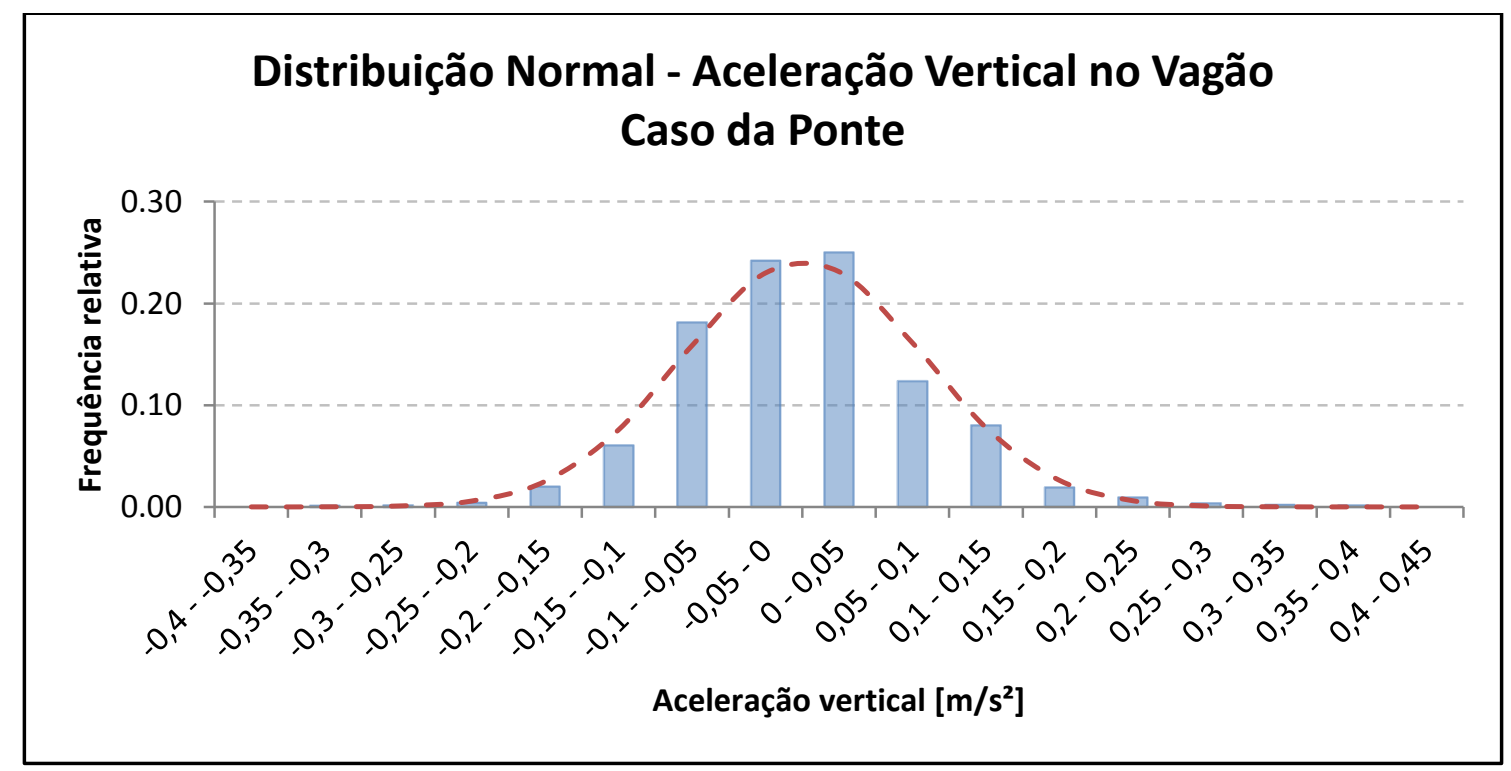

Figura 10.3: Histograma e curva distribuição normal para a aceleração vertical no interior do primeiro vagão - Caso da Ponte. Fonte: Autor.

Como se pode perceber na Figura 10.2 e Figura 10.3, as acelerações verticais no interior do vagão são superiores no estudo de caso do viaduto em relação ao estudo de caso da ponte. Porém, em todas as análises, os valores máximos obtidos foram inferiores ao limite de conforto "muito bom" especificado pelo Eurocode $\left(1,0 \mathrm{~m} / \mathrm{s}^{2}\right)$. 
A probabilidade de se ultrapassar os limites estabelecidos pela norma para o estudo de caso do viaduto é apresentada na Tabela 10.1 e, para o estudo de caso da ponte, na Tabela 10.2. Assim, a probabilidade de ultrapassar o nível de conforto "muito bom" é praticamente nula, sendo de $1,44 \times 10^{-15}$ e de $4,70 \times 10^{-34}$ para os casos do viaduto e da ponte, respectivamente. São valores que atestam a confiabilidade dos projetos da via e das obras de arte aqui discutidos em ambos os estudos de caso, quanto ao conforto dos passageiros.

Tabela 10.1: Probabilidade de ultrapassar os limites estabelecidos no Eurocode - Estudo de caso do Viaduto. Fonte: Autor.

\begin{tabular}{|c|c|c|}
\hline Nível de Conforto & Aceleração $\left[\mathrm{m} / \mathbf{s}^{\mathbf{2}}\right.$ ] & Probabilidade \\
\hline \hline Muito bom & 1,0 & $1,44 \mathrm{E}-15$ \\
\hline Bom & 1,3 & $1,02 \mathrm{E}-26$ \\
\hline Aceitável & 2,0 & $6,83 \mathrm{E}-60$ \\
\hline
\end{tabular}

Tabela 10.2: Probabilidade de ultrapassar os limites estabelecidos no Eurocode - Estudo de caso da Ponte. Fonte: Autor.

\begin{tabular}{|c|c|c|}
\hline Nível de Conforto & Aceleração $\left[\mathrm{m} / \mathbf{s}^{\mathbf{2}}\right]$ & Probabilidade \\
\hline \hline Muito bom & 1,0 & $4,70 \mathrm{E}-34$ \\
\hline Bom & 1,3 & $4,04 \mathrm{E}-56$ \\
\hline Aceitável & 2,0 & $8,72 \mathrm{E}-130$ \\
\hline
\end{tabular}

Em relação à análise de distribuição estatística para a aceleração vertical do tabuleiro, o valor analisado corresponde ao nó no meio do vão da estrutura e com afastamento correspondente à posição do trilho mais externo em relação ao eixo da seção transversal, sendo que no caso da ponte, este nó localiza-se no vão central da estrutura.

A seguir, são apresentados os histogramas e as curvas de distribuição normal para a aceleração obtida no tabuleiro do viaduto e da ponte. 


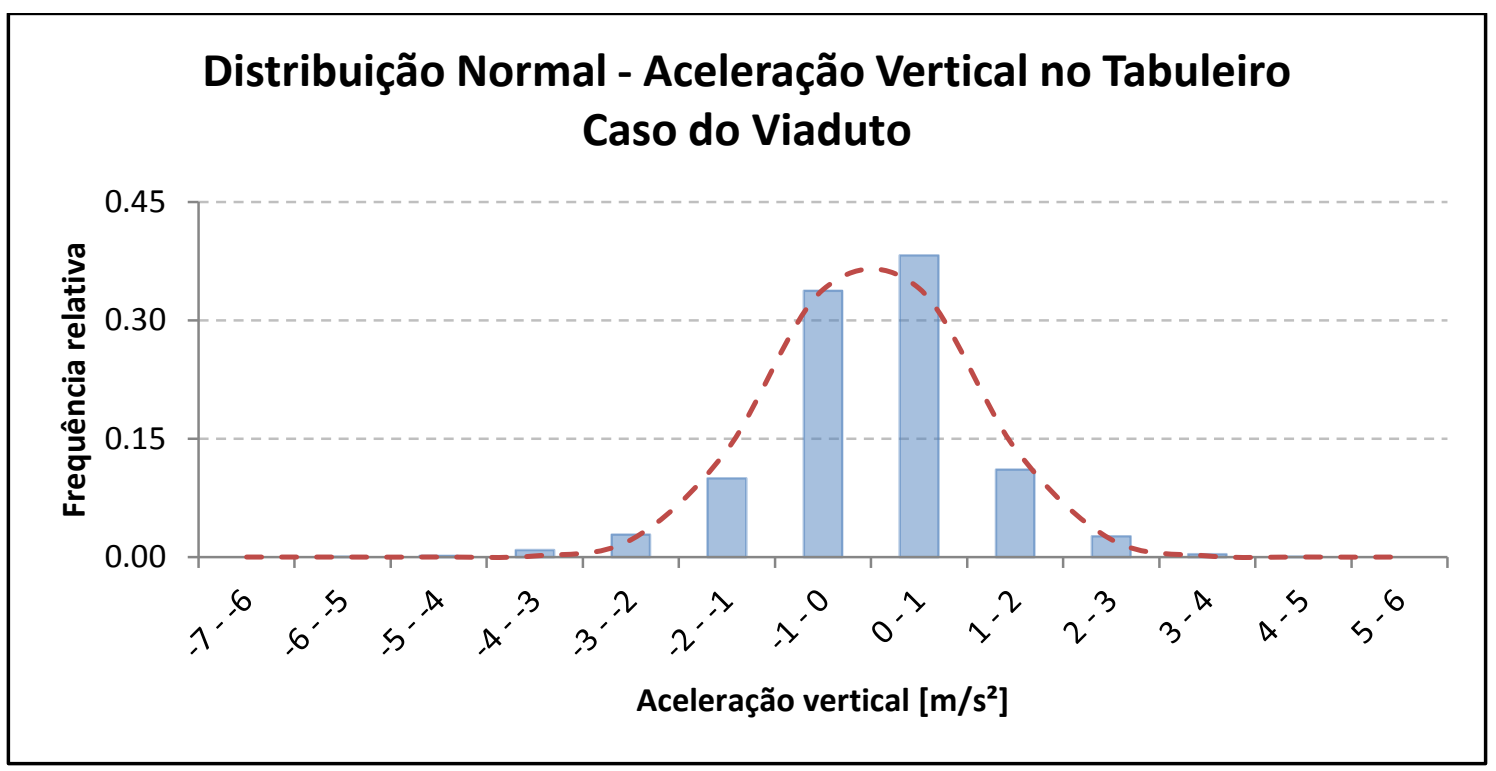

Figura 10.4: Histograma e curva distribuição normal para a aceleração vertical no tabuleiro - Caso do Viaduto. Fonte: Autor.

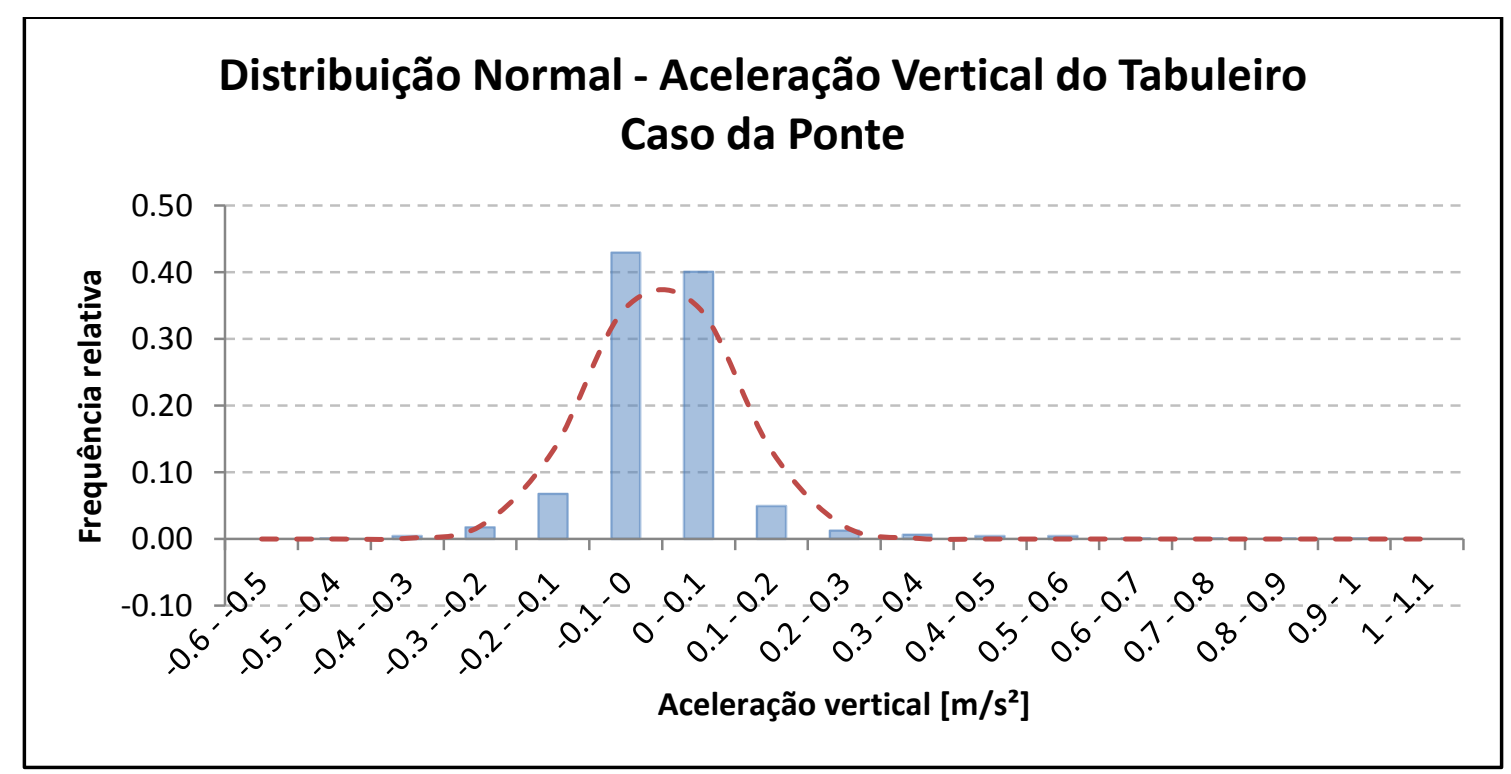

Figura 10.5: Histograma e curva distribuição normal para a aceleração vertical no tabuleiro - Caso da Ponte. Fonte: Autor.

Como esta análise de distribuição estatística está sendo realizada para o estudo de caso com a presença de lastro, calculou-se a probabilidade de se ultrapassar o limite de aceleração vertical do tabuleiro de $3,5 \mathrm{~m} / \mathrm{s}^{2}$, de acordo com o especificado pelo Eurocode. Assim, constatou-se que esta probabilidade foi de $8,31 \times 10^{-4}$ para o caso do viaduto e de $5,48 \times 10^{-259}$ para o caso da ponte. Apesar de a probabilidade de ocorrência encontrada para 
o caso do viaduto não ser tão baixa, ambos os casos garantem a confiabilidade dos projetos das estruturas das obras de arte e da via, sob o ponto de vista da estabilidade do lastro. 


\section{CONCLUSÕES}

Este trabalho estuda uma metodologia para a análise dinâmica de pontes ferroviárias para trens de alta velocidade, considerando a modelagem do trem e da estrutura de forma desacoplada, sendo conectados por meio das forças de interação. A metodologia parte do pressuposto de tabuleiro rígido e indeslocável, sendo isso corrigido mediante um processo iterativo, conforme apresentado no capítulo 8 . Constata-se que a metodologia apresenta bom desempenho quanto à convergência, de forma que foram necessárias apenas três iterações para obter um desvio de $-0,361 \%$ entre a segunda e terceira iteração.

A metodologia é suficientemente simples para ser realizada dentro de escritórios de projetos, sem que seja necessário o desenvolvimento de ferramentas complexas para a análise de pontes com interação veículo-estrutura, podendo ser utilizada também em caso de pontes rodoviárias. Porém, ressalta-se que a realização das análises exige custo computacional não indiferente, visto que a discretização da malha da estrutura deve ser suficientemente fina para garantir uma boa precisão em relação à passagem do veículo, já que as cargas que descrevem a passagem do trem são aplicadas a cada um dos nós ao longo da posição do trilho. No caso de trens de alta velocidade, isto significa, também, usar uma alta densidade de nós na malha de elementos finitos. Naturalmente, poder-se-ia pensar em manter uma discretização menos densa da malha de elementos finitos, porém sofisticando-se a rotina de carregamento, de forma a interpolar a posição das rodas dos vagões, distribuindo-se as cargas pelos nós adequados. Além disso, em se tratando de trens de alta velocidade, o Eurocode especifica que seja avaliada uma gama de velocidades em que o trem possa trafegar, sendo o limite de $20 \%$ acima da máxima velocidade de projeto da estrutura. Neste sentido, a análise dinâmica deve ser realizada para todas essas velocidades.

Conforme comentado no capítulo 2, atualmente não existem prescrições normativas brasileiras para pontes ferroviárias, principalmente para obras de arte de vias de alta velocidade. Neste sentido, percebe-se um campo em que Brasil tem muito espaço a desenvolver, inclusive em relação à consideração de análises dinâmicas, já que a norma cancelada para pontes prescrevia simplesmente a utilização de uma análise estática com a consideração de fator de majoração das cargas. Além disso, a antiga norma brasileira não citava prescrições em relação às acelerações do tabuleiro e ao conforto dos passageiros. Em contrapartida, este assunto se encontra em grande desenvolvimento na Europa, sendo o Eurocode uma boa referência. 
Para os estudos de caso realizados neste trabalho, viaduto e ponte, o Eurocode indica a possibilidade de se dispensar a análise dinâmica para velocidades inferiores ou iguais a $200 \mathrm{~km} / \mathrm{h}$. No caso do viaduto, isso pode ser observado no fluxograma da Figura 11.1, por se tratar de uma ponte com um único vão e, ainda, com a primeira frequência do modo de flexão dentro dos limites da Figura 6.10 do Eurocode (Figura 11.2). Para a ponte, a dispensa da análise pode ser explicada por se tratar de estrutura contínua, conforme mostra a Figura 11.3. Para velocidades superiores a $200 \mathrm{~km} / \mathrm{h}$, como algumas das realizadas nesta tese, a análise dinâmica deve ser realizada, tanto para o caso do viaduto, quanto da ponte.

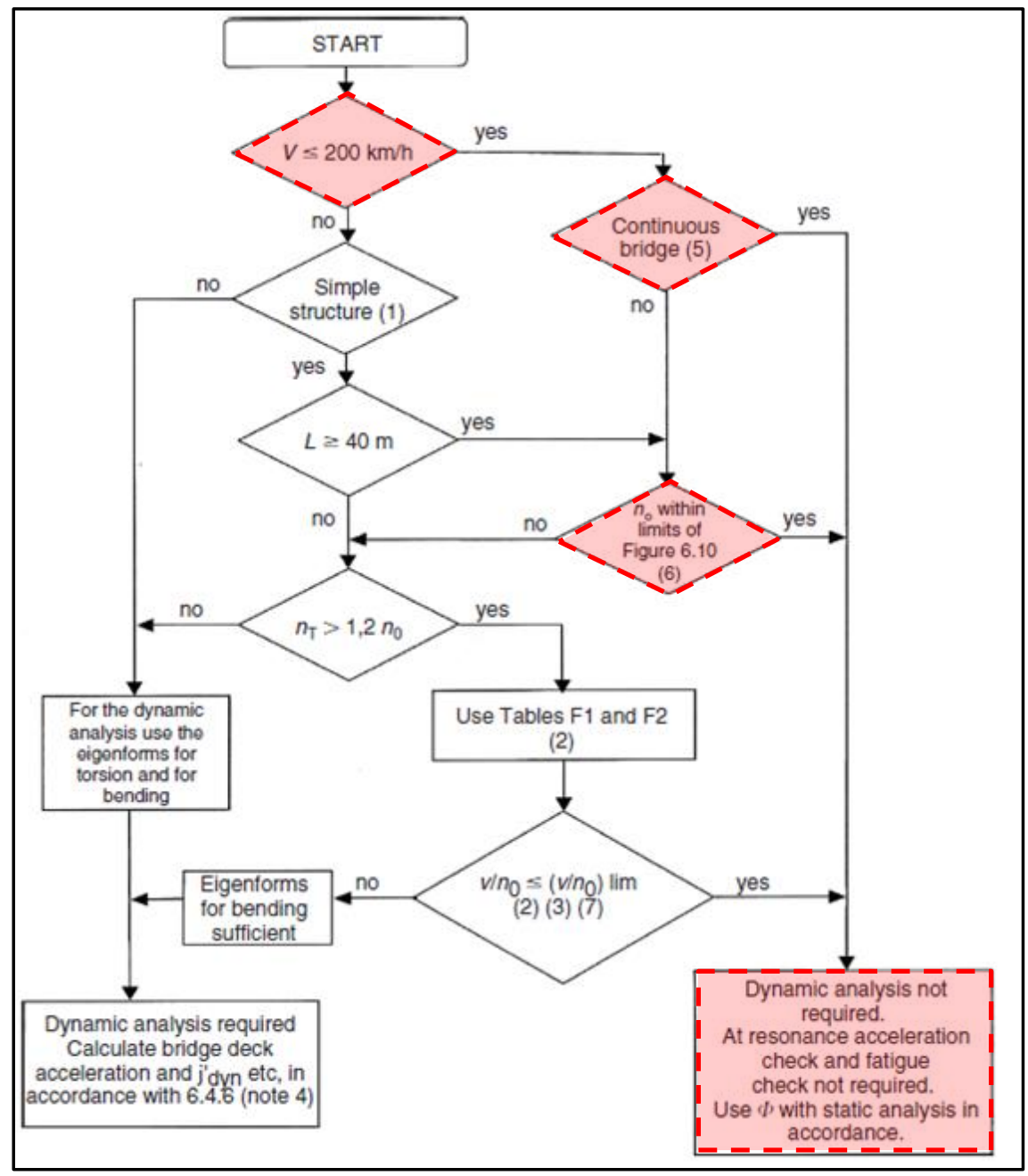

Figura 11.1: Fluxograma aplicado para o estudo de caso do Viaduto. Fonte: EN 1991-2 (2003) - adaptado. 
The upper limit of $n_{0}$ is governed by dynamic enhancements due to track irregularities and is given by :

$n_{0}=94,76 L^{-0,748}$

The lower limit of $n_{0}$ is governed by dynamic impact criteria and is given by :

$n_{0}=80 / L$

for $4 \mathrm{~m} \leq L \leq 20 \mathrm{~m}$

$n_{0}=23,58 L^{-0,592}$

for $20 \mathrm{~m}<L \leq 100 \mathrm{~m}$

where:

$n_{0}$ is the first natural frequency of the bridge taking account of mass due to permanent actions,

$L$ is the span length for simply supported bridges or $L_{\Phi}$ for other bridge types.

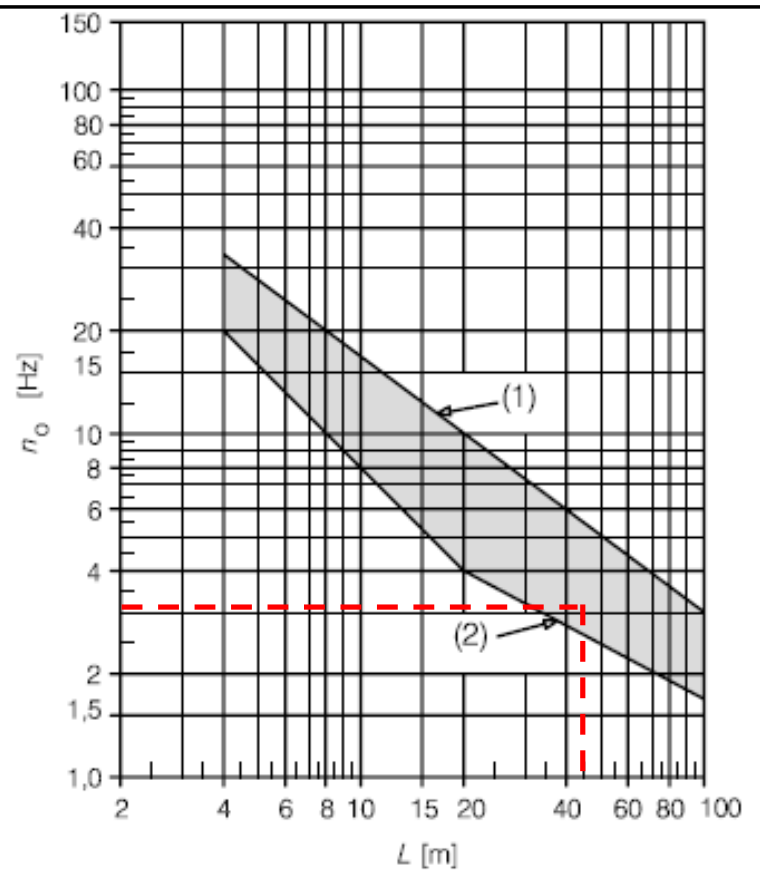

Key

(1) Upper limit of natural frequency

(2) Lower limit of natural frequency

Figura 11.2: Figura 6.10 do Eurocode aplicada para o estudo de caso do Viaduto. Fonte: EN 1991-2 (2003) - adaptado.

Apesar do exposto acima, a análise dinâmica foi realizada para todas as velocidades, verificando-se a intensificação das respostas para velocidades mais altas.

Com relação à análise modal do veículo e das estruturas, conforme já apresentado no capítulo 7 deste trabalho, existe alguma proximidade entre $05^{\circ}$ modo de vibração do trem e $01^{\circ}$ modo do viaduto, sendo o primeiro de rotação em torno do eixo longitudinal e deslocamento horizontal transversal e, o segundo, de flexão no plano horizontal, com frequências de $2,197 \mathrm{~Hz}$ e $1,967 \mathrm{~Hz}$, respectivamente. Apesar de as frequências serem próximas e poder haver uma amplificação da resposta, estes modos estão relacionados às respostas do trem e do viaduto no plano horizontal, não sendo analisadas neste trabalho. $O$ estudo dos deslocamentos no plano horizontal poderia ser pertinente no caso de determinar esforços transferidos para os pilares e fundações. Porém, a discussão dos esforços na estrutura, como um todo, não foi perseguida na tese, muito embora tivesse sido extremamente simples, já que o tratamento dos dados de saída do ADINA seria análogo. 0 foco da tese foi colocado na discussão da verificação de dois estados limites, a saber, o conforto do passageiro e a estabilidade do lastro. Entretanto, outros estados limites de serviço ou últimos poderiam ter sido incorporados, de forma simples. 


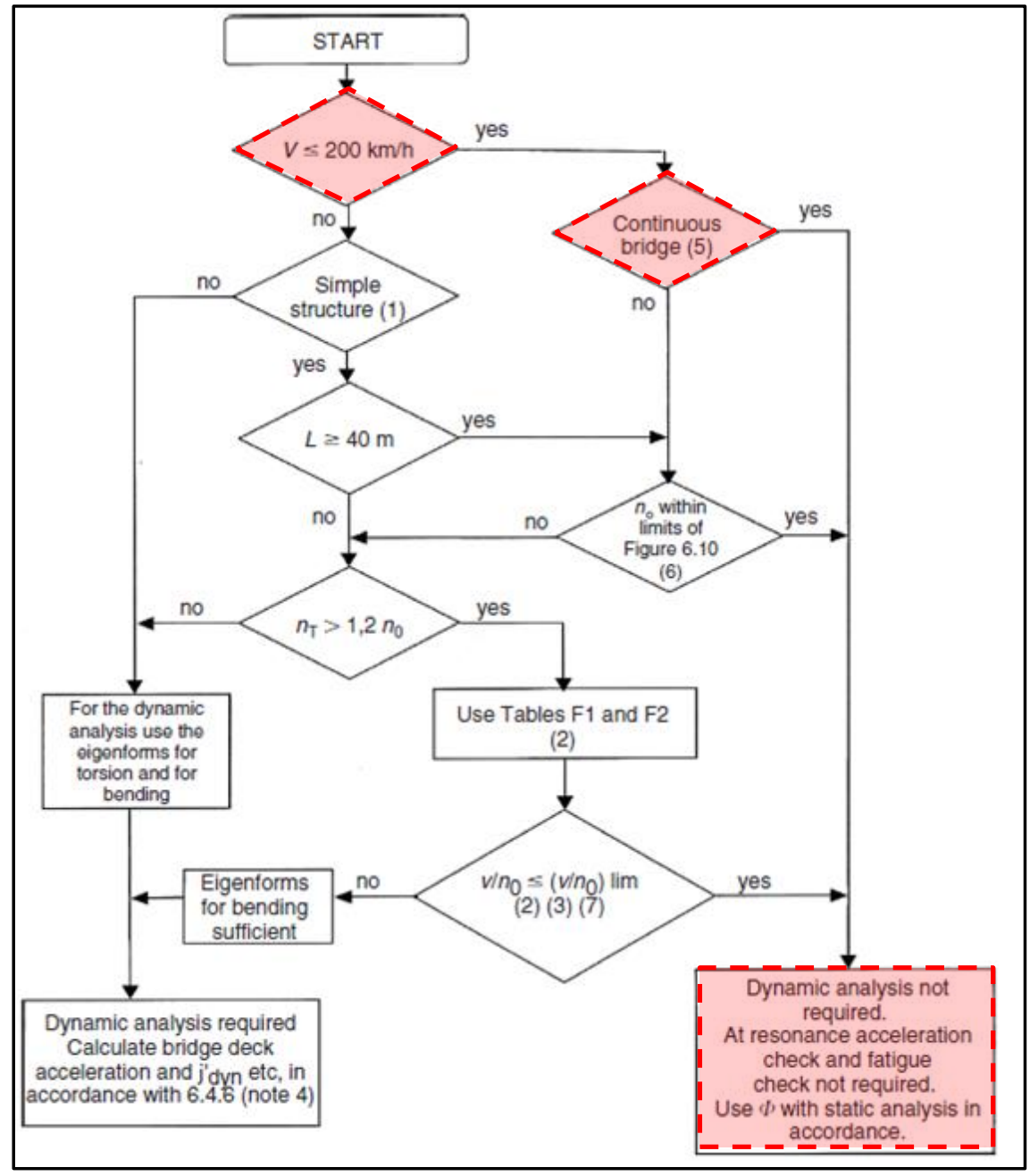

Figura 11.3: Fluxograma aplicado para o estudo de caso da Ponte. Fonte: EN 1991-2 (2003) - adaptado.

Ainda em relação à análise modal, observa-se também alguma proximidade entre o $3^{\circ}$ modo de vibração do trem com $04^{\circ}$ modo de vibração da ponte, com frequências de $0,895 \mathrm{~Hz}$ e $0,92 \mathrm{~Hz}$ e modos de rotação em torno do eixo horizontal transversal e flexão no plano vertical, respectivamente; neste caso, pode haver alguma amplificação da resposta.

Para as forças de interação obtidas, percebe-se que ocorre uma elevação nos valores no instante em que o trem entra na estrutura e a oscilação e amplitude das forças aumentam com o acréscimo da velocidade. Observa-se que a diferença entre os picos das forças de interação é menor no caso do viaduto em relação ao caso da ponte.

Com respeito aos deslocamentos do tabuleiro, observa-se uma boa correspondência entre as respostas para os casos com e sem a presença do lastro, sendo da ordem de $14 \mathrm{~mm}$ para o viaduto e de $20 \mathrm{~mm}$ para a ponte. Porém, vale comentar que a 
consideração do lastro no modelo numérico das estruturas foi feito por meio de elementos visco-elásticos sem massa. Desta forma, o peso do lastro, que dá uma importante contribuição para a resposta do deslocamento vertical do tabuleiro, foi desprezado. Isso se deve à forma com que as estruturas foram modeladas, com a utilização de elementos de casca. No caso da consideração do lastro, o ideal é fazer a modelagem do conjunto estrutura e lastro mediante elementos sólidos, o que incidiria sobre o custo computacional das análises.

Ainda em relação aos deslocamentos verticais do tabuleiro, observa-se que existe um aumento da amplitude da oscilação com o acréscimo da velocidade. No caso do viaduto, percebe-se que para as velocidades de $230 \mathrm{~km} / \mathrm{h}$ e $240 \mathrm{~km} / \mathrm{h}$ os picos de deslocamentos ocorrem com a passagem do terceiro vagão sobre o nó avaliado (meio do vão na posição do trilho mais externo em relação ao eixo da seção transversal da estrutura). Para as velocidades de $260 \mathrm{~km} / \mathrm{h}$ e $264 \mathrm{~km} / \mathrm{h}$ percebe-se um aumento da resposta mesmo quando o trem deixa a estrutura, observando-se, portanto, um caso ressonante do trem com a estrutura. No caso da ponte, a amplitude de oscilação da resposta aumenta no primeiro e segundo vãos para a velocidade de $180 \mathrm{~km} / \mathrm{h}$ e no terceiro vão para a velocidade de $240 \mathrm{~km} / \mathrm{h}$. Em geral, os deslocamentos obtidos para todas as análises foram muito baixos, sendo praticamente condicionados pelo efeito do peso próprio da estrutura.

Em relação ao estado limite de conforto dos passageiros, tanto para o caso do viaduto quanto da ponte, as acelerações verticais no interior do vagão são muito baixas, sendo inferiores ao limite de $1,0 \mathrm{~m} / \mathrm{s}^{2}$, correspondente ao nível de conforto "muito bom" especificado pelo Eurocode. Nos dois casos analisados, percebe-se um aumento da resposta com o acréscimo da velocidade e um pico da aceleração no instante que o trem entra na estrutura, porém este valor também é inferior ao limite referido. No caso do viaduto, para velocidades mais baixas a aceleração não oscila muito e seu valor aumenta à medida que o trem avança para o final da estrutura; para velocidades maiores, percebe-se uma maior oscilação da resposta, bem como de sua amplitude. No caso da ponte, a oscilação é maior comparada à do viaduto, sendo que os picos tendem a crescer com o aumento da velocidade e a apresentar certa regularidade para velocidades entre $210 \mathrm{~km} / \mathrm{h}$ e $264 \mathrm{~km} / \mathrm{h}$. Em geral, as acelerações obtidas para os casos sem o lastro são ligeiramente superiores às obtidas para os casos sem o lastro. No caso do viaduto, os valores foram de $0,248 \mathrm{~m} / \mathrm{s}^{2} \mathrm{e}$ $0,241 \mathrm{~m} / \mathrm{s}^{2}$ para os casos sem e com lastro, respectivamente, encontrados para a velocidade de $264 \mathrm{~km} / \mathrm{h}$. No caso da ponte, os valores foram de $0,378 \mathrm{~m} / \mathrm{s}^{2}$ e $0,376 \mathrm{~m} / \mathrm{s}^{2}$ para os casos sem e com lastro, respectivamente, obtidos para a velocidade de $350 \mathrm{~km} / \mathrm{h}$. 
Para a verificação do estado limite de estabilidade da via, percebe-se uma grande diferença entre as respostas para os casos sem e com a presença do lastro. Conforme já comentado, o estudo de caso utilizado corresponde a uma via com a presença do lastro, porém o mesmo projeto foi considerado para o caso sem o lastro a fim de comparação de resultados. No caso do viaduto, as acelerações verticais do tabuleiro sem o lastro foram superiores ao limite estabelecido pelo Eurocode de $5,0 \mathrm{~m} / \mathrm{s}^{2}$. Neste caso, observa-se que não é possível adotar a mesma geometria e parâmetros para os casos com e sem o lastro.

Ainda sobre as acelerações observadas no tabuleiro, os resultados aumentam com o acréscimo da velocidade e os picos das acelerações ocorrem nos instantes em que os truques se encontram sobre o nó analisado (no meio do vão do viaduto, localizado na posição do trilho mais externo em relação ao eixo da seção transversal). No caso do viaduto, as amplitudes das oscilações aumentam com a passagem dos vagões sobre o nó para as velocidades de $260 \mathrm{~km} / \mathrm{h}$ e $264 \mathrm{~km} / \mathrm{h}$. Apesar de a maioria dos resultados apresentarem valores inferiores ao limite de $3,5 \mathrm{~m} / \mathrm{s}^{2}$ indicado no Eurocode para o caso com lastro, o valor máximo percebido foi de $5,34 \mathrm{~m} / \mathrm{s}^{2}$. Porém, de acordo com a Figura 9.4, percebe-se que existem apenas alguns picos discretos com valores acima do limite e ainda, conforme o capítulo 11, a probabilidade de se ultrapassar o valor de $3,5 \mathrm{~m} / \mathrm{s}^{2}$ é muito baixa $\left(8,31 \times 10^{-4}\right)$. Vale comentar também que estes picos ocorrem num intervalo de tempo muito pequeno, não havendo tempo suficiente para que ocorra a desestabilização do lastro. Com relação às acelerações no tabuleiro da ponte, os valores obtidos são inferiores ao encontrados para o viaduto e ao limite estabelecido pelo Eurocode, sendo o valor máximo de $1,03 \mathrm{~m} / \mathrm{s}^{2}$ observado no primeiro vão para a velocidade de $350 \mathrm{~km} / \mathrm{h}$.

Por fim, em relação à análise de distribuição estatística realizada, a probabilidade de superar os limites de aceleração no interior do vagão e do tabuleiro, estabelecidos pelo Eurocode para os casos com lastro é desprezável, sendo, porém, superior para os casos do viaduto. Percebe-se que os fatores que mais condicionam a resposta dinâmica correspondem à solução estrutural apresentada, bem como os parâmetros utilizados, tanto para o trem quanto para a estrutura. 


\section{SUGESTÕES PARA TRABALHOS FUTUROS}

A metodologia aqui apresentada pode ser aplicada tanto para pontes ferroviárias quanto para pontes rodoviárias, com outras considerações além das adotadas neste trabalho. Além disso, a metodologia pode ser aplicada para o dimensionamento estrutural, tanto do tabuleiro quanto dos pilares, ou ainda, para análise de qualquer resposta do veículo e da ponte.

Em relação à modelagem, sugere-se a utilização de massas concentradas para a representação do lastro sobre a estrutura, bem como a consideração de diferentes materiais para a caracterização do lastro e dormentes.

Outra variável a ser analisada refere-se às irregularidades dos trilhos no plano horizontal, que podem amplificar a resposta da estrutura nesta direção, bem como ser uma excitação condicionante para o dimensionamento dos pilares, especialmente superpostas aos efeitos de vento e sismo.

Um ponto a explorar refere-se à aplicação de um estudo de caso real sem a presença do lastro, de forma a comparar os resultados obtidos principalmente em relação à aceleração vertical do tabuleiro, visto que as análises realizadas aqui apresentaram valores acima do limite estabelecido pelo Eurocode. Além disso, a via sem a presença do lastro apresenta grande diferença de rigidez entre a via sobre a ponte e a via sobre o terreno; neste caso, sugere-se a elaboração de modelos numéricos que contenham zonas de transição nestas regiões, que podem alterar significativamente o comportamento dinâmico da estrutura e do comboio.

Sugere-se também a comparação da metodologia apresentada em relação a uma ferramenta desenvolvida com a consideração da interação comboio-estrutura de forma acoplada. Vale comentar que esta análise não foi realizada em função da não disponibilidade de uma ferramenta disponível para esse propósito.

Outro aspecto importante para a vida útil da estrutura refere-se à fadiga, que deve ser verificada com base nos resultados das análises dinâmicas, especialmente para os casos em houver em ressonância com a estrutura. 
13. REFERÊNCIAS BIBLIOGRÁFICAS

[1] ADINA - Automatic Dynamic Incremental Nonlinear Analysis Software: versão 8.9.1. Desenvolvido pela ADINA R\&D, Inc. Massachusetts, 2013. Disponível em: http://www.adina.com.

[2] ALARCÃO, D. e BENTO COELHO, J. L., 2008, Modelação de Ruído de Tráfego Ferroviário, Acústica, Coimbra, Portugal.

[3] CALÇADA, R., DELGADO, R. and CAMPOS e MATOS, A., 2008, Bridges for HighSpeed Railways

[4] CALÇAdA, R., DELGado, R., GOICOLEA, J. M. and GABALdóN, F., 2008, Journal Dynamic of High-Speed Railway Bridges.

[5] CALÇADA, R., 2014, Notas de Aula da Disciplina PEF 5799 - Infraestrutura Ferroviária: Modelação e Monitoração, Escola Politécnica, Universidade de São Paulo.

[6] CASAL, H. B., 2010, Comportamento dinâmico de pontes ferroviárias de alta velocidade com via não balastrada, Dissertação de Mestrado, Instituto Superior Técnico, Universidade Técnica de Lisboa.

[7] CHEN, R., WANG, P., and WEI, X., 2013, Treck-bridge longitudinal interaction of continuous welded rails on arch bridge, Hindawi Publishing Corporation Mathematical Problems in Engineering, Volume 2013, Article ID 494137, 8 pages

[8] CLOUGH, R. W. and Penzien, J., 1995, Dynamics on Structures, Third Edition.

[9] CORREA, W. L., 2003, Vibrações em Pontes Ferroviárias. Dissertação, COPPE/UFRJ, Rio de Janeiro, RJ, Brasil.

[10] CORREA, W. L., 2008, Controle das Vibrações Induzidas pela Interação Dinâmica entre Trens-Trilhos-Dormentes-Estrutura de Aço de Pontes Ferroviárias. Tese, COPPE/UFRJ, Rio de Janeiro, RJ, Brasil.

[11] COSTA, P. A., LOPES, P., CALÇADA, R. and SILVA CARDOSO, A., 2012, Efficiency of Ballast Mats for the Reduction of Vibrations Induced by Traffic A Parametric Study, Proceedings of the First International Conference on Railway Technology, Civil-Comp Press, Stirlingshire, Scotland, Paper 121. 
[12] COSTA, P. A., P., CALÇADA, R. and SILVA CARDOSO, A., 2012, Influence of train dynamic modelling strategy on the prediction of track-ground vibrations induced by railway traffic, Proceedings of the Institution of Mechanical Engineers, Part F: Journal of Rail and Rapid Transit, published online 6.

[13] COSTA, P. A., P., CALÇADA, R. and SILVA CARDOSO, A., 2012, Track-ground vibrations induced by railway traffic In-situ measurements and validation of a $2.5 \mathrm{D}$ FEM-BEM model, Journal Soil Dynamics and Earthquake Engineering, 32, 11-28.

[14] COUNCIL DIRECTIVE 96/48/EC of 23 July 1996 on the interoperability of the transEuropean high-speed rail system. The Council of the European Union.

[15] CUNHA, P. G., 2011, Análise Dinâmica de Pontes Ferroviárias: uma Metodologia Simplificada, Dissertação de Mestrado, Escola Politécnica, Universidade de São Paulo.

[16] DELGADO, R. and CALÇADA, R., 2012, Dynamic Effects Induced by High Speed Traffic on Rail Bridges, International Journal of Railway Technology, Volume 1, Issue 1, Pages 87-104.

[17] DENG, L., 2009, System identification of bridge and vehicle based on their coupled vibration, Thesis for degree of Doctor of Philosophy, Huazhong University of Science \& Technology, China.

[18] ERRI D 214/RP 9, 1999, Railway Bridges for Speeds > 200km/h - Final Report, European Rail Research Institute.

[19] EUROPEAN STANDARD, EN 1991-2, 2003, Actions of Structures - Part 2: Traffic Loads on Bridges.

[20] EUROPEAN STANDARD, EN 1990-Annex A2, 2005, Annex A2: Application for Bridges (Normative).

[21] FIGUEIREDO, H., CALÇADA, R. e DELGADO, R., 2009, Soluções estruturais para pontes ferroviárias em linhas de alta velocidade, Texto de suporte à disciplina Dinâmica de Estruturas em Vias Férreas de Alta Velocidade do Programa Doutoral em Engenharia Civil, Universidade do Porto, Portugal.

[22] FIGUEIREDO, H., CALÇADA, R. e DELGADO, R., 2009, Aspectos regulamentares no cálculo de pontes ferroviárias de linhas de alta velocidade, Texto de suporte à disciplina Dinâmica de Estruturas em Vias Férreas de Alta Velocidade do Programa Doutoral em Engenharia Civil, Universidade do Porto, Portugal. 
[23] FRÝBA, L., 1996, Dynamics of Railway Bridges.

[24] GILLET, G., 2010, Simply supported composite railway a bridge - a comparasion of ballasted and ballastless track alternatives, Master of Science Thesis, Royal Institute of Technology, Stockholm, Sweden.

[25] INTERNATIONAL ORGANIZATION FOR STANDARDIZATION, ISO 2631-4, 2001. Mechanical vibration and shock -- Evaluation of human exposure to whole-body vibration -- Part 4: Guidelines for the evaluation of the effects of vibration and rotational motion on passenger and crew comfort in fixed-guideway transport systems.

[26] JAMES, G., 2003, Analysis of Traffic Load Effects, Doctoral Thesis, Structural Engineering Division, Royal Institute of Technology,SE-100 44 Stockholm, Sweden.

[27] LOPES, P., AlVES COSTA, P., CALÇADA, R. and SILVA CARDOSO, A., 2012, Modelling of Vibrations in Tunnels using the Finite Element Method with Perfectly Matched Layers, Proceedings of the First International Conference on Railway Technology, Civil-Comp Press, Stirlingshire, Scotland, Paper 117.

[28] MAGALHÃES, H. M. P., 2013, Development of Advanced Computational Models of Railway Vehicles, Dissertation for degree of Master of Mechanical Engineering, Instituto Superior Técnico, Universidade Técnica de Lisboa.

[29] MARTINS, F.,2008, Variante do Alcácer do Sal - Enquandramento, definição geral da obra e execução, Encontro Nacional Betão Estrutural, Portugal.

[30] MINISTÉRIO DO PLANEJAMENTO. Disponível em: <http://www.pac.gov.br/ noticia/b>. Acesso em 19/04/2015.

[31] MONTENEGRO e ALMEIDA, P., CALÇADA, R. and VILA POUCA, N., 2012, A Wheel-Rail Contact Model Pre-Processor for Train-Structure Dynamic Interaction Analysis, Proceedings of the First International Conference on Railway Technology, Civil-Comp Press, Stirlingshire, Scotland, Paper 9.

[32] NEVES, S.G.M., AZEVEDO, A.F.M. and CALÇADA R., 2012, A direct method for analyzing the vertical vehicle-structure interaction, Journal Engineering Structures, 34, 414-420.

[33] PIERINGER, A. and KROPP, W., 2010, A time-domain model for high-frequency wheel-rail interaction, 10ème Congrès Français d'Acoustique, Lyon. 
[34] PINTO, J. R. C. M. L., 2007, Dinâmica de pontes em viga caixão em linhas ferroviárias de alta velocidade, Dissertação para obtenção do grau de Mestre em Estruturas de Engenharia Civil, Universidade do Porto, Portugal.

[35] REVISTA O EMPREITEIRO. Disponível em: <http://www.oempreiteiro.com.br/ Publicacoes/9745/Olimpiada_de_1964_com_trembala_operando_recoloca_Japao_ no_cenario_global.aspx>. Acesso em 19/04/2015.

[36] RIBEIRO, D. R. F., 2004, Comportamento dinâmico de pontes sob acção de tráfego ferroviário a alta velocidade. Dissertação para obtenção do grau de Mestre em Estruturas de Engenharia Civil, Universidade do Porto, Portugal.

[37] RIBEIRO, D., CALÇADA, R. e DELGADO, R., 2009, Metodologias de análise dinâmica do sistema ponte-comboio, Texto de suporte à disciplina Dinâmica de Estruturas em Vias Férreas de Alta Velocidade do Programa Doutoral em Engenharia Civil, Universidade do Porto, Portugal.

[38] RIBEIRO, D., CALÇADA, R., DELGADO, R., BREHM, M. and ZABEL, V., 2012, Finite Element Model Updating of a Bowstring-Arch Railway Bridge based on Experimental Modal Parameters, Journal Engineering Structures, 40, 413-435.

[39] RIBEIRO, D. R. F., 2012, Efeitos dinâmicos induzidos por tráfego em pontes ferroviárias - modelação numérica calibração e validação experimental, Tese de Doutorado, Universidade do Porto.

[40] ROCHA, J. M., HENRIQUES, A. A. and CALÇADA, R., 2012, Safety assessment of a short span railway bridge for high-speed traffic using simulation techniques, Journal Engineering Structures, 40, 141-154.

[41] ROSSIGALI, C. E., 2006, Estudos probabilísticos para modelos de cargas móveis em pontes rodoviárias no Brasil, Dissertação de Mestrado, Universidade Federal do Rio de Janeiro.

[42] SANTOS, E. F., 2007, Análise e Redução de Vibrações em Pontes Rodoviárias. Dissertação, COPPE/UFRJ, Rio de Janeiro, RJ, Brasil.

[43] SALCHER, P., PRADLWARTER, H. and ADAM, C., 2014, Reliability of high-speed railway bridges with respect to uncertain characteristics, Proceedings of the 9th International Conference on Structural Dynamics, EURODYN, Porto, Portugal. 
[44] STEFFENS, D. M., 2005, Identification and Development of a Model of Railway Track Dynamic Behaviour, Thesis for Degree of Master of Engineering, Faculty of Built Environment and Engineering, Queensland University of Technology.

[45] Disponível em: <http://viajedetrem.blogspot.com.br/>. Acesso em 11/04/2015.

[46] Disponível em: <http://www.snipview.com/q/ICE\%202>. Acesso em 11/04/2015.

[47] Disponível em: <http://www.talgoamerica.com/history.aspx>. Acesso em $11 / 04 / 2015$.

[48] Disponível em: <http://www.freefoto.com/preview/25-10-2/TGV-Duplex-train>. Acesso em 11/04/2015.

[49] Disponível em: <https://blogostoso.wordpress.com/tag/thalys/>. Acesso em $11 / 04 / 2015$.

[50] Disponível em: <http://www.lancashirebusinessview.co.uk/virgin-wins-rail-servicesrights-promises-link-blackpool-Iondon-42927/>. Acesso em 12/04/2015.

[51] Disponível em: <http://kem-m-akode.blogspot.com.br/2012/08/vamos-falar-detgv.html>. Acesso em 12/04/2015.

[52] Disponível em: <http://news.frbiz.com/china_railway_15_bureau_headquarters397354.html>. Acesso em 12/04/2015.

[53] Disponível em: <http://www.raillynews.com/2013/istanbul-ankara-speed-railwaymay-open-february/>. Acesso em 19/04/2015.

[54] Disponível em: <http://www.infraestruturasdeportugal.pt/rede/ferroviaria/mapa>. Acesso em 14/11/2016.

[55] Disponível em: <http://www.pengest.pt/Pontes-/-Viadutos/refer-ep-rede-ferroviarianacional-variante-entre-a-estacao-do-pinheiro-e-o-km-94-da-linha-do-sul-2ofase.html>. Acesso em 15/11/2016.

[56] Disponível em: <http://www.trilhos.com.br/trilho-padrao-uic.html>. Acesso em $18 / 11 / 2016$.

[57] Disponível em: <http://www.portalaction.com.br/probabilidades/62-distribuicaonormal>. Acesso em 05/12/2016.

[58] Disponível em<http://www.uic.org/high-speed-database-maps\#\&gid=1\&pid=7>. Acesso em 05/03/2017. 
[59] Disponível em <http://www.uic.org/high-speed-database-maps\#\&gid=1\&pid=8>. Acesso em 05/03/2017.

[60] Disponível em <http://www.uic.org/high-speed-database-maps\#\&gid=1\&pid=14>. Acesso em 05/03/2017.

[61] Disponível em <http://www.uic.org/high-speed-database-maps\#\&gid=1\&pid=15>. Acesso em 05/03/2017. 


\section{ANEXO}

Este anexo apresenta, de forma sucinta, as etapas utilizadas na metodologia desenvolvida neste trabalho, de forma a ilustrar e detalhar a entrada e saída de dados dentro do ADINA, bem como o manuseio destes dados em planilhas EXCEL. Observa-se que, devido ao tamanho das planilhas utilizadas, não será possível apresentá-las em toda sua extensão, desta forma, serão apresentadas apenas parte delas.

1) Determinação do perfil de irregularidade em cada trilho definido no espaço.

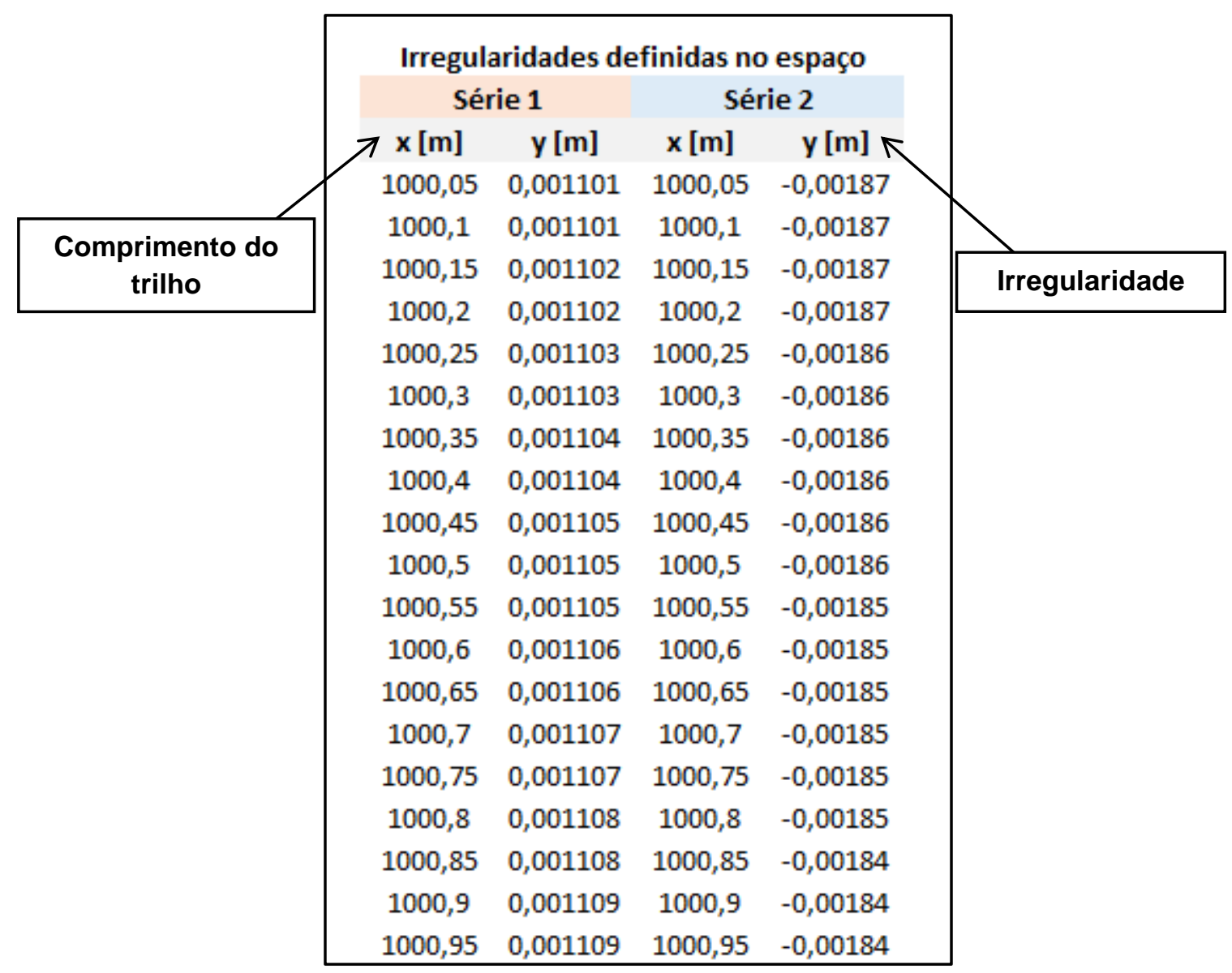

Figura A. 1: Perfil de irregularidade em cada trilho 
2) Determinação do perfil de irregularidade em cada trilho definido no tempo em função da discretização da malha para cada velocidade.

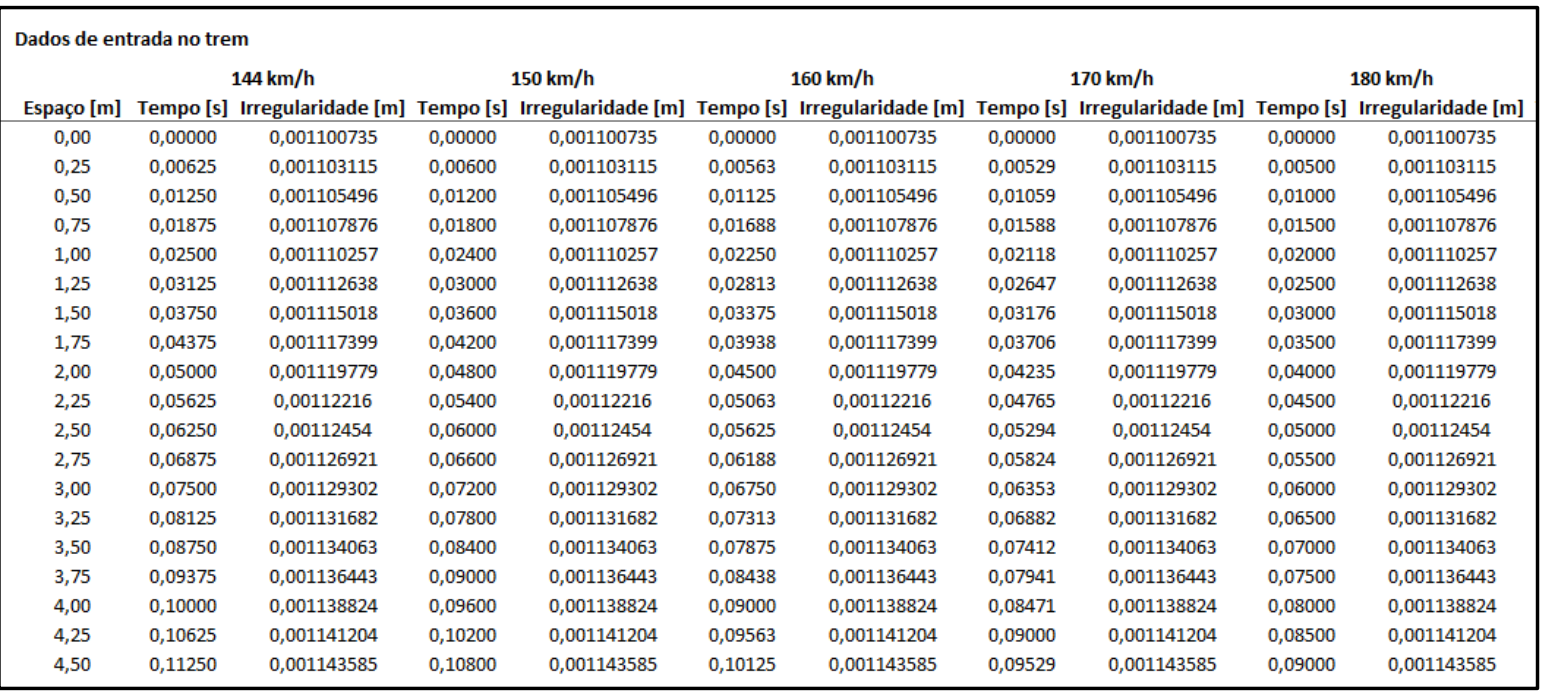

Figura A. 2: Perfil de irregularidade para o trilho 1 para cada velocidade

\begin{tabular}{|c|c|c|c|c|c|c|c|c|c|c|}
\hline \multicolumn{11}{|c|}{ Dados de entrada no trem } \\
\hline Espaço [m] & Tempo [s] & Irregularidade $[\mathrm{m}]$ & Tempo [s] & Irregularidade [m] & Tempo [s] & Irregularidade [m] & Tempo [s] & Irregularidade [m] & Tempo [s] & Irregularidade [m] \\
\hline 0,25 & 0,00625 & $-0,00186298$ & 0,00600 & $-0,00186298$ & 0,00563 & $-0,00186298$ & 0,00529 & $-0,00186298$ & 0,00500 & $-0,00186298$ \\
\hline 0,50 & 0,01250 & $-0,001854294$ & 0,01200 & $-0,001854294$ & 0,01125 & $-0,001854294$ & 0,01059 & $-0,001854294$ & 0,01000 & $-0,001854294$ \\
\hline 0,75 & 0,01875 & $-0,001845607$ & 0,01800 & $-0,001845607$ & 0,01688 & $-0,001845607$ & 0,01588 & $-0,001845607$ & 0,01500 & $-0,001845607$ \\
\hline 1,00 & 0,02500 & $-0,00183692$ & 0,02400 & $-0,00183692$ & 0,02250 & $-0,00183692$ & 0,02118 & $-0,00183692$ & 0,02000 & $-0,00183692$ \\
\hline 1,75 & 0,04375 & $-0,00181086$ & 0,04200 & $-0,00181086$ & 0,03938 & $-0,00181086$ & 0,03706 & $-0,00181086$ & 0,03500 & $-0,00181086$ \\
\hline 2,00 & 0,05000 & $-0,001802174$ & 0,04800 & $-0,001802174$ & 0,04500 & $-0,001802174$ & 0,04235 & $-0,001802174$ & 0,04000 & $-0,001802174$ \\
\hline 2,25 & 0,05625 & $-0,001793487$ & 0,05400 & $-0,001793487$ & 0,05063 & $-0,001793487$ & 0,04765 & $-0,001793487$ & 0,04500 & $-0,001793487$ \\
\hline 2,50 & 0,06250 & $-0,0017848$ & 0,06000 & $-0,0017848$ & 0,05625 & $-0,0017848$ & 0,05294 & $-0,0017848$ & 0,05000 & $-0,0017848$ \\
\hline 2,75 & 0,06875 & $-0,001776114$ & 0,06600 & $-0,001776114$ & 0,06188 & $-0,001776114$ & 0,05824 & $-0,001776114$ & 0,05500 & $-0,001776114$ \\
\hline 3,00 & 0,07500 & $-0,001767427$ & 0,07200 & $-0,001767427$ & 0,06750 & $-0,001767427$ & 0,06353 & $-0,001767427$ & 0,06000 & $-0,001767427$ \\
\hline 4,25 & 0,10625 & $-0,001723994$ & 0,10200 & $-0,001723994$ & 0,09563 & $-0,001723994$ & 0,09000 & $-0,001723994$ & 0,08500 & $-0,001723994$ \\
\hline 4,50 & 0,11250 & $-0,001715307$ & 0,10800 & $-0,001715307$ & 0,10125 & $-0,001715307$ & 0,09529 & $-0,001715307$ & 0,09000 & $-0,001715307$ \\
\hline
\end{tabular}

Figura A. 3: Perfil de irregularidade para o trilho 2 para cada velocidade 
3) Determinação do perfil de irregularidade em cada roda do trem. A planilha abaixo deve ser obtida para cada velocidade e considera a defasagem da irregularidade em cada roda para o instante em que o trem passa sobre 0 determinado ponto.

\begin{tabular}{|c|c|c|c|c|c|c|c|c|c|c|c|c|c|c|c|}
\hline \multicolumn{16}{|c|}{ Irregularidades aplicadas no modelo do trem - V=144km $/ \mathrm{h}$} \\
\hline \multicolumn{2}{|c|}{ Roda 1} & \multicolumn{2}{|c|}{ Roda 2} & \multicolumn{2}{|c|}{ Roda 3} & \multicolumn{2}{|c|}{ Roda 4} & \multicolumn{2}{|c|}{ Roda 5} & \multicolumn{2}{|c|}{ Roda 6} & \multicolumn{2}{|c|}{ Roda 7} & \multicolumn{2}{|c|}{ Roda 8} \\
\hline$t[s]$ & $\delta z[\mathrm{~m}]$ & $t[s]$ & $\delta z[\mathrm{~m}]$ & $t[s]$ & $\delta z[\mathrm{~m}]$ & $t[s]$ & $\delta z[\mathrm{~m}]$ & $t[s]$ & $\delta z[\mathrm{~m}]$ & $t[s]$ & $\delta z[\mathrm{~m}]$ & $t[s]$ & $\delta z[\mathrm{~m}]$ & $t[s]$ & $\delta z[\mathrm{~m}]$ \\
\hline 0,00000 & 0,00136 & 0,00000 & $-0,00123$ & 0,00000 & 0,00132 & 0,00000 & $-0,00129$ & 0,00000 & 0,00113 & 0,00000 & $-0,00178$ & 0,00000 & 0,00110 & 0,00000 & $-0,00187$ \\
\hline 0,00625 & 0,00136 & 0,00625 & $-0,00122$ & 0,00625 & 0,00132 & 0,00625 & $-0,00128$ & 0,00625 & 0,00113 & 0,00625 & $-0,00177$ & 0,00625 & 0,00110 & 0,00625 & $-0,00186$ \\
\hline 0,01250 & 0,00137 & 0,01250 & $-0,00122$ & 0,01250 & 0,00132 & 0,01250 & $-0,00128$ & 0,01250 & 0,00113 & 0,01250 & $-0,00176$ & 0,01250 & 0,00111 & 0,01250 & $-0,00185$ \\
\hline 0,01875 & 0,00137 & 0,01875 & $-0,00121$ & 0,01875 & 0,00133 & 0,01875 & $-0,00127$ & 0,01875 & 0,00113 & 0,01875 & $-0,00175$ & 0,01875 & 0,00111 & 0,01875 & $-0,00185$ \\
\hline 0,02500 & 0,00138 & 0,02500 & $-0,00121$ & 0,02500 & 0,00133 & 0,02500 & $-0,00127$ & 0,02500 & 0,00114 & 0,02500 & $-0,00174$ & 0,02500 & 0,00111 & 0,02500 & $-0,00184$ \\
\hline 0,03125 & 0,00138 & 0,03125 & $-0,00120$ & 0,03125 & 0,00134 & 0,03125 & $-0,00126$ & 0,03125 & 0,00114 & 0,03125 & $-0,00173$ & 0,03125 & 0,00111 & 0,03125 & $-0,00183$ \\
\hline 0,03750 & 0,00138 & 0,03750 & $-0,00120$ & 0,03750 & 0,00134 & 0,03750 & $-0,00126$ & 0,03750 & 0,00114 & 0,03750 & $-0,00172$ & 0,03750 & 0,00112 & 0,03750 & $-0,00182$ \\
\hline 0,04375 & 0,00139 & 0,04375 & $-0,00119$ & 0,04375 & 0,00134 & 0,04375 & $-0,00125$ & 0,04375 & 0,00114 & 0,04375 & $-0,00172$ & 0,04375 & 0,00112 & 0,04375 & $-0,00181$ \\
\hline 0,05000 & 0,00139 & 0,05000 & $-0,00119$ & 0,05000 & 0,00135 & 0,05000 & $-0,00125$ & 0,05000 & 0,00115 & 0,05000 & $-0,00171$ & 0,05000 & 0,00112 & 0,05000 & $-0,00180$ \\
\hline 0,05625 & 0,00140 & 0,05625 & $-0,00118$ & 0,05625 & 0,00135 & 0,05625 & $-0,00124$ & 0,05625 & 0,00115 & 0,05625 & $-0,00170$ & 0,05625 & 0,00112 & 0,05625 & $-0,00179$ \\
\hline 0,06250 & 0,00140 & 0,06250 & $-0,00118$ & 0,06250 & 0,00136 & 0,06250 & $-0,00123$ & 0,06250 & 0,00115 & 0,06250 & $-0,00169$ & 0,06250 & 0,00112 & 0,06250 & $-0,00178$ \\
\hline 0,06875 & 0,00140 & 0,06875 & $-0,00117$ & 0,06875 & 0,00136 & 0,06875 & $-0,00123$ & 0,06875 & 0,00115 & 0,06875 & $-0,00168$ & 0,06875 & 0,00113 & 0,06875 & $-0,00178$ \\
\hline 0,07500 & 0,00141 & 0,07500 & $-0,00117$ & 0,07500 & 0,00136 & 0,07500 & $-0,00122$ & 0,07500 & 0,00116 & 0,07500 & $-0,00167$ & 0,07500 & 0,00113 & 0,07500 & $-0,00177$ \\
\hline 0,08125 & 0,00141 & 0,08125 & $-0,00116$ & 0,08125 & 0,00137 & 0,08125 & $-0,00122$ & 0,08125 & 0,00116 & 0,08125 & $-0,00166$ & 0,08125 & 0,00113 & 0,08125 & $-0,00176$ \\
\hline 0,08750 & 0,00142 & 0,08750 & $-0,00115$ & 0,08750 & 0,00137 & 0,08750 & $-0,00121$ & 0,08750 & 0,00116 & 0,08750 & $-0,00165$ & 0,08750 & 0,00113 & 0,08750 & $-0,00175$ \\
\hline 0,09375 & 0,00142 & 0,09375 & $-0,00115$ & 0,09375 & 0,00138 & 0,09375 & $-0,00121$ & 0,09375 & 0,00116 & 0,09375 & $-0,00165$ & 0,09375 & 0,00114 & 0,09375 & $-0,00174$ \\
\hline 0,10000 & 0,00142 & 0,10000 & $-0,00114$ & 0,10000 & 0,00138 & 0,10000 & $-0,00120$ & 0,10000 & 0,00117 & 0,10000 & $-0,00164$ & 0,10000 & 0,00114 & 0,10000 & $-0,00173$ \\
\hline
\end{tabular}

Figura A. 4: Perfil de irregularidade para cada roda do trem

4) Carregamento das irregularidades no modelo do trem dentro do ADINA. As irregularidades foram consideradas como deslocamentos em função do tempo em cada roda do trem.

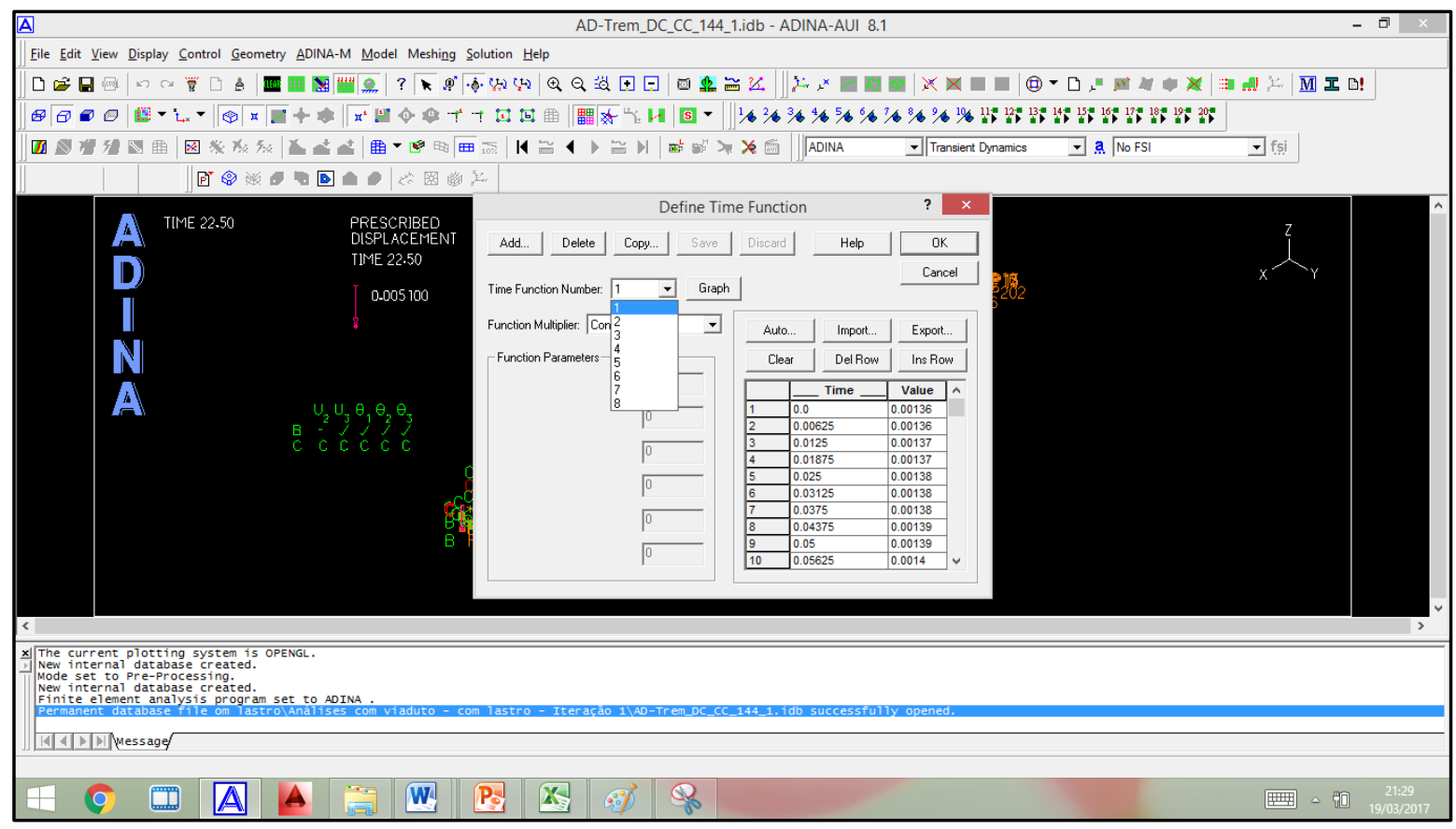

Figura A. 5: Funções das irregularidades no modelo do trem no ADINA 
Após a inserção das funções no modelo do trem dentro do ADINA, deve-se realizar o processamento dinâmico do modelo. Observa-se que deve ser realizado um modelo para cada velocidade analisada.

5) Obtenção das forças de interação em cada roda. As forças de interação extraídas do ADINA para cada uma das rodas do trem são levadas para o EXCEL em forma de tabelas para serem transformadas em funções que descrevem a passagem do trem sobre a estrutura. Esse procedimento deve ser realizado para cada velocidade analisada.

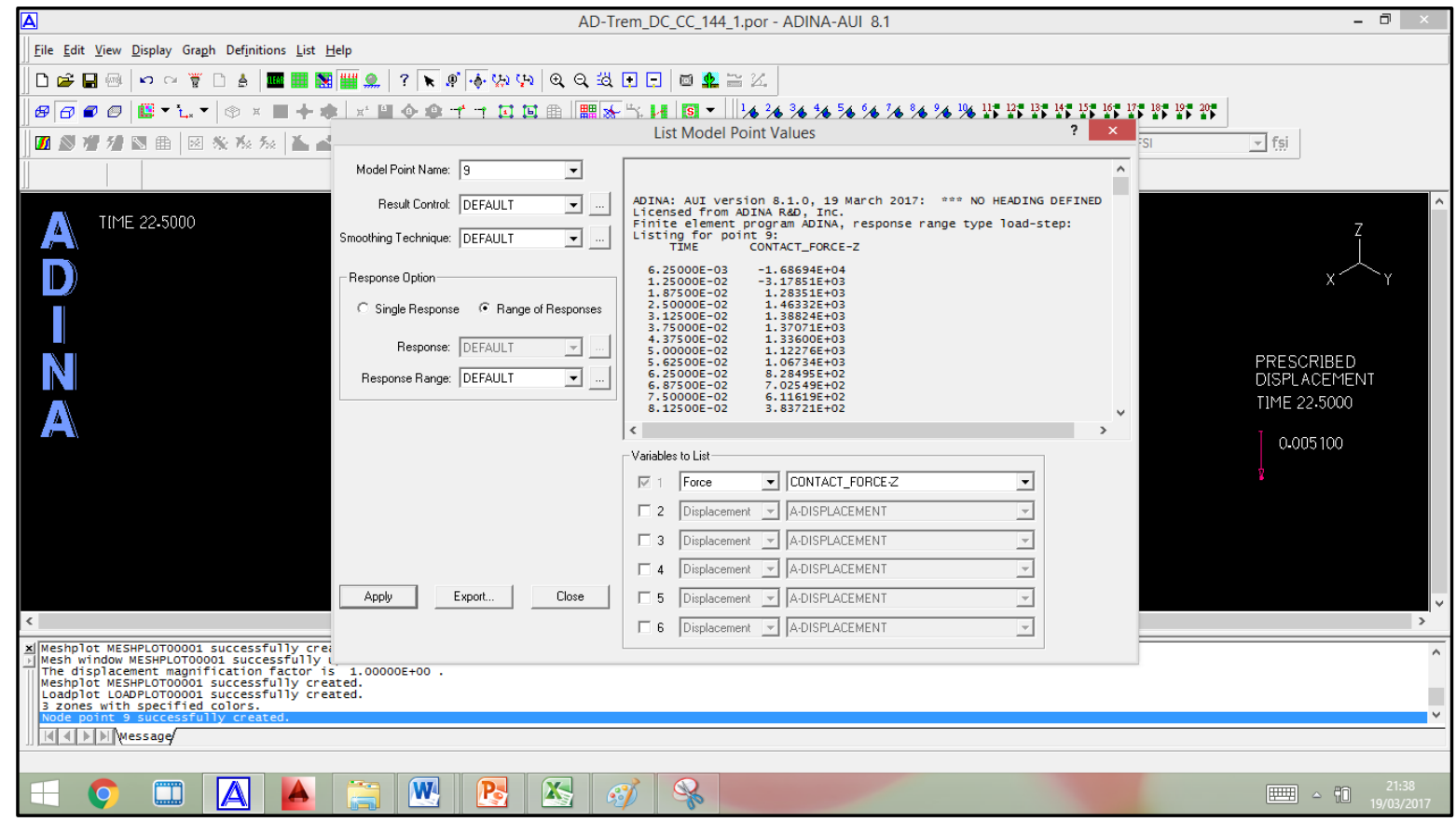

Figura A. 6: Forças de interação extraídas do ADINA

\begin{tabular}{|c|c|c|c|c|c|c|c|c|c|c|c|c|c|c|c|}
\hline \multicolumn{16}{|c|}{ Forças de Interação } \\
\hline \multicolumn{2}{|c|}{ Roda 1 - nó 9} & \multicolumn{2}{|c|}{ Roda 2 - nó 10} & \multicolumn{2}{|c|}{ Roda 3- nó 11} & \multicolumn{2}{|c|}{ Roda 4 - nó 12} & \multicolumn{2}{|c|}{ Roda 5 - nó 13} & \multicolumn{2}{|c|}{ Roda 6 - nó 14} & \multicolumn{2}{|c|}{ Roda 7- nó 15} & \multicolumn{2}{|c|}{ Roda 8 - nó 16} \\
\hline$t[s]$ & $\mathrm{Fz}[\mathrm{m}]$ & $t[s]$ & $\mathrm{Fz}[\mathrm{m}]$ & $t[s]$ & $\mathrm{Fz}[\mathrm{m}]$ & $t[s]$ & $\mathrm{Fz}[\mathrm{m}]$ & $t[s]$ & $\mathrm{Fz}[\mathrm{m}]$ & $t[s]$ & $\mathrm{Fz}[\mathrm{m}]$ & $t[s]$ & $\mathrm{Fz}[\mathrm{m}]$ & $t[s]$ & $\mathrm{Fz}[\mathrm{m}]$ \\
\hline 0,00000 & 75250,00000 & 0,00000 & 75250,00000 & 0,00000 & 75250,00000 & 0,00000 & 75250,00000 & 0,00000 & 75250,00000 & 0,00000 & 75250,00000 & 0,00000 & 75250,00000 & 0,00000 & 75250,00000 \\
\hline 0,00625 & 58380,60000 & 0,00625 & 43751,40000 & 0,00625 & 58173,10000 & 0,00625 & 43416,50000 & 0,00625 & 56975,30000 & 0,00625 & 40544,70000 & 0,00625 & 56841,00000 & 0,00625 & 40028,10000 \\
\hline 0,01250 & 72071,49000 & 0,01250 & 80144,50000 & 0,01250 & 72171,25000 & 0,01250 & 80350,48000 & 0,01250 & 72619,08000 & 0,01250 & 81839,89000 & 0,01250 & 72830,26000 & 0,01250 & 82114,93000 \\
\hline 0,01875 & 76533,51000 & 0,01875 & 76492,42000 & 0,01875 & 76646,06000 & 0,01875 & 76505,89000 & 0,01875 & 76522,06000 & 0,01875 & 76423,23000 & 0,01875 & 76540,81000 & 0,01875 & 76357,18000 \\
\hline 0,02500 & 76713,32000 & 0,02500 & 76505,18000 & 0,02500 & 76649,03000 & 0,02500 & 76518,80000 & 0,02500 & 76689,11000 & 0,02500 & 76540,60000 & 0,02500 & 76682,02000 & 0,02500 & 76569,05000 \\
\hline 0,03125 & 76638,24000 & 0,03125 & 76605,47000 & 0,03125 & 76749,79000 & 0,03125 & 76617,95000 & 0,03125 & 76631,04000 & 0,03125 & 76564,91000 & 0,03125 & 76708,16000 & 0,03125 & 76564,29000 \\
\hline 0,03750 & 76620,71000 & 0,03750 & 76462,70000 & 0,03750 & 76612,24000 & 0,03750 & 76468,44000 & 0,03750 & 76625,00000 & 0,03750 & 76522,10000 & 0,03750 & 76728,53000 & 0,03750 & 76512,51000 \\
\hline 0,04375 & 76586,00000 & 0,04375 & 76442,70000 & 0,04375 & 76546,46000 & 0,04375 & 76452,74000 & 0,04375 & 76541,83000 & 0,04375 & 76366,31000 & 0,04375 & 76550,24000 & 0,04375 & 76410,25000 \\
\hline 0,05000 & 76372,76000 & 0,05000 & 76218,14500 & 0,05000 & 76477,02000 & 0,05000 & 76223,32900 & 0,05000 & 76482,92000 & 0,05000 & 76316,61000 & 0,05000 & 76456,91000 & 0,05000 & 76276,56000 \\
\hline 0,05625 & 76317,34000 & 0,05625 & 76149,92900 & 0,05625 & 76241,99600 & 0,05625 & 76152,48700 & 0,05625 & 76253,97000 & 0,05625 & 76129,30300 & 0,05625 & 76314,35000 & 0,05625 & 76118,99700 \\
\hline 0,06250 & 76078,49500 & 0,06250 & 75896,17800 & 0,06250 & 76172,95400 & 0,06250 & 75955,25600 & 0,06250 & 76132,85600 & 0,06250 & 75964,85500 & 0,06250 & 76159,87000 & 0,06250 & 75949,50600 \\
\hline 0,06875 & 75952,54900 & 0,06875 & 75822,78700 & 0,06875 & 75928,93000 & 0,06875 & 75728,40700 & 0,06875 & 75974,81100 & 0,06875 & 75802,83200 & 0,06875 & 76063,06700 & 0,06875 & 75721,32500 \\
\hline 0,07500 & 75861,61900 & 0,07500 & 75574,17300 & 0,07500 & 75807,59800 & 0,07500 & 75661,75300 & 0,07500 & 75881,30100 & 0,07500 & 75643,86300 & 0,07500 & 75823,59700 & 0,07500 & 75650,01500 \\
\hline 0,08125 & 75633,72100 & 0,08125 & 75519,88000 & 0,08125 & 75724,83800 & 0,08125 & 75426,95600 & 0,08125 & 75654,36300 & 0,08125 & 75493,82200 & 0,08125 & 75710,99500 & 0,08125 & 75472,71000 \\
\hline 0,08750 & 75594,73200 & 0,08750 & 75360,94900 & 0,08750 & 75512,70300 & 0,08750 & 75385,14000 & 0,08750 & 75556,97500 & 0,08750 & 75362,68600 & 0,08750 & 75582,08700 & 0,08750 & 75338,37440 \\
\hline 0,09375 & 75396,54300 & 0,09375 & 75191,65640 & 0,09375 & 75488,86300 & 0,09375 & 75184,89590 & 0,09375 & 75445,34900 & 0,09375 & 75192,89270 & 0,09375 & 75523,95700 & 0,09375 & 75222,07740 \\
\hline 0,10000 & 75332,74850 & 0,10000 & 75188,43980 & 0,10000 & 75306,85540 & 0,10000 & 75176,74580 & 0,10000 & 75408,50900 & 0,10000 & 75184,47590 & 0,10000 & 75337,38280 & 0,10000 & 75127,62700 \\
\hline
\end{tabular}

Figura A. 7: Forças de interação obtidas para cada uma das rodas 
6) Determinação das funções aplicadas no modelo da estrutura. A partir das forças de interação, são determinadas as funções que descrevem o tráfego do trem sobre a estrutura. A função em cada nó da malha da estrutura equivale ao valor da força de interação no instante em que o trem se encontra sobre aquela posição e zero para os demais instantes. O procedimento deve ser realizado para cada velocidade analisada.

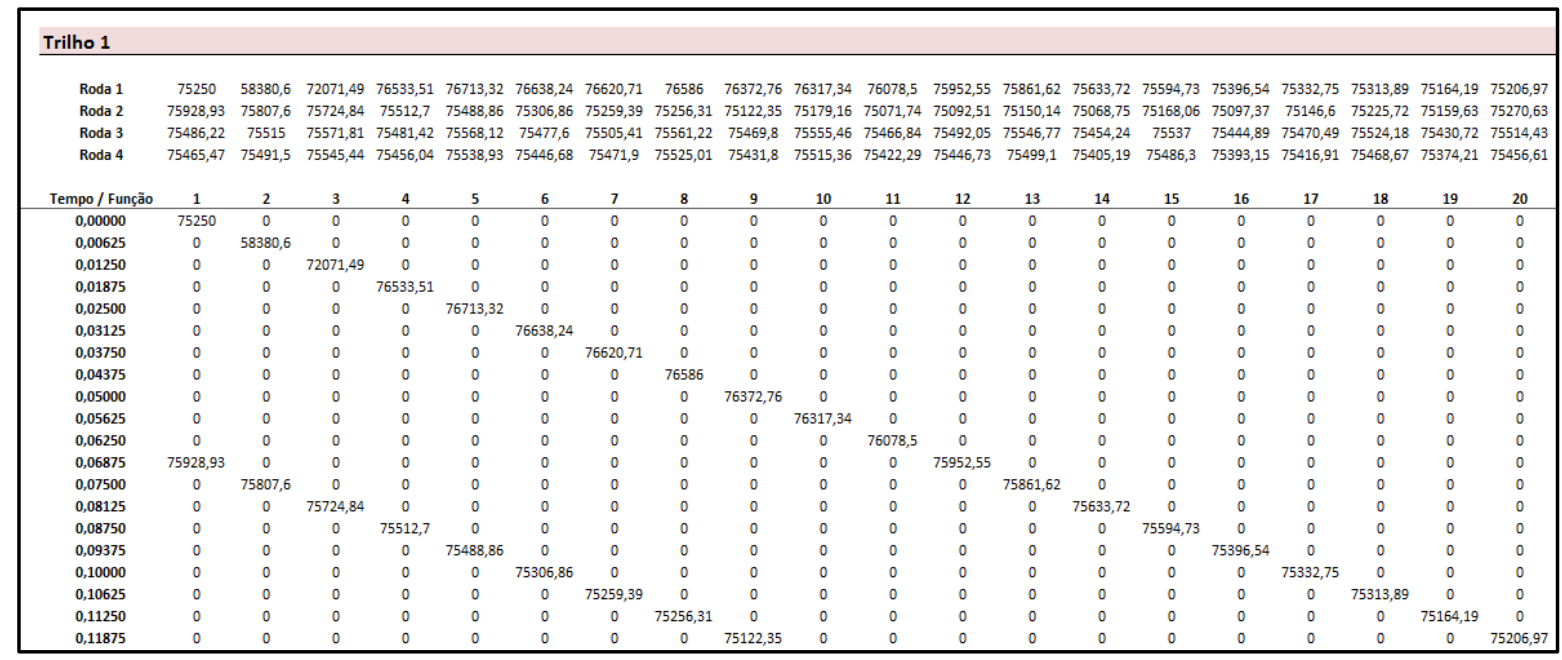

Figura A. 8: Funções para cada nó da malha do trilho 1

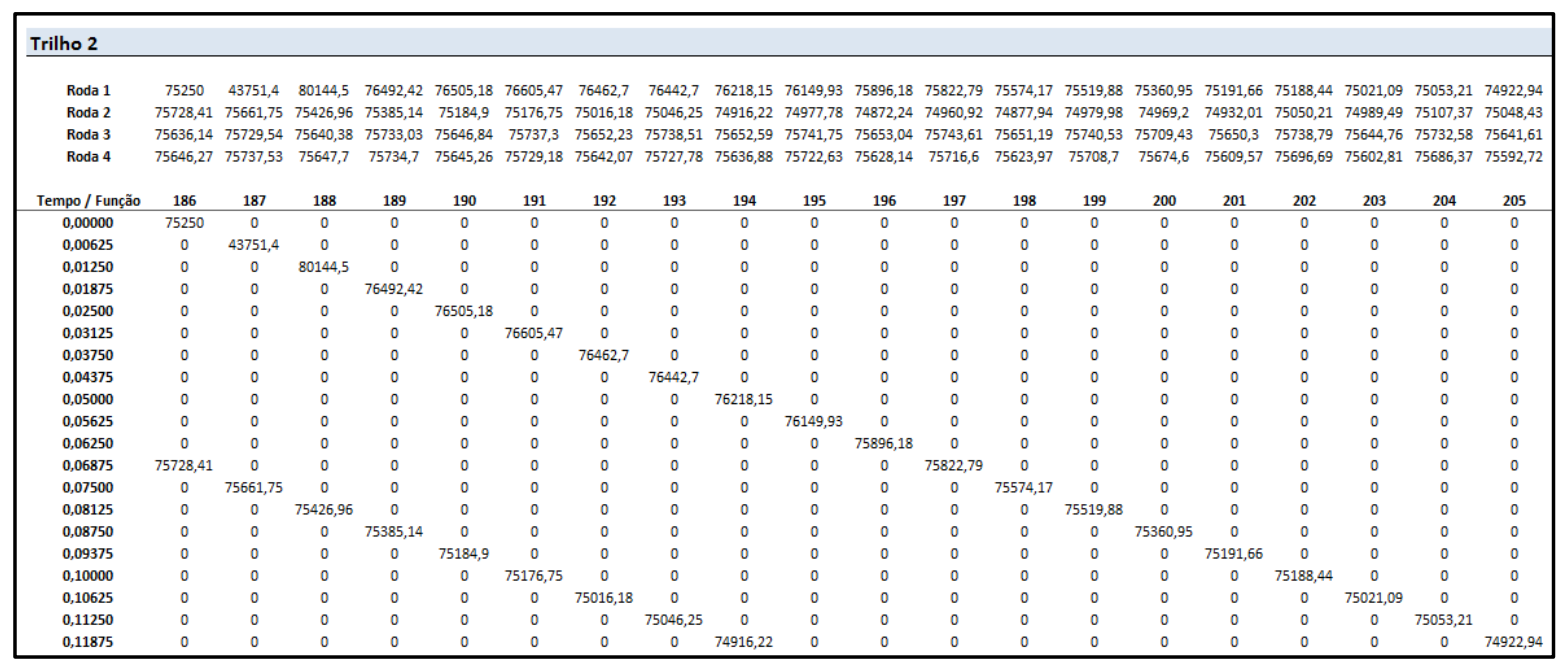

Figura A. 9: Funções para cada nó da malha do trilho 2

7) Carregamento das funções no modelo da estrutura. Para inserir as funções do passo anterior dentro do ADINA, utilizou-se a função MACRO disponível no ADINA para facilitar o processo, uma vez que, para o modelo do viaduto foram necessárias 370 funções e, para o modelo da ponte, 962 funções. A rotina 
apresentada tem a função de realizar o upload dessas informações dentro do programa. O ADINA tem uma programação própria cujos arquivos são apresentados em Bloco de Notas com extensão “.ses".

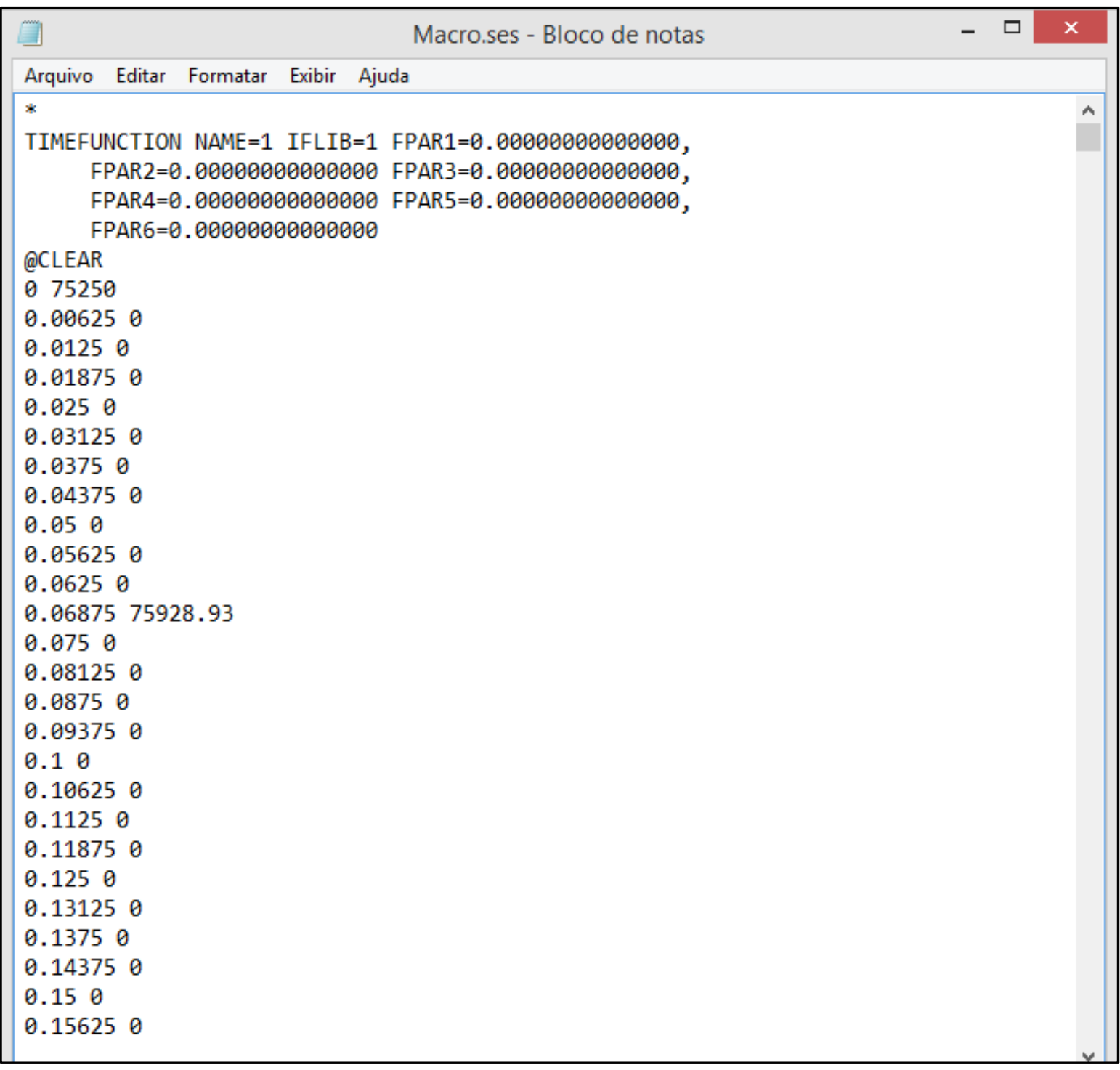

Figura A. 10: Macro para upload das funções dentro do ADINA

Uma vez inseridas as funções no ADINA, deve-se realizar o processamento dinâmico do modelo. Observa-se que o procedimento deve ser realizado para cada velocidade analisada.

8) Obtenção dos deslocamentos verticais do tabuleiro. Para a correção da consideração de tabuleiro rígido e indeslocável, deve ser obtido o histórico no tempo dos deslocamentos verticais em cada nó dos trilhos para cada velocidade. Para isso, é necessário definir no ADINA os nós onde se quer 
extrair os resultados e, novamente, para otimização do processo, utilizou-se a função MACRO do ADINA para indicar os nós de interesse.

\begin{tabular}{|c|c|c|}
\hline Gerar no.ses - Bloco de notas & $\square$ & $\times$ \\
\hline Arquivo Editar Formatar Exibir & & \\
\hline NODEPOINT NAME $=37$ SUBSTRUC $=0$ REUSE $=1 \quad$ NODE $=37$ & & $\wedge$ \\
\hline NODEPOINT NAME $=43$ SUBSTRUC $=0$ REUSE $=1 \quad$ NODE $=43$ & & \\
\hline NODEPOINT NAME $=49$ SUBSTRUC $=0$ REUSE $=1 \quad$ NODE $=49$ & & \\
\hline NODEPOINT NAME $=55$ SUBSTRUC $=0$ REUSE $=1$ NODE $=55$ & & \\
\hline NODEPOINT NAME $=276$ SUBSTRUC $=0$ REUSE $=1$ NODE $=276$ & & \\
\hline NODEPOINT NAME $=282$ SUBSTRUC $=0$ REUSE $=1$ NODE $=282$ & & \\
\hline NODEPOINT NAME $=288$ SUBSTRUC $=0$ REUSE $=1$ NODE $=288$ & & \\
\hline NODEPOINT NAME $=294$ SUBSTRUC $=0$ REUSE $=1$ NODE $=294$ & & \\
\hline NODEPOINT NAME $=300$ SUBSTRUC $=0$ REUSE $=1$ NODE $=300$ & & \\
\hline NODEPOINT NAME $=306$ SUBSTRUC $=0$ REUSE $=1$ NODE $=306$ & & \\
\hline NODEPOINT NAME $=312$ SUBSTRUC $=0$ REUSE $=1 \quad$ NODE $=312$ & & \\
\hline NODEPOINT NAME $=620$ SUBSTRUC $=0$ REUSE $=1$ NODE $=620$ & & \\
\hline NODEPOINT NAME $=626$ SUBSTRUC $=0$ REUSE $=1$ NODE $=626$ & & \\
\hline NODEPOINT NAME $=632$ SUBSTRUC $=0$ REUSE $=1$ NODE $=632$ & & \\
\hline NODEPOINT NAME $=638$ SUBSTRUC $=0$ REUSE $=1$ NODE $=638$ & & \\
\hline NODEPOINT NAME $=814$ SUBSTRUC $=0$ REUSE $=1$ NODE $=814$ & & \\
\hline NODEPOINT NAME $=820$ SUBSTRUC $=0$ REUSE $=1$ NODE $=820$ & & \\
\hline NODEPOINT NAME $=938$ SUBSTRUC $=0$ REUSE $=1$ NODE $=938$ & & \\
\hline NODEPOINT NAME $=944$ SUBSTRUC $=0$ REUSE $=1$ NODE $=944$ & & \\
\hline NODEPOINT NAME $=950$ SUBSTRUC $=0$ REUSE $=1$ NODE $=950$ & & \\
\hline NODEPOINT NAME $=956$ SUBSTRUC $=0$ REUSE $=1$ NODE $=956$ & & \\
\hline NODEPOINT NAME $=1141$ SUBSTRUC $=0$ REUSE $=1 \quad$ NODE $=1141$ & & \\
\hline NODEPOINT NAME $=1147$ SUBSTRUC $=0$ REUSE $=1 \quad$ NODE $=1147$ & & \\
\hline NODEPOINT NAME $=1153$ SUBSTRUC $=0$ REUSE $=1 \quad$ NODE $=1153$ & & \\
\hline NODEPOINT NAME $=1336$ SUBSTRUC $=0$ REUSE $=1$ NODE $=1336$ & & \\
\hline NODEPOINT NAME $=1342$ SUBSTRUC $=0$ REUSE $=1 \quad$ NODE $=1342$ & & \\
\hline NODEPOINT NAME $=1348$ SUBSTRUC $=0$ REUSE $=1 \quad$ NODE $=1348$ & & \\
\hline NODEPOINT NAME $=1354$ SUBSTRUC $=0$ REUSE $=1$ NODE $=1354$ & & \\
\hline NODEPOINT NAME $=1360$ SUBSTRUC $=0$ REUSE $=1$ NODE $=1360$ & & \\
\hline NODEPOINT NAME $=1366$ SUBSTRUC $=0$ REUSE $=1 \quad$ NODE $=1366$ & & \\
\hline NODEPOINT NAME $=1372$ SUBSTRUC $=0$ REUSE $=1 \quad$ NODE $=1372$ & & \\
\hline NODEPOINT NAME $=1716$ SUBSTRUC $=0$ REUSE $=1 \quad$ NODE $=1716$ & & \\
\hline
\end{tabular}

Figura A. 11: Macro para indicação dos nós de interesse no ADINA

Para os nós indicados na Figura A. 11, são obtidos os deslocamentos no tempo para cada velocidade. 


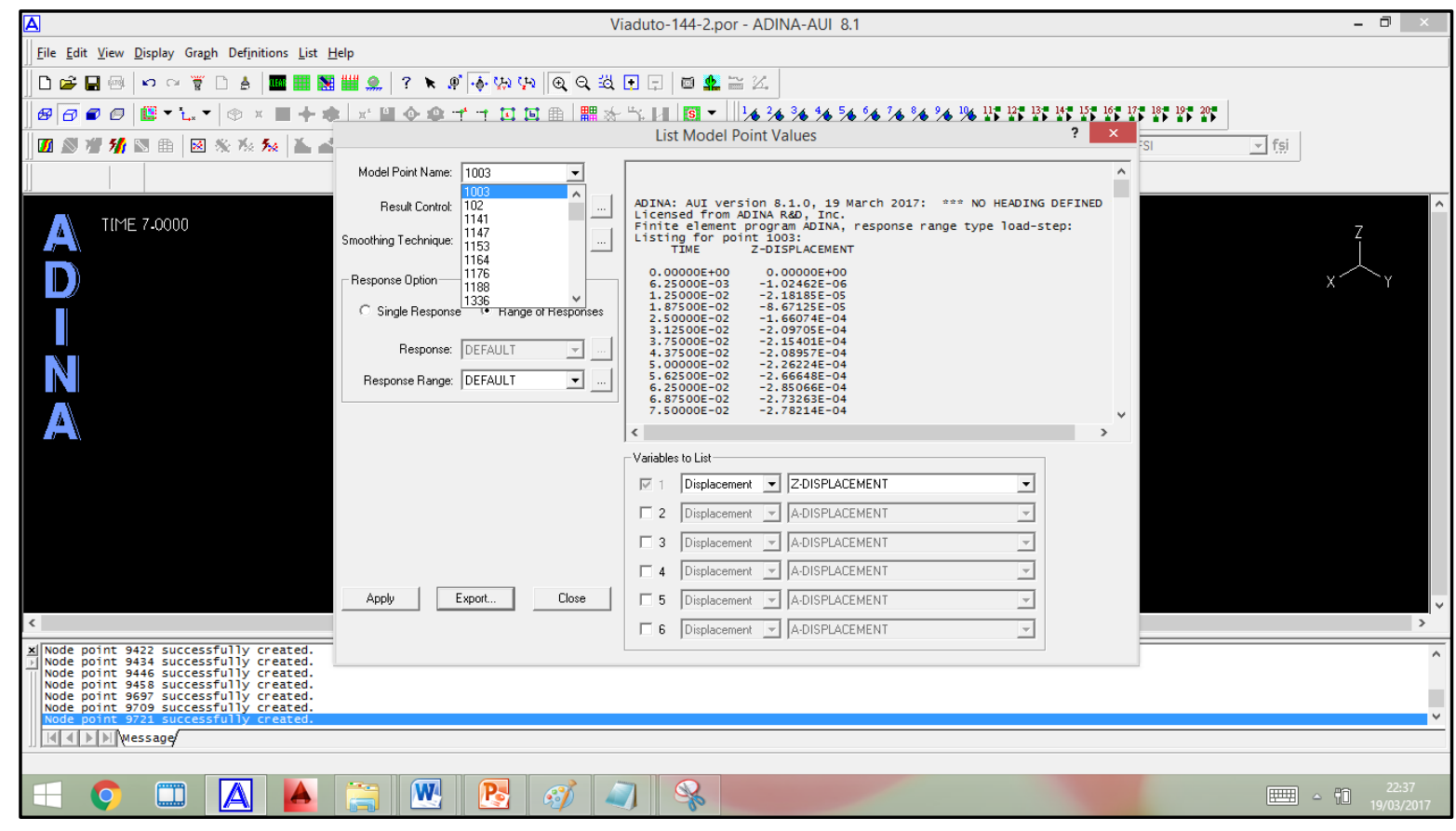

Figura A. 12: Extração de deslocamento vertical do ADINA 
Arquivo Editar Formatar Exibir Ajuda

ADINA: AUI version 8.1.0, 22 October 2016: *** NO HEADING DEFINED ***

Licensed from ADINA R\&D, Inc.

Finite element program ADINA, response range type load-step:

Listing for point 1003:

TIME Z-DISPLACEMENT
$0.00000 \mathrm{E}+00$
$0.00000 \mathrm{E}+00$
$6.25000 \mathrm{E}-03$
$-1.02498 \mathrm{E}-06$
1.25000E-02
$-2.19903 E-05$
$1.87500 \mathrm{E}-02$
$-8.74426 \mathrm{E}-05$
2. $50000 \mathrm{E}-02$
$-1.67263 \mathrm{E}-04$
$3.12500 \mathrm{E}-02$
$-2.10510 \mathrm{E}-04$
$3.75000 \mathrm{E}-02$
$-2.15282 E-04$
4. $37500 \mathrm{E}-02$
$-2.08296 \mathrm{E}-04$
$5.00000 \mathrm{E}-02$
$-2.25900 \mathrm{E}-04$
$5.62500 \mathrm{E}-02$
$-2.67114 \mathrm{E}-04$
6.25000E-02
$-2.85658 E-04$
$6.87500 \mathrm{E}-02$
$-2.73173 \mathrm{E}-04$
7. $50000 \mathrm{E}-02$
$-2.77705 \mathrm{E}-04$
$8.12500 \mathrm{E}-02$
$-3.38410 \mathrm{E}-04$
$8.75000 \mathrm{E}-02$
$-4.14150 \mathrm{E}-04$
$9.37500 \mathrm{E}-02$
$-4.52691 \mathrm{E}-04$
$1.00000 \mathrm{E}-01$
$-4.60010 \mathrm{E}-04$
$1.06250 \mathrm{E}-01$
$-4.67584 \mathrm{E}-04$
$1.12500 \mathrm{E}-01$
$-5.21448 \mathrm{E}-04$
$1.18750 \mathrm{E}-01$
$-5.95437 E-04$
1. $25000 \mathrm{E}-01$
$-6.30614 \mathrm{E}-04$
1. $31250 \mathrm{E}-01$
$-6.52217 \mathrm{E}-04$
1. $37500 \mathrm{E}-01$
$-6.69018 \mathrm{E}-04$

Figura A. 13: Resultado de deslocamento vertical do ADINA

As respostas obtidas na Figura A. 13 são exportadas para o EXCEL, para serem manuseadas e extrair as informações de interesse. 


\begin{tabular}{|c|c|c|c|c|c|c|c|c|c|c|c|c|c|c|}
\hline & 1 & 2 & 3 & 4 & 5 & 6 & 7 & 8 & 9 & 10 & 11 & 12 & 13 & 14 \\
\hline Rótulos de Linha & 37 & 43 & 49 & 55 & 66 & 78 & 90 & 102 & 276 & 282 & 288 & 294 & 300 & 306 \\
\hline 0.00000 & 0.00000000 & 0.00000000 & 0.00000000 & 0.00000000 & 0.00000000 & 0.00000000 & 0.00000000 & 0.00000000 & 0.00000000 & 0.00000000 & 0.00000000 & 0.00000000 & 0.00000000 & 0.00000000 \\
\hline 0.00625 & -0.00003189 & -0.00002923 & -0.00002752 & -0.00002697 & -0.00008050 & -0.00007320 & -0.00006687 & -0.00006093 & -0.00002393 & -0.00002185 & -0.00002014 & -0.00001875 & -0.00001762 & -0.00001670 \\
\hline 0.01250 & -0.00008662 & -0.00008335 & -0.00008063 & -0.00007928 & -0.00028839 & -0.00026817 & -0.00025009 & -0.00023290 & -0.00007472 & -0.00007132 & -0.00006839 & -0.00006587 & -0.00006366 & -0.00006167 \\
\hline 0.01875 & -0.00010323 & -0.00010259 & -0.00010188 & -0.00010210 & -0.00044609 & -0.00042308 & -0.00040234 & -0.00038263 & -0.00009994 & -0.00009864 & -0.00009770 & -0.00009702 & -0.00009649 & -0.00009600 \\
\hline 0.02500 & -0.00009491 & -0.00009469 & -0.00009503 & -0.00009674 & -0.00045588 & -0.00043809 & -0.00042245 & -0.00040787 & -0.00009544 & -0.00009532 & -0.00009572 & -0.00009655 & -0.00009767 & -0.00009898 \\
\hline 0.03125 & -0.00008408 & -0.00008462 & -0.00008562 & -0.00008784 & -0.00040307 & -0.00039030 & -0.00037954 & -0.00036981 & -0.00008782 & -0.00008868 & -0.00008997 & -0.00009159 & -0.00009346 & -0.00009549 \\
\hline 0.03750 & -0.00007034 & -0.00007127 & -0.00007293 & -0.00007602 & -0.00034282 & -0.00033380 & -0.00032655 & -0.00032027 & -0.00007653 & -0.00007815 & -0.00008027 & -0.00008281 & -0.00008564 & -0.00008867 \\
\hline 0.04375 & -0.00006169 & -0.00006291 & -0.00006463 & -0.00006757 & -0.00033278 & -0.00032442 & -0.00031759 & -0.00031162 & -0.00006850 & -0.00007026 & -0.00007246 & -0.00007503 & -0.00007790 & -0.00008100 \\
\hline 0.05000 & -0.00006487 & -0.00006726 & -0.00006981 & -0.00007330 & -0.00036555 & -0.00035752 & -0.00035108 & -0.00034555 & -0.00007495 & -0.00007729 & -0.00007995 & -0.00008286 & -0.00008593 & -0.00008909 \\
\hline 0.05625 & -0.00007469 & -0.00007831 & -0.00008197 & -0.00008644 & -0.00035984 & -0.00035471 & -0.00035109 & -0.00034839 & -0.00008927 & -0.00009272 & -0.00009648 & -0.00010046 & -0.00010457 & -0.00010873 \\
\hline 0.06250 & -0.00007450 & -0.00007920 & -0.00008417 & -0.00009000 & -0.00030113 & -0.00030030 & -0.00030065 & -0.00030177 & -0.00009443 & -0.00009946 & -0.00010479 & -0.00011035 & -0.00011604 & -0.00012177 \\
\hline 0.06875 & -0.00011590 & -0.00011760 & -0.00012072 & -0.00012611 & -0.00037946 & -0.00036774 & -0.00035886 & -0.00035139 & -0.00012686 & -0.00012953 & -0.00013305 & -0.00013727 & -0.00014201 & -0.00014711 \\
\hline 0.07500 & -0.00017666 & -0.00017850 & -0.00018098 & -0.00018561 & -0.00059704 & -0.00057195 & -0.00055025 & -0.00053023 & -0.00018578 & -0.00018770 & -0.00019045 & -0.00019385 & -0.00019775 & -0.00020195 \\
\hline 0.08125 & -0.00016948 & -0.00017555 & -0.00018186 & -0.00018973 & -0.00065916 & -0.00063937 & -0.00062250 & -0.00060715 & -0.00019428 & -0.00020027 & -0.00020693 & -0.00021408 & -0.00022153 & -0.00022909 \\
\hline 0.08750 & -0.00015045 & -0.00015682 & -0.00016407 & -0.00017330 & -0.00060046 & -0.00058759 & -0.00057769 & -0.00056937 & -0.00017874 & -0.00018587 & -0.00019385 & -0.00020252 & -0.00021170 & -0.00022121 \\
\hline 0.09375 & -0.00014557 & -0.00015306 & -0.00016126 & -0.00017123 & -0.00052289 & -0.00051628 & -0.00051211 & -0.00050934 & -0.00017833 & -0.00018674 & -0.00019586 & -0.00020552 & -0.00021558 & -0.00022588 \\
\hline 0.10000 & -0.00012704 & -0.00013585 & -0.00014563 & -0.00015733 & -0.00044668 & -0.00044458 & -0.00044475 & -0.00044628 & -0.00016593 & -0.00017612 & -0.00018712 & -0.00019877 & -0.00021087 & -0.00022327 \\
\hline 0.10625 & -0.00012017 & -0.00012972 & -0.00013976 & -0.00015133 & -0.00045941 & -0.00045772 & -0.00045784 & -0.00045909 & -0.00016064 & -0.00017108 & -0.00018221 & -0.00019391 & -0.00020607 & -0.00021856 \\
\hline 0.11250 & -0.00012744 & -0.00013894 & -0.00015077 & -0.00016392 & -0.00050016 & -0.00050004 & -0.00050209 & -0.00050548 & -0.00017486 & -0.00018687 & -0.00019943 & -0.00021241 & -0.00022566 & -0.00023902 \\
\hline 0.11875 & -0.00013330 & -0.00014702 & -0.00016088 & -0.00017589 & -0.00047680 & -0.00048154 & -0.00048808 & -0.00049586 & -0.00018912 & -0.00020332 & -0.00021809 & -0.00023329 & -0.0002487 & -0.00026440 \\
\hline
\end{tabular}

Figura A. 14: Deslocamento vertical do tabuleiro em cada nó da malha na posição do trilho

9) Obtenção dos deslocamentos verticais de interesse. Para a correção da consideração de tabuleiro rígido e indeslocável, é necessário obter o deslocamento vertical do tabuleiro para o instante em que cada roda do trem passa sobre aquela posição. Esse procedimento deve ser feito para cada velocidade analisada.

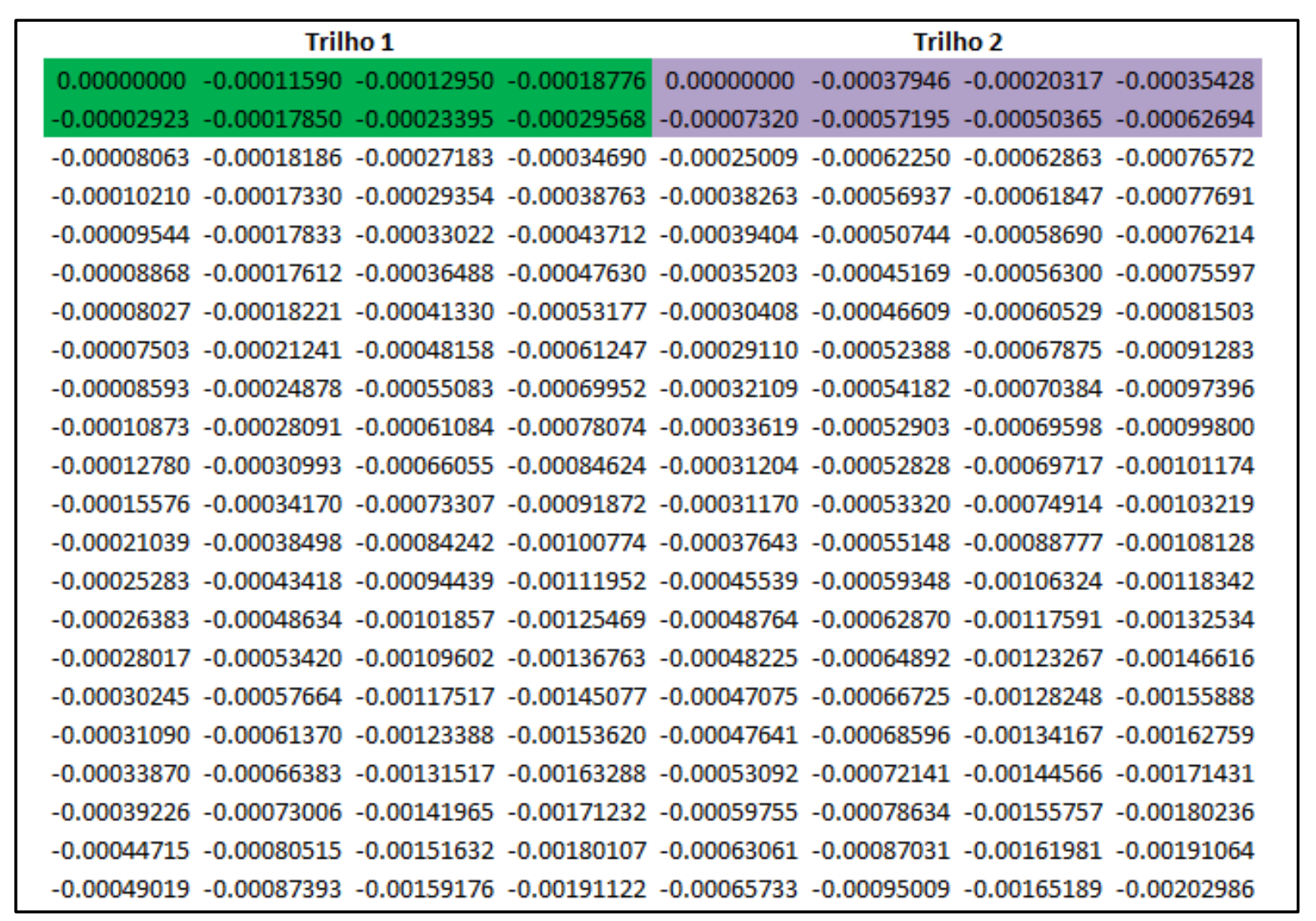

Figura A. 15: Deslocamento vertical do tabuleiro em cada roda do trem 
10) Determinação do novo perfil de irregularidade. Para a determinação do novo perfil de irregularidade, deve-se somar os valores obtidos na Figura A. 15 aos valores apresentados para o primeiro perfil de irregularidades, definido na Figura A. 4.

\begin{tabular}{|c|c|c|c|c|c|c|c|c|c|c|c|c|c|c|c|}
\hline \multicolumn{16}{|c|}{ Iteração 2} \\
\hline \multicolumn{2}{|c|}{ Roda 1} & \multicolumn{2}{|c|}{ Roda 2} & \multicolumn{2}{|c|}{ Roda 3} & \multicolumn{2}{|c|}{ Roda 4} & \multicolumn{2}{|c|}{ Roda 5} & \multicolumn{2}{|c|}{ Roda 6} & \multicolumn{2}{|c|}{ Roda 7} & \multicolumn{2}{|c|}{ Roda 8} \\
\hline$t[s]$ & $\delta \mathrm{z}[\mathrm{m}]$ & $t[s]$ & $\delta z[\mathrm{~m}]$ & $t[s]$ & $\delta z[\mathrm{~m}]$ & $t[s]$ & $\delta z[\mathrm{~m}]$ & $t[s]$ & $\delta z[\mathrm{~m}]$ & $t[s]$ & $\delta z[\mathrm{~m}]$ & $t[s]$ & $\delta z[\mathrm{~m}]$ & $t[s]$ & $\delta z[\mathrm{~m}]$ \\
\hline 0.00000 & 0.00136 & 0.00000 & -0.00123 & 0.00000 & 0.00120 & 0.00000 & -0.00167 & 0.00000 & 0.00100 & 0.00000 & -0.00198 & 0.00000 & 0.00091 & 0.00000 & -0.00223 \\
\hline 0.00625 & 0.00134 & 0.00625 & -0.00130 & 0.00625 & 0.00114 & 0.00625 & -0.00185 & 0.00625 & 0.00090 & 0.00625 & -0.00227 & 0.00625 & 0.00081 & 0.00625 & -0.00249 \\
\hline 0.01250 & 0.00129 & 0.01250 & -0.00147 & 0.01250 & 0.00114 & 0.01250 & -0.00190 & 0.01250 & 0.00086 & 0.01250 & -0.00239 & 0.01250 & 0.00076 & 0.01250 & -0.00262 \\
\hline 0.01875 & 0.00127 & 0.01875 & -0.00160 & 0.01875 & 0.00116 & 0.01875 & -0.00184 & 0.01875 & 0.00084 & 0.01875 & -0.00237 & 0.01875 & 0.00072 & 0.01875 & -0.00262 \\
\hline 0.02500 & 0.00128 & 0.02500 & -0.00160 & 0.02500 & 0.00115 & 0.02500 & -0.00177 & 0.02500 & 0.00081 & 0.02500 & -0.00233 & 0.02500 & 0.00067 & 0.02500 & -0.00260 \\
\hline 0.03125 & 0.00129 & 0.03125 & -0.00155 & 0.03125 & 0.00116 & 0.03125 & -0.00171 & 0.03125 & 0.00077 & 0.03125 & -0.00230 & 0.03125 & 0.00064 & 0.03125 & -0.00258 \\
\hline 0.03750 & 0.00130 & 0.03750 & -0.00150 & 0.03750 & 0.00116 & 0.03750 & -0.00172 & 0.03750 & 0.00073 & 0.03750 & -0.00233 & 0.03750 & 0.00058 & 0.03750 & -0.00263 \\
\hline 0.04375 & 0.00131 & 0.04375 & -0.00148 & 0.04375 & 0.00113 & 0.04375 & -0.00177 & 0.04375 & 0.00066 & 0.04375 & -0.00239 & 0.04375 & 0.00050 & 0.04375 & -0.00272 \\
\hline 0.05000 & 0.00131 & 0.05000 & -0.00151 & 0.05000 & 0.00110 & 0.05000 & -0.00179 & 0.05000 & 0.00060 & 0.05000 & -0.00241 & 0.05000 & 0.00042 & 0.05000 & -0.00278 \\
\hline 0.05625 & 0.00129 & 0.05625 & -0.00152 & 0.05625 & 0.00107 & 0.05625 & -0.00177 & 0.05625 & 0.00054 & 0.05625 & -0.00239 & 0.05625 & 0.00034 & 0.05625 & -0.00279 \\
\hline 0.06250 & 0.00127 & 0.06250 & -0.00149 & 0.06250 & 0.00105 & 0.06250 & -0.00176 & 0.06250 & 0.00049 & 0.06250 & -0.00239 & 0.06250 & 0.00028 & 0.06250 & -0.00280 \\
\hline 0.06875 & 0.00125 & 0.06875 & -0.00148 & 0.06875 & 0.00102 & 0.06875 & -0.00176 & 0.06875 & 0.00042 & 0.06875 & -0.00243 & 0.06875 & 0.00021 & 0.06875 & -0.00281 \\
\hline 0.07500 & 0.00120 & 0.07500 & -0.00154 & 0.07500 & 0.00098 & 0.07500 & -0.00178 & 0.07500 & 0.00031 & 0.07500 & -0.00256 & 0.07500 & 0.00012 & 0.07500 & -0.00285 \\
\hline 0.08125 & 0.00116 & 0.08125 & -0.00162 & 0.08125 & 0.00093 & 0.08125 & -0.00181 & 0.08125 & 0.00021 & 0.08125 & -0.00273 & 0.08125 & 0.00001 & 0.08125 & -0.00294 \\
\hline 0.08750 & 0.00115 & 0.08750 & -0.00164 & 0.08750 & 0.00089 & 0.08750 & -0.00184 & 0.08750 & 0.00014 & 0.08750 & -0.00283 & 0.08750 & -0.00012 & 0.08750 & -0.00308 \\
\hline 0.09375 & 0.00114 & 0.09375 & -0.00163 & 0.09375 & 0.00084 & 0.09375 & -0.00186 & 0.09375 & 0.00007 & 0.09375 & -0.00288 & 0.09375 & -0.00023 & 0.09375 & -0.00321 \\
\hline 0.10000 & 0.00112 & 0.10000 & -0.00162 & 0.10000 & 0.00080 & 0.10000 & -0.00187 & 0.10000 & -0.00001 & 0.10000 & -0.00292 & 0.10000 & -0.00031 & 0.10000 & -0.00329 \\
\hline 0.10625 & 0.00112 & 0.10625 & -0.00162 & 0.10625 & 0.00077 & 0.10625 & -0.00188 & 0.10625 & -0.00007 & 0.10625 & -0.00297 & 0.10625 & -0.00039 & 0.10625 & -0.00335 \\
\hline
\end{tabular}

Figura A. 16: Novo perfil de irregularidades em cada roda do trem

As irregularidades obtidas na Figura A. 16 devem ser aplicadas no modelo do trem e então, deve-se realizar novamente todo o procedimento aqui descrito, até que se observe a convergência dos resultados entre a última iteração e a do passo anterior. 